\title{
A Systemic Functional Linguistic Analysis of Teen Dialogue In Teen Films of Different Ratings
}

\author{
by
}

Shayna Lewis

\begin{abstract}
A thesis submitted to the Faculty of Graduate and Postdoctoral Affairs in partial fulfillment of the requirements for the degree of

Master of Arts

in
\end{abstract}

Applied Linguistics and Discourse Studies

Carleton University

Ottawa, Ontario

(C) 2021, Shayna Lewis 


\begin{abstract}
Language is one factor which may contribute to film rating assignments in the United States. However, linguistic concerns have been largely reduced to isolated instances of profanity. Furthermore, many US films feature characters under age 18, mirroring the audience demographic most restricted by ratings. This thesis examines peer language of teenage characters in two films, exploring the extent to which non-explicit dialogue may also contribute to a film's rating. To this end, Systemic Functional Linguistics is employed to analyse textual and interpersonal features of dialogue in How to Train Your Dragon (PG) and The Hunger Games (PG-13). Results show that Dragon illustrates a protagonist's linguistic shift in gaining acceptance among a pre-established peer group. Meanwhile, Games emphasizes its protagonist's linguistic adaptation through several idiosyncratic relationships. Findings suggest that a stronger grasp of language might be needed to follow the underlying tones in the PG-13 film.
\end{abstract}

Keywords: film language, film ratings, Systemic Functional Linguistics, teen film, peer talk 


\section{Acknowledgements}

I would like to begin by thanking my Lord and Saviour, Jesus Christ, for being the ultimate storyteller and sharing that love of storytelling with me.

I would like to extend my utmost and sincerest gratitude to my two thesis supervisors. Firstly, to Dr. Jaffer Sheyholislami, for taking me on as a student before having even met me in person. Jaffer, I cannot thank you enough for your leap of trust in agreeing to monitor this project, and for your gentle and wise feedback to always keep me seeking improvement. In addition, to Dr. Tracy Hodgson-Drysdale, for your devotion and commitment to supervising this thesis. Tracy, you taught me about SFL and helped inspire the direction for this project; thank you for your keen guidance and friendly presence throughout my time at Carleton.

On this note, I would also like to acknowledge the brilliance and congeniality of my professors and peers at Carleton University's School of Linguistics and Language Studies. The community I experienced in my short time at Carleton will help mark this experience as a positive one. It has been a pleasure to be a Raven with you all.

Finally, I would like to deeply thank my family for their continuous support that allowed me to complete this thesis. To Britt and Grady, my sister and brother-in-law, thank you for your unwavering encouragement and genuine care for my own well-being in addition to the thesis itself. To my parents, thank you for accommodating for me during a pandemic, for being my "research committee" by watching movies with me, and for your unconditional, selfless love. The love and appreciation that I have for each one of you far surpasses any words I might be able to convey. 


\section{Table of Contents}

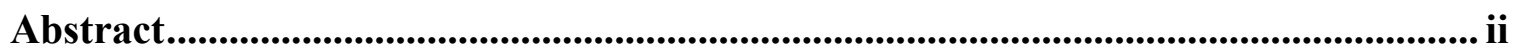

Acknowledgements .............................................................................................................ii

Table of Contents ............................................................................................................... iv

List of Tables ........................................................................................................... vii

Chapter 1: Introduction ............................................................................................................ 1

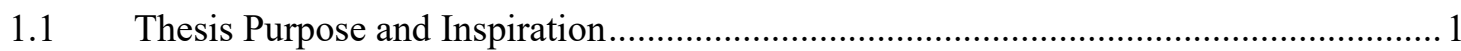

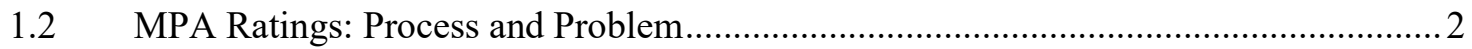

1.3 Methodological Consideration: Systemic Functional Linguistics ................................5

$1.4 \quad$ Thesis Outline

Chapter 2: Literature Review................................................................................................... 8

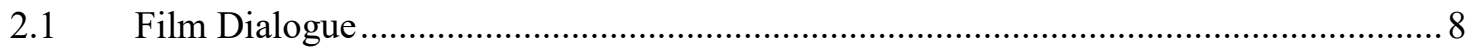

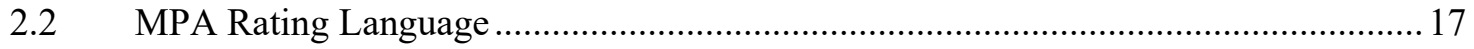

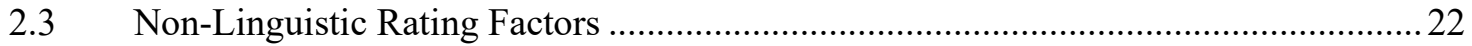

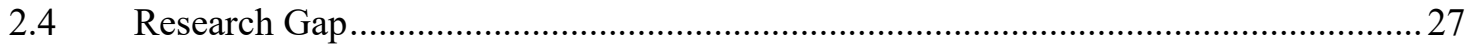

Chapter 3: Theory and Definitions ........................................................................................ 31

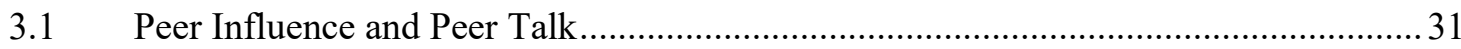

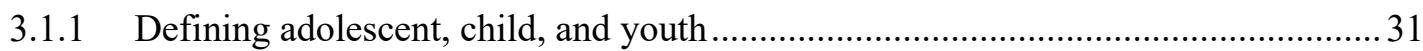

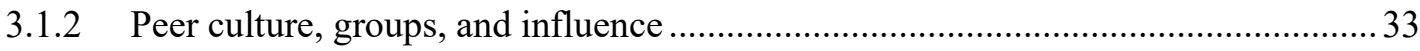

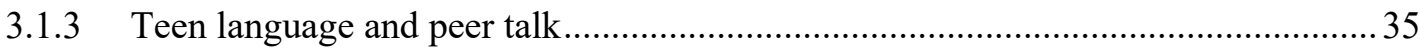

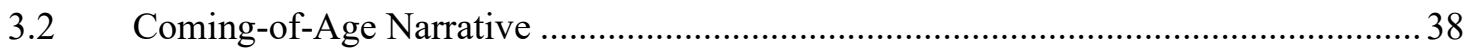

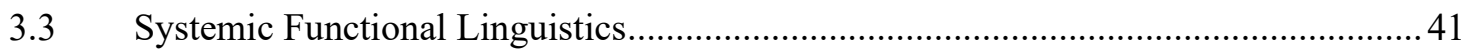

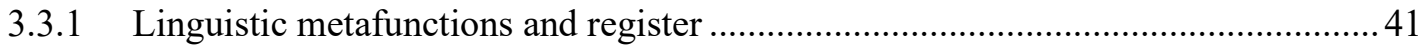

3.3.2 Mode: Lexical density, grammatical intricacy, and thematic structure.................... 43

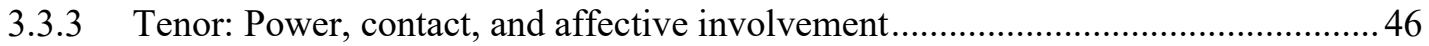


Chapter 4: Methods ............................................................................................................... 49

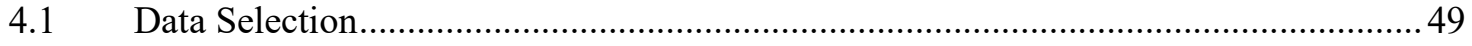

4.1.1 How to Train Your Dragon (2010) ……………………………………………....5 51

4.1.2 The Hunger Games (2012)........................................................................... 52

4.2 Data Collection and Analysis ……………………...............................................52

Chapter 5: Results.................................................................................................................. 57

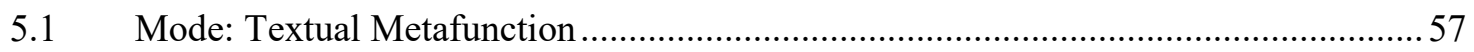

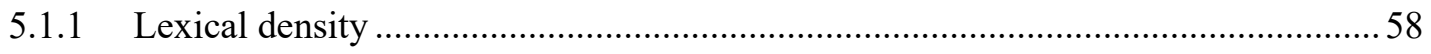

5.1.2 Grammatical intricacy ………………………………………………………... 61

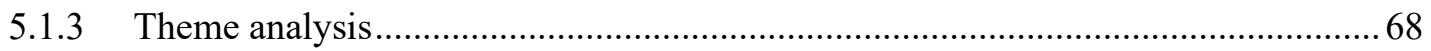

5.2 Tenor: Interpersonal Metafunction ...................................................................

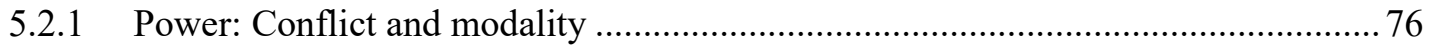

5.2.2 Contact: Conversation length and frequency …………………………………........ 81

5.2.3 Affective involvement: Smallwords and vocatives................................................. 85

Chapter 6: Discussion ......................................................................................................... 93

$6.1 \quad$ Revisiting the Research Questions .........................................................................93

6.1.1 Textual metafunction ................................................................................. 93

6.1.2 Interpersonal metafunction................................................................................... 97

Chapter 7: Conclusion ........................................................................................................... 104

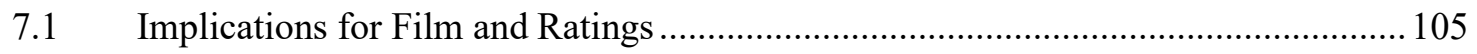

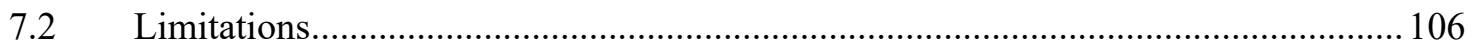

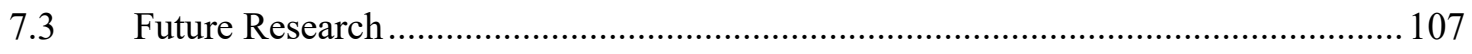

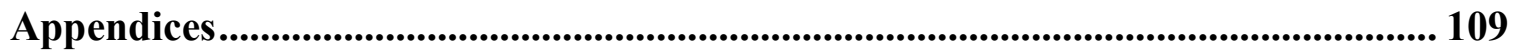

Appendix A Scene Dispersion.......................................................................................... 109

A.1 Scene dispersion in How to Train Your Dragon ………………………………..... 109

A.2 Scene dispersion in The Hunger Games ……………………………………..... 110 
Appendix B Line Dispersion

B.1 Line dispersion in How to Train Your Dragon ................................................... 111

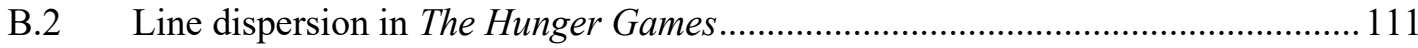

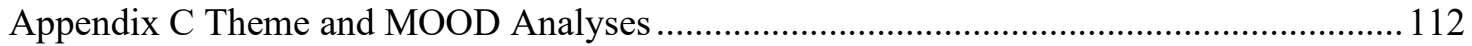

C.1 Theme and MOOD analysis in How to Train Your Dragon .................................. 113

C.2 Theme and MOOD analysis in The Hunger Games............................................... 177

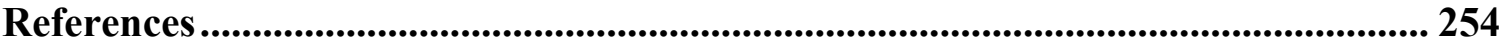




\section{List of Tables}

Table 1: Motion Picture Association Ratings ……………............................................... 3

Table 2: Linguistic Metafunctions and Register Variables (adapted from Eggins, 2004) 43

Table 3: Teenage Characters Analyzed in Selected Films............................................... 54

Table 4: Lexical Density of Character Dialogue in How to Train Your Dragon ............. 58

Table 5: Lexical Density of Character Dialogue in The Hunger Games .......................... 58

Table 6: Grammatical Intricacy of Character Dialogue in How to Train Your Dragon ... 62

Table 7: Grammatical Intricacy of Character Dialogue in The Hunger Games ............... 62 


\section{Chapter 1: Introduction}

\subsection{Thesis Purpose and Inspiration}

This thesis seeks to investigate how a Systemic Functional Linguistics (SFL) analysis of film dialogue could reveal similarities and differences between linguistic choices and film ratings. As further explained below, a film in the United States that receives a rating due to its use of language typically involves instances of profane content. While this is still a valid area of concern, such a perspective largely ignores the vast creative uses of language in favour of the appearance of specific words. From an SFL perspective, language may communicate implicit or explicit ideological values (Eggins, 2004) that are not being fully addressed in the ratings process. Therefore, this thesis aims to see if a broader understanding of language may offer additional insight into the language in films of different ratings beyond isolated words and phrases. By exploring the contextual and functional uses of language in two films, this thesis hopes to discover if greater differences exist apart from the allowance of profanity.

The inspiration for this thesis came from a commercial in which a six-year-old boy claims that "everyone deserves kindness at Christmas." I was struck by the boy's mature and altruistic sentiment, and was prompted to think about children in media. However, the child-adult dynamic appeared quite formal in tone, and I became intrigued at the thought of studying language used among children and youth. Given that teenagers in particular interact with their peers more frequently during adolescence (Nippold, 2000), I sought to study the range of teens' language use with their peers in media. This also led me to think about other forms of media which offer fuller depictions of children's language on screen beyond a relatively short commercial. I became intrigued 
by film because of the manner in which language is communicated; its lengthier stories begin as written scripts that appear to audiences as spoken dialogue. As such, my focus shifted to studying teenaged characters as this age demographic appears more frequently in American film.

When researching films with young characters, I noticed that these films had been assigned a variety of ratings. Film ratings in the United States serve many purposes, with the primary one being their aim to help parents discern a film's appropriateness for their children (Shafaei et al., 2020). In addition, ratings play a key role in the distribution of films, as they may affect age-based filters placed on streaming platforms as well as box office returns in theatres (Shafaei et al., 2020). As a result, these ratings may discourage or outright ban young viewers from watching films depending on the rating they receive. Furthermore, it is not entirely clear as to how the rating descriptions or justifications are decided upon (Potts \& Belden, 2009). The use of language to justify ratings seems to limit the expansiveness of what language entails by focusing solely on profanity.

Therefore, I sought to study non-explicit aspects of language in movies of different ratings that are spoken by characters reflecting the age of restricted audiences.

\subsection{MPA Ratings: Process and Problem}

In the United States, the Motion Picture Association (MPA) assigns ratings by way of its ratings board, the Classification and Ratings Administration (CARA). CARA's purpose is to inform parents of a film's content so as to help them determine whether they might allow their child to watch a given film (MPA, 2018). The board consists of one chair, three senior members, and 8-13 anonymous raters, all of whom are parents with no connections to the film industry (MPA, 2018). Once a filmmaker submits their film to the 
ratings board, raters are required to watch the film together and then independently fill out a ballot. The ballot results are then announced and members collectively determine a final rating and the factors justifying this decision. Filmmakers may then decide to accept the rating, edit and resubmit the film for a different rating, appeal to reject the rating, or in certain cases, release the film unrated (MPA, 2018).

The MPA's (2020) five ratings and definitions may be seen in Table 1. The G, PG, and PG-13 ratings are considered unrestricted, meaning that anyone aged 17 and under may watch a film assigned one of those ratings (Potts \& Belden, 2009). The restricted $\mathrm{R}$ and $\mathrm{NC}-17$ ratings, however, prohibit younger audiences from watching films under certain conditions.

Table 1: Motion Picture Association Ratings

\begin{tabular}{|c|c|c|}
\hline Rating Name & $\begin{array}{c}\text { MPA Definition } \\
\text { (from MPA, 2020) }\end{array}$ & $\begin{array}{c}\text { Unrestricted or } \\
\text { Restricted }\end{array}$ \\
\hline $\begin{array}{c}\text { General Audiences } \\
\text { (G) }\end{array}$ & All ages admitted & Unrestricted \\
\hline $\begin{array}{c}\text { Parental Guidance Suggested } \\
\text { (PG) }\end{array}$ & $\begin{array}{c}\text { Some material may not be } \\
\text { suitable for children }\end{array}$ & Unrestricted \\
\hline $\begin{array}{c}\text { Parents Strongly Cautioned } \\
\text { (PG-13) }\end{array}$ & $\begin{array}{c}\text { Some material may be } \\
\text { inappropriate for children } \\
\text { under 13 }\end{array}$ & Unrestricted \\
\hline $\begin{array}{c}\text { Restricted } \\
\text { (R) }\end{array}$ & $\begin{array}{c}\text { Contains some adult material; } \\
\text { those under 17 require an } \\
\text { accompanying parent or } \\
\text { guardian }\end{array}$ & Restricted \\
\hline $\begin{array}{c}\text { No One 17 and Under } \\
\text { Admitted } \\
\text { (NC-17) }\end{array}$ & $\begin{array}{c}\text { Clearly adult; no one below } \\
17 \text { admitted }\end{array}$ & Restricted \\
\hline
\end{tabular}

The MPA's emphasis on defining the allowance of adult content in films may be partially explained from its historical foundations. The first iteration of a ratings system 
in the United States took the form of the Hays Code, created in 1927 and enforced in the early 1930s (Kozloff, 2007; Dibbets, 1999). The Code was meant to prohibit filmmakers from including certain types of content in their films (Cressman et al., 2009). Although the system and ratings have evolved significantly from the initial do's-and-don'ts list, it is still predicated on a somewhat subjective notion of acceptable versus unacceptable content. In the MPA's (2018) words, [w] hile raters adhere to general guidelines to determine a movie rating, as parents' opinions on sex, profanity, and violence evolve throughout the years, the board's ratings have adjusted to reflect those changing views. The board continuously strives to ensure the ratings mirror the concerns of American parents. (p. 17) The ratings' focus on controversial content may be problematic as it enforces an inherently negative connotation on regulations meant to protect the interests of young viewers. While mature or explicit content is certainly important to consider, it does not encompass the entire moviegoing experience. From a language perspective, reducing the entirety of a film's dialogue to the inclusion of particular words disregards the much higher proportion of non-explicit language in a film. This is significant because, while the profane terms may heighten the intensity of specific dialogue, it is in understanding the dialogue in its entirety that the overall story may also be understood. In this regard, language has a critical role in allowing audiences to grasp the meaning of a film, yet there is little attention being paid to characters' language in the context of its usage. In light of these concerns, one may be prompted to ask: How do the linguistic choices of teenage characters in teen-centred films vary based on a film's rating? 


\subsection{Methodological Consideration: Systemic Functional Linguistics}

One way to address this concern is to use Systemic Functional Linguistics (SFL) to illustrate how language use is strongly tied to its context. SFL views any instance of language use as one output among a series of choices through which meaning can be made (Eggins, 2004). As such, a linguistic production both reflects and contributes to the system in which it is used (Halliday \& Matthiessen, 2004). SFL offers a theoretical understanding of language's contextual usage, while also providing "an analytical methodology which permits the detailed and systematic description of language patterns" (Eggins, 2004, p. 21). Under this framework, any instance of language use is believed to carry three layers of meaning: what is being said, who is involved, and how it is communicated. Using SFL terminology, these meanings correspond to ideational, interpersonal, and textual metafunctions, or meanings about language as it is being used. In this way, the crucial storytelling purpose of language may be considered as more than merely explicit words. Rather, it may be understood as a series of specific linguistic choices to explore a topic, the relationships among characters, and how they communicate, which may also reveal a film's intentional and underlying messages.

Language is a highly suitable film component for analysis as it must meet a general grammatical standard in order to be understood, yet specific choices are made in order to convey a particular story. While the ideational meaning of (profane) terms is a key feature in language, the interpersonal and textual metafunctions in film dialogue have not been studied in as much detail, particularly from a ratings perspective. Furthermore, ratings might suggest that some films are suited for audiences of a certain age, yet the explanations for these ratings are not clearly justified. One particular area of interest is 
the difference between the PG and PG-13 ratings, as both ratings are unrestricted but still ambiguously defined with a suggested age in the latter rating (Medved, 2001; Wilson, Linz, \& Randall, 1990). Therefore, using SFL to further excavate the broader language patterns used in film may help the MPA determine what warrants a PG and PG-13 rating. To address the aforementioned concerns, this thesis will investigate the textual and interpersonal metafunctions of dialogue in PG and PG-13 films; in other words, exploring the structure of the dialogue and relationships among the characters as seen through language. The research question and sub-questions guiding this thesis are as follows:

Do the linguistic choices of teenage characters in teen-centred films vary based on a film's rating, and if so, how?

a) How do these choices vary textually between films with different ratings?

b) How do these choices vary interpersonally because of the relationship between teen characters?

To seek possible answers to these questions, an SFL analysis will be conducted on the teen dialogue from two films: How to Train Your Dragon (PG) and The Hunger Games (PG-13). These films were selected as the highest-grossing teen-centred films in their respective rating released in the 2010s. In this way, both films focused on teenage characters while limiting the amount of researcher bias in their selection. Each line of peer dialogue is identified within transcripts from both films and analyzed using SFL, focusing on how the language was communicated and who was involved. Thus, the research questions may be addressed by examining textual and interpersonal dimensions of language among teen characters. Such research may help explain the similarities or 
differences between language used in films of different ratings, providing a wider understanding of the context in which language is used.

\subsection{Thesis Outline}

Chapter 2 of this thesis includes a review of the literature that focuses on film dialogue and film ratings. This determines the topics and results have already been studied with other methodologies so as to establish a research gap to be addressed.

Chapter 3 provides a theoretical background to help ground this study. Teenage peer talk and the coming-of-age trope detail the interpersonal and linguistic behaviours of teens in both the real world and in media. In addition, SFL and its notions of register and metafunctions are further discussed to explain the functional value of language.

Chapter 4 explains the methodology used to conduct the study. This chapter rationalizes how films, scenes, and characters were selected, in addition to what components of SFL were used to analyze their language.

Chapter 5 presents the results of the study. An SFL analysis of both films illustrates how teenaged peers use language with one another with several key examples to reveal what was discovered in the study.

Chapter 6 discusses the significance of the results from the previous chapter. By revisiting the research questions and situating this study among past literature, this chapter determines what contributions this study will offer to academic research.

Finally, Chapter 7 concludes this thesis by summarizing its contents. In addition, this chapter suggests potential implications on film language and ratings, and acknowledges both limitations and future areas of study to consider beyond this thesis. 


\section{Chapter 2: Literature Review}

This chapter will review previous studies that have been conducted on film language and film ratings. Investigating such topics will reveal the extent and types of research that have examined various factors, linguistic or otherwise, that may have contributed to a film's rating or reception. As a result, this review will build a foundation that will identify existing patterns as well as gaps for future research. Although there has been little research conducted on these topics, the first and second sections of this review will focus on film language and ratings. Section 2.1 covers the film dialogue itself, discovering patterns related to a particular feature of language or communication. Section 2.2 focuses on film ratings, particularly the language used by the MPA to justify why a film has received a given rating. In addition, Section 2.3 will briefly account for nonlinguistic factors that may cause a film to earn a particular rating, such as parental influence as well as sexual, violent, or drug-related content. Following this summary of the literature, Section 2.4 will identify a research gap which this thesis hopes to address.

\subsection{Film Dialogue}

Although there have been some studies examining film dialogue, there is surprisingly little research which focuses on language used by teen characters. However, those that do exist tend to be precautionary examinations of explicitness in dialogue, or more exploratory investigations as to the teenagers' linguistic creativity. Research on explicitness in Italian dubs from 1970s Hollywood youth films found the vulgarity of certain lines to have been mitigated, particularly those related to sexuality (Zanotti, 2012). The dubs for American Graffiti and Grease refined the characters to create a more innocent portrayal of teenagers, while The Lords of Flatbush drastically revised the script 
so as to completely alter the story (Zanotti, 2012). In addition, one study found an overall decrease in the frequency of sexual talk in teen-oriented films over time, although specific talk about innuendos and past intercourse did increase (Callister et al., 2011). However, other findings of "teen queen" films released after 1990 revealed that much of the dubbed dialogue retained the vulgar nature of the original English text, and sometimes added a word or two to heighten the intensity (Ciampi, 2019). This may reveal a relaxation of Italian dubbing standards in more recent decades in terms of the presence of profanity that may closely reflect original English dialogue.

Such studies already begin to reveal a trend in research to examine the prevalence of sexual content in films with teen characters. Teen films have historically been closely tied to storylines that involve romance or sex as a part of adolescents' everyday life (Schmidt, 2002). However, Schmidt (2002) also mentions how American Graffiti had a profound influence in "[d]eveloping a level of social critique in what had been a frivolous juvenille $[\mathrm{sic}]$ subgenre... investing an already established commercial film formula with thematic complexities never before associated with it" (pp. 196-7). Although this particular film may contain a story centred on American values, it may raise concerns to see dialogue being heavily manipulated in an attempt to reach different audiences. In one sense, mitigating the dialogue's vulgarity may allow a film to earn a more open rating that encourages audiences of a wider age range to watch it. On the other hand, there may be an ambiguous grey area as to how much dialogue can afford to be changed before it becomes a different story. What adds even more complexity to this situation is that these films centre around teenagers, and too much dialogue manipulation-either in mitigating or enhancing the vulgarity — may exclude audiences who reflect the ages of a film's main 
characters. Sexual content may be a sensitive topic among this age group, and it is important that filmmakers and dubbers understand the potential repercussions of how dialogue is used or changed.

One approach for examining the creative uses of language amongst teens may focus on linguistic features in films over a period of time. The Italian dubs of Englishlanguage films Sixteen Candles, Clueless, and Juno began accommodating for spoken discourse features such as hesitations and false starts (Bonsignori, 2015). In addition, Italian translations took on a variety of techniques such as paraphrasing or using long forms of original words (Bonsignori, 2015). Another study focused on specific use of compliments, both in their syntactic structure and creativity, in Clueless and Mean Girls. The most frequently occurring structure in the films involves someone claiming that a noun is or looks a certain way, which is also the most common pattern in spontaneous conversations (Ciampi, 2015). However, compliments in film dialogue are much more likely to use creative structures that do not follow a particular grammatical formula, which is rarely seen in spontaneous conversations (Ciampi, 2015). This may be reflective of the film medium, which allows several writers to create several drafts of a script that allows much more time to consider language use than spontaneous conversations (actor improvisations notwithstanding). It would also be interesting to see which characters employed these creative structures most frequently and how they were perceived by their peers. This may provide some insight as to the effectiveness of given speech patterns at achieving the characters' goals within a given scene. Furthermore, this may also prompt more reflection and research as to the roles of media and real-life conversations in influencing one another's dialogue, suggesting that it may be a two-way process. 
The use and frequency of swearing is one of the more pertinent topics in the literature examining language in film. One study found that swearing frequency in PG and PG-13 films that starred and were targeted towards teenagers had decreased over time, although it always remained quite present in these films (Cressman et al., 2009). That being said, many of the studies dealing with profanity in film have opted for studying specific films through case studies. One study found 449 instances of swearing (including euphemisms) and 53 unique profane terms in the R-rated Bad Boys II (Kristiano \& Ardi, 2018). Out of nine semantic categories for organizing the terms, sexual references had the most unique terms with 12 , although most categories contained a variety of different terms (Kristiano \& Ardi, 2018). Similarly, the 322 swear words used by the character of Jordan Belfort in The Wolf of Wall Street, another R-rated film, were categorized according to the manner in which they are used. Over $73 \%$ of the swear words used by Belfort were claimed to have been used emphatically, so as to enhance the weight and impact of his statements by conveying more emotion (Bram \& Putra, 2019). It is interesting to see how Cressman et al.'s (2009) study of films with more open ratings prioritize the quantity of profanity in their films, while the two studies on R-rated films focus on what types of words were being used. Bram and Putra (2019) in particular begin to examine the functionality of swearing in particular contexts and the role that these words serve in a line of dialogue. This raises concern about profanity in films targeted towards younger audiences not being considered in their context of use. Cressman et al.'s (2009) work is helpful to discover the existence of certain words, however the importance of understanding why and how such language is being used, and to what effect in the story, has yet to be studied. 
In addition to swearing, a handful of recent studies have analyzed interpersonal communication patterns of film characters through dialogue, two of which examined The Devil Wears Prada. Politeness was commonly portrayed as seeking common ground or interests, while impolite "bald on record" tactics to bluntly and harshly share one's thoughts (Probosini, 2020). Similarly, tactics such as condescension and ridicule were used to convey impoliteness to other characters (Ratri \& Ardi, 2019). Both sets of researchers carefully selected this film for the purposes of examining how its characters use politeness strategies, in addition to its international recognizability. The film, as well as these studies, may offer a specific example of workplace communication and power dynamics across professional hierarchies. However, although the researchers had watched the film, neither study accounted for the paralinguistic features of the dialogue, such as tone, rate, or pitch of speech. In the case of politeness, the delivery of particular words may be just as, if not more significant as the words themselves, which may have been worth exploring in more detail.

These studies all apply a communication theory to film dialogue, which is similar to the theoretical approach in this thesis. That being said, these studies are again concerned with the existence and frequency of various communication strategies as ways to convey perceived power. While there can be value in identifying communication strategies among speaking characters, the repercussions of these strategies cannot truly be felt unless the dynamic between all characters involved is analyzed. One study uses critical discourse analysis to reveal ideologies in dialogue depicting racial groups in The Great Debaters film (Silalahi, Rafli, \& Dewanti, 2021). While such studies are important to critique and draw connections to real world events, there is also value in exploratory 
studies that seek to uncover conversational habits beyond a critical approach. One example of this approach is a thesis which unveils speaker strategies of a diverse cast of characters by applying SFL in a stage play that was later turned into an $\mathrm{HBO}$ film (Webster, 2017). The study used a conversation analysis to expand on a dyad's relationship, showing the length of clauses per character's speaking turn and the progression of speaking strategies over three scenes (Webster, 2017). One other study was found to use SFL with film, focusing on university students' academic writing in film studies (Donohue, 2012). Thus, the description of terms and consideration of how film language is represented may be useful when studying a script. Chapters 3 and 4 will further define which components of SFL have been used in this study and rationalize why those strategies were chosen.

As either primary or secondary components to some of these studies, the use of language based on gender became another area of interest. Some research has found that male teens and adults in teen-oriented films were found to swear more than both female teens and adults (Cressman et al., 2009). In the same study, males were more likely to use one of the seven dirty words (as defined by the Federal Communications Commission), while females were more likely to use words that could be classified as mild language (Cressman et al., 2009). A more comprehensive study on this topic discussed the stereotype of men being smarter than women given the greater likelihood that men pursue science, technology, engineering, and mathematics (STEM) professions. By counting the word associations of characters to stereotypical jobs and adjectives for brilliance over 50 years of film, females were more strongly associated with their stereotyped roles and less often associated with intelligent terms (Gálvez, Tiffenberg, \& Altszyler, 2019). What is 
not accounted for, however, is the proportion of male and female characters being examined, or the amount of dialogue attributed to a particular character. In addition, while stereotyped roles were mentioned in the study's methods section, the individual words that were most frequently associated with each gender were also omitted. Including this information in the results may have revealed which specific stereotypes are most strongly associated with each gender, and thus what professions have been most traditionally associated with characters on screen. Meanwhile, in a case study, cross-sex pairings of characters in He's Just Not That Into You shared many of the same conversational styles. Both characters asked many questions, although the male tended to try to control the conversation and use more intensifiers, swear words, and tag questions (among others) while the female used more qualifiers and silence (Aryani, 2016). It is still noteworthy, if a bit troubling, to see the differences in male and female portrayals on screen from these studies. Male language is being portrayed aggressively through vulgarity and dominance, while female characters appear to use softer, more docile language (Cressman et al., 2009; Aryani, 2016). In addition, male characters are more often associated with terms related to intellect, and female characters had a stronger association with female stereotyped roles than male characters did to male stereotyped roles (Gálvez, Tiffenberg, \& Altszyler, 2019). These may have potentially harmful effects on each gender, both in males for perhaps feeling a need to demonstrate aggression and brilliance, while females may feel subordinate and purposed to a certain kind of job. In considering these factors, it is important to portray characters to be as well-rounded as possible, not just for their skills or jobs but in their personalities and relationships to other characters. 
An interesting observation that can be made about many studies examining the language in American teen-oriented films is that the films themselves often illustrate a high school experience. Although films like Sixteen Candles and Clueless have been justified for examination because of their status as cult classics (Bonsignori, 2015), the common high school setting is prevalent across the samples. Perhaps this may add an increased pressure on translators to capture culturally specific references when retelling a story in a different language and country. From a more critical standpoint, while high schools are certainly featured in many movies with young characters, they do not encompass all teen-oriented films. Schools provide a relatability that may be more accessible to audiences than other settings, although it is not necessary for a teenager to be in school in order to understand the teen experience. It may be helpful to explore teens in other contexts so as to broaden the perception of what may be considered a teen film.

The loyalty of dubbed dialogue to the wording in its original language is another intriguing area of inquiry. Some of the aforementioned studies revealed the techniques used by Italian translators when transferring an American film into an Italian context, particularly on topics of sex, violence, and drugs. The mitigated changes in 1970s dialogue may be largely attributed to commercial interests, explaining that the "suitable for all" rating in Italy is the most desired one (Zanotti, 2012). However, contrasting findings may reveal a shift in Italian dubbing preferences towards retaining the intensity or explicitness of English language at the expense of a more open rating (Ciampi, 2019). However, within the dubbing studies, word definitions take precedence over the linguistic structure of the dialogue. One exception may be seen in the existence and positions of various parts of speech in a clause (Ciampi, 2015), although the focus remains on 
translation choices rather than the effect of these choices on the characters. Differences between two languages regarding lexicon or clause structure may cause some challenges in transferring both denotative and connotative meanings of certain lines of dialogue. One example comes from examining English-Indonesian translations of phrasal compounds in Spider-Man: Into the Spider-Verse. Every example was found to be an "ideal acceptable" translation based on accuracy, clarity, and natural usage (Krisnadi \& Ardi, 2018). That being said, drawing such conclusions may be highly dependent on the person or people determining the legitimacy of the translation, thus the fluency of the evaluator in both languages is imperative.

Lastly, some similar studies have focused on swearing in a television context, largely conducted by the same team of researchers. The use of profanity in prime time television programs was shown to have increased from 1990 to 1994; although profanity decreased in 1997, that year saw an increase in language classified as stronger swear words (Kaye \& Saplosky, 2001). In focusing on speakers, television characters aged 20 and younger rarely swore, but "voiced offensive words equally to others their age and to adults" (Kaye \& Saplosky, 2004, p. 445). Similar quantities of total profanity were also found in programs rated TV-PG versus TV-14, although the TV-14 programs contained harsher words (Kaye \& Saplosky, 2004). Lastly, one study found that swear words uttered on shows from broadcast networks were considered more offensive than those on cable and premium channels (Saplosky, Shafer, \& Kaye, 2011). Perhaps the targeted audience of broadcast networks would set up an expectation for more family-friendly content that would suggest instances of profanity to be alarming, unlike more adult programs on premium networks. These studies present an interesting analysis of how 
program timing, audience, and network may play a role in how language is used and perceived in different TV shows. At the time of writing this thesis, many TV programs are released through online streaming services. A similar study across streaming platforms, and potentially a comparison to other TV channels, may be an interesting new direction to continue these areas of study.

\subsection{MPA Rating Language}

The vast majority of studies concerning film ratings have considered what adult content appears on-screen and to what severity. Some studies observe language as one among several factors to determine the extent of ratings creep; that is, whether or not more adult content has been included and accepted into films tailored towards younger audiences. One examination of PG-13 films found that language was the third-most cited reason for a film's rating, closely trailing behind sexual and violent content (Leone \& Osborn, 2004). That being said, the researchers' questions and hypotheses were aimed towards sex and violence. Although they also investigated the presence of language, nudity, and mature themes, these factors were not deeply expand upon. One study on ratings creep between PG-13 and R films found that language was more commonly cited as a ratings concern for $\mathrm{R}$ films, while theme exclusively appeared in PG-13 films (Leone $\&$ Houle, 2006). The vagueness of the term theme may be concerning given its prevalence among PG-13 films (Leone \& Houle, 2006). It is also worth noting that both sets of researchers studied films released within quite a narrow time frame, between 2000 and either 2002 (Leone \& Osborn, 2004) or to 2004 (Leone \& Houle, 2006), following the introduction of a new MPA policy. Such findings may show an immediate effect on 
films following the policy's creation, although ratings creep may not be an accurate term to reflect only 2-4 years' worth of data.

This small window was not, however, an issue in other studies of ratings creep, which reveal trends in the types of descriptors used in film ratings over time. Over a 12year period, non-MPA ratings organizations were found to have given films higher scores to suggest that they had found the content to be increasingly more explicit (Thompson \& Yokota, 2004). Of the scores related to profanity, the PG-rated films received an average score of 2.6 while PG-13 films had a 4.8 average on a scale of 10 (Thompson \& Yokota, 2004). One study of ratings creep amongst the top 20 highest-grossing PG-13 films from 1988, 1997, and 2006 did not see a significant increase in adult language (Leone \& Barowski, 2011). Most of the concern with the PG-13 ratings was, yet again, with regards to sexual content (Leone \& Barowski, 2011). This again illustrates how the use of a swear word in any capacity may warrant a film to earn a rating, yet this raises questions as to whether or not there is more to the language that is worth investigation. The PG-13 rating is highly coveted in the film industry due to their profitability and ability to push the boundary of what constitutes unrestricted content (Leone \& Osborn, 2004). For this reason, "not only are studios trimming scenes of sexual contact or bloodshed that would otherwise garner an R-rating, they are adding an 'F word' to a movie that would normally be rated PG to secure a PG-13" (Leone \& Osborn, 2004, p. 88).

Another interesting observation with regards to the perception of profanity on screen over time can be seen in Leone and Barowski's (2011) coding system. The researchers adopted the same coding system used in Kaye and Saplosky's (2004) study of swearing among television characters under age 20. Leone and Barowski (2011) counted 
the number of instances in which words appeared into one of four categories: sexual body parts and behaviour, excretory words, mild-other, and strong-other. The examples provided for mild-other words were largely religious-oriented words derived from Christianity, whereas strong-other words were seen as emotion-laden words or cruel nicknames (Leone \& Barowski, 2011). Although Leone and Barowski’s (2011) coding of swear words "does not include any assessment of graphicness or awareness of characters' ages or behaviors" (p. 61), the term mild inherently suggests a less intense word would fall into this category. This, combined with the fact that sexual and excretory terms had their own categories, may reveal a Western desensitization towards religious profanity on screen. Or, alternatively, there may be a resistance to acknowledging religious profanity as its own category of swear words.

It is interesting to see how studies such as Kaye and Sapolosky's (2004) that focus on children's language on screen may be used as a guideline when examining adult language. This may still raise additional questions as to the significance of speaker and audience in the context of language use, and if the use of profanity should be judged differently depending on the age of the user. While swear words may certainly trigger shocking responses from parents and children alike, it is still important to explore how characters are using this language. One example may be seen in the analysis of over 300 profane terms used by Jordan Belfort in The Wolf of Wall Street that were categorized by function in the story (Bram \& Putra, 2019). This study begins to show how swearing may take place and may help explain how language contributes to a rating assignment. Understanding the purposes behind a word choice may be of greater practical value than learning the specific words themselves. 
Some studies have also investigated the language used by the MPA itself to further describe the degree to which these factors are present in a film; these terms are defined as ratings descriptors (MPA, 2018). Such terms may justify ratings in films based on core content (ex. language, sexuality, violence), quantity (ex. brief, some, pervasive), quality (ex. intense, shocking), and/or context of their usage (ex. adolescent sexuality, sci-fi violence) (Potts \& Belden 2009). Interestingly, the core content term language has been found to be the most commonly cited descriptor across PG, PG-13, and $\mathrm{R}$ ratings (Potts \& Belden, 2009). The PG-13 rating saw an increase in the use of language while PG had a decrease in the qualitative descriptor mild language over time (Potts \& Belden, 2009). Another study of ratings descriptors contained a corpus of 5,500 films, and also found the most commonly appearing modifier for profanity in the PG and PG-13 films to be mild (Shafaei et al., 2020). Among other organizations who offer film rating details to parents, language was the most commonly stated reason behind the MPA assigning a rating other than $\mathrm{G}$ (Thompson \& Yokota, 2004). The descriptors used for PG films include brief and mild, while PG-13 descriptors were strong, brief, sex-related, and crude, with one instance of crude sexual dialogue involving teens (Thompson \& Yokota, 2004). This further adds to the ambiguity of the film ratings based on subjective opinions, particularly at the PG and PG-13 level when there is still open access to all audiences. The definitions of mild and strong leave a great deal of room for interpretation, and may benefit from receiving MPA-ordained guidelines for both the type of word and context of its use.

Language appears frequently as a descriptor across films of all ratings, yet for PG and PG-13 films, mild and strong are prevalent qualitative descriptors. Although it is a 
difficult task for Classification and Ratings Administration (CARA) members to briefly describe the language used in promotional materials, these terms are still quite vague and subjective. As seen above, one framework had interpreted mild to almost exclusively constitute religious terminology used in vain (Leone \& Barowski, 2011; Kaye \& Saplosky, 2004). Furthermore, one's definition of the term strong may be classified differently from members of CARA. Not only do the characters within a story play a key role when using language, but the perspective of the external audience interpreting the words is a crucial component of film language research. Some researchers have made efforts to gather the insights from organizations and parents outside of the MPA (Thompson \& Yokota, 2004; Walsh \& Gentile, 2001). In both cases, the researchers found that the non-MPA parties were more strict or conservative in their views as to whether or not a film contained a more adult behaviour. Perhaps this is reflective of a need to diversify CARA members so as to include parents who will offer a variety of perspectives when discussing film ratings.

There is also an alternative perspective brought up with regards to the amount of profanity used in teen films. Despite language being one of the most commonly cited rating descriptors (Potts \& Belden, 2009; Thompson \& Yokota, 2004), the specific instances of swearing in the highest-grossing PG and PG-13 teen films has decreased since the inception of the PG-13 rating (Cressman et al., 2009). On the one hand, this may reflect a shift within the industry to encourage PG and PG-13 films to appeal to younger audiences who may closer reflect the ages of the characters seen on screen. That being said, these studies reveal how much ambiguity still exists within the ratings system, as two films may share the same content descriptor of language and possess very 
different quantities and types of profane terms being used. The rating descriptors begin to address some of these discrepancies, although there is also some room for interpretation with these terms. In this regard, it is puzzling to consider why film language has not been studied in more depth so as to clarify what might be expected of film dialogue.

That being said, the higher frequency of studies that examine swearing in both dialogue and ratings may be explained due to the relative ease of quantifying profane terms. Although the majority of the language-related modifiers from Thompson and Yokota's (2004) study came from R-rated films, this still reveals a concern of language used in films, which has not been explored as deeply in the literature as violence or sex. In addition, if the ratings creep hypothesis is to be believed, then it may be important to examine how PG and PG-13 films could still inherit words that, for the time being, are largely reserved for R-rated films. Furthermore, if ratings creep has been associated with the use of adult language (Leone $\&$ Barowski, 2011), then it may be worth consideration as to whether or not adult language only constitutes the use of profanity. Although this study will not be delving into ratings creep or adult characters, it may be a starting point from which further studies may truly compare the language of characters of different ages beyond isolated instances of swearing.

\subsection{Non-Linguistic Rating Factors}

Although film ratings and language are the primary areas of focus in this study, this section will briefly summarize some relevant studies pertaining to ratings and topics outside of language. Many of these studies have focused on sexual content, violence, and drug and alcohol consumption, in addition to the role of parents and media in censoring such content. Such topics have been explored due to concern for child exposure to and 
uptake of risky habits (Dalton et al., 2006) and the ratings' main purpose of informing parents about a film's content (MPA, 2018). Therefore, the selected studies in this section include non-linguistic content that can speak to larger perceptions of films and ratings.

One key area of concern deals with filmic depictions of risk behaviours that affect one's health. One study found an increase in the frequency of smoking and tobacco usage from 2010 to 2018 among top-grossing US films (Tynan et al., 2019). This may be especially concerning when considering the literature's belief that films are influential in adolescent smoking behaviours (Sargent, 2005; Tynan et al., 2019). Similar concerns have also been raised among violent actions in film, in that "the behavioral context in which violence is presented in films may change the nature of adolescents' perceptions about violence" (Bleakley, Romer, \& Jamieson, 2014, p. 76). This remark was made in light of results showing that PG-13 and R-rated films had a similar number of instances in which a violent character performed another risk behaviour, while this was significantly lower for G and PG films (Bleakley, Romer, \& Jamieson, 2014).

Two studies presented an overlapping interest in the depiction of violence within The Lord of the Rings universe, explaining how the films evade being classified as either children's stories or R-rated spectacles (apart from an extended edition of one film). One study notes how a survey with over 36,000 respondents used children's film and family film least frequently in terms of how they would describe The Hobbit films (Schmeink, 2016). Instead, respondents were more likely to classify the film as a world of fantasy. Meanwhile, the second study qualitatively reveals how The Lord of the Rings films earned PG-13 ratings for violence compared to more graphic images used by R-rated films (Afra, 2016). These studies are valuable to help explain both what audiences think 
about a film and perhaps why they would have this impression. Schmeink's (2016) survey of audience impressions may be useful for the MPA to garner feedback after a film's release, so as to determine whether the film was appropriately rated. This would be a large quantity of information to analyze, but may help ensure that CARA raters are accurately reflecting parents' beliefs for ratings. Meanwhile, Afra's (2016) study may show how a guideline could be created to outline specific examples of mature content at each rating level. That being said, this guideline would have to stay updated overtime to match the MPA's (2018) mandate of staying current with social views. However, these studies may help show how the MPA can become more transparent when communicating with audiences, and especially parents.

Some studies have also questioned the appropriateness of ratings for the particular age group that is permitted to watch certain films. Shafaei et al. (2020) use a corpus of over 5,500 film scripts and a rating predictability model to predict the films' ratings, based on word context, emotions, genres, and similarities to other films. Their model was more successful than previous prediction models at identifying a film's rating, particularly at predicting R and PG-13 films than PG and G (Shafaei et al., 2020). This finding is less surprising given the fact that any instance of a profane word would automatically garner a film at least a PG-13 rating (Afra, 2016). Studies using prediction models may raise an important economical point of anticipating a rating early on in the production process. Rather than spending millions of dollars to create a film and then have it rated afterwards, models such as Shafaei et al.'s (2020) could give filmmakers an idea of what their script might be rated before shooting begins. It may also warrant some concern, though, as to how much interference with source material could affect the 
overall story the film is trying to portray. Using a more specific case study, participants in Schmeink's (2016) survey had selected children's story the least frequently as the type of story audiences associated with The Hobbit movies, largely due to violence and scariness. Such a study reveals how the manipulation of source material may be done by filmmakers in order to gain the desirable PG-13 rating. Therefore, a closer investigation of the language of films that have similar storylines but different ratings may help illustrate how a message is conveyed differently at each rating.

Parents played an interesting role in one study finding that middle school students had seen a median of 17 out of 50 films classified as "extremely violent," many of which contained sexual violence (Sargent et al., 2002). Older children, particularly males and/or those whose parents did not have a high school education, were more likely to have seen an extremely violent film (Sargent et al., 2002). Moreover, 55\% of 9 to 12 -year-old children in another study were permitted to watch R-rated films, with about $51 \%$ of parents checking a film's rating beforehand (Dalton et al., 2006). Such studies raise an interesting question as to parents' experiences and comfort with certain material that may influence whether or not their child would watch a certain film. It is important to note that the student samples in both studies were limited to Vermont and New Hampshire and future studies of students in other states would be necessary to draw broader conclusions. Lastly, and perhaps most concerningly, it is surprising to see that just over half of the parents consult the ratings before allowing their child to watch an R-rated film (Dalton et al., 2006). One potential reason that may contribute to this statistic may be the lack of detail provided about the ratings' justifications, which allows other organizations to 
explicate on the detail of a film. That being said, having more information directly offered from CARA itself may help it gain credibility among parents.

One final area of investigation in the literature is concerned with the validity of ratings across film and other media. In a sample of 276 films which were evaluated by parents, one study concluded that only $63 \%$ of PG films were given the "green light" for 8-12-year-olds, compared to $60 \%$ of PG-13 films for 13-17-year-olds (Walsh \& Gentile, 2001). However, elements of the sample selection remain unclear, including the years in which the films were released and how "popularity" is determined. This may intuitively represent high-grossing films, but may also be determined based on other objective or subjective factors. Another study used developmental and social science research to discover differences in how younger and older children interpret violent and sexual images on screen, which is not reflected in the current rating system. The study comments on the flaws of the current system in assigning their ratings based on the amount rather than context of sex and violence (Wilson, Linz, \& Randall, 1990). Such studies may have been important instigators in discussing how ratings could be given to films; that being said, they were done between 20-30 years ago. It is somewhat surprising that these have not inspired more discussions about instilling content-based ratings rather than aged-based ratings in the present day (Leone \& Osborn, 2004). Although age is a relatively easy means to categorize individuals, it may not be an accurate determinant of everyone's development at a given stage of life (Wilson, Linz, \& Randall, 1990).

Each of these sections presents important findings with regards to the portrayal of more contentious topics on screen and the potentially harmful effects on (young) audiences. Where language may be considered as a unique factor, however, is that the 
content of language may overlap with every one of these subjects. Perhaps this may be a contributing factor as to why it has been researched in less depth than these other topics, as language may contribute to the portrayal of sex, violence, or drug use. In the case of language, however, the directions of previous studies have concentrated on the mere appearance of certain words without spending as much time discussing their repercussions within a story.

\subsection{Research Gap}

As discussed, there is relatively little linguistic and communication research on the language used in films, and even less studying teenaged or child dialogue. The literature found which discuss films, ratings, and film language help shed light on different categories of words that appear in films (Bonsignori, 2015; Bram \& Putra, 2019; Ciampi, 2015; Cressman et al., 2009; Krisnadi \& Ardi, 2018; Kristiano \& Ardi, 2018; Probosini, 2020; Ratri \& Ardi, 2019; Zanotti, 2012). The vast majority of studies in this review focus on the existence and quantity of particular types of words in films, such as swearing or inappropriate language (Cressman et al., 2009; Bram \& Putra, 2019; Kristiano \& Ardi, 2018; Zanotti, 2012), miscommunication (Aryani, 2016), and types of English phrases (Bonsignori, 2015; Ciampi, 2015; Krisnadi \& Ardi, 2018; Zanotti, 2012). In addition, some studies consider the translation concerns of English films into other languages, discussing how some of the original words and meanings may be lost or manipulated in this process (Zanotti, 2012; Bonsignori, 2015; Ciampi, 2015; Ciampi, 2019). Furthermore, many of these studies offer a positive contribution in attempting to clarify (or, at least, address the concern of) ambiguous modifying terms used to justify a film's rating (Leone \& Barowski, 2011; Leone \& Houle, 2006; Leone \& Osborn, 2004; 
Potts \& Belden, 2009; Thompson \& Yokota, 2004; Shafaei et al., 2020; Walsh \& Gentile, 2001; Wilson, Linz, \& Randall, 1990). Several of these studies also use a diachronic approach to examining language and ratings, meaning that they investigate the change of language use or rating justifications over a period of time (Bonsignori, 2015; Callister et al., 2011; Cressman et al., 2009; Leone \& Houle, 2006; Leone \& Osborn, 2004; Potts \& Belden, 2009; Thompson \& Yokota, 2004). In addition, other studies consider the potential influences of film ratings amongst young viewers, many of which are concerned with factors apart from language (Callister et al., 2011; Dalton, et al., 2006; Sargent, 2005; Sargent et al., 2002; Tynan et al., 2019).

All of that being considered, many of the studies in this review either examine the existence of individual words, or the holistic purpose of an entire line of dialogue. However, there has been little consideration paid to how words are strung together within clauses and sentences to illustrate how film characters use language. Only a few studies have investigated the functions of language in specific films (Webster, 2017; Ciampi, 2015; Bram \& Putra, 2019; Probosini, 2020; Ratri \& Ardi, 2019). The majority of studies that examine language functionality focus on one component of the language itself rather than a deeper exploration of the repercussions of these words amongst other characters. In addition, the scopes of many previous studies have been quite large, either examining changes over several years or using a corpus of hundreds or thousands of films to indicate macro-level trends. Even with studies that focus on individual films, there is still a larger interest in the frequency with which linguistic items appear in dialogue.

Furthermore, when exploring the ratings and descriptors over time, the language analyses appear more quantitative in nature, and are often combined or conflated with 
analyses for sex, violence, and drug use. The studies that focus solely on language and film ratings are primarily concerned with the frequency and explicitness of profanity without paying as much attention to how it is being used. In particular, there has been little consideration of how one character's language may change or evolve during their story as seen through their interactions with other characters. Through this lens, language may provide additional insight into the worlds and development of the characters, and may further reveal if differences exist in language use among films of different ratings. Lastly, there have been few studies of film language that have examined films between 2010-2019. Exceptions to this have examined The Wolf of Wall Street (Bram \& Putra, 2019) and Spider-Man: Into the Spider-Verse (Krisnadi \& Ardi, 2019), but there has not been a great deal of research published within the last 10 years about the last 10 years in terms of film dialogue analysis.

This thesis will address a current research gap by discussing how teen characters' language changes over the course of a film as seen through their relationships with other teens. This perspective may invite the possibility to consider that language use may differ at a given point in a story so as to reveal different stages of maturation that a character may reach during their journey. In this regard, the adolescent years provide a favourable age range to study character development, not only to contribute to underdeveloped research, but because this age group is often attributed with coming-of-age narratives (Schmidt, 2002). Furthermore, this thesis will also compare findings across films of different ratings that feature adolescent characters. In this way, a closer investigation of filmic dialogue may clarify some of the ambiguity in film ratings that considers language to be a key reason behind assigning a rating. 
The term language encompasses many more features of communication than individual words, which requires a theoretical framework that will explain how language may be organized and applied in real situations. In this regard, the theories of peer talk and SFL may help explain aspects of (teen) language in coming-of-age stories, as will be discussed in the following chapter. As Webster (2017) claims, "studies of dialogue in drama and verbal art" are "where the linguistic resources for conveying interpersonal meaning become the stuff of artistic craft and genius" (p. 8). 


\section{Chapter 3: Theory and Definitions}

This chapter will introduce key theories to help guide the forthcoming study. The selected theories are believed to best address the research questions by providing an understanding of age-related and situational uses of language. These theories will later be used to interpret results and reveal how two films of different ratings use language. Section 3.1 discusses peer influence and specifically peer talk that will examine the purpose and nature of (verbal) interactions that take place amongst children and teenagers. Peer influence and talk may allow deeper understanding as to how teen characters use language to be realized as legitimate community members amongst peers who contribute to one's coming of age (Ochs \& Schieffelin, 2011). Furthermore, Section 3.2 defines and provides a historical background of coming-of-age in literature and film, as it is a popular narrative trope in stories starring young characters. Finally, Systemic Functional Linguistics (SFL) in Section 3.3 focuses on language use and its functions that will analyze situations in which peer talk is taking place. By applying SFL to a film context focusing on teens, this study may reveal the linguistic structures of young characters' dialogue in films of different ratings.

\subsection{Peer Influence and Peer Talk}

Before immediately discussing the meaning of peer talk, it is important to first establish a few key terms and overarching principles that contribute to this theory. This section will begin by outlining how adolescent and other related terms will be defined, followed by an explanation of peers and peer culture that will help situate peer talk.

\subsubsection{Defining adolescent, child, and youth}


Multiple terms may be used to describe young people, although there is no single, ubiquitous label that is used to define this group (The UN Refugee Agency, 2001). Age and biological development are commonly cited as reasonings for classifying an individual as a child or adolescent (UNHCR, 2001). Before proceeding with definitions from different fields of study, it is worth noting that cultural values and events may be a more important signifier as to whether or not a young person has been ushered into adulthood (UNHCR, 2001). This is particularly true for the period of adolescence where, depending on the culture, young people may be allowed or restricted from behaving in a certain way or performing certain activities (UNHCR, 2001; Androutsopoulos \& Georgakopoulou, 2003). For the purposes of this thesis, age will act as a starting point in defining youth, followed by a brief exploration of various events and stages that may be experienced during that time through a Western lens.

From a humanitarian perspective, UNICEF (1989) identifies a child to be any person under the age of 18, although the UNHCR (2001) claims that age alone is not a sufficient measure by which to determine who is seen as a child. Meanwhile, a developmental perspective may distinguish more specific phases within this age period based on key events and behaviours that typically take place at particular times. The American Academy of Pediatrics (2020) refers to developmental milestones as "the average ages when children develop new skills or abilities, related to moving, speaking, learning, socializing, and caring for themselves" (para. 2). Erik Erikson proposed an eight-stage approach to psychosocial development across the lifespan, with the fifth stage of adolescence occurring between ages 12-18 (Gilleard \& Higgs, 2016; McLeod, 2018). This fifth stage is marked physically by the onset of puberty and psychosocially as the 
transitory period wherein adolescents negotiate "the morality learned by the child, and the ethics to be developed by the adult" (Erikson, 1950, p. 263) in a search for their own identities (Gilleard \& Higgs, 2016; McLeod, 2018). These identity searches involve a discovery of the roles they inherit upon reaching adulthood. As Erikson (1950) notes:

... it is the ideological outlook of a society that speaks most clearly to the adolescent who is eager to be affirmed by his peers, and is ready to be confirmed by rituals, creeds, and programs which at the same time define what is evil, uncanny, and inimical (p. 263). For the purposes of this thesis, I will consider an adolescent and a teenager to be a person between and including the ages of 12-18, in line with Erikson's stages of psychosocial development. In addition, this will account for the soft age barriers used in studies examining film rating appropriateness, which considers those within ages 13-17 to be suitable age groups for the PG-13 film rating (Walsh \& Gentile, 2001; Wilson, Linz, \& Randall, 1990). Thus, allowing one extra year on each end of this range may account for a transition period one undergoes into and out of adolescence. Furthermore, I will also consider a child to be anyone between the ages of $0-11$ years old, and youth as the broader term referring to all young people aged 18 and below. As noted by Androutsopoulos and Georgakopoulou (2003), youth is not a term intended to assume a homogeneous adolescent experience, but rather to distinguish this demographic from an adult population. In order to understand adolescent peer dynamics and relationships which may contribute to linguistic behaviour, the following subsection will discuss peer culture as it relates to older children and adolescents.

\subsubsection{Peer culture, groups, and influence}

Youth culture was first introduced in academia as the period where adolescents gain an autonomy not granted during childhood while rejecting the roles that they must 
inherit as adults (Parsons, 1942). Role confusion is also the key conflict mentioned by Erikson (1950) who, as previously mentioned, discussed the strain teenagers face in negotiating ideologies between childhood and adulthood. Peers play an increasingly valuable role in this transitory period as teenagers begin spending more time together and initiating informal groups themselves rather than relying on group formation from adults (Brown \& Dietz, 2009).

Merriam-Webster (2020) defines a peer as "one that is of equal standing with another... especially: one belonging to the same societal group especially based on age, grade, or status" (entry 1). That being said, there is some room for variance as to who may be considered a peer among adolescents. Some open-endedness exists as to what constitutes a peer group due to factors like size, membership, inter- and intra-group dynamics, and effect on individual beliefs and behaviours (Brown \& Dietz, 2009). Some uncertainty exists on the topic, given that it is difficult for adults to study younger peer dynamics without infiltrating their authentic actions (Brown \& Dietz, 2009). For this study, I will be considering adolescent peers to be two or more characters within the 1218-year-old age range who interact with one another.

Peer relationships may become more complex in adolescence due to a higher frequency of peer interactions and adoption of more complex interpersonal behaviours; these actions may reflect teens' search for both individual identity and group validation (Kirkham \& Moore, 2013). In addition to weaving through different types of relationships, one's status or popularity within dyads and groups, although fickle, become more important due to the reciprocal influence among peers (Brown \& Larson, 2009). Adolescent peer influence may also be the result of selection and socialization effects 
(Brechwald \& Prinstein, 2011). The former sees how teens associate with people sharing common interests, while the latter examines the gradual convergence of behaviours that peers exhibit over time. Establishing peer groups based on similar interests or features may prompt adolescents to give themselves or others labels that reflect these characteristics or lifestyles (Sussman et al., 2007). Teenagers may become more competent in peer communication and gain a unique group identity (in part) through peer talk (Goodwin \& Kyratzis, 2011).

\subsubsection{Teen language and peer talk}

Peers play a key role during the transitory period of adolescence in influencing many social behaviours, including how one speaks (Stenström, Andersen, \& Hasund, 2002). Even though teenagers "too often are defined as inadequate communicators or language users" (Thurlow, 2003, p. 51), there is little research of language use and communicative competence beyond early childhood. This is surprising given the fact that a great deal of language skills are developed after one enters grade school. The tendency of research on "language and its role in living and in learning... has been to focus on aspects of language and literacy for the early or the middle years" (Christie, 2012, p. 1). That being said, research at the secondary school level does exist, albeit less consistently (Christie, 2012). However, it is naive to assume that linguistic development ends once a young child learns the building blocks of a given language, or, that adolescent language use is less deserving of academic inquiry. From an SFL perspective, understanding such developments may be helpful in improving educational practices. In other words, "[b]y achieving a linguistic description of the nature of the changes over the years of 
childhood, adolescence, and young adulthood, we have a powerful tool with which to address students' development in schools." (Christie, 2012, p. 3).

Later language development, according to Nippold (2006), may be considered as the linguistic changes that take place from age six onward. Although much of one's language acquisition takes place before age six, the later years see a refinement of skills that reflect "metalinguistic, cognitive, and social development; the newly acquired ability to read; and growth in world knowledge and experience" (Nippold, 2006, p. 369). Between the ages of 12-20, significant developments take place in areas of syntax, semantics, and pragmatics (Nippold, 2000). For instance, teenagers have been found to properly use longer and more complex clauses (Nippold, 2014) and understand more figurative expressions (Nippold, 2006). Teens spend more time with peers and not only speak with them more frequently, but discuss topics that they would not necessarily speak about with their families (Nippold, 2014; Nippold, 2000). In addition, teens show an improved intuition with regards to social etiquette, turn-taking, asking questions, and improved narrative, expository, and persuasive discourse (Nippold, 2014).

Adolescent language may be associated with characteristics such as "[v]ernacular use, linguistic creativity, [and] playfulness" among others (Androutsopoulos \& Georgakopoulou, 2003, p. 5). In addition, language is a key tool used by teenagers to experiment with and formulate their identity, and further identify with peer groups (Androutsopoulos \& Georgakopoulou, 2003; Kirkham \& Moore, 2013). As said by Stenström, Andersen, and Hasund (2002):

One thing the youngest and oldest teenagers have in common is their concern about friendships, relations and social networks. In fact, most of the conversations, regardless of the speakers' age, revolve around this. There is, of course, nothing exclusively youth- 
like in being concerned about friendship, but the intensity and amount of time they spend talking about it reflects that adolescence is a period in life where identity building is largely formed in peer group interaction. Who you are is largely a matter of who you hang out with. (p. 29, emphasis added)

Language is a key mechanism through which young people may socialize one another into peer groups (Kyratzis, 2004). As discussed, peer interactions during adolescence increase in terms of frequency and complexity, meaning that teens use language in creative ways with one another to create a distinct culture from that of adults (Androutsopoulos \& Georgakopoulou, 2003). The field of peer talk as a form of peer interaction studies the linguistic exchanges that take place among children and teenagers. Sometimes this may take place in teaching scenarios, but most often may manifest in deeming what norms are considered appropriate and inappropriate (Goodwin \& Kyratzis, 2007). This differs from other forms of peer exchange in its belief that children are agents in their own learning and socialization, with natural language being the key data source in research (Blum-Kulka \& Snow, 2004). Peer talk research among children is much less developed than child-adult interactions, and may be rooted in a variety of linguistic, social science, or educational perspectives (Blum-Kulka \& Snow, 2004). What is crucial about youth's peer talk is that it is not simply a replication of adult language in younger people. Rather, youth language helps children and teens build their own, wholly unique culture that they actively create and maintain through language (Kyratzis, 2004).

The theories of peer influence and peer talk demonstrate how powerful of a role fellow teens play in one another's lives during the transitory period of adolescence. Research in this field acknowledges both the creativity of young people's language and the influence they have on one another. That being said, many of the studies in Chapter 2 
on film language have emphasized what is being spoken, with less consideration of who is speaking and how they are doing so. By exploring these latter two components among teen peers in film, this thesis will unpack how language may show teen characters coming-of-age, and how this may vary by film rating.

\subsection{Coming-of-Age Narrative}

Origins of the coming-of-age narrative may be traced back to $18^{\mathrm{h}}$ century German literature, through a genre known as the Bildungsroman (plural: Bildungsromane). Translating to 'formation novel' (bildung + roman), such stories originally referred to "the early emotional development and moral education of its protagonist" (Millard, 2007, p. 2). The Bildungsroman thus features a protagonist facing novel situations, which help produce an inward change as the protagonist navigates between social and individual realms (Garrett, 2019). Within an American context, the literary Bildungsroman has been characterized by high intensity and explicitness in how protagonists share their struggles of transition. This garnered criticism from European writers for the exposure of characters' privacy, leaving almost no area off-limits for deep, sometimes humiliating self-explorations (Tolchin, 2000). In spite of these remarks, the Bildungsroman has been particularly resonant within American culture, as it may be seen as a reflection of the United States' emancipation from British rule (Millard, 2007). In a sense, the USA has had to endure their own "coming of age," establishing their own norms and practices as a result of their independence. Thus, the coming-of-age tale may mirror a nation's journey to discovering their own identity through the adventures of an individual character. It is also worth noting that coming of age is not exclusive to the teenage years, as the term may reflect growth and maturity at any age or stage of life. That being said, the narrative 
has typically focused on the childhood or adolescent transitions into adulthood, which may be more easily relatable to wider audiences. Young protagonists have also been an effective metaphorical stand-in as representations of the cultural zeitgeist at a particular point in history (Schmidt, 2002).

It was not until the mid-1950s that deep, challenging explorations of young people could be found on American film. With families being drawn towards the novelty of television, the film industry began catering to teenage audiences, which contributed to the conception of a "teenager" emerging within popular culture (Schmidt, 2002). Films starring James Dean, such as Rebel Without a Cause, had early depictions of teenage angst and struggles from a complex protagonist's point of view (Schmidt, 2002). The burgeoning youth culture also brought concerns over the dismantling of an image of a homogenized, middle-class America that had been striving for uniformity (Bernstein \& Chatelain, 2016). In spite of the threats of teenage rebellion, films that depicted the complexities of young people proved to be quite popular, and thus represented a shift within the film industry to cater to younger audiences.

Coming-of-age films gradually saw the inclusion of more "sexually and socially provocative content" in the 1960s (Schmidt, 2002, p. 60). The acceptance of such material among audiences contributed to the end of the Hays Code and creation of the MPA ratings. As a result, the late 1960s and early 1970s depicted a "cultural revolution in American social values" (Schmidt, 2002, p. 91) amidst the backdrop of the Vietnam War and African American civil rights movement. The late 1970s and 80s' bawdy teen comedies may be seen as a renaissance period for teen films that gradually included a wider representation of characters (Driscoll, n.d.; Hughes, 2019). This continued into the 
1990s which shed more light on perspectives from the African American community (Schmidt, 2002). The late 1990s and early 2000s explored more narratives with female protagonists, though not always in a positive light (Kelly \& Pomerantz, 2009). The 2000s and 2010s saw many adaptations from young adult novels and book series, which may be seen as more direct descendants of the Bildungsroman (Lynley, 2017). Furthermore, these films examined the ups and downs of friendships and relationships, with LGBTQ+ characters, digital technologies, and mental health playing a larger role in the $2010 \mathrm{~s}$ (Corrigan, 2012; Smith, 2012; Roberts, 2019).

The coming-of-age genre is not always easy to identify, as it has the ability to borrow tropes from other well-established genres and thus may lack some conventions on its own (Schmidt, 2002). That being said, it resembles the Bildungsroman in how it portrays a (young) character's journey as they enter into a new situation or acquire new knowledge, accepting the uncertainties they are almost guaranteed to face (Roberts, 2019). Sometimes this involves physically leaving a comfortable place or experiencing physical changes as they journey to a new place (Bernstein \& Chatelain, 2016), while other films feature conflict and relationships with parents, friends, siblings, or lovers (Schmidt, 2002). At other times, coming-of-age stories serve to more deeply explore a character's emotional struggles, loneliness, or loss of innocence (Schmidt, 2002). These combinations may vary depending on the stage of life being examined, yet all of these factors contribute to the decisions made, crises experienced, and transitions achieved by entering a new phase of life. 


\subsection{Systemic Functional Linguistics}

This study will rely on SFL both for a theoretical understanding of language and the analytical framework for examining film dialogue. The theory of SFL sees language as a social semiotic system, with social pertaining to how people use language in context and semiotic in that language exists as a series of choices used to make meaning (Eggins, 2004). In other words, language users select the appropriate aspects of language to carry out a social function. The two basic purposes of language in one's environment, as suggested by Halliday and Matthiessen (2004), are to make sense of our experiences and enact social relationships. Thus, rather than seeking to determine the correctness of one's grammar, functional analyses examine language as it is naturally used in context and determine what purpose each linguistic unit serves in a clause, as well as the role of clauses in a larger text (Eggins, 2004). As such, labels are assigned to linguistic units based on the purposes they serve in relation to the rest of the text, rather than identifying isolated parts of speech (Christie, 2012). Furthermore, SFL focuses on the systemic role of language, in that it explores linguistic patterns in everyday occurrences that are reflective of the larger system in which it takes place.

\subsubsection{Linguistic metafunctions and register}

In order to understand how language is used in particular contexts, SFL outlines three linguistic metafunctions that describe different qualities of the language (Halliday \& Matthiessen, 2004). In other words, three kinds of meaning are being conveyed about language in any given instance where language is being used (Eggins, 2004). The first of these is the ideational metafunction which identifies what is being discussed in a piece of text. The second metafunction is the interpersonal metafunction that explores who is 
involved and the relationship they share through a text. Lastly, the textual metafunction examines how language is organized and communicated through a particular medium. Identifying the meanings conveyed through these metafunctions may help determine the purpose language is serving in a particular register.

Halliday and Matthiessen (2004) define register as "a functional variety of language" (p. 27), meaning that linguistic choices are made based on what is deemed appropriate in particular situations. Within a given context, SFL sees register as being enacted by the language choices made in an immediate and specific situation as part of a broader culture. As such, SFL recognizes three register variables that correspond with the three linguistic metafunctions to describe how language is used in a given situation (Eggins, 2004). The first of these variables is the field, which describes the ideational content or subject matter being discussed in the language. Secondly, the tenor variable accounts for the interpersonal dimension by examining the people involved and the relationship they share. The third register variable is that of mode, which determines the textual qualities of spoken or written language that may exhibit tendencies of a given medium (Eggins, 2004; Bloor \& Bloor, 2004).

For example, this thesis may be considered a register or a specific situation that reflects and reproduces the linguistic structure of master's theses at Carleton University. The field of this thesis is a study that was conducted on film language and film ratings using SFL. The tenor may explore the relationship between myself, the master's student authoring this thesis, and my supervisors and thesis committee, and potentially academics, parents, or members of the film industry. Lastly, the mode may see this as a written document that exhibits more tendencies pertaining to formal written language as 
opposed to spoken language. A summary of the linguistic metafunctions and their corresponding register variables and analytical systems may be seen in Table 2.

Table 2: Linguistic Metafunctions and Register Variables (adapted from Eggins, 2004)

\begin{tabular}{|c|c|c|}
\hline METAFUNCTION & DEFINITION & REGISTER VARIABLE \\
\hline $\begin{array}{c}\text { Ideational } \\
\text { (What?) }\end{array}$ & What is being talked about & Field \\
\hline $\begin{array}{c}\text { Interpersonal } \\
\text { (Who?) }\end{array}$ & $\begin{array}{c}\text { The relationship roles } \\
\text { between interactants }\end{array}$ & Mode \\
\hline $\begin{array}{c}\text { Textual } \\
\text { (How?) }\end{array}$ & $\begin{array}{c}\text { The role of language in the } \\
\text { interaction }\end{array}$ & \\
\hline
\end{tabular}

This study places a particular emphasis on the mode and tenor register variables as revealed through the textual and interpersonal metafunctions, respectively. The following sections will explain the necessary terms that will be used to understand the register analysis described in Chapter 4.

\subsubsection{Mode: Lexical density, grammatical intricacy, and thematic structure}

The three components of the textual metafunction used in this study to help uncover the dialogue's mode are lexical density, grammatical intricacy, and thematic structure. Lexical density refers to the number of open-class, content carrying words in proportion to all words used. Eggins (2004) defines content carrying words as nouns, main verbs, adverbs, and adjectives. Thus, non-content carrying words consist of prepositions, conjunctions, auxiliary verbs, and pronouns (Eggins, 2004). For example, a lexically sparse clause might say that the dog jumped, but a denser version of that clause might add that the large, five-year-old golden retriever jumped. Both dog and large, fiveyear-old golden retriever refer to the same core concept, however the latter constituent contains more content carrying terms to convey that idea. 
The second component involves examining the grammatical intricacy, which refers to the number of clauses found in a sentence. A clause may be indicated by the inclusion of at least two word groups that show structural agreement and a shared descriptive function (Bloor \& Bloor, 2004). For example, The dog jumped may be considered one clause and one sentence (which is also called a clause simplex). However, The dog jumped while the cat was sitting quietly on the fence contains two clauses in one sentence (i.e. a clause complex): The dog jumped and while the cat was sitting quietly on the fence. It is also worth noting that a group is a grammatical unit containing one or more words that refer to the same core concept. For example, the dog is a noun group consisting of an article the and a noun $\operatorname{dog}$.

Lastly, the thematic structure identifies the content being disclosed at the beginning of a clause (Bloor \& Bloor, 2004). Studying the thematic structure may help reveal the significance of ordering the linguistic components in a particular way so as to achieve a communicative purpose. Thematic components may be identified within one of two categories, the first of which is that of theme. Defined as "the point of departure in the message" (Halliday \& Matthiessen, 2004, p. 64), the theme(s) is/are the contents found at the start of a clause. Themes may be further specified as topical, interpersonal, or textual in nature. The topical theme is represented by the first process (verb group), participant(s) (noun group), or circumstance (prepositional phrase) from which all other ideas are stated (Bloor \& Bloor, 2004). A clause may only have one topical theme; in other words, the first process, participant, or circumstance that appears in a clause is assigned as that clause's topical theme. Before the topical theme, however, might appear one or several interpersonal or textual themes. Both types of themes may introduce or 
continue a line of thought without containing the core material in the topical theme. Their key difference, however, lies in the personal value being added or implied through a given term. Interpersonal themes, as the name suggests, may add an expression of one's opinion or attitude, or otherwise acknowledge another party. Textual themes are more neutral conjunctive terms which continue from a previous idea, and may also take the form of verbal pauses and hesitations such as $u m$ or $u h$ (Bloor \& Bloor, 2004). The second category of thematic structure is that of rheme, which constitutes all of the remaining parts of a clause following the topical theme.

The following three examples illustrate how the thematic structure of sentences may be labelled:

Example 1: The dog jumped.

\begin{tabular}{|c|c|}
\hline The dog & jumped. \\
\hline Theme:topical (participant) & Rheme \\
\hline
\end{tabular}

Example 2: In September, the dog had jumped over the fence.

\begin{tabular}{|c|c|}
\hline In September, & the dog had jumped over the fence. \\
\hline Theme:topical (circumstance) & Rheme \\
\hline
\end{tabular}

Example 3: Well, dear reader, in September, the dog had jumped over the fence.

\begin{tabular}{|c|c|c|c|}
\hline Well, & dear reader, & in September, & the dog had jumped over the fence. \\
\hline Theme:textual & Theme:interpersonal & Theme:topical & Rheme \\
\hline
\end{tabular}

Studying the textual metafunction within teen characters' film dialogue shows some similarities to research conducted by Nippold (2000; 2014) regarding teens' syntactic clause constructions. However, this thesis uses an SFL framework to discover the creativity and functions of the choices made for teen dialogue. Studying dialogue in a film script presents an intriguing area for SFL analysis, given that scripts are written 
documents intended to be orally performed by multiple speakers. Written and spoken language exhibits different tendencies, not only in terms of spontaneity but also in complexity. Spoken discourse is often found to have lower lexical density (i.e. fewer content carrying words in relation to all words) and higher grammatical intricacy (i.e. many clauses per sentence) (Eggins, 2004). However, written language is typically the opposite - showing higher lexical density (i.e. more content carrying words in relation to all words) and lower grammatical intricacy (i.e. fewer clauses per sentence) (Eggins, 2004). Therefore, this textual analysis also may reveal if film scripts may have closer resemblance to spoken or written texts. Furthermore, studying the organization of various themes within these sentences may reveal if there is significance to how such content is ordered. Foregrounding particular types of words might offer insight as to how films of different ratings introduce new dialogue and enact personality traits of their characters.

\subsubsection{Tenor: Power, contact, and affective involvement}

In SFL, an interpersonal analysis may help determine a text's tenor to provide insight into the amount of power, frequency of contact, and level of affective involvement that characters bring to a scene (Eggins, 2004). In addition, given that films are also communicating to a real-world audience, there may also be information being conveyed to people watching the film that may also be considered. To extract this information, the roles and attitudes of speakers and recipients in dialogue revealing peer dynamics may be studied through the MOOD system. The MOOD system involves breaking down clauses to identify five functional components:

- Subject: The noun or pronoun group which is performing the action in the clause. 
- Finite: The first verb in a verb group which "makes the proposition definite" (Eggins, 2004, p. 152).

- Predicator: The remaining elements of the verb group; in clauses with only one verb, the Predicator and Finite may be represented as the same verb.

- Complement: A noun group that is being affected by an action.

- Adjunct: An additional component related to circumstance, modality, assessment, polarity, or continuation from a previous clause.

These five labels are also grouped according to their membership to the clause's MOOD (Subject, Finite) and RESIDUE (Predicator, Complement, Adjunct). The MOOD contains the core argument being expressed in a clause, while the RESIDUE contains more descriptive information that adds context to the MOOD.

The following example clauses have been labelled using MOOD structures:

\section{Example 1: The dog jumped.}

\begin{tabular}{|l|l|l|}
\hline \multicolumn{2}{|c|}{ The dog } & \multicolumn{2}{c|}{ jumped. } \\
\hline Subject & Finite & Predicator \\
\hline & & RESIDUE \\
\hline
\end{tabular}

Example 2: Did the large, five-year-old golden retriever jump?

\begin{tabular}{|c|c|c|}
\hline Did & the large, five-year-old golden retriever & jump? \\
\hline Finite & Subject & Predicator \\
\hline & MOOD & RESIDUE \\
\hline
\end{tabular}

Example 3: The dog jumped while the cat was eating food in the house.

\begin{tabular}{|l|l|c|}
\hline The dog & \multicolumn{2}{|c|}{ jumped } \\
\hline Subject & Finite & Predicator \\
\hline \multicolumn{2}{|c|}{ MOOD } & RESIDUE \\
\hline
\end{tabular}




\begin{tabular}{|c|c|c|c|c|c|}
\hline while & the cat & was & eating & food & in the house. \\
\hline Adjunct & Subject & Finite & Predicator & Complement & Adjunct \\
\hline & \multicolumn{2}{|c|}{ MOOD } & \multicolumn{3}{c|}{ RESIDUE } \\
\hline
\end{tabular}

In summary, the theory of SFL states that language is realized among a set of choices that must be understood in relation to its context (Bloor \& Bloor, 2004; Halliday \& Matthiessen, 2004). SFL also identifies three types of meaning being communicated through language: the subject matter, the people involved, and the method of delivery. As noted in past chapters, the MPA ratings system largely justifies language-based decisions on profanity usage. In SFL terms, the ratings evaluate the ideational content that helps justify the field of a particular film. However, the interpersonal and textual metafunctions have not been given the same degree of consideration from a ratings perspective. This is a critical area to consider as the ideational content only accounts for one-third of the variables which constitute context. Furthermore, the field of language is highly sensitive to both tenor and mode, as the relationship among speakers and textual resources available may strongly motivate what information is communicated. Therefore, this study focuses on how the registers of a PG and PG-13 rating portray interpersonal and textual dimensions of language among characters who reflect the age demographic most affected by ratings. An SFL analysis of film language may provide unique revelations of the linguistic tactics used to showcase characters and situations. 


\section{Chapter 4: Methods}

This chapter explains how the forthcoming study was conducted as well as the rationale behind this method. Having discussed the theoretical foundation in Chapter 3 , this section outlines the practical steps taken to design this study, collect data, and analyze the findings. This will illustrate one approach through which SFL may be used to reveal linguistic choices in film dialogue. In addition, this method has been selected to specifically address the research questions and sub-questions:

Do the linguistic choices of teenage characters in teen-centred films vary based on a film's rating, and if so, how?

a) How do these choices vary textually between films with different ratings?

b) How do these choices vary interpersonally because of the relationship between teen characters?

Section 4.1 outlines how the data were selected; that is, the specific films and characters. In addition, this section briefly summarizes each film to provide a basic foundation of their plotlines. Following this overview, Section 4.2 explains and justifies the process by which the data will be analyzed in relation to the research questions.

\subsection{Data Selection}

Before beginning this study and selecting its films, a pilot study was conducted to examine scenes involving child or teenage characters from popular films released between the 1980 s and early 2000 s. The purpose of this small-scale investigation was to build a historical foundation of how young characters used language when interacting among their peers leading up to, but not including, the 2010s. In addition, many components of SFL were applied to this pilot study as a means of examining a wide range 
of language features. This helped determine which elements would become the primary criteria of analysis in the main study.

The current study selected one film from each of the PG and PG-13 film ratings that focused on adolescent characters in order to address the research questions. In addition, focusing on one film per rating encouraged a thorough investigation of characters' contexts and changing relationships. The PG and PG-13 ratings were decided upon as these ratings are accessible to younger audiences who may witness characters close to their age behaving on screen. Some research has explored the distinction between the unrestricted PG-13 and restricted R ratings (Afra, 2016; Leone \& Houle, 2006), although less attention has been exclusively paid to PG and PG-13 distinctions.

The selection of the two films was inspired by Cressman et al.'s (2009) corpus of the highest-grossing American teen films from the 1980s, 1990s, and 2000s. Cressman et al.'s (2009) criteria of what constitutes a teen film required that a film:

- contains a storyline focused on teens aged 12-17 years (this thesis extended the age range to 18 years);

- has a teenage protagonist; and

- has teenage major and minor characters.

The highest-grossing PG and PG-13 films from the 2010s on BoxOfficeMojo.com that met the above criteria were selected for this study. This ensured a methodical selection procedure based on audience popularity that discouraged any researcher bias.

This resulted in the two films being the PG-rated How to Train Your Dragon (2010) and PG-13-rated The Hunger Games (2012). Both films contain a coming-of-age storyline featuring teenage characters undergoing internal transformations as a result of 
their changing external circumstances. Although no researcher preferences were placed into the selection of these films, they present a few similarities that may lend themselves well for analysis. Firstly, both films were adapted from youth-oriented book series and were the first film entries in their respective film franchises. In addition, both films are set in other time periods, with How to Train Your Dragon occurring in a Viking past and The Hunger Games in a dystopian future. This contrasts many previous studies that have focused on teen films that focus on characters in present-day American school settings (Zanotti, 2012; Bonsignori, 2015; Ciampi, 2015; Ciampi, 2019). That being said, there is a training element in both films that is evocative of a school context.

\subsubsection{How to Train Your Dragon (2010)}

Dragon centres around a 15-year-old boy named Hiccup, who is the son of a Viking village leader. Hiccup has been perceived by the villagers to be significantly inferior to his father, both in his scrawny appearance and timidity around dragons, who are the village enemies. Hiccup has reached an age that allows him and his peers to enroll in dragon training, where pupils learn how to defeat and kill dragons. While walking through the woods, he finds a night fury dragon that he had injured on a previous night raid. Hiccup, initially perceiving himself as cowardly for not killing the dragon, forms a friendship with the creature and develops an affinity for peacefully handling dragons. This shocks his peers and villagers, especially when he refuses to kill a dragon for his final test. When his father and adult crew leave to find the nest of a dangerous mother dragon, Hiccup rallies his peers and teaches them that dragons are not so different from humans. The teens then travel to the nest to save the Vikings and dragons from the 
mother dragon, killing her in the process. The film ends with the humans and dragons peacefully living together, with Hiccup comparing the dragons to their pets.

\subsubsection{The Hunger Games (2012)}

Games takes place in the land of Panem, composed of 12 districts and an affluent Capitol. Each year, the districts must offer one male and female tribute aged 12 to 18 to participate in the Hunger Games, an event in which tributes must kill one another until one survivor is crowned a champion. In the impoverished District 12, 16-year-old Katniss volunteers as the female tribute in order to spare her 12-year-old sister, while male tribute Peeta is also conscripted. All of the tributes receive training prior to entering the Games; Katniss struggles with her likeability but earns high praise for her bow and arrow skills. Upon entering the arena, Katniss and Peeta are separated and Peeta's alliance unsuccessfully tries to kill Katniss. When it is announced that two winners may be crowned if they come from the same district, Katniss reunites with Peeta and forces a romantic relationship with him that earns sympathy from home viewers. When Katniss and Peeta become the final two tributes, the Capitol Gamemakers revoke their previous announcement so there can only be one victor. However, Katniss intends to rebel by eating poisonous berries with Peeta so that they die with no winner being crowned. Just before they do this, the Gamemakers yell at them to stop, announcing them both as the winners. Although they both return home, the victory leaves everyone unsettled as Panem's president is immensely displeased that someone successfully upset his system.

\subsection{Data Collection and Analysis}

Once the films were selected, a transcript of each film was retrieved online and both films were watched to corroborate the dialogue in the transcripts. In cases where an 
occasional word in the transcript slightly differed from the final movie dialogue, the movie dialogue was used in the analysis. This is because the final film is the only product that most filmgoers, parents and children alike, would have the opportunity to see. Therefore, the language that was actually used in the film is the primary reference that parents may have in the case that they want to contact the rating board.

After identifying the teen characters in each film, every situation which featured two or more of these characters talking with one another was identified as a scene. The scenes were divided in the transcript based on an indication that a new action and/or audience had changed the purpose of a given interaction. This involved both initiations of conversations as well as endings to those conversations, indicated either through dialogue or a written cue in the transcript itself (see Appendix A for characters' scene dispersions). Once the scenes were divided, each character's lines of dialogue were numerically labelled so as to provide a consistent reference point across all areas of analysis (see Appendix B for characters' line dispersions). Although an adult character would occasionally be present, no dialogue spoken by nor aimed towards the adult was analyzed in the study. This allowed the focus to remain on teenagers in light of the research questions, emphasizing teenage characters as both speakers and audiences.

The final list of characters whose dialogue was examined in both films may be seen in Table 3, along with their gender and age. In addition, each character was assigned one of three roles pertaining to the purpose they serve in the overall story, in line with Cressman et al.'s (2009) labels for teen-centred film characters. The protagonist is indicated by the character around whom the story is focused. The major character is indicated by the character who most directly assists in furthering the protagonist's story, 
sharing many one-on-one scenes with the protagonist. Finally, minor characters are identified as those who do not play as large of a role in furthering the main story, but still serve a functional purpose of building the story world. In total, six characters' dialogue were analyzed in Dragon (four male, two female), along with eight characters' dialogue in Games (four male, four female). A scene was thus indicated by the presence of two or more of the characters below; this typically involved characters in speaking roles, although some characters were occasionally non-speaking audience members.

Table 3: Teenage Characters Analyzed in Selected Films

\begin{tabular}{|c|c|c|c|}
\hline Film & Character & Demographics & Film Role \\
\hline \multirow{4}{*}{$\begin{array}{c}\text { How To Train } \\
\text { Your Dragon } \\
\text { (PG) }\end{array}$} & Hiccup & Male, 15 & Protagonist \\
\cline { 2 - 4 } & Astrid & Female, 15 & Major Character \\
\cline { 2 - 4 } & Ruffnut & Male, 14 & Minor Character \\
\cline { 2 - 4 } & Snotlout & Female, 14 & Minor Character \\
\hline \multirow{7}{*}{$\begin{array}{c}\text { The Hunger Games } \\
\text { (PG-13) }\end{array}$} & Fishlegs & Male, 15 & Minor Character \\
\cline { 2 - 4 } & Katniss & Female, 16, District 12 & Protagonist \\
\cline { 2 - 4 } & Primrose & Male, 17, District 12 & Major Character \\
& Thresh & Male, 18, District 12 & Minor Character \\
\cline { 2 - 4 } & Cato & Male, 18, District 11 & Minor Character \\
\cline { 2 - 4 } & Clove & Female, 15, District 2 & Minor Character \\
\hline
\end{tabular}

The textual and interpersonal metafunctions were then analyzed to best address the research questions with unique insight. These metafunctions would reveal qualities of each film's mode and tenor, respectively, to determine how dialogue was structured and 
who was involved. As addressed in Chapter 2 when explaining the research gap, the majority of past literature on film language and ratings emphasizes the meanings of words or phrases present in the language; in SFL terminology, the focus has been on the ideational content. Not only has this research rarely used SFL as a theoretical foundation or analytical method, but it has not deeply considered the textual and interpersonal dimensions of context. Therefore, dedicating this study entirely to the textual and interpersonal metafunctions would allow the comparison of language to be done with greater ease while offering the most unique research contribution.

The first area of analysis in addressing the textual metafunction is that of lexical density. For each character, every word in a given line of dialogue was coded as either a content carrying word (ex. noun, adjective, verb, etc.) or a non-content carrying word (ex. pronoun, preposition, conjunction, etc.). From this point, the percentage of content carrying words in relation to the total number of words spoken by that character was calculated, with the percentage representing the lexical density of their dialogue.

To determine the grammatical intricacy of each character's dialogue, the number of sentences were counted and coded as either a simple sentence (i.e. containing one clause) or complex sentence (i.e. containing more than one clause). Similarly, the percentage of simple sentences in relation to the total number of sentences spoken could be calculated for each character.

Finally, in examining the thematic structures, a theme analysis was conducted to determine how characters' dialogue was organized in terms of foregrounded content. Topical, interpersonal, and textual themes at the front of sentences, in addition to the rheme element at the end, were labelled for each line of dialogue. Once all of these 
language features were coded for each character, they were compared against other characters within the same film, as well as with characters across films.

For the interpersonal metafunction, each line of dialogue was labelled according to the five MOOD labels (Subject, Finite, Predicator, Complement, and Adjunct), and subsequently grouped as part of the MOOD or RESIDUE. From this information, the dialogue was analyzed in terms of the three components of tenor in a given register or situation - power, contact, and affective involvement. By studying the presence and location of MOOD labels in a line of dialogue, the functions of a character and their speech in a given scene could be explored in relation to other contextual details. Some of these details include the other characters present, the point in the story at which lines were said, and responses that the lines would trigger from other characters. One or two features from the MOOD analysis were analyzed for each facet of tenor to discover similarities and differences of their usage across characters and films. In this way, nuances could be determined within each film, while also exploring how characters of similar status across a PG and PG-13 film communicated their lines of dialogue.

The following chapter will summarize the results from this analysis, providing examples of key patterns that were found. 


\section{Chapter 5: Results}

This chapter summarizes key findings that were retrieved upon conducting an SFL analysis on How to Train Your Dragon and The Hunger Games transcripts. Both films explore coming-of-age narratives through teen protagonists (Hiccup in Dragon and Katniss in Games), major characters (Astrid in Dragon and Peeta in Games), and several minor characters. Following the division and coding of scenes and character lines (see Appendices A and B, respectively), the textual and interpersonal metafunctions were analyzed in the dialogue. This helped address the research questions' inquiry of film language variance in teen-centred films with different ratings. Furthermore, this draws attention to relatively underdeveloped areas of research in film dialogue by focusing on the mode (textual) and tenor (interpersonal) in linguistic context.

Section 5.1 examines the textual metafunction with regards to the ratio of contentcarrying words (lexical density), simple and complex sentences (grammatical intricacy), and foregrounded contents in those sentences (theme analysis). Section 5.2 analyzes the interpersonal metafunction according to three dimensions of tenor in a given situation: power, contact, and affective involvement as seen through the MOOD system. Appendix C shows the entire theme and interpersonal analysis for both films, with selected examples included in this chapter.

\subsection{Mode: Textual Metafunction}

The textual qualities of teen characters' dialogue in both films has been broken down in this section according to lexical density, grammatical intricacy, and thematic structure. Thus, the organization of these findings begins at the word level and moves outwards to studying the organization of these words and significance of this structure. 


\subsubsection{Lexical density}

The lexical density analysis explores the ratio of content- and non-content words.

Summarized results from the lexical density findings can be seen in Tables 4 and 5 to the nearest whole number, with the characters' rows colour-coordinated by sex.

Table 4: Lexical Density of Character Dialogue in How to Train Your Dragon

\begin{tabular}{|c|c|c|c|}
\hline Character & Total Words & $\begin{array}{c}\text { Content Words } \\
\text { (\% of Total) }\end{array}$ & $\begin{array}{c}\text { Non-Content Words } \\
\text { (\% of Total) }\end{array}$ \\
\hline Hiccup & 452 & $231(51 \%)$ & $221(49 \%)$ \\
\hline Astrid & 385 & $205(53 \%)$ & $180(47 \%)$ \\
\hline Tuffnut & 218 & $109(50 \%)$ & $109(50 \%)$ \\
\hline Ruffnut & 84 & $39(46 \%)$ & $45(54 \%)$ \\
\hline Snotlout & 130 & $73(56 \%)$ & $57(44 \%)$ \\
\hline Fishlegs & 136 & $79(58 \%)$ & $57(42 \%)$ \\
\hline
\end{tabular}

Table 5: Lexical Density of Character Dialogue in The Hunger Games

\begin{tabular}{|c|c|c|c|}
\hline Character & Total Words & $\begin{array}{c}\text { Content Words } \\
\text { (\% of Total) }\end{array}$ & $\begin{array}{c}\text { Non-Content Words } \\
\text { (\% of Total) }\end{array}$ \\
\hline Katniss & 651 & $347(53 \%)$ & $304(47 \%)$ \\
\hline Peeta & 481 & $261(54 \%)$ & $220(46 \%)$ \\
\hline Gale & 237 & $120(51 \%)$ & $117(49 \%)$ \\
\hline Rue & 110 & $48(44 \%)$ & $62(56 \%)$ \\
\hline Primrose & 26 & $15(58 \%)$ & $11(42 \%)$ \\
\hline Thresh & 20 & $11(55 \%)$ & $9(45 \%)$ \\
\hline Cato & 69 & $37(55 \%)$ & $32(45 \%)$ \\
\hline Clove & 50 & $26(52 \%)$ & $24(48 \%)$ \\
\hline
\end{tabular}


In both films, most characters had between $0-10 \%$ difference in the percentage of content and non-content words used, usually with content words having the higher percentage. Four of Dragon's six characters were within this $10 \%$ range, while two had a larger difference between content and non-content words in their dialogue. These characters, Snotlout and Fishlegs, had differences of 12\% and 16\% respectively, and were also the characters with the fewest number of lines. Snotlout is a character who feigns a sense of machismo or toughness who often focuses on describing actions (content words are underlined):

Snotlout 1: Why read words when you can just kill the stuff the words tell you stuff about? Snotlout 6: If that dragon shows either of its faces, I'm gonna-- There!

Meanwhile, Fishlegs is a studious teen who offers a lot of content-based information about various species of dragons:

Fishlegs 2: Oh and there's this other one that has these spines that look like trees... Fishlegs 8: If you were planning on getting eaten, I'd definitely go with the Gronckle.

Teen-centred films have historically included characters with identifiable behaviours or traits (Hughes, 2019). In Dragon, the traits conveyed by Snotlout and Fishlegs might warrant a greater concentration of content words in their dialogue. Snotlout's attempts to impress his peers are emphasized in his planned actions of standing up to dragons. Meanwhile, the bookish Fishlegs conveys information about the dragons from a more factual, descriptive perspective. Yet, despite Ruffnut having more lines than these two, she actually has the fewest number of words, and is the only character in Dragon whose dialogue uses mostly non-content words. This may be partially explained by the fact that many of her lines take place with her twin brother, Tuffnut - the minor character with the most lines: 
Tuffnut 4: Take that one, it has a flower on it. Girls like flowers.

Ruffnut 3: Ooops, now it has $\underline{\text { blood on it. }}$

Ruffnut 9: Okay, I've been stuck with you since birth and that was never there before.

While Ruffnut's lines are not solely directed towards Tuffnut, her role in the story may place less emphasis on specific content words. Rather, Ruffnut may rely upon the banter created by her relationship with Tuffnut as a way to illustrate the rapport developed among peers. In this way, the function of Ruffnut's behaviour may be to reinforce Hiccup's status as a group outsider. This notion of Hiccup's exclusion is set up in the first peer interaction, which shows how he is not accepted by his peers:

Ruffnut 1: I'm hoping for some mauling, like on my shoulder or lower back. Astrid 2: Yeah, it's only fun if you get a scar out of it.

Hiccup 1: Yeah, no kidding, right? Pain. Love it.

Tuffnut 2: Oh great. Who let him in?

Meanwhile in Games, six of the eight characters had up to $10 \%$ differential between their use of content versus non-content words. However, the two characters who had a greater range were the youngest female characters, Primrose and Rue, both of whom only spoke in three scenes. Interestingly, the girls' patterns were in opposition to one another, in that Primrose had the highest percentage of content words while Rue had the highest percentage of non-content words. Most of Primrose's lines contain between one and three words, with her longer lines often containing more non-content words:

Primrose 1: $\underline{\text { No! }} \underline{\text { No! }}$

$$
* * *
$$

Primrose 10: $\underline{\text { Just }} \underline{\text { try }}$ to win, if you can.

Keeping Primrose's lines brief and lexically dense may convey her as a juvenile character by limiting her range of linguistic abilities. In her scenes, Primrose appears extremely fearful of her surroundings and unwilling to accept what is going on around 
her. Thus, the brevity and frequent use of no may cause audiences to see her in an infantile state that makes Katniss' sacrifice for her especially poignant.

Meanwhile, despite also having three scenes and only three more lines than Primrose, Rue's character has over four times as many words, the majority of which are non-content words:

Rue 3: Yeah, he's okay. I think he's down by the river.
$* * *$

Rue 11: Okay. So, if we hear that it means we're okay and we'll be back real soon.

Given Rue's age being the same as Primrose along with her attachment to Katniss, audiences may view Rue as a pseudo-sister to Katniss while in the arena. However, the length of Rue's lines starkly contrasts the brevity of Primrose's lines, despite Rue also being in stressful situations. Thus, Rue may represent a more linguistically matured version of Primrose forced to grow up in a new environment. The sophistication of her language may make her death appear to be a loss of potential and thus a difficult moment for both Katniss and audiences.

What may be derived from these analyses of lexical densities is that the characters who contain a wide range of content versus non-content words may have a particular impact on the stories. In this way, Dragon appears to be a more objective illustration of the world in which the peers exist, while Games heightens the emotional impact between characters that will also hopefully resonate with audiences.

\subsubsection{Grammatical intricacy}

Shifting towards the grammatical intricacy, the sentences within each character's lines of dialogues were counted and categorized as simple or complex sentences. A summary of the findings across both films can be found in Tables 6 and 7 to the nearest whole number, with the characters' rows colour-coordinated by sex. 
Table 6: Grammatical Intricacy of Character Dialogue in How to Train Your Dragon

\begin{tabular}{|c|c|c|c|}
\hline Character & Total Sentences & $\begin{array}{c}\text { Simplex Sentences } \\
\text { (\% of Total*) }\end{array}$ & $\begin{array}{c}\text { Complex Sentences } \\
\text { (\% of Total*) }\end{array}$ \\
\hline Hiccup & 104 & $78(75 \%)$ & $26(25 \%)$ \\
\hline Astrid & 88 & $75(85 \%)$ & $13(15 \%)$ \\
\hline Tuffnut & 42 & $28(67 \%)$ & $14(33 \%)$ \\
\hline Ruffnut & 18 & $16(89 \%)$ & $2(11 \%)$ \\
\hline Snotlout & 24 & $19(79 \%)$ & $5(21 \%)$ \\
\hline Fishlegs & 26 & $20(77 \%)$ & $6(23 \%)$ \\
\hline
\end{tabular}

Table 7: Grammatical Intricacy of Character Dialogue in The Hunger Games

\begin{tabular}{|c|c|c|c|}
\hline Character & Total Sentences & $\begin{array}{c}\text { Simplex Sentences } \\
\text { (\% of Total) }\end{array}$ & $\begin{array}{c}\text { Complex Sentences } \\
\text { (\% of Total) }\end{array}$ \\
\hline Katniss & 151 & $129(85 \%)$ & $22(15 \%)$ \\
\hline Peeta & 90 & $67(76 \%)$ & $23(24 \%)$ \\
\hline Gale & 49 & $36(73 \%)$ & $13(27 \%)$ \\
\hline Rue & 20 & $16(80 \%)$ & $4(20 \%)$ \\
\hline Primrose & 13 & $12(92 \%)$ & $1(8 \%)$ \\
\hline Thresh & 6 & $6(100 \%)$ & $0(0 \%)$ \\
\hline Cato & 16 & $13(81 \%)$ & $3(19 \%)$ \\
\hline Clove & 12 & $11(92 \%)$ & $1(8 \%)$ \\
\hline
\end{tabular}

At least two-thirds of each character's dialogue across both films consisted of simple sentences, suggesting that the dialogue structure aligns more strongly to tendencies of written language than spoken language. Written language often contains fewer clauses within a sentence, while spoken language often condenses more clauses 
into fewer, longer sentences (Eggins, 2004). In addition, written texts may typically be revised and polished into focused sentences, while spoken texts are typically more spontaneous and thus produce several related clauses in one sentence (Eggins, 2004). Such a finding reveals that these scripts, despite being spoken by actors, adhere to the structural dialogue patterns of written language.

Additional insight may be seen in the gender differences in sentence structures. In both films, at least $80 \%$ of each female character's dialogue consists of simple sentences. This finding may reveal a sophistication of female characters to focus their language into fewer sentences. Interestingly, the female characters tend to use complex sentences in moments when they are challenging or explaining something to a listener, which often involves a male. Examples in Dragon can be seen from both Ruffnut and Astrid (clause divisions in complex sentences are marked with //):

Tuffnut 10: It's a birthmark.

Ruffnut 9: Okay, I've been stuck with you since birth, // and that was never there before. $* * *$

Astrid 49: I bet // he's really frightened now. What are you gonna do about it?

Hiccup 43: Probably something stupid.

Similar instances take place in Games, although the listener was typically female. Katniss sometimes used complex sentences with Peeta, but frequently employed them with Rue and Primrose:

Katniss 55: Now, this green stuff is gonna smoke like crazy, // so as soon as you light it, // move to the next fire. Light this one last, // and I'll meet you back over there.

Rue 7: Right.

Katniss 56: And then, I'll destroy their stuff // while they're chasing you.

One interpretation might suggest that the female characters are more likely to use multiple clauses in their sentences when they are encouraging other characters to confess or take action. In these moments, female characters might have less concern for the 
structure of their own dialogue, but ensure that their thoughts are being conveyed in however many clauses are required. Such a finding would reveal an intention in the females' dialogue to gain information or encourage other characters to act, which may help establish a positive peer relationship.

Meanwhile, in most cases, the male characters contained a higher percentage of complex sentences than their female counterparts. In Dragon, all four of the male characters had a wider range of simple and complex sentence percentages than the two female characters. In contrast to the female results, this may reveal that male characters have a greater tendency to alternate between using independent and dependent clauses in their speech. However, this may arguably come at the expense of efficiency in how they deliver their thoughts. Furthermore, since the characters in Dragon appear throughout the film, their linguistic behaviour can be traced throughout the film. Snotlout and Fishlegs' use of complex sentences occurs more frequently at the beginning of the story, and gradually decreases as the story progresses.

Snotlout 2: You guys read, // I'll go kill stuff.

Fishlegs 2: Oh and there's this other one // that has these spines // that look like trees... $* * *$

Fishlegs 14: I'm okay.

Fishlegs 15: Less okay.

Snotlout 13: I can't miss!

Snotlout 14: What's wrong, buddy?

Meanwhile, Tuffnut uses complex sentences throughout the film without substantial differences at any given point. This may be partially explained by his many scenes with Ruffnut, and both characters share a sibling mockery throughout the film.

Tuffnut 4: Take that one, // it has a flower on it. Girls like flowers.

Ruffnut 3: Ooops, now it has blood on it. $* * *$

Hiccup 52: Ruff, Tuff, find out // if it has a limit. Make it mad. 
Ruffnut 13: That's my specialty.

Tuffnut 21: Since when? Everyone knows // I'm more irritating. See?

These results show that every character does not necessarily undergo a linguistic transformation over the course of a film. That said, it may make those transformations that do take place more significant in contrast to those whose development is limited. Hiccup uses complex sentences throughout the script, although his stretches of dialogue are longer and contain more sentences towards the film's end.

Hiccup 8: I left my axe back at the ring.

Hiccup 9: You guys go on ahead // and I'll catch up with you.

$$
* * *
$$

Hiccup 28: It looks like // they're hauling in their kill.

Astrid 27: What does that make us?

Hiccup 29: What my dad wouldn't give to find this.

Hiccup 30: It's satisfying // to know that all of our food has been dumped down a hole. $* * *$

Hiccup 41: Three hundred years and I'm the first Viking // who wouldn't kill a dragon! Astrid 47: First to ride one, though.

Astrid 48: So...

Hiccup 42: ... I wouldn't kill him // because he looked just as frightened as I was. I looked at him // and saw myself.

Hiccup demonstrates an increased willingness to open up as a character through his ability to disclose more information. In this case, efficiency may actually be a detriment to his character by discouraging him from opening up to audiences. Yet, Hiccup's elaboration in his latter scenes reveal more details about his personality that allows growth to take place.

Meanwhile, Games had some stark differences across its male characters. Peeta and Gale showed similar findings to the males in Dragon in that they had a higher percentage of complex sentences compared to the female characters. Peeta uses complex sentences throughout the story, although the majority occur in the first half of the scenes, prior to entering the arena. 
Katniss 45: How would they change you?

Peeta 8: I don't know. Turn me into something // I'm not. I just don't want to be another part of their game, you know?

Katniss 46: You mean // you wouldn't kill anyone?

Peeta 9: No. I'm sure // I would, // just like anybody else when the time came. But, you know, // I just keep wishing // I could think of a way to show them // that they don't own me. You know, // if I'm gonna die, // I wanna still be me.

Peeta 22: I should have gone to you, // I should have just gone out in the rain and... Katniss 73: Ssh. Ssh.

Katniss 74: You feel hot.

Peeta 23: I remember // the first time I saw you. Your hair was in two braids instead of one. And I remember // when you... you sang in music assembly, // the teacher said; //

'Who knows the Valley Song?' And your hand shot straight up. $* * *$

Peeta 41: We know // Thresh took off. Cato's gonna be by the Cornucopia, // he's not gonna go someplace // he doesn't know. Foxface, she could be anywhere.

Peeta's excerpts containing complex sentences also takes place in longer stretches of dialogue. Similar findings can be seen in Gale's lines, although they are confined to only two scenes.

Gale 1: What are you gonna do with that // when you kill it?

Katniss 6: Damn you, Gale! It's not funny!

Gale 2: What are you gonna do with a hundred pound deer, Catnip? It's Reaping Day, // the place is crawling with Peacekeepers.

$* * *$

Gale 8: You root for your favorites, // you cry when they get sick. It's sick!

Katniss 12: Yeah.

Gale 9: If no one watches, // they don't have a game. It's as simple as that. $* * *$

Gale 23: Listen to me, // you're stronger than they are. You are. Get to a bow.

Katniss 35: I may not have a bow...

Gale 24: You will // if you show 'em how good you are. They just want a good show, // that's all they want. If they don't have a bow, // then you make one, okay? You know how to hunt.

Similar to Peeta, many of Gale's lines containing complex sentences also feature simple sentences to supplement an idea. Both of these male characters play important roles within Katniss' journey, which is evident in their long stretches of dialogue. The 
relationships among these characters will be explored in detail in the next subsections, but the grammatical structure of their dialogue introduces the role of these males in aiding the protagonist.

Such findings with Peeta and Gale gain even more significance in contrast to the other male characters in Games, Thresh and Cato. These two characters are the only males across both films who have over $80 \%$ of their dialogue being structured in simple sentences. Interestingly, they also have fewer lines than every character from Dragon and are among the least frequent speakers in Games. Thresh only speaks five lines in one scene, while Cato's four lines are divided between two scenes; thus, there are much fewer opportunities for complex sentences to take place. In addition, the urgency of their environment may force them to word things concisely in order to mitigate wasted time. Still, it is worth noting that male minor characters in Games have the lowest percentage of complex sentences (Thresh, $0 \%$ ) and the highest percentage of complex sentences (Gale, 27\%). When comparing this finding in Dragon, the findings are the same; Snotlout has the lowest percentage of complex sentences at $21 \%$ and Tuffnut has the highest at $33 \%$. Furthermore, the range of percentages is much wider in the PG-13 Games than the PG Dragon. A 27\% range exists between Thresh and Gale's complex sentences percentages, while this range is only $12 \%$ between Snotlout and Tuffnut.

One final observation can be made when calculating a total average for lexical density and grammatical intricacy across all characters in each film. With lexical density, the characters in Dragon average 54\% of their dialogue containing content words, while this number in Games is $53 \%$. These two numbers remain quite close to one another, despite Games having over 200 more words to include. However, a wider difference can 
be seen in the average grammatical intricacy percentages; in Dragon, $79 \%$ of characters' dialogue was framed in simple sentences, while this number was $85 \%$ for Games. In other words, the PG film contained more content words and complex sentences, while the PG-13 film had more non-content words and simple sentences.

\subsubsection{Theme analysis}

The final subsection exploring the textual metafunction will disclose the topical, interpersonal, and textual themes in the dialogue. As discussed in Chapter 3, each clause may only contain one topical theme, after which the latter components of the clause are considered to be part of the rheme. Prior to the topical theme, each clause may include interpersonal or textual themes that do not contain the main content of a clause, but still communicate contextual cues (Eggins, 2004).

Both films and all characters therein contained a wide array of unique themes. However, the protagonists and major characters had more unique themes that also allowed subtle tendencies to emerge upon closer analysis. Beginning with Dragon, protagonist Hiccup's earlier lines had many interpersonal and textual themes conveying a sense of hesitation before his one-word topical themes, most of which are nouns and pronouns (see Appendix C.1 for the full theme analysis of Dragon):

HICCUP 2:

\begin{tabular}{|c|c|c|c|}
\hline So, & I guess & it & 's just you and me huh? \\
\hline Theme:textual & Theme:interpersonal & Theme:topical & Rheme \\
\hline
\end{tabular}

$\cdots$

HICCUP 14:

\begin{tabular}{|c|c|c|}
\hline I know & this & looks really bad, \\
\hline Theme:interpersonal & Theme:topical & Rheme \\
\hline
\end{tabular}




\begin{tabular}{|c|c|c|c|}
\hline but & you see.. & this & is, uh... \\
\hline Theme:textual & Theme:textual & Theme:topical & Rheme \\
\hline
\end{tabular}

After Hiccup begins having one-on-one interactions with Astrid, he starts using textual themes less frequently. In addition, his use of interpersonal themes shifts from more qualifying clauses to the use of no and other characters' names. The significance of names will be discussed in Section 5.2.3, but for now, it is worth noting that the foregrounded material in Hiccup's lines are taking on a more emotional quality. This is further revealed by the fact that the topical themes Hiccup uses in the latter half of the scenes contain a much higher concentration of verbs and $I$ :

Astrid 38: What are you going to do?

Hiccup 35: Put an end to this. I have to try.

$* * *$

Hiccup 49: Ruff, Tuff, watch your backs. Move, Fishlegs!

Hiccup's shift in his use of themes reveal a self-confidence developing in being able to foreground the actions he commands of himself and others. His transition becomes especially prevalent when comparing it to themes used by Astrid. In the first half of the film, Astrid often uses verbs as her topical and interpersonal themes:

Astrid 1: No turning back.

$* * *$

Astrid 6: Is this some kind of a joke to you? Our parents' war is about to become ours.

Figure out what side you're on.

$* * *$

Astrid 17: Get down! Run! Run!

Unlike Hiccup, Astrid asserts herself as a character guided by action. However, after more one-on-one conversations with Hiccup, her topical themes often involve more nouns or noun groups, and occasionally interrogative and conjunctive words:

Astrid 42: Yep. The rest of us would have done it. So why didn't you?

Astrid 43: Why didn't you? 
Hiccup 41: Whatever! I wouldn't! Three hundred years and I'm the first Viking who wouldn't kill a dragon!

Astrid 47: First to ride one, though.

Astrid 48: So...

This transition shows how both characters inherit traits previously demonstrated by the other. Hiccup uses more action-oriented terms while also using $I$ as a topical theme 11 times in the last six scenes (in comparison, he had used $I$ as a topical theme 10 times in the first 19 scenes). Meanwhile, Astrid develops a sensitivity in her dialogue that shows a newfound patience and not rushing to complete a particular action. The two characters' themes reveal how they prioritize different types of communicative purposes at various points in their dialogue after interacting with one another more frequently.

In Games, there is less of a chronological effect on the types of themes found in Katniss' and Peeta's dialogue. As discussed above, all of the characters use many unique themes in their dialogue, and these themes often only appear once. What adds an extra layer to Games' case is that Katniss never has more than three scenes with any minor character; thus, some of her topical themes are only used with particular characters. With her younger sister, Primrose, Katniss often calls her by name and gives verb-fronted commands in their interactions (see Appendix C.2 for the full theme analysis of Games):

Katniss 25: Go find mom.

Primrose 6: No!

Katniss 26: Prim, go find mom.

Primrose 7: No!

$* * *$

Katniss 29: Prim, I don't have much time. Prim, listen. You're gonna be okay. Don't take any extra food from them...

In contrast, when Katniss interacts with Rue, she gives instructions using more descriptive language: 
Katniss 55: Now this green stuff is gonna smoke like crazy, so as soon as you light it, move on to the next fire. Light this one last and I'll meet you back over there.

Rue 7: Right.

Katniss 56: And then, I'll destroy their stuff while they're chasing you.

With Primrose, Katniss' directions are short and straightforward, while with Rue the themes are more descriptive, circumstantial events. Despite using slightly different techniques when giving Primrose and Rue instructions, there are still consistencies to Katniss' themes when resorting to her comforting instincts:

Primrose 1: No! No!

Katniss 1: Shh, it's okay, you were just dreaming. You were dreaming.

$* * *$

Katniss 61: It's okay. You're okay. You're okay. You're okay.

Rue 13: Did you blow up the food?

Katniss begins by saying that it is okay, and then repetitively states that you are okay. You is Katniss' second-most frequently used topical theme in the script behind I; you is said 20 times by Katniss as a topical theme and $I$ is said 36 times. Unlike Hiccup's gradual escalation of using $I$ as a topical theme as the film progressed, Katniss uses $I$ frequently throughout the film. However, one subtle change that can be noted is that, after interacting with Peeta more in the games themselves, she begins using we more frequently as well. In one of their first interactions, both Katniss and Peeta concentrate on using singular I's and you's:

Katniss 46: You mean you won't kill anyone?

Peeta 9: No. I'm sure I would, just like anybody else when the time came. But, you

know, I just keep wishing I could think of a way to show them that they don't own me. You know, if I'm gonna die, I wanna still be me. Does that make any sense?

Katniss 47: Yeah. I just can't afford to think like that.

Peeta 10: I know.

It can also be seen that Peeta particularly uses a lot of interpersonal and textual themes in his monologue, particularly you know as if to seek validation from Katniss. His 
interpersonal themes often involve him using similar clauses such as I just don't think, I guess, I just hope, I remember, and I never even knew - singular pronouns and verbs that involve mental processes. Peeta's use of metacognitive terms in his dialogue is reflective of late adolescent language patterns (Nippold, 2006). As mentioned above, however, Katniss eventually begins to integrate him into her themes once she and Peeta reunite through the word we:

Peeta 17: They already found me.

Katniss 68: We'll just get you some medicine.

Peeta 18: I'm not gonna get many parachutes.

Katniss 69: We'll figure something out.

Rather than suggesting that she alone will solve these tasks, or even using let's to put an action-oriented term in the foreground, Katniss emphasizes the partnership of her and Peeta in doing things together using we. After competing separately in the games until this point, using we may be a way for her to recover from Rue's death by clinging to what she has with Peeta. In this way, Peeta's discursive patterns may not have as direct of an influence on Katniss' discursive patterns as Astrid's may have had on Hiccup's. However, his mere presence may have been enough for Katniss to change how she constructs her sentences to intentionally include him. In this way, the significance of having a (relatively) long-term companionship may influence how both characters speak so as to be considerate of the other party:

Katniss 91: We could go home. We could. We're the only team left.

Peeta 40: We could go home.

While all of the characters had several topical themes that were only spoken once, the protagonists and major characters had some overarching patterns that emerged in addition to their one-time topical themes. Most of the minor characters, however, did not have the same overarching patterns in their use of themes, but mostly contained a variety 
of one-off topical themes. The overall lack of clear topical theme patterns among minor characters may be a function of their roles as being secondary to the protagonist and major character. Such characters may not organize their thoughts in a consistent enough way to emerge as a leader, and may still be susceptible to changes as they progress through adolescence. Some exceptions and examples will be discussed below, but the overall unclear pattern among topical themes in minor characters may suggest that their (linguistic) identity is still under formation.

Among Dragon's minor characters, many of the topical themes used were question and circumstantial words, as well as occasional verbs. Interpersonal and textual themes are not abundant, but are occasionally used to link ideas from previous lines or gather one's thoughts:

Tuffnut 5: Wait, you mean read?

Ruffnut 4: While we're still alive?

Snotlout 1: Why read words when you can just kill the stuff the words tell you stuff about?

Fishlegs 1: Oh! I've read it, like, a hundred times. There's this water dragon that sprays boiling water on your face. And there's this other one that buries itselffor like a week... Tuffnut 6: Yeah, that sounds great. There was a chance I was going to read that... Ruffnut 5: ...but now...

Snotlout 2: You guys read, I'll go kill stuff.

Fishlegs 2: Oh and there's this other one that has these spines that look like trees... $* * *$

Tuffnut 9: It's gonna be me. It's my destiny. See?

Fishlegs 3: Your mom let you get a tattoo?

Tuffnut 10: It's not a tattoo. It's a birthmark.

Ruffnut 9: Okay, I've been stuck with you since birth, and that was never there before.

Tuffnut 11: Yes it was. You've just never seen me from the left side until now.

Snotlout 5: It wasn't there yesterday. Is it a birthmark or a today-mark?

$* * *$

Snotlout 6: If that dragon shows either of his faces, I'm gonna-There!

Astrid 7: Hey!

Ruffnut 10: It's us, idiots.

Tuffnut 12: Your butts are getting bigger. We thought you were a dragon.

Snotlout 7: Not that there's anything wrong with a dragon-esque figure. 
Many of the characters share the same topical themes both within the same scene and across multiple scenes, making their individual identity harder to discern. However, the minor characters' topical themes are often non-content words that preface many content words in the rheme. These function terms build up full explanations as touched on in the previous sections. For instance, Fishlegs starts off his earlier lines of dialogue with there before going on to explain various dragon species. In addition, Tuffnut, who has the most unique topical themes of the minor characters, does not simply respond to Fishlegs' question by exclaiming birthmark, but fully explains that it is not a tattoo but instead a birthmark. To compare, when Katniss is about to leave Primrose in Games, Primrose gives Katniss a pin and says the following:

Primrose 12: To protect you.

Primrose does not explain what the pin is protecting Katniss from in the rheme, nor does she say that this is to protect you, but it is implied from the scene's context. In this way, the linguistic material requires the audience to fill in some connections that are ellipsed and thus not explicitly stated in Games' dialogue, unlike Dragon's themes leading into more detailed explanations.

Games' minor characters' use of themes shows more prevalent individual tendencies than in Dragon. This is especially noticeable with Gale, who prefaces his lines with many if or what if textual themes:

Gale 6: What if they did? Just one year. What if everyone just stopped watching?

Katniss 10: But they won't, Gale.

Gale 7: What if they did? What if we did?

Katniss 11: It won't happen.

Gale 8: You root for your favorites, you cry when they get killed. It's sick!

Katniss 12: Yeah.

Gale 9: If no one watches, then they don't have a game. It's as simple as that. ... 
Katniss 19: I'm never having kids.

Gale 17: I might. If I don't live here.

Katniss 20: But you do live here.

Gale 18: I know. But if I didn't.

$* * *$

Gale 23: Get to a bow.

Katniss 35: I may not have a bow...

Gale 24: You will if you show 'em how good you are. They just want a good show, that's all they want. If they don't have a bow, then you make one, okay?

Gale's use of hypothetical terms might suggest his denial of his or Katniss' current situation. However, Katniss provides more grounded responses to Gale by limiting non-topical themes to convey a sense of certainty, even when she does not know the outcome. Perhaps Katniss' focus on staying present and using language to reflect this stance allowed her to survive in the games, rather than allowing herself to daydream about life beyond the games. That being said, Gale's wishful thinking may prompt Katniss to consider how dire the system is, and perhaps inspire her to stand up to the Capitol much later.

Since the audience follows Katniss' perspective throughout the competition itself, the scenes which feature one of the four remaining minor characters-Rue, Thresh, Cato, and Clove - are sporadic. Furthermore, their language may be reflective of their responses to an incredible amount of stress. All of the characters have fewer unique topical themes than Gale, but the one other character whose personality begins to reveal itself through topical themes is Cato. In his final monologue, in which most of his lines take place, Cato's topical themes include some action-oriented terms:

Cato 2: Go on, shoot. And we'd both go down and you'd win.

Cato 3: Go on. I'm dead anyway! I always was, right? I didn't know that until now. Isn't that what they want, huh?

Cato 4: No! I can still do this. I can still do this. One more kill. It's the only thing I know how to do. Bring pride to my district. Not that it matters. 
Cato foregrounds words such as go on, shoot, and one more kill, which heightens the intensity of the scene as he, Katniss, and Peeta are the only people remaining. In addition, he frequently uses $I$ as a topical theme, which may be an attempt to convince both himself and Katniss of his domineering presence. These two categories of themes may jointly reveal that he views himself as a killer who also tries to manipulate others into succumbing to his wishes. Again, this may be hard to discern this as his whole identity, but both Cato and Gale illustrate very specific functions that they serve in Katniss' story. This notion will be expounded on in the following section discussing the interpersonal dimension of language.

\subsection{Tenor: Interpersonal Metafunction}

The second half of this chapter will focus on qualities of the language that help reveal the interpersonal dimension of the characters' situations. To examine each film's tenor using the MOOD system, this section is organized according to three tenets of tenor in a given register: the (in)equality of power, frequency of contact, and degree of affective involvement between participants. Each subsection will contain 1-2 examples of the MOOD analysis in its full illustration, while subsequent examples will be written in italics. Appendix C contains the entire MOOD analyses for How to Train Your Dragon and The Hunger Games, respectively (combined with theme analyses).

\subsubsection{Power: Conflict and modality}

One way to examine power in peer situations is to study the conflict between the protagonist and major character. In Dragon, Astrid initially rejects Hiccup's attempts to begin a conversation with her (see Appendix C.1 for the full MOOD analysis in Dragon): HICCUP 2:

\begin{tabular}{|c|c|c|c|c|c|c|}
\hline So, & I guess & it & 's & just & you and me & huh? \\
\hline
\end{tabular}




\begin{tabular}{|c|c|c|c|c|c|c|}
\hline Adjunct & Adjunct:Mood & Subject & Finite & Adjunct:Mood & Complement & Adjunct \\
\hline & \multicolumn{4}{|c|}{ MOOD } & RESIDUE & \\
\hline
\end{tabular}

ASTRID 3:

\begin{tabular}{|c|}
\hline No. \\
\hline Adjunct:Polarity \\
\hline MOOD \\
\hline
\end{tabular}

\begin{tabular}{|c|c|}
\hline Just & you. \\
\hline Adjunct:Mood & Subject \\
\hline \multicolumn{2}{|c|}{ MOOD } \\
\hline
\end{tabular}

Later in the film, Astrid starts taking a competitive interest in Hiccup once he starts excelling in dragon training, reflecting research suggesting that prestige may play a role in peer selection (Brown \& Larson, 2009). That being said, she is not aiming to ingratiate herself with Hiccup, but rather discover the secret to his unprecedented success using commands and questions:

Astrid 13: Start talking! Are you training with someone?

Meanwhile in Games, it is Peeta who initiates the first interaction with Katniss through questions and statements, although she does not verbally respond (see Appendix C. 2 for the full MOOD analysis in Games):

PEETA 1:

\begin{tabular}{|c|c|c|c|}
\hline Have & you & met & him? \\
\hline Finite & Subject & Predicator & Complement \\
\hline \multicolumn{2}{|c|}{ MOOD } & \multicolumn{2}{|c|}{ RESIDUE } \\
\hline
\end{tabular}




\begin{tabular}{|c|}
\hline Haymitch? \\
\hline Complement \\
\hline RESIDUE \\
\hline
\end{tabular}

\section{PEETA 2:}

\begin{tabular}{|c|c|c|c|c|}
\hline You know, & Katniss, & he & is & our mentor. \\
\hline $\begin{array}{c}\text { Adjunct: } \\
\text { Conjunctive }\end{array}$ & Adjunct:Vocative & Subject & Finite & Complement \\
\hline & RESIDUE... & \multicolumn{2}{|c|}{ MOOD } & $\ldots$ RESIDUE \\
\hline
\end{tabular}

Shortly thereafter, however, Katniss begins making commands of Peeta to reveal a more aggressive tendency during their training:

Katniss 39: Throw that metal thing over there.

Peeta 4: What? No. Haymitch said we're not supposed to show our skills.

Katniss 40: I don't care what Haymitch said.

Both films set up their main characters with a disjointed relationship; in both cases, the female speaks more aggressively towards the male, although their roles in the film are different. However, the films diverge in how they bring the characters closer together and balance disagreements with pacifying tactics. More specifically, the ways in which protagonists use politeness behaviours or modal adjuncts to reveal qualities of their relationships. Modal adjuncts influence the subject and/or finite of the clause, and serve "to indicate some aspect of the speaker/writer's attitude to the message" (Bloor \& Bloor, 2004, p. 55). Beginning with Dragon, Hiccup begins his peer interactions by frequently using I guess as a modal adjunct preceding the subject of his clauses:

Hiccup 3: So I guess we'll share-

Astrid 4: Read it. 
In his initial interactions with his peers, Hiccup has a timidity being portrayed through the use of I guess as a modal clause to mitigate the supposed weight of his ideas. This is known as a metaphor of modality (Halliday \& Matthiessen, 2004), in which "a clause expressing the modalization is appended to the main clause" (Eggins, 2004, p. 175). In other words, by attaching I guess to his sentence, Hiccup is alleviating the impact of his statement by framing from his perspective rather than an objective truth. In comparison, if I guess were to be omitted, the example above would read as So, we'll share. This still contains some hesitation by beginning with $\mathrm{So}$, yet the sentence takes on a more factual tone. Hiccup's use of modal adjuncts combined with Astrid's blunt rejections illustrates a meekness in Hiccup and a power that Astrid has in her ability to reject him outright and allow her to maintain independence from him. It is also worth noting that read in Astrid's fourth line is referring to how she had read a book in past tense with an ellipsed subject $I$, rather than a present-tense command towards Hiccup to read the book. This may further illustrate Astrid's dismissal of Hiccup's suggestion to share the book through her belief that she is smarter from having already read the book and does not need to revisit it, at least not with Hiccup. However, as the film progresses, Hiccup stops using this modal adjunct which portrays his ability to speak with authority.

Hiccup 49: Ruff, Tuff, watch your backs! Move, Fishlegs!

Interestingly, Astrid also uses a metaphor of modality towards the end of the film leading up to her main point:

Astrid 49: I bet he's really frightened now.

In this way, the two characters have seemingly switched techniques; Hiccup has shortened the MOOD constituent to speak with certainty while Astrid prefaces her 
sentence with a metaphor of modality. However, given that Astrid has been depicted as a character with some power over Hiccup, using I bet may also be an outward claim of her beliefs that could still have influence over Hiccup. Using a metaphor of modality in this context may still demonstrate her power to encourage Hiccup to take action. That being said, it is a more nuanced example of power that enables Hiccup to become a more confident version of himself than simply rejecting or dismissing his ideas altogether.

Metaphors of modality are also used in Games, particularly in one scene where Peeta and Katniss have a conversation the night before entering the arena.

Katniss 46: You mean you won't kill anyone?

Peeta 9: No. I'm sure I would, just like anybody else when the time came. But, you know, I just keep wishing I could think of a way to show them that they don't own me.

This scene allows both characters to discuss their mindsets prior to entering the arena, and affirms the limited power they both have in relation to the Capitol running the games. The fact that their dialogue contains several complex sentences may reveal a less polished nature to the characters' thoughts, being reminiscent of spoken language. Both characters want to survive, but they speak with little conviction about how to make a statement in doing so, particularly in Peeta's dialogue. Katniss rejects Peeta's notion with more authority, only using one modal adjunct to supplement her belief:

Katniss 47: I just can't afford to think like that.

Katniss and Peeta gently push against one another's stances about surviving the games with some modal terms. However, at the end of the film, Katniss shows firm rejection through a lack of modal terms, only using should once in response to Peeta's modulated claim that the Capitol has to have only one victor. As a result, the brief 
argument between them is much more authoritative in tone. Peeta ultimately submits to Katniss, showing that he is now more strongly influenced by her than the Capitol:

Peeta 52: One of us has to die, they have to have their victor.

Katniss 101: No. They don't. Why should they?

Peeta 53: No!

Katniss 102: Trust me.

The two films reveal how modality may both heighten and diminish one's level of power in a given context. However, whereas Hiccup emerges as a powerful character after modelling Astrid's behaviours, Katniss begins as an authoritative presence who recruits Peeta to her position. The peer influence is also significant in considering the other potential adult sources of power that characters could have followed; Hiccup could have been swayed by his father and Katniss by the people running the games. While Hiccup is aided by Astrid to fight for the same cause as his father, Katniss is assisted by Peeta in an attempt to rebel against the Gamemakers. This further illustrates that demonstrations of power are significant not only in who is involved, but in the cause for such power. As seen in the following subsection, part of the reason for the strength of the influence and solidarity seen amongst the teens may be attributed to the amount of contact they share throughout their respective films.

\subsubsection{Contact: Conversation length and frequency}

An immediate difference in the characters' contact with their peers can be seen through the frequency of protagonist dialogue in the first portion of each film (see Appendix A for scene dispersions and Appendix B for line dispersions). In Dragon, Hiccup only speaks nine lines of dialogue among his peers between scenes 1-12, which is nearly half of the 25 scenes selected for analysis. In comparison, Tuffnut speaks 18 lines by that same point, while Ruffnut has 11 and Snotlout is close behind with eight. That 
being said, Astrid only had eight lines by this point, meaning that both she and Hiccup spoke nearly 50 of their 57 lines between scenes 13-25. In this way, both characters have the opportunity to develop alongside one another and take on linguistic attributes of the other person. The fact that Hiccup and Astrid almost always appear in the same scenes together, sometimes alone, presents an environment allowing such linguistic development to take place. Peer influence in adolescence is often reciprocal, indicating that teens spend a large amount of time with one another to allow that influence to take place (Brown \& Larson, 2009). In Dragon, the lack of dialogue spoken by both Hiccup and Astrid in the earlier scenes emphasizes the stark differences they initially exhibit, with Hiccup's frequent modal adjuncts and Astrid's blunt statements. However, after spending more time with one another, Hiccup and Astrid not only decrease their own tendencies, but also start to take on the patterns used by the other character.

Meanwhile, Games takes a reverse approach in introducing Katniss' dialogue with peers. By the end of scene 12, Katniss has spoken 63 of her 106 lines of dialogue, and her spoken interactions only occur in dyads with different characters. Interestingly, in some interactions, she is a member of the group, but does not speak any lines. Rather than waiting until the latter half to shift peer emphasis to Katniss, the film is centred on her perspective as she shifts from familiar interactions with Primrose and Gale towards newer peers in Peeta and Rue. While Hiccup's personal development largely develops through interactions with Astrid, Katniss' interactions with Primrose and Gale parallel her next set of interactions with Rue and Peeta.

Furthermore, the length of interactions may also indicate the degree of contact between various sets of characters. Conversations without "any clear pragmatic purpose" 
(Eggins, 2004, p. 101) among those with less contact tend to be brief and emphasize agreement, while those among frequent interactants are typically longer and stress disagreement. Although many of the interactions in both films have a motive from at least one character, the length of the interactions between the protagonist and major character are also much longer as the films progress. In Dragon, the first interaction between Hiccup and Astrid is merely three sentences long, spread over two lines. Their subsequent interactions continue to be brief with Astrid often shutting down Hiccup's initiations and exiting the scene before he could seriously respond. However, as the pair interact more frequently, Hiccup speaks in longer chunks, to which Astrid becomes more accepting (see Appendix C.1 for the full MOOD analysis in Dragon):

ASTRID 32:

\begin{tabular}{|c|c|c|}
\hline Are & you & serious? \\
\hline Finite & Subject & Complement:Attributive \\
\hline \multicolumn{2}{|c|}{} & RESIDUE \\
\hline
\end{tabular}

HICCUP 32:

\begin{tabular}{|c|}
\hline Yes. \\
\hline Adjunct:Polarity \\
\hline MOOD \\
\hline
\end{tabular}

ASTRID 33:

\begin{tabular}{|c|}
\hline Okay. \\
\hline Minor clause \\
\hline
\end{tabular}

Towards the end of the film, Astrid is still not afraid to question Hiccup, although it is with the intent of determining how she can support him going forward:

Hiccup 38: I couldn't.

Astrid 44: That's not an answer. 
Hiccup 39: Why is this so important to you all of a sudden?

Astrid 45: Because I want to remember what you say right now.

Hiccup and Astrid's longest scenes have a total of 20 lines, and contain several clauses and sentences within each line. The contact that increases over the course of the film has also resulted in a convergence of tactics among the characters-Astrid being willing to accept Hiccup's views and Hiccup being willing to challenge Astrid's.

Meanwhile, in Games, easily the longest scene of peer talk takes place between Katniss and Gale with 39 lines and a mix of simple and complex sentences between both characters. The length of Katniss' interaction with Gale is partially indicative of the close relationship shared between the characters. This is also contrasted with the much shorter interactions with most other characters, apart from Peeta. Similar to Hiccup and Astrid, Katniss and Peeta's first interaction is relatively brief, containing six sentences over three lines that are all spoken by Peeta. Although their longest scene only contains 15 lines between both characters, Katniss and Peeta's scenes occur back-to-back to indicate that they are in frequent contact with one another. In fact, almost all of the dialogue in the second half of the transcript (Scenes 13-24) is spoken solely by Katniss and Peeta; the exceptions come from Scene 17 between Clove and Thresh, and Cato makes an appearance in Scene 22 (see Appendix C.2 for the full MOOD analysis in Games).

Scene 13:

Katniss 66: I'm not going to leave you. I'm not going to do that.

Peeta 16: Why not?

Scene 14:

Katniss 67: Nobody's gonna find you in here.

Peeta 17: They already found me.

Therefore, if taken as one long scene, this would contain much more dialogue than the scenes between Katniss and Gale. However, while Katniss and Peeta become 
closer over the course of the film, there is still a degree of disconnect between them that is reflected in the frequent, sometimes abrupt scene changes. These may prompt a tonal shift in their dialogue that does not allow audiences to witness the end of a conversation, unlike the interaction between Katniss and Gale. Therefore, the intimacy established between Katniss and Gale early in the film may still be recalled with audiences as she interacts with Peeta. Thus, the length of uninterrupted time among characters may arguably supersede the number of scenes used to establish contact.

\subsubsection{Affective involvement: Smallwords and vocatives}

One linguistic component that may reveal characters' affective involvement with one another relates to how they use casual filler words in moments of tension. Certain modal adjuncts may be defined as smallwords, which are "represented by 'tags' (innit, yeah), 'hedges' (just, like, sort of) and empathizers (you know)" (Stenström, Andersen, \& Hasund, 2002, p. 65). Such such unnecessary terms may have contributed to negative perceptions of teen language use (Stenström, Andersen, \& Hasund, 2002); however, the use of smallwords in film may play a key function in how a character impacts their peers.

The most common modal adjunct in both cases is the word just; Dragon used the term 14 times and Games 19 times as a modal adjunct. Only Dragon used like as a hedge, while both films included yeah as modal adjuncts, particularly among the minor characters (see Appendix C.1 for the full MOOD analysis in Dragon):

RUFFNUT 1:

\begin{tabular}{|c|c|c|c|c|c|}
\hline I & 'm & hoping & for some mauling, & $\underline{\text { like }}$ & $\begin{array}{c}\text { on my shoulder or } \\
\text { lower back. }\end{array}$ \\
\hline Subject & Finite & Predicator & $\begin{array}{c}\text { Adjunct: } \\
\text { Circumstance }\end{array}$ & $\begin{array}{c}\text { Adjunct: } \\
\text { Contintuity }\end{array}$ & $\begin{array}{c}\text { Adjunct: } \\
\text { Circumstance }\end{array}$ \\
\hline \multicolumn{2}{|c|}{ MOOD } & \multicolumn{5}{|c|}{ RESIDUE } \\
\hline
\end{tabular}


ASTRID 2:

\begin{tabular}{|c|c|c|l|c|}
\hline Yeah, & it & 's & only & fun... \\
\hline Adj:Continuity & Subject & Finite & Adjunct:Mood & Complement:Attribute \\
\hline & \multicolumn{3}{|c|}{ MOOD } & RESIDUE \\
\hline
\end{tabular}

What is perhaps most striking about the use of smallwords is their presence during moments of tension. In the earlier portions of both films, the characters may have a greater mental capacity to play with language during less stressful scenes. In Dragon, however, smallwords are noticeably absent in the final battle, only being used twice over the 26-line scene. As such, the characters only communicate the words that are absolutely necessary to efficiently move forward with directions. Dialogue instead focuses on other RESIDUE components of predicators, complements, and circumstantial adjuncts:

Hiccup 54: There!

Hiccup 55: Go help the others!

However, in Games, villainous characters employ smallwords for a different purpose, as first seen in Clove's domineering interaction over Katniss (see Appendix C.2 for the full MOOD analysis in Games):

CLOVE 1:

\begin{tabular}{|c|c|c|c|c|c|}
\hline Yeah, & well & we & \multicolumn{2}{|c|}{ killed } & her. \\
\hline Adjunct: Continuity & Adj: Continuity & Subject & Finite & Predicator & Complement \\
\hline & & \multicolumn{2}{|c|}{ MOOD } & \multicolumn{2}{c|}{ RESIDUE } \\
\hline
\end{tabular}

By inserting superfluous words, Clove draws out the suspense that raises tension in her scene. Clove's smallwords may show a feigned exertion of power over Katniss, heightening the intensity of her dialogue. Given the lack of contact between Katniss and Clove to this point, their intensifying terms may be an attempt to assert power, although 
Clove ends up being killed in that scene. However, her death may have also given Katniss greater motivation to rebel against the Gamemakers after they announce that only one victor would be crowned. Although it is necessary for Katniss to survive, it may also invite greater emotional investment from the audience due to the fact that a greater enemy still exists in those who run the games. Thus, the stalling tactics may also cause Katniss to wrestle with the implications of Clove's death, who is merely a victim in an oppressive system. Thus, the longer stretches of dialogue humanize other characters and evoke sympathy since all of the teens, like Katniss, are also trying to survive.

The final linguistic factor to be explored regarding affective involvement is the use of vocatives or names. In addition to being a potential site for linguistic creativity, names may also be a key identity marker through which teens experiment with their own identity as well as establish cultural norms (Lytra, 2003; Huffaker \& Calvert, 2005; Starks, Leech, \& Willoughby, 2012). The majority of vocatives in both films involve a character's first name, which may be considered neutral in terms of formality. It is less formal than referring to someone by a title and last name, while being more formal than a nickname. In the beginning of Dragon, a distance is created early between Hiccup and his peers from the fact that they refuse to call him by name:

Tuffnut 2: Oh great. Who let him in?

$* * *$

Hiccup 2: So, I guess it's just you and me huh?

Astrid 3: No. Just you.

In choosing to use pronouns in lieu of Hiccup's name, his peers illustrate the emotional separation they are creating with Hiccup. However, once Hiccup shows success in training, Fishlegs is the first character to refer to him by his first name:

Fishlegs 6: Hey Hiccup, I've never seen a Gronckle do that before. 
After establishing a relationship, both Hiccup and Astrid begin to address one another by their first names:

Hiccup 31: Astrid, we have to think this through carefully/

Astrid 32: Hiccup, we just discovered the dragon's nest...

Acknowledging one another name may suggest an increased connection between Hiccup and Astrid. The fact that Hiccup does not use vocatives for the others until Scene 23 may suggest that he requires a considerable amount of time to establish a relationship before using such terms.

Keeping this in mind, Games introduces the neutral vocative through Katniss when referring to Gale in their first conversation:

\section{Katniss 6: Damn you, Gale!}

The use of the vocative combined with profanity suggests an immediate level of comfort that has already been established between the two characters. Swearing may be common in teen peer circles, particularly when adults are not around to monitor its usage (Evaldsson \& Cekaite, 2010). It is also interesting to compare this comfort in referring to Gale by his name with Peeta's use of vocatives for Katniss. In their first interaction, Katniss refuses to speak, but Peeta is immediately willing to refer to her by her first name, setting him up as a personable character:

Peeta 2: You know, Katniss, he is our mentor.

This may be an early attempt from Katniss to distance herself from Peeta when only one winner - one survivor - can be crowned. In Scene 7, Katniss is willing to talk to Peeta through a command, although she still refuses to include any kind of vocative:

Katniss 39: Throw that metal thing over there. 
Although Katniss has begun speaking to Peeta, there is still an emotional distance between them evident in her unwillingness to say his name to his face. At this point, Peeta also stops calling Katniss by name until they meet up in the arena:

\section{Peeta 14: Katniss.}

Peeta 15: Katniss.

Katniss 66: No! I'm not going to leave you.

Although she initially refuses to call him by his name, Katniss eventually reciprocates when Peeta tells stories about their childhood interactions:

Peeta 21: I think about that all the time. How I tossed you that bread.

Katniss 72: Peeta!

Before entering the games, Peeta had publicly admitted to having a crush on her which, until this point, had been unrequited. After she says Peeta in her 72nd line, Katniss goes on to use Peeta five more times in her next 34 lines. Interestingly, Peeta only uses Katniss one more time after this point, meaning that he uses fewer vocatives referring to Katniss than she does towards him. This may suggest that he feels less pressure to force a connection with Katniss, perhaps suggesting growth in not calling out to Katniss to gain her attention. Not only does Katniss call Peeta by name, but she also uses the same profane term towards him that she had said to Gale:

\section{Katniss 96: You scared me to death. Damn you!}

Katniss' dialogue harkens back to her interactions with Gale as a sign that she has grown more comfortable with Peeta as well. Katniss emotionally connects with Peeta by using the same techniques of peer talk that she had used with her close friend from home.

In addition to these more neutral vocatives, both films have a few instances in which characters use more creative names when referring to peers. In Dragon, Hiccup shortens the names of Snotlout, Fishlegs, Ruffnut, and Tuffnut during the final battle: 
Hiccup 49: Ruff, Tuff, watch your backs!

$* * *$

Hiccup 52: Lout, Legs, hang in its blind spot.

Meanwhile, Games also features Katniss shortening Primrose to Prim:

Katniss 2: It's your first year, Prim.

The brevity offered by these one-syllable substitutes of full names may illustrate a closeness that has been developed or established between characters. That being said, there are some contextual factors to consider that may have contributed to these names being given. For instance, in Dragon, these vocatives are used in the midst of the final battle sequence where Hiccup is directing commands to particular people. While the brevity may be used to save time, it is still significant that Hiccup would feel comfortable referring to his peers in this casual way. It may actually be a bigger risk to change one's behavioural pattern in the middle of a battle, which speaks again to the level of comfort Hiccup now has with his peers.

In addition, both films have instances of more playful vocatives suggesting a degree of comfort with other characters in the first half of each film. Snotlout in Dragon uses a broad term to seek Astrid's attention during training:

Snotlout 3: Watch out, babe.

In Games, Gale also provides a more personal twist on Katniss' name:

Gale 2: What are you gonna do with a hundred pound deer, Catnip?

However, Goodwin and Kyratzis (2011) note that sometimes insults may help peers establish connections to one another and their culture. This may be seen in Ruffnut's general disparaging comment towards Tuffnut and Snotlout, and both Tuffnut's and Ruffnut's creative insults towards each other near the film's end:

Ruffnut 10: It's us, idiots. 


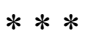

Tuffnut 23: Troll!

Ruffnut 14: Butt elf!

Lastly, characters from both films also have an instance in which vocatives are used in a more intimidating fashion. In Dragon, this takes place when Snotlout is attempting to annoy a dragon in the final battle:

Snotlout 15: What's wrong, buddy?

In Games, Thresh calls Katniss by her district number when letting her escape:

Thresh 5: Just this time, Twelve.

In addition, although not always phrased as a vocative, Clove uses nicknames to taunt Katniss by alluding to Peeta and Rue:

Clove 1: Where's lover boy? ... Well, it's too bad that you couldn't help your little friend. That little girl, what was her name again? Rue?

Both films attempt to show dominance over someone else, although using slightly different tactics. Snotlout uses a broad term that may be taken as a mildly derogatory putdown to a non-human creature. In Games, however, the other tributes use personal terms that deeply relate to and affect Katniss. Thresh saying Twelve on its own is not intimidating, but it reduces Katniss' identity to her home district and maintains an emotional distance between them. It is also not known whether or not Thresh knew of Katniss' name prior to this scene, and District 12 may have been the only means he had of identifying her. However, Clove chooses to torment Katniss by referring to the relationship she has with Peeta and Rue. She also reveals that she did know Rue's name, but first chooses to mock her as your little friend and that little girl to torment Katniss. Thresh chooses to maintain their status as competitors by avoiding names, while Clove makes the insults emotionally involved by using personal nicknames. In this way, 
Dragon opts for broad terms that may be more easily recognizable as positive or negative out of its contextual usage in this film. However, Games requires the audience to pay greater attention to the connotative uses of certain names to understand the positive or negative intention of its usage.

The present analysis contains intriguing similarities and differences amongst the protagonists, major characters, and minor characters across the PG film How to Train Your Dragon and PG-13 film The Hunger Games. The following chapter will further compare and contrast these findings while discussing their implications for peer talk and language study in films. 


\section{Chapter 6: Discussion}

This chapter will revisit the research questions and discuss connections between the results of the study and previous literature. The remainder of this chapter will seek to explain how these results may or may not answer the research questions:

Do the linguistic choices of teenage characters in teen-centred films vary based on a film's rating, and if so, how?

a) How do these choices vary textually between films with different ratings?

b) How do these choices vary interpersonally because of the relationship between teen characters?

Where possible, this chapter will draw connections to literature on film language and ratings, as well as teenage peer dynamics, that have been reviewed in this thesis. This will help situate the study within a broader network of literature in both addressing a research gap while comparing these findings to those in other studies.

\subsection{Revisiting the Research Questions}

Section 6.1.1 will address the textual metafunction to answer sub-question a), while Section 6.1.2 will address the interpersonal metafunction to answer sub-question b). Answers to these sub-questions will contribute to answering the main research question: Do the linguistic choices of teenage characters in teen-centred films vary based on a film's rating, and if so, how?

\subsubsection{Textual metafunction}

Sub-question a) in this thesis asks: How do these choices vary textually between films with different ratings? In examining the structures of the two films, the PG-13 Games has a wider range of percentages in individual characters' uses of content words 
and simple sentences compared to those in the PG Dragon. This may help address subquestion a) as it may suggest that variance, while subtle, does exist in how films of different ratings formulate dialogue. The narrower ranges in Dragon might suggest that the film, which may be more widely viewed by younger audiences, has a slightly more predictable and consistent grammatical makeup. On the other hand, the more restrictive Games may opt for a wider range of textual choices that reflect the characters' demographics and personalities. Thus, it may be easier for audiences to follow along with Dragon's characters that have a more moderate range of variance, whereas Games has a wider range of language behaviours among its characters. Furthermore, the higher proportion of content words may be reflective of the fact that concrete terms are able to be defined by children prior to more abstract ones in later adolescence (Nippold, 2006).

Such a finding is significant as it may suggest that maturity is not just defined by one's ability to tolerate graphic material, but also in following along with a larger array of linguistic nuances that aid one's understanding of a film. While concern with defining appropriateness in film ratings has been in academic literature for several decades (Wilson, Linz, \& Randall, 1990), the concern has still largely been placed on explicit content. Some studies have shown benefits to studying the differences of phrases used among genders (Aryani, 2016; Gálvez, Tiffenberg, \& Altszyler, 2019) or films in different decades (Ciampi, 2015), yet do not consider the developmental appropriateness of language. However, the comparison across ratings in this study may help expand the perceptions and definitions of appropriateness in film ratings.

Another revealing difference between the two films may be seen in the behaviour of the minor characters. In Dragon, all the teen characters are members of the same peer 
group, and the minor characters do not explicitly question others' popularity or status.

The one exception to this is Hiccup, who is initially scoffed at for his ineptitude but later gains positive attention from his success in training. This aligns with research claiming that adolescents' peer behaviour may be highly influenced by one's "perception of their peers' behavioral norms" (Brechwald \& Prinstein, 2011, p. 170, emphasis in original). The minor characters' collective interest in Hiccup is sparked by the subversion of social norms in that the clumsy, timid Hiccup can successfully handle dragons. Furthermore, the minor characters take on a lessened role as the film progresses, but show little change in their actual dialogue. When their perception of Hiccup changes to see him as a valuable and knowledgeable member, they all allow him more space to talk and emerge as a leader. In considering how they organize their thoughts through dialogue, the minor characters do not undergo the same degree of change compared to language used by protagonist Hiccup and major character Astrid. In this way, the characters serve to illustrate the changes seen in Hiccup rather than their individual transformation, showing how he eventually fits into their consistent group identity.

Where Games provides intriguing insight on minor characters is in the variance among characters of the same age and gender. This may be most prominent in the differences in the content word ratios of Rue and Primrose (females, age 12) and grammatical organization of dialogue from Gale and Cato (males, age 18). Despite shared demographic features, the dialogue among these characters had the widest range of percentages in the respective categories. In addition, both sets of pairings package their dialogue differently; Rue often foregrounds her dialogue with more concepts than Primrose, while Cato's commands starkly contrast Gale's pondering what if scenarios. 
This may speak to the range of development that takes place during the adolescent years, which includes linguistic behaviours (Christie, 2012). Such a finding is intriguing as it begins to reveal linguistic tendencies of individual characters. Some research has begun to explore this topic in examining how teen characters use compliments (Ciampi, 2015), but this has not been an extensively covered topic.

Part of the reason why teen linguistic behaviour might vary so greatly in Games is not only due to individuation, but perhaps the lack of a central peer group being followed throughout the film. Language may be a key factor in individual and group identities among youth (Androutsopoulos \& Georgakopoulou, 2003), but they may require a peer audience to allow these identities to take shape. For instance, as seen in Table 5, the lexical density percentages for Katniss, Peeta, and Gale—all of whom are older teens from District 12 - only differentiate by $3 \%$. Thus, it may be surmised that characters' home environment and age together might play a subtle role in their linguistic choices. Dragon's characters are themselves within a narrower age range and use language more closely to their peers than the wider patterns seen in Games. This further emphasizes the earlier point in how film ratings that are only open to older audiences may also allow a greater range in linguistic behaviour that more mature viewers can associate with particular characters.

The minor characters' dialogue may somewhat address sub-question a) in how the films emphasize the role of these characters rather than the changes they exhibit over time. Dragon has the same characters gradually speak less to invite the protagonist into the conversation without drastically changing their specific habits, while Games altogether introduces and removes characters with a range of linguistic tendencies. Yet, 
although both films offer a different perspective into the role of minor characters' dialogue, it is difficult to definitively claim that the sub-question is being addressed. This is due to the range of what constitutes a minor character, as there is quite a bit of variance in the roles they serve in their respective stories that makes it harder to compare the textual qualities. For instance, comparing the dialogue of a character who has four lines in Games (Cato, Clove) is not easily done against a character who has 27 lines in Dragon (Tuffnut). Therefore, drawing conclusive findings among minor characters' dialogue across ratings is challenging when there is so much variance within the definition of a minor character. The language of minor characters specifically has not been a widely covered topic in the literature, and research that does exist is somewhat unclear as to the role of certain characters in a given film. Thus, future studies may increase understanding of language used by film characters who may not undergo the same degree of changes as a protagonist, but strengthen the bond and identity of a peer group.

\subsubsection{Interpersonal metafunction}

Sub-question b) in this thesis asks: How do these choices vary interpersonally because of the relationship between teen characters? Beginning with power in film language, an interesting difference between the two films may be observed in how the major characters assist the protagonist's journey. Although both films involve a romantic storyline between the protagonist and major character, it was not the primary focus of either film, unlike films in past studies (Aryani, 2016). Rather, both films' major character served a key role in the shift in the protagonists' language. The PG film saw Hiccup's language choices illustrate his transition from a meek to authoritative character among his peers after his interactions with the more assertive Astrid. By emphasizing the 
minor characters' dialogue in the first half of the story, Dragon establishes a rapport among members of the group in which Hiccup has a small and inferior presence. Through his interactions with Astrid, Hiccup gradually eliminates his use of hesitations and more clearly articulates his thoughts, which helps him gain his peers' respect and obedience to defeat a tangible enemy. Meanwhile, the PG-13 film sees Katniss use commands and dialogue about her present situation to convey her as an authoritative, grounded character. In opposition to Dragon, Peeta is the more timid character who initially suggested that they stand up to the Capitol, but Katniss prompts him to actually follow the action through. Throughout the film, she is the one driven to action in order to protect Peeta, and eventually recruits him to defy the games' rules. Peers in the games are set up as foes to be eliminated, but as more teens are killed, Katniss' priorities could afford to shift from her peers to challenging the larger, adult-run society. These findings also show how power may develop or change over the course of a film, adding to research that identifies power demonstrations in film language (Ratri \& Ardi, 2019).

The trajectories of Hiccup and Katniss may address sub-question b) in that the two films have opposing purposes for protagonist demonstrations of power. Hiccup undergoes an individual identity shift in order to emerge as a powerful character, all the while remaining in the same environment. In this way, Hiccup uses power as a sign of growth that reflects his newfound willingness to embrace and defeat the perilous situation before him. On the other hand, Katniss is shown to maintain her strong identity while being challenged to adapt to shifting environments and circumstances. Instead of growing into her power, Katniss instead asserts her power and leadership role in various relationships, eventually subverting the Capitol's control of her life. 
The amount of contact among Dragon's teens illustrates how the characters choose to subscribe to and participate in the same peer group. It has also been found in research that teens might align themselves with a group through either participation or a verbal declaration (Sussman et al., 2007). Rather than explicitly labelling their roles within the group, the characters share experiences together through dragon training in addition to activities outside of training. As a result, the teens share a large amount of dialogue amongst each other, with the final scenes featuring all six teens in speaking roles. However, the language indicates that Hiccup has been granted leadership through the group's interest in asking him questions and obeying his commands. Such practices are indicative of the group's shared youth identity (Androutsopoulos \& Georgakopoulou, 2003 ) as courageous, dragon-riding teens under Hiccup's lead. Meanwhile, the peer setting in Games provides a much different basis for analyzing contact. There is not a consistent peer group established throughout the film, and the majority of interactions exist as dyads with Katniss. That being said, this in itself may speak to a shift in peer grouping behaviours as one grows up that may categorize friends based on specific roles they serve in one's life. Teenage years see the formation of many new relationships, most notably romantic relationships, along with new dimensions of peer networks. As such, while dyads may still rely upon group norms, the inner workings of one-on-one relations are not necessarily the same as group dynamics (Brown \& Larson, 2009).

These points may help answer sub-question b) with respect to how films of different ratings portray the presence of peers. While the PG film emphasizes group harmony and identity formed through the group's teamwork, the PG-13 film presents a more isolating picture of adolescence that emphasizes idiosyncrasies of the dyad. Such a 
revelation may help clarify concerns in literature of the ambiguous ratings descriptor of theme which may distinguish films of different ratings (Leone \& Houle, 2006). In addition, Katniss' relationship with Peeta has the most contact, and eventually evolves to contain a romantic element. It is worth noting that Hiccup and Astrid eventually form a romantic connection as well, although this does not come at the expense of their peer relationships; if anything, Hiccup is brought closer to the group. Dragon's characters may represent a typically juvenile depiction of how relationships are formed in relatively controlled settings, featuring several friends and one closer friend. Meanwhile, Games' illustration of contact individualizes relationships and faces the reality that certain connections are prioritized in different phases of life.

Affective involvement may be seen through the use of both smallwords and vocatives. Dragon's gradual omission of smallwords may be suggestive of Hiccup's increasing confidence, while Games extends scenes of tension by adding in smallwords. Past research has identified that teen-oriented films have more closely reflected spontaneous dialogue over time, although this is partially attributed to changes in acting styles (Bonsignori, 2015). While such choices made beyond a script may contribute to the dialogue's perceived realism, the emotional impact of smallwords is not a quality to be overlooked. Smallwords may be part of a broader category of teenage slang that may contribute to negative perceptions of teen talk (Stenström, Andersen, \& Hasund, 2002). However, findings in this study reveal that these seemingly meaningless words carry a more significant impact to a story's affective value. For instance, an audience may feel an increased connection towards Hiccup's growth into a valiant leader in the PG Dragon, as seen partially through omitting smallwords. However, PG-13 Games illustrates nuances 
beyond the mere inclusion or absence of such words, revealing how they may be wielded by certain characters to increase audience investment into their actions. Thus, incorporating such words into scripts may not only allow the dialogue to appear more reminiscent of authentic teen talk, but allow the story to be more potently resonant.

Lastly, the films' use of vocatives shows a similar affective growth in both Hiccup and Katniss through the frequency and willingness with which they call others by their names. However, examining the complexity of nicknames is significant not only to establish if a connection exists among characters, but also the quality of that connection. In the case of Dragon, the nicknames that are used are typically generic terms that may be easily identifiable as an attempt to be endearing (babe) or belittling (idiots, buddy). Even in cases with more creative monikers (troll, butt elf), they do not specifically play on a characteristic of the other person, but function as an attempt at mockery and humour. Such findings also reflect past studies which have found nicknames to be "a linguistic resource that the peer group members in question skilfully [sic] exploit in order to trigger, construct and sustain playful teasing exchanges and actively participate in them" (Lytra, 2003, p. 49). These terms further emphasize, as highlighted earlier, that the minor characters employing these terms do not have a suitable maturity level to become leaders within this group. However, Hiccup's divergence from the group in his resistance to mocking his peers through nicknames further allows him to fulfill the leadership role.

When looking at Games' use of creative nicknames, they contain a quality that is more specific to the story world and their emotional value is not as clearly understood out of context. For instance, when Thresh calls Katniss Twelve, an out-of-context interpretation may see this as an endearing attempt to earn favour with Katniss by 
referring to her home district. However, the real context of Thresh's nickname may suggest that he is intending to create more distance with her by avoiding the use of her real name. This decision may have made it easier for Thresh to kill Katniss later on if the opportunity presented itself later in the film. Another example is in Gale's use of Catnip to refer to Katniss; the play on words does not immediately suggest whether there is a positive or negative connotation attached to the name. That being said, the use of such a nickname is demonstrative of the closeness of their relationship, although the context would be needed to suggest its emotional quality. Such a finding also reflects a more nuanced portrayal of nicknames to suggest that there need not always be a bullying connotation to these terms, which may also represent more common adolescent nicknaming practices (Starks, Leech, \& Willoughby, 2012).

The examples from both films help address sub-question b) by showing variance not just in the words used, but in the affective value they seek to add to a film. The PG film typically uses terms that younger children will readily recognize as a humorous component in either an appeasing or disparaging way. When viewing these words out of context, they are more easily understood as connoting a particular attitude towards the recipient. In this way, these accessible nicknames allow younger audiences to grasp their intended emotional impact. On the other hand, the more neutral terms in the PG-13 might require a greater degree of concentration from the audience to understand how such terms are being used to illustrate the relationship. This is evocative of other studies which categorize the contextual usage of explicit terms (Bram \& Putra, 2019), although now it is being broadened to include non-explicit terms that communicate relational information. Such terms are not used in attempts at humour in the same way as Dragon, but instead 
may express the depth of a sentimental connection between two characters. In this way, the names being used in Games may contain a greater emotional weight due to contextual cues and their specificity to particular characters.

In using these findings to revisit the main research question, there may be some variance in how teenage characters in teen-centred films of different ratings use language. Dragon's textual structure may allow audiences to receive fuller linguistic explanations to follow along with the story. On the other hand, Games might place a greater onus on the audience to follow the underlying tone of the conversation rather than the explicit information. The interpersonal metafunction in the dialogue may also reflect relevant topics for audiences at a particular phase of life. Hiccup's journey in Dragon may be pertinent to elementary school children who encounter the same group of students every day and are required to embrace their circumstances. Meanwhile, Katniss' situation in Games might resonate more strongly with high schoolers' transitions of peers and classes, along with identity formation and maintenance during these changes. While such conclusions are not exclusive to students in particular grades, these findings may reveal how language may serve a key role in determining rating appropriateness. Intentional or not, the language choices in How to Train Your Dragon and The Hunger Games might assume its audiences possess a certain degree of developmental maturity to resonate with the story. Continued academic pursuits on this topic may further reveal how linguistic choices in characters' dialogue may uncover storytelling tactics used in film. 


\section{Chapter 7: Conclusion}

This thesis sought to uncover how non-profane language is used and may differ between US teen-oriented films rated PG and PG-13. The main research question which guided the study asked: Do the linguistic choices of teenage characters in teen-centred films vary based on a film's rating, and if so, how? In addition, two sub-questions specifically inquired about the variance in the textual and interpersonal metafunctions as seen in these linguistic choices. A literature review found two key research gaps pertaining to film ratings and language that guided the academic approach used in this thesis. Firstly, the literature concentrating on film ratings has been largely concerned with the prevalence of explicit content, without frequently focusing on the age of the characters involved. For this reason, the theory of teenage peer talk was discussed to reflect the language behaviours of both teenage characters and audiences who are most affected by ratings. In addition, the coming-of-age trope in novels and film helped explain the teenage experience as depicted in media. Furthermore, there was relatively little research which deeply considered the context in which film language was used. To address this concern, Systemic Functional Linguistics (SFL) provided an appropriate theoretical and methodological foundation for this study. SFL views language as having a functional purpose of making meaning through a series of choices to achieve a social purpose (Eggins, 2004). The study thus intended to help clarify how language was used in films with different ratings, focusing on how it was delivered and who was involved.

Two films were selected using Cressman et al.'s (2009) criteria to identify the highest-grossing teen-centred films rated PG and PG-13 from the 2010s. This resulted in the selected films being How to Train Your Dragon (2010, rated PG) and The Hunger 
Games (2012, rated PG-13). The textual and interpersonal metafunctions were then explored in transcripts of scenes involving peer talk from both films. The textual analysis discovered the proportion of descriptive content words to functional non-content words (lexical density), simple to complex sentences (grammatical intricacy), as well as order of contents in a clause (thematic structure). Meanwhile, the interpersonal metafunction was analyzed through the linguistic portrayals of power, contact, and affective involvement. The results found that Dragon's language used more descriptive terms and complex sentences, allowing the dialogue to contain fuller explanations with a lower percentage of variance among characters. In comparison, Games' dialogue used more functional terms and simple sentences, although tendencies were more idiosyncratically tied to particular characters. Dragon portrayed a narrative of self-confidence through Hiccup and peer acceptance on the part of the minor characters. However, Games illustrated a narrative of self-preservation as Katniss maintained several aspects of her linguistic identity while navigating between fleeting peer relationships. A discussion of these findings suggested that the contextual features of dialogue in Dragon and Games might reflect relevant topics to child and teenage audiences, respectively. In addition, the language might subtly imply that a stronger grasp of language is required to follow along with the PG-13 film for its greater reliance on more functional (versus descriptive) dialogue.

\subsection{Implications for Film and Ratings}

This thesis reveals that there is significance to the language used in films of different ratings beyond profanity. The findings from this study combined with (lack of) past research may emphasize the academic need to uncover the language of film scripts from an SFL perspective. Some recent studies have considered that filmmakers may have 
a particular rating in mind while a film is being crafted, even though ratings are assigned after a film is completed (Shafaei et al., 2020). However, studies using SFL may help expound upon how a film may not only receive a particular rating through profanity, but write effective dialogue to tell a desired story. This may help ensure a more efficient screenwriting process that results in more critically or commercially successful films being produced.

In addition, conducting more SFL analyses of larger film texts may encourage a shift in how ratings are perceived in the first place. In the ratings system, a swear word has the power to dictate if an entire film receives a particular rating without considering the script or dialogue as a whole. Yet, a film's "appropriateness" may encompass more than profanity, but also the manner in which its characters communicate various themes. Thus, reducing the linguistic qualities of a film to profanity may limit the potential information that ratings can offer; however, this offering could be more substantial if language is examined in its context of usage. On a broader scale, studying language and film ratings may reflect clickbait practices seen in a wider (social) media environment. A catchy soundbite, video clip, or written line has the potential to be pulled out of context as a headline or stand-alone image to (inaccurately) represent a story. In this regard, SFL studies in film could encourage both creators and audiences in the entertainment sector to seek understanding of context rather than exploiting certain buzzwords.

\subsection{Limitations}

This thesis faced a handful of notable limitations when being produced. Firstly, the researcher worked on this thesis remotely during the COVID-19 pandemic, meaning that some physical resources could not be accessed. This did not greatly hinder the final 
product, although some challenges arose in gathering information almost exclusively online. In addition, as discussed in previous sections, the limited amount of research on film language and ratings, especially with SFL, required this study to forge a new model of research. While this still contributes to research gaps, it provided some challenges to construct an appropriate design that would address the research questions. Lastly, while this study aimed to address a research gap by exploring film language in its context, such research is not generalizable across all PG and PG-13 films. The nature of SFL research is that its extensive detail provides a well-rounded understanding of specific pieces of text. However, selecting the highest-grossing teen-oriented US films from the 2010s in each rating is not reflective of the large repository of Hollywood films.

\subsection{Future Research}

This thesis may be a foundation from which future studies expand the literature of film language and ratings. If access is available to such documents, one area of inquiry may explore how language differs in various versions of a script. Studying rewrites or actor improvisations may reveal what linguistic choices are made to revise a script so as to make the writing process more efficient. Another field of investigation may explore the language used by various (stereotypical) character tropes in teen films such as intelligence, athleticism, or toughness. Studying the language choices may reveal strategies used to convey characters with a given trait and further unpack adolescent identities on screen. In addition, a deeper exploration of language used by minor or secondary characters in a film may be an intriguing area of study. Such characters may not be involved in the main storyline, but still carry a wide range of narrative purposes in aiding a protagonist's journey that may benefit from such clarification. Lastly, future 
research may consider studying ratings and linguistic standards of films produced in other countries. This may reveal how rating structures differ by country, and may invite comparison as to how various countries use language in films of comparable ratings.

The Motion Picture Association strives to provide parents with enough information to determine if their child should watch a film. In spite of this good intention, the information being communicated has almost exclusively focused on the amount and severity of explicit content in a film. This thesis is proposing that non-explicit factors may have value in determining how a film should be rated, which may be partially identified through a film's language. While these factors may not be obvious concerns, they still contribute to a wider message being conveyed in a film about the relationships among its characters and manner in which dialogue is presented. As shown previously, language is an integral part of the film industry, yet it contains several layers of meaning that are not being fully addressed in the ratings process. However, SFL analyses may help clarify and illuminate these additional meanings that are being conveyed in dialogue. Through such studies, the value of film language in its multitude of meanings may be better understood so as to consider all contextual cues in film ratings beyond the use of explicit terms. Therefore, this thesis hopes not only to inform parents of linguistic techniques in storytelling, but protect the interests of young people who are of a critical age in forming their beliefs and identity. Films may be considered to be part of the entertainment industry, but that does not disregard the influence they may have on the lives of those who consume them. 


\section{Appendices}

\section{Appendix A Scene Dispersion}

The following tables outline the role of each character in How to Train Your

Dragon (A.1) and The Hunger Games (A.2) scenes. An $S$ indicates that a character spoke in a given scene; a $P$ shows that a character was present but did not speak.

\section{A.1 Scene dispersion in How to Train Your Dragon}

\begin{tabular}{|c|c|c|c|c|c|c|}
\hline Scene \# & Hiccup & Astrid & Tuffnut & Ruffnut & Snotlout & Fishlegs \\
\hline 1 & $S$ & $S$ & $S$ & S & $\mathrm{P}$ & $\mathrm{P}$ \\
\hline 2 & & & $\mathrm{~S}$ & $\mathrm{~S}$ & & \\
\hline 3 & $S$ & $S$ & & & & \\
\hline 4 & S & $S$ & $\mathrm{~S}$ & $S$ & S & $\mathrm{S}$ \\
\hline 5 & & & $S$ & $S$ & & \\
\hline 6 & & $S$ & & & $S$ & \\
\hline 7 & $S$ & $\mathrm{~S}$ & $\mathrm{~S}$ & $\mathrm{~S}$ & $\mathrm{P}$ & $\mathrm{P}$ \\
\hline 8 & $P$ & $P$ & $S$ & $\mathrm{~S}$ & $S$ & $S$ \\
\hline 9 & $S$ & $S$ & $S$ & $S$ & $S$ & $S$ \\
\hline 10 & $S$ & $\mathrm{P}$ & $S$ & $S$ & $\mathrm{P}$ & $S$ \\
\hline 11 & $\mathrm{P}$ & $\mathrm{P}$ & $\mathrm{S}$ & $\mathrm{P}$ & $\mathrm{S}$ & $\mathrm{P}$ \\
\hline 12 & $\mathrm{P}$ & $\mathrm{P}$ & $S$ & $\mathrm{P}$ & $\mathrm{P}$ & $\mathrm{P}$ \\
\hline 13 & $S$ & $S$ & & & & \\
\hline 14 & $S$ & $S$ & & & & \\
\hline 15 & $S$ & $S$ & & & & \\
\hline 16 & $\mathrm{~S}$ & $S$ & & & & \\
\hline 17 & $S$ & $S$ & & & & \\
\hline 18 & S & $S$ & & & & \\
\hline 19 & $S$ & $S$ & & & & \\
\hline 20 & $S$ & $S$ & & & & \\
\hline 21 & $S$ & $\mathrm{~S}$ & $\mathrm{~S}$ & $\mathrm{~S}$ & $S$ & $\mathrm{~S}$ \\
\hline 22 & $S$ & $S$ & $P$ & $\mathrm{P}$ & $S$ & $P$ \\
\hline 23 & $S$ & $S$ & $S$ & $\mathrm{~S}$ & $S$ & $\mathrm{~S}$ \\
\hline 24 & & $S$ & $\mathrm{~S}$ & $S$ & & \\
\hline 25 & S & S & & & & \\
\hline
\end{tabular}




\section{A.2 Scene dispersion in The Hunger Games}

\begin{tabular}{|c|c|c|c|c|c|c|c|c|}
\hline Scene \# & Katniss & Peeta & Gale & Rue & Primrose & Thresh & Cato & Clove \\
\hline 1 & $\mathrm{~S}$ & & & & $\mathrm{~S}$ & & & \\
\hline 2 & S & & $S$ & & & & & \\
\hline 3 & $\mathrm{~S}$ & & & & $\mathrm{~S}$ & & & \\
\hline 4 & $\mathrm{~S}$ & & & & $S$ & & & \\
\hline 5 & $\mathrm{~S}$ & & S & & & & & \\
\hline 6 & $\mathrm{P}$ & $\mathrm{S}$ & & & & & & \\
\hline 7 & $S$ & S & & & & & & \\
\hline 8 & $\mathrm{~S}$ & $S$ & & & & & & \\
\hline 9 & $\mathrm{P}$ & $\mathrm{S}$ & & & & & $\mathrm{S}$ & $\mathrm{P}$ \\
\hline 10 & $\mathrm{~S}$ & & & $\mathrm{~S}$ & & & & \\
\hline 11 & $\mathrm{~S}$ & & & $\mathrm{~S}$ & & & & \\
\hline 12 & $\mathrm{~S}$ & & & S & & & & \\
\hline 13 & $\mathrm{~S}$ & $\mathrm{~S}$ & & & & & & \\
\hline 14 & $\mathrm{~S}$ & $\mathrm{~S}$ & & & & & & \\
\hline 15 & $\mathrm{~S}$ & $\mathrm{~S}$ & & & & & & \\
\hline 16 & S & $\mathrm{S}$ & & & & & & \\
\hline 17 & $\mathrm{P}$ & & & & & $\mathrm{S}$ & & $\mathrm{S}$ \\
\hline 18 & $\mathrm{~S}$ & $\mathrm{~S}$ & & & & & & \\
\hline 19 & $\mathrm{~S}$ & $\mathrm{~S}$ & & & & & & \\
\hline 20 & $\mathrm{~S}$ & $\mathrm{~S}$ & & & & & & \\
\hline 21 & $\mathrm{~S}$ & $\mathrm{~S}$ & & & & & & \\
\hline 22 & $\mathrm{~S}$ & $\mathrm{~S}$ & & & & & $\mathrm{~S}$ & \\
\hline 23 & $\mathrm{~S}$ & $\mathrm{~S}$ & & & & & & \\
\hline 24 & $\mathrm{~S}$ & $S$ & & & & & & \\
\hline
\end{tabular}




\section{Appendix B Line Dispersion}

The following tables outline the number of lines spoken by each character across 25 scenes in How to Train Your Dragon (B.1) and 24 scenes in The Hunger Games (B.2). The total percentages have been rounded to the nearest whole number.

\section{B.1 Line dispersion in How to Train Your Dragon}

\begin{tabular}{|c|c|c|}
\hline Character & Number of Lines & Percentage of Selected Dialogue \\
\hline Hiccup & 57 & $30 \%$ \\
\hline Astrid & 57 & $30 \%$ \\
\hline Tuffnut & 27 & $14 \%$ \\
\hline Ruffnut & 16 & $9 \%$ \\
\hline Snotlout & 16 & $9 \%$ \\
\hline Fishlegs & 15 & $8 \%$ \\
\hline TOTAL & $\mathbf{1 8 8}$ & $\mathbf{1 0 0 \%}$ \\
\hline
\end{tabular}

\section{B.2 Line dispersion in The Hunger Games}

\begin{tabular}{|c|c|c|}
\hline Character & Number of Lines & Percentage of Selected Dialogue \\
\hline Katniss & 106 & $46 \%$ \\
\hline Peeta & 58 & $25 \%$ \\
\hline Gale & 27 & $12 \%$ \\
\hline Rue & 15 & $7 \%$ \\
\hline Primrose & 12 & $5 \%$ \\
\hline Thresh & 5 & $2 \%$ \\
\hline Cato & 4 & $2 \%$ \\
\hline Clove & 4 & $\mathbf{1 0 0} \%$ \\
\hline TOTAL & $\mathbf{2 3 1}$ & \\
\hline
\end{tabular}




\section{Appendix C Theme and MOOD Analyses}

The following appendices contain the entire transcripts combined with theme and MOOD analyses for How to Train Your Dragon (C.1) and The Hunger Games (C.2). Each scene title lists off the characters who speak in that scene; a character's name in brackets indicates that they are present, but do not speak. The speaker of each line, in addition to their line number, are indicated at the top of each table. The first row of each table contains the line of dialogue spoken by a given character; the second row contains the thematic analysis; and the third and fourth rows contain the MOOD analysis. Abbreviated terms are as follows:

- Theme:top: Topical theme

- Theme:int: Interpersonal theme

- Theme:text: textual theme

- Neg: Negative

- Adj: Adjunct

- Circ: Circumstance

- Conj: Conjunction

- Cont: Continuity

In addition, a clause may be labelled as a minor clause if there is no MOOD constituent either overtly stated or implied through ellipsed dialogue (Eggins, 2004). In these cases, such clauses do not receive labels. 


\section{C.1 Theme and MOOD analysis in How to Train Your Dragon}

\section{Scene 1: Astrid, Tuffnut, Ruffnut, Hiccup}

ASTRID 1:

\begin{tabular}{|c|c|}
\hline No turning & back. \\
\hline Theme:topical & Rheme \\
\hline Finite:Negative & Adjunct:Circumstantial \\
\hline MOOD & RESIDUE \\
\hline
\end{tabular}

\section{TUFFNUT 1:}

\begin{tabular}{|c|c|c|c|c|}
\hline I hope & I & \multicolumn{2}{|c|}{ get } & some serious burns. \\
\hline Theme:int & Theme:top & \multicolumn{3}{|c|}{ Rheme } \\
\hline Adj:Mood & Subject & Finite & Predicator & Complement \\
\hline \multicolumn{3}{|c|}{ MOOD } & \multicolumn{3}{|c|}{ RESIDUE } \\
\hline
\end{tabular}

RUFFNUT 1:

\begin{tabular}{|c|c|c|c|c|c|}
\hline I & 'm & hoping & $\begin{array}{c}\text { for some } \\
\text { mauling, }\end{array}$ & like & $\begin{array}{c}\text { on my shoulder } \\
\text { or lower back. }\end{array}$ \\
\hline Theme:top & \multicolumn{5}{|c|}{ Rheme } \\
\hline Subject & Finite & Predicator & Adj:Circ & Adj:Cont & Adj:Circ \\
\hline \multicolumn{5}{|c|}{ MOOD } & \multicolumn{5}{|c|}{ RESIDUE } \\
\hline
\end{tabular}

ASTRID 2:

\begin{tabular}{|c|c|c|c|c|c|}
\hline Yeah, & it & 's & only & fun & $\begin{array}{c}\text { if you get a } \\
\text { scar out of it. }\end{array}$ \\
\hline Theme:text & Theme:top & \multicolumn{3}{|c|}{ Rheme } \\
\hline Adj:Cont & Subject & Finite & Adj:Mood & Complement:Attribute & Adj:Circ \\
\hline & \multicolumn{3}{|c}{ MOOD } & \multicolumn{2}{c|}{ RESIDUE } \\
\hline
\end{tabular}

\section{HICCUP 1:}




\begin{tabular}{|c|c|c|}
\hline Yeah, & no kidding, & right? \\
\hline Theme:text & Theme:top & Rheme \\
\hline Adj:Conj & Finite:Neg & Adj:Cont \\
\hline & MOOD & \\
\hline
\end{tabular}

\begin{tabular}{|c|}
\hline Pain. \\
\hline Theme:top \\
\hline Subject \\
\hline MOOD \\
\hline
\end{tabular}

\begin{tabular}{|c|c|c|}
\hline \multicolumn{2}{|c|}{ Love } & it. \\
\hline \multicolumn{2}{|c|}{ Theme:top } & Rheme \\
\hline Finite & Predicator & Complement \\
\hline MOOD & & RESIDUE \\
\hline
\end{tabular}

\section{TUFFNUT 2:}

\begin{tabular}{|c|}
\hline Oh great. \\
\hline Minor clause \\
\hline
\end{tabular}

\begin{tabular}{|c|c|c|c|c|}
\hline Who & \multicolumn{2}{|c|}{ let } & him & in? \\
\hline Theme:top & \multicolumn{3}{|c|}{ Rheme } \\
\hline WH/Subject & Finite & Predicator & Complement & Adj:Circ \\
\hline MOOD & \multicolumn{3}{|c}{ RESIDUE } \\
\hline
\end{tabular}

\section{Scene 2: Tuffnut, Ruffnut}

TUFFNUT 3:

\begin{tabular}{|c|c|c|}
\hline Get & your hands & off my shield! \\
\hline
\end{tabular}




\begin{tabular}{|c|c|c|}
\hline Theme:top & \multicolumn{2}{|c|}{ Rheme } \\
\hline Predicator & Complement & Adj:Circ \\
\hline & RESIDUE \\
\hline
\end{tabular}

RUFFNUT 2:

\begin{tabular}{|c|c|c|c|}
\hline There & are & like & a million shields! \\
\hline Theme:top & & Rheme \\
\hline Subject & Finite & Adj:Cont & Complement \\
\hline \multicolumn{2}{|c|}{ MOOD } & \multicolumn{2}{c|}{ RESIDUE } \\
\hline
\end{tabular}

\section{TUFFNUT 4:}

\begin{tabular}{|c|c|c|c|c|c|}
\hline Take & that one, & it & has & a flower & on it. \\
\hline Theme:top & Rheme \\
\hline Predicator & Complement \\
\hline \multicolumn{2}{|c|}{ RESIDUE } & Theme:top & \multicolumn{3}{|c|}{ Rheme } \\
\hline & \multicolumn{2}{|c|}{ MOOD } & \multicolumn{2}{|c|}{ RESIDUE } \\
\hline
\end{tabular}

\begin{tabular}{|c|c|c|c|}
\hline Girls & \multicolumn{2}{|c|}{ like } & flowers. \\
\hline Theme:top & \multicolumn{3}{|c|}{ Rheme } \\
\hline Subject & Finite & Predicator & Complement \\
\hline \multicolumn{2}{|c|}{ MOOD } & \multicolumn{2}{|c|}{ RESIDUE } \\
\hline
\end{tabular}

RUFFNUT 3:

\begin{tabular}{|c|c|c|c|c|c|}
\hline Ooops, & now & it & has & blood & on it. \\
\hline Theme:text & Theme:top & \multicolumn{5}{|c|}{ Rheme } \\
\hline Adj:Cont & Adj:Circ & Subject & Finite & Complement & Adj:Circ \\
\hline & RESIDUE... & \multicolumn{2}{|c|}{ MOOD } & \multicolumn{2}{|c|}{...RESIDUE } \\
\hline
\end{tabular}

\section{Scene 3: Hiccup, Astrid}


HICCUP 2:

\begin{tabular}{|c|c|c|c|c|c|c|}
\hline So, & I guess & it & 's & just & you and me & huh? \\
\hline Theme:text & Theme:int & Theme:top & \multicolumn{4}{|c|}{ Rheme } \\
\hline \multirow[t]{2}{*}{ Adj:Conj } & Adj:Mood & Subject & Finite & Adj:Mood & Complement & Adj:Cont \\
\hline & \multicolumn{4}{|c|}{ MOOD } & RESIDUE & \\
\hline
\end{tabular}

ASTRID 3:

\begin{tabular}{|c|}
\hline No. \\
\hline Theme:int \\
\hline Adj:Polarity \\
\hline MOOD \\
\hline
\end{tabular}

\begin{tabular}{|c|c|}
\hline Just & you. \\
\hline Theme:int & Theme:top \\
\hline Adj:Mood & Subject \\
\hline & MOOD \\
\hline
\end{tabular}

Scene 4: Tuffnut, Ruffnut, Snotlout, Fishlegs, Astrid, Hiccup

TUFFNUT 5:

\begin{tabular}{|c|c|c|c|}
\hline \multirow{2}{*}{ Wait, } & you & mean & read? \\
\hline Theme:top & Theme:top & \multicolumn{2}{|c|}{ Rheme } \\
\hline Predicator & Subject & Finite & Predicator \\
\hline RESIDUE & \multicolumn{2}{|c|}{ MOOD } & RESIDUE \\
\hline
\end{tabular}

RUFFNUT 4:

\begin{tabular}{|c|}
\hline While we're still alive? \\
\hline Theme:top \\
\hline Adj:Circ \\
\hline
\end{tabular}




\section{RESIDUE}

SNOTLOUT 1:

\begin{tabular}{|c|c|c|}
\hline Why & read & words \\
\hline Theme:top & \multicolumn{2}{|c|}{ Rheme } \\
\hline WH/Adj:Circ & Predicator & Complement \\
\hline \multicolumn{3}{|c|}{ RESIDUE } \\
\hline
\end{tabular}

\begin{tabular}{|c|c|c|c|c|c|}
\hline when & you & can & just & kill & $\begin{array}{c}\text { the stuff the } \\
\text { words tell you } \\
\text { stuff about? }\end{array}$ \\
\hline Theme:text & Theme:top & \multicolumn{4}{|c|}{ Rheme } \\
\hline WH/Adj:Circ & Subject & Finite & Adj:Mood & Predicator & Complement \\
\hline RESIDUE... & \multicolumn{3}{|c|}{ MOOD } & \multicolumn{3}{c|}{...RESDIUE } \\
\hline
\end{tabular}

FISHLEGS 1:

\begin{tabular}{|c|}
\hline Oh! \\
\hline Minor clause \\
\hline
\end{tabular}

\begin{tabular}{|c|c|c|c|c|c|}
\hline I & 've & read & it, & like, & seven times. \\
\hline Theme:top & \multicolumn{5}{|c|}{ Rheme } \\
\hline Subject & Finite & Predicator & Complement & Adj:Cont & Adj:Circ \\
\hline \multicolumn{2}{|c|}{ MOOD } & \multicolumn{4}{|c|}{ RESIDUE } \\
\hline
\end{tabular}

\begin{tabular}{|c|c|c|c|c|c|}
\hline There & 's & $\begin{array}{c}\text { this water } \\
\text { dragon that }\end{array}$ & sprays & boiling water & $\begin{array}{c}\text { on your } \\
\text { face. }\end{array}$ \\
\hline Theme:top & \multicolumn{5}{|c|}{ Rheme } \\
\hline Adj:Circ & Finite & Subject & Predicator & Complement & Adj:Circ \\
\hline RESIDUE... & \multicolumn{2}{|c|}{ MOOD } & \multicolumn{3}{|c|}{...RESIDUE } \\
\hline
\end{tabular}




\begin{tabular}{|c|c|c|c|c|c|c|}
\hline And & there & \multicolumn{1}{|c|}{ 's } & $\begin{array}{c}\text { this } \\
\text { other } \\
\text { one that }\end{array}$ & buries & itself & $\begin{array}{c}\text { for like } \\
\text { a } \\
\text { week... }\end{array}$ \\
\hline Theme:text & Theme:top & \multicolumn{5}{|c|}{ Rheme } \\
\hline Adj:Cont & Adj:Circ & Finite & Subject & Predicator & Complement & Adj:Circ \\
\hline & RESIDUE... & \multicolumn{2}{|c|}{ MOOD } & \multicolumn{3}{|c}{...RESIDUE } \\
\hline
\end{tabular}

\section{TUFFNUT 6:}

\begin{tabular}{|c|c|c|c|c|}
\hline Yeah, & that & \multicolumn{2}{|c|}{ sounds } & great. \\
\hline Theme:text & Theme:top & \multicolumn{3}{c|}{ Rheme } \\
\hline Adj:Cont & Subject & Finite & Predicator & Complement:Attributive \\
\hline & \multicolumn{2}{|c|}{ MOOD } & \multicolumn{3}{|c|}{ RESIDUE } \\
\hline
\end{tabular}

\begin{tabular}{|c|c|c|}
\hline There & was & a chance that I was going to read that... \\
\hline Theme:top & \multicolumn{2}{|c|}{ Rheme } \\
\hline Adj:Circ & Finite & Subject \\
\hline RESIDUE & & MOOD \\
\hline
\end{tabular}

RUFFNUT 5:

\begin{tabular}{|l|}
\hline ... but now... \\
\hline Minor clause \\
\hline
\end{tabular}

SNOTLOUT 2:

\begin{tabular}{|c|c|c|c|c|c|c|}
\hline You guys & \multicolumn{2}{|c|}{ read, } & I & 'll & go kill & \multicolumn{1}{c|}{ stuff. } \\
\hline Theme:top & \multicolumn{2}{|c|}{ Rheme } & Theme:top & \multicolumn{3}{c|}{ Rheme } \\
\hline Subject & Finite & Predicator & Subject & Finite & Predicator & Complement \\
\hline \multicolumn{2}{|c|}{ MOOD } & RESIDUE & \multicolumn{2}{|c|}{ MOOD } & \multicolumn{2}{c|}{ RESIDUE } \\
\hline
\end{tabular}

\section{FISHLEGS 2:}




\begin{tabular}{|c|c|c|c|c|c|c|}
\hline Oh & and & there & 's & $\begin{array}{c}\text { this } \\
\text { other } \\
\text { one that }\end{array}$ & has & $\begin{array}{c}\text { these spines } \\
\text { that look } \\
\text { like trees... }\end{array}$ \\
\hline Theme:text & Theme:text & Theme:top & \multicolumn{4}{|c|}{ Rheme } \\
\hline \multirow[t]{2}{*}{ Adj:Cont } & Adj:Cont & Adj:Circ & Finite & Subject & Predicator & Complement \\
\hline & & RESIDUE... & \multicolumn{2}{|c|}{ MOOD } & \multicolumn{2}{|c|}{...RESIDUE } \\
\hline
\end{tabular}

HICCUP 3:

\begin{tabular}{|c|c|c|c|c|}
\hline So & I guess & we & 'll & share-- \\
\hline Theme:text & Theme:int & Theme:top & \multicolumn{2}{|c|}{ Rheme } \\
\hline Adj:Conj & Adj:Mood & Subject & Finite & Predicator \\
\hline & \multicolumn{3}{|c|}{ MOOD } & RESIDUE \\
\hline
\end{tabular}

ASTRID 4:

\begin{tabular}{|c|c|c|}
\hline \multicolumn{2}{|c|}{ Read } & it. \\
\hline \multicolumn{2}{|c|}{ Theme:top } & Rheme \\
\hline Finite & Predicator & Complement \\
\hline MOOD & & RESIDUE \\
\hline
\end{tabular}

HICCUP 4:

\begin{tabular}{|c|c|}
\hline All mine & then. \\
\hline Theme:top & Rheme \\
\hline Complement & Adj:Cont \\
\hline \multicolumn{2}{r}{} \\
\hline
\end{tabular}

\section{Wow, so okay.}

Minor clause

\begin{tabular}{|c|c|c|c|}
\hline I & 'll & see & you-- \\
\hline
\end{tabular}




\begin{tabular}{|c|c|c|c|}
\hline Theme:top & \multicolumn{3}{c|}{ Rheme } \\
\hline Subject & Finite & Predicator & Complement \\
\hline \multicolumn{2}{|c|}{ MOOD } & \multicolumn{2}{c|}{ RESIDUE } \\
\hline
\end{tabular}

HICCUP 5:

\begin{tabular}{|c|}
\hline Tomorrow. \\
\hline Theme:top \\
\hline Adj:Circ \\
\hline RESIDUE \\
\hline
\end{tabular}

Scene 5: Tuffnut, Ruffnut

RUFFNUT 6:

\begin{tabular}{|c|c|c|c|}
\hline Do & you & ever & bathe? \\
\hline Theme:int & Theme:top & \multicolumn{2}{|c|}{ Rheme } \\
\hline Finite & Subject & Adj:Mood & Predicator \\
\hline \multicolumn{3}{|c|}{ MOOD } & RESIDUE \\
\hline
\end{tabular}

TUFFNUT 7:

\begin{tabular}{|c|c|c|c|c|}
\hline If & you & don't & like & it, \\
\hline Theme:text & Theme:top & \multicolumn{3}{|c|}{ Rheme } \\
\hline Adj:Circ & Subject & Finite:Neg & Predicator & Complement \\
\hline RESIDUE... & \multicolumn{2}{|c|}{ MOOD } & \multicolumn{2}{|c|}{...RESIDUE } \\
\hline
\end{tabular}

\begin{tabular}{|c|c|c|c|c|}
\hline then & just & \multicolumn{2}{|c|}{ get } & your own blind spot. \\
\hline Theme:top & Theme:int & \multicolumn{2}{|c|}{ Theme:top } & Rheme \\
\hline Adj:Circ & Adj:Mood & Finite & Predicator & Complement \\
\hline RESIDUE.. & \multicolumn{2}{|c|}{ MOOD } & & \multicolumn{2}{|c|}{...RESIDUE } \\
\hline
\end{tabular}


RUFFNUT 7:

\begin{tabular}{|c|c|c|c|c|c|}
\hline How about & I & \multicolumn{2}{|c|}{ give } & you & one! \\
\hline Theme:top & \multicolumn{5}{|c|}{ Rheme } \\
\hline WH/Adj:Circ & Subject & Finite & Predicator & Complement & Complement \\
\hline RESIDUE... & \multicolumn{2}{|c|}{ MOOD } & \multicolumn{3}{c}{...RESIDUE } \\
\hline
\end{tabular}

\section{Scene 6: Snotlout, Astrid}

SNOTLOUT 3:

\begin{tabular}{|l|c|}
\hline Watch out, & babe. \\
\hline Theme:top & Rheme \\
\hline Predicator & Adj:Vocative \\
\hline \multicolumn{2}{c}{} \\
\hline
\end{tabular}

\begin{tabular}{|c|c|c|c|}
\hline I & 'll & take care & of this. \\
\hline Theme:top & \multicolumn{3}{|c|}{ Rheme } \\
\hline Subject & Finite & Predicator & Adj:Circ \\
\hline \multicolumn{2}{|c|}{ MOOD } & \multicolumn{2}{|c|}{ RESIDUE } \\
\hline
\end{tabular}

ASTRID 5:

\begin{tabular}{|c|}
\hline Hey! \\
\hline Minor clause \\
\hline
\end{tabular}

SNOTLOUT 4:

\begin{tabular}{|c|c|c|c|}
\hline The sun & was & in my eyes, & Astrid. \\
\hline Theme:top & \multicolumn{3}{|c|}{ Rheme } \\
\hline Subject & Finite & Adj:Circ & Adj:Vocative \\
\hline \multicolumn{2}{|c|}{ ROOD } & \multicolumn{2}{c|}{ RESIDUE } \\
\hline
\end{tabular}

SNOTLOUT 4: 


\begin{tabular}{|c|c|c|c|c|c|}
\hline What & do & you & want & me & to do, \\
\hline Theme:top & \multicolumn{5}{|c|}{ Rheme } \\
\hline WH/Complement & Finite & Subject & Predicator... & Complement & ...Predicator \\
\hline RESIDUE... & \multicolumn{2}{|c|}{ MOOD } & \multicolumn{3}{|c|}{$\ldots$ RESIDUE } \\
\hline
\end{tabular}

\begin{tabular}{|c|c|}
\hline block out & the sun? \\
\hline Theme:top & Rheme \\
\hline Predicator & Complement \\
\hline \multicolumn{2}{|c|}{ RESIDUE } \\
\hline
\end{tabular}

\begin{tabular}{|c|c|c|c|}
\hline I & could & do & that, \\
\hline Theme:top & \multicolumn{3}{|c|}{ Rheme } \\
\hline Subject & Finite & Predicator & Complement \\
\hline \multicolumn{2}{|c|}{ MOOD } & \multicolumn{2}{|c|}{ RESIDUE } \\
\hline
\end{tabular}

\begin{tabular}{|c|c|c|c|c|c|}
\hline but & I & don't & have & time & right now! \\
\hline Theme:text & Them:top & \multicolumn{4}{|c|}{ Rheme } \\
\hline Adj:Conj & Subject & Finite:Neg & Predicator & Complement & Adj:Circ \\
\hline & \multicolumn{2}{|c|}{ MOOD } & \multicolumn{3}{|c|}{ RESIDUE } \\
\hline
\end{tabular}

\section{Scene 7: Tuffnut, Ruffnut, Hiccup, Astrid}

TUFFNUT 8:

\begin{tabular}{|c|}
\hline Oooh! \\
\hline Minor clause \\
\hline
\end{tabular}

\begin{tabular}{|c|c|}
\hline Love & on the battlefield! \\
\hline Theme:top & Rheme \\
\hline
\end{tabular}




\begin{tabular}{|c|c|}
\hline Subject & Adj:Circ \\
\hline MOOD & RESIDUE \\
\hline
\end{tabular}

RUFFNUT 8:

\begin{tabular}{|c|c|c|c|}
\hline She & could & do & \multicolumn{1}{c|}{ better. } \\
\hline Theme:top & \multicolumn{3}{|c|}{ Rheme } \\
\hline Subject & Finite & Predicator & Complement:Attributive \\
\hline \multicolumn{2}{|c|}{ MOOD } & \multicolumn{2}{c|}{ RESIDUE } \\
\hline
\end{tabular}

\section{HICCUP 6:}

\begin{tabular}{|c|c|c|c|c|c|}
\hline Just... & let & me... & why & don't & you... \\
\hline Theme:int & Theme:int & Theme:top & Theme:top & \multicolumn{2}{|c|}{ Rheme } \\
\hline Adj:Mood & Finite & Subject & WH/Adj:Circ & Finite:Neg & Subject \\
\hline \multicolumn{3}{|c|}{ MOOD } & \multicolumn{3}{|c|}{ MOOD } \\
\hline
\end{tabular}

Gobber (adult): Well done, Astrid.

ASTRID 6:

\begin{tabular}{|c|c|c|c|}
\hline Is & this & some kind of a joke & to you? \\
\hline Theme:int & Theme:top & \multicolumn{2}{|c|}{ Rheme } \\
\hline Finite & Subject & Complement & Adj:Circ \\
\hline \multicolumn{2}{|c|}{ MOOD } & \multicolumn{2}{|c|}{ RESIDUE } \\
\hline
\end{tabular}

\begin{tabular}{|c|c|c|c|c|}
\hline Our parents' war & is & about & to become & ours. \\
\hline Theme:top & \multicolumn{4}{|c|}{ Rheme } \\
\hline Subject & Finite & Adj:Circ & Predicator & Complement \\
\hline \multicolumn{2}{|c|}{ MOOD } & \multicolumn{3}{|c|}{ RESIDUE } \\
\hline
\end{tabular}

\section{Figure out}

what side you 're

on. 


\begin{tabular}{|l|c|c|c|c|}
\hline Theme:top & \multicolumn{4}{|c|}{ Rheme } \\
\hline Predicator & Complement & Subject & Finite & Adj:Circ \\
\hline \multicolumn{2}{|c|}{ RESIDUE... } & \multicolumn{2}{|c|}{ MOOD } & ...RESIDUE \\
\hline
\end{tabular}

\section{Scene 8: Tuffnut, Ruffnut, Snotlout, Fishlegs}

TUFFNUT 9:

\begin{tabular}{|c|c|c|c|}
\hline It & 's & gonna be & me. \\
\hline Theme:top & & Rheme \\
\hline Subject & Finite & Predicator & Complement \\
\hline \multicolumn{2}{|c|}{ MOOD } & \multicolumn{2}{c|}{ RESIDUE } \\
\hline
\end{tabular}

\begin{tabular}{|c|c|c|}
\hline It & 's & my destiny. \\
\hline Theme:top & \multicolumn{2}{|c|}{ Rheme } \\
\hline Subject & Finite & Complement \\
\hline \multicolumn{2}{|c|}{ MOOD } & RESIDUE \\
\hline
\end{tabular}

\begin{tabular}{|c|}
\hline See? \\
\hline Theme:top \\
\hline Predicator \\
\hline RESIDUE \\
\hline
\end{tabular}

FISHLEGS 3:

\begin{tabular}{|c|c|c|c|c|}
\hline Your mom & let & you & get & a tattoo? \\
\hline Theme:top & \multicolumn{4}{|c|}{ Rheme } \\
\hline Subject & Finite & Complement & Predicator & Complement \\
\hline \multicolumn{2}{|c|}{ MOOD } & \multicolumn{3}{|c|}{ RESIDUE } \\
\hline
\end{tabular}

TUFFNUT 10: 


\begin{tabular}{|c|c|c|}
\hline It & 's not & a tattoo. \\
\hline Theme:top & \multicolumn{2}{|c|}{ Rheme } \\
\hline Subject & Finite:Neg & Complement \\
\hline \multicolumn{3}{|c|}{ MOOD } \\
\hline
\end{tabular}

\begin{tabular}{|c|c|c|}
\hline It & 's & a birthmark. \\
\hline Theme:top & \multicolumn{2}{|c|}{ Rheme } \\
\hline Subject & Finite & Complement \\
\hline \multicolumn{3}{|c|}{ MOOD } \\
\hline
\end{tabular}

\section{RUFFNUT 9:}

\begin{tabular}{|c|c|c|c|c|c|}
\hline Okay, & I & 've & been stuck & with you & since birth, \\
\hline Theme:text & Theme:top & \multicolumn{4}{|c|}{ Rheme } \\
\hline Adj:Cont & Subject & Finite & Predicator & Adj:Circ & Adj:Circ \\
\hline & \multicolumn{2}{|c|}{ MOOD } & \multicolumn{3}{|c|}{ RESIDUE } \\
\hline
\end{tabular}

\begin{tabular}{|c|c|c|c|c|c|}
\hline and & that & was & never & there & before. \\
\hline Theme:text & Theme:top & \multicolumn{4}{|c|}{ Rheme } \\
\hline Adj:Conj & Subject & Finite & Adj:Mood:Neg & Adj:Circ & Adj:Circ \\
\hline & \multicolumn{5}{|c|}{ MOOD } \\
\hline
\end{tabular}

TUFFNUT 11:

\begin{tabular}{|c|c|c|}
\hline Yes & it & was. \\
\hline Theme:int & Theme:top & Rheme \\
\hline Adj:Polarity & Subject & Finite \\
\hline \multicolumn{3}{|c|}{ MOOD } \\
\hline
\end{tabular}




\begin{tabular}{|c|c|c|c|c|c|c|c|}
\hline You & 've & just & never & seen & me & $\begin{array}{c}\text { from the } \\
\text { left side }\end{array}$ & until now. \\
\hline Theme:top & \multicolumn{7}{|c|}{ Rheme } \\
\hline Subject & Finite & $\begin{array}{c}\text { Adj: } \\
\text { Mood }\end{array}$ & $\begin{array}{c}\text { Adj: } \\
\text { Mood:Neg }\end{array}$ & Predicator & Complement & $\begin{array}{c}\text { Adj: } \\
\text { Circ }\end{array}$ & $\begin{array}{c}\text { Adj: } \\
\text { Circ }\end{array}$ \\
\hline \multicolumn{7}{|c|}{ MOOD } & \multicolumn{7}{c|}{ RESIDUE } \\
\hline
\end{tabular}

SNOTLOUT 5:

\begin{tabular}{|c|c|c|c|}
\hline It & wasn't & there & yesterday. \\
\hline Theme:top & & Rheme \\
\hline Subject & Finite:Neg & Adj:Circ & Adj:Circ \\
\hline \multicolumn{2}{|c|}{ MOOD } & \multicolumn{2}{|c|}{ RESIDUE } \\
\hline
\end{tabular}

\begin{tabular}{|c|c|c|}
\hline Is & it & a birthmark or a today-mark? \\
\hline Theme:int & Theme:top & Rheme \\
\hline Finite & Subject & Complement \\
\hline \multicolumn{2}{|c|}{ MOOD } & RESIDUE \\
\hline
\end{tabular}

\section{Scene 9: Snotlout, Astrid, Ruffnut, Tuffnut, Fishlegs, Hiccup}

SNOTLOUT 6:

\begin{tabular}{|c|c|c|c|}
\hline If that dragon shows either of its faces, & I & 'm & gonna-- \\
\hline Theme:top & \multicolumn{3}{|c|}{ Rheme } \\
\hline Adj:Circ & Subject & Finite & Predicator \\
\hline RESIDUE... & \multicolumn{2}{|c|}{ MOOD } & ...RESIDUE \\
\hline
\end{tabular}

\section{There!}

Theme:top 


\begin{tabular}{|c|}
\hline Adj:Circ \\
\hline RESIDUE \\
\hline
\end{tabular}

ASTRID 7:

\begin{tabular}{|c|}
\hline Hey! \\
\hline Minor clause \\
\hline
\end{tabular}

RUFFNUT 10:

\begin{tabular}{|c|c|c|c|}
\hline It & 's & us, & idiots. \\
\hline Theme:top & \multicolumn{3}{|c|}{ Rheme } \\
\hline Subject & Finite & Complement & Adj:Vocative \\
\hline \multicolumn{2}{|c|}{ MOOD } & \multicolumn{2}{c|}{ RESIDUE } \\
\hline
\end{tabular}

\section{TUFFNUT 12:}

\begin{tabular}{|c|c|c|c|}
\hline Your butts & are & getting & bigger. \\
\hline Theme:top & \multicolumn{3}{|c|}{ Rheme } \\
\hline Subject & Finite & Predicator & Complement:Attributive \\
\hline \multicolumn{2}{|c|}{ MOOD } & \multicolumn{2}{c|}{ RESIDUE } \\
\hline
\end{tabular}

\begin{tabular}{|c|c|c|c|}
\hline We thought & you & were & a dragon. \\
\hline Theme:int & Theme:top & \multicolumn{2}{|c|}{ Rheme } \\
\hline Adj:Mood & Subject & Finite & Complemen \\
\hline \multicolumn{3}{|c|}{ MOOD } & RESIDUE \\
\hline
\end{tabular}

SNOTLOUT 7:

\begin{tabular}{|c|c|c|c|c|c|}
\hline Not & that & there & is & anything wrong & $\begin{array}{c}\text { with a dragon- } \\
\text { esque figure. }\end{array}$ \\
\hline Theme:int & $\begin{array}{c}\text { Theme: } \\
\text { int }\end{array}$ & $\begin{array}{c}\text { Theme: } \\
\text { top }\end{array}$ & \multicolumn{3}{|c}{ Rheme } \\
\hline
\end{tabular}




\begin{tabular}{|c|c|c|c|c|c|}
\hline $\begin{array}{c}\text { Finite: } \\
\text { Mod:Neg... }\end{array}$ & Adj:Conj & Subject & $\begin{array}{c}\text {..Finite: } \\
\text { Mod:Neg }\end{array}$ & Complement & Adj:Circ \\
\hline \multicolumn{2}{|c|}{ MOOD } & \multicolumn{2}{c|}{ RESIDUE } \\
\hline
\end{tabular}

ASTRID 8:

\begin{tabular}{|c|}
\hline Wait. \\
\hline Theme:top \\
\hline Predicator \\
\hline RESIDUE \\
\hline
\end{tabular}

TUFFNUT 13:

\begin{tabular}{|c|c|c|c|}
\hline Oh, & I & 'm & hurt. \\
\hline Theme:text & Theme:top & \multicolumn{2}{c|}{ Rheme } \\
\hline Adj:Cont & Subject & Finite & Complement:Attributive \\
\hline & \multicolumn{2}{|c|}{ MOOD } & RESIDUE \\
\hline
\end{tabular}

\begin{tabular}{|c|c|c|c|}
\hline I & am & very much & hurt. \\
\hline Theme:top & \multicolumn{3}{|c|}{ Rheme } \\
\hline Subject & Finite & Adj:Mood & Complement:Attributive \\
\hline \multicolumn{3}{|c|}{ MOOD } & RESIDUE \\
\hline
\end{tabular}

FISHLEGS 4:

\begin{tabular}{|c|c|c|c|c|}
\hline $\begin{array}{c}\text { Chances of } \\
\text { survival }\end{array}$ & are & dwindling & $\begin{array}{c}\text { into single } \\
\text { digits }\end{array}$ & now... \\
\hline Theme:top & \multicolumn{4}{|c|}{ Rheme } \\
\hline Subject & Finite & Predicator & Adj:Circ & Adj:Circ \\
\hline \multicolumn{2}{|c|}{ MOOD } & \multicolumn{3}{|c}{ RESIDUE } \\
\hline
\end{tabular}

HICCUP 7: 


\begin{tabular}{|l|}
\hline Look out! \\
\hline Theme:top \\
\hline Predicator \\
\hline RESIDUE \\
\hline
\end{tabular}

\section{FISHLEGS 5:}

\begin{tabular}{|c|}
\hline Oh. \\
\hline Minor clause \\
\hline
\end{tabular}

\begin{tabular}{|c|}
\hline Wrong head. \\
\hline Theme:top \\
\hline Complement \\
\hline RESIDUE \\
\hline
\end{tabular}

\section{Scene 10: Fishlegs, Tuffnut, Ruffnut, Hiccup}

\section{FISHLEGS 6:}

\begin{tabular}{|c|c|c|c|c|c|c|}
\hline Hey & Hiccup, & I & 've & never & seen & $\begin{array}{c}\text { a Gronkle do } \\
\text { that before. }\end{array}$ \\
\hline $\begin{array}{c}\text { Theme: } \\
\text { int }\end{array}$ & $\begin{array}{c}\text { Theme: } \\
\text { int }\end{array}$ & $\begin{array}{c}\text { Theme: } \\
\text { top }\end{array}$ & \multicolumn{3}{|c|}{ Rheme } \\
\hline $\begin{array}{c}\text { Adj: } \\
\text { Conj }\end{array}$ & $\begin{array}{c}\text { Adj: } \\
\text { Vocative }\end{array}$ & Subject & Finite & $\begin{array}{c}\text { Adj: } \\
\text { Mood:Neg }\end{array}$ & Predicator & Complement \\
\hline & & \multicolumn{5}{c|}{ MOOD } \\
\hline
\end{tabular}

TUFFNUT 14:

\begin{tabular}{|c|c|c|c|c|}
\hline How & 'd & you & do & that? \\
\hline Theme:top & \multicolumn{4}{|c|}{ Rheme } \\
\hline WH/Adj:Circ & Finite & Subject & Predicator & Complement \\
\hline
\end{tabular}




\begin{tabular}{|c|c|c|}
\hline RESIDUE $\ldots$ & MOOD & ...RESIDUE \\
\hline
\end{tabular}

RUFFNUT 11:

\begin{tabular}{|c|c|c|c|}
\hline It & was & really & cool. \\
\hline Theme:top & \multicolumn{3}{|c|}{ Rheme } \\
\hline Subject & Finite & Adj:Mood & Complement:Attributive \\
\hline \multicolumn{3}{|c|}{ MOOD } & RESIDUE \\
\hline
\end{tabular}

HICCUP 8:

\begin{tabular}{|c|c|c|c|c|}
\hline I & \multicolumn{2}{|c|}{ left } & my axe & back in the ring. \\
\hline Theme:top & \multicolumn{3}{|c|}{ Rheme } \\
\hline Subject & Finite & Predicator & Complement & Adj:Circ \\
\hline MOOD & \multicolumn{3}{|c}{ RESIDUE } \\
\hline
\end{tabular}

\section{HICCUP 9:}

\begin{tabular}{|c|c|c|c|c|c|c|c|}
\hline You guys & \multicolumn{2}{|c|}{ go on ahead } & and & I & 'll & catch up & with you. \\
\hline $\begin{array}{c}\text { Theme: } \\
\text { top }\end{array}$ & \multicolumn{2}{|c|}{ Rheme } & $\begin{array}{c}\text { Theme: } \\
\text { text }\end{array}$ & $\begin{array}{c}\text { Theme: } \\
\text { top }\end{array}$ & \multicolumn{3}{|c|}{ Rheme } \\
\hline Subject & Finite & Predicator & Adj:Conj & Subject & Finite & Predicator & Adj:Circ \\
\hline \multicolumn{2}{|c|}{ MOOD } & RESIDUE & & \multicolumn{2}{|c|}{ MOOD } & \multicolumn{2}{|c|}{ RESIDUE } \\
\hline
\end{tabular}

\section{Scene 11: Fishlegs, Snotlout, Tuffnut (Hiccup)}

FISHLEGS 7:

\begin{tabular}{|l|}
\hline Hey Hiccup! \\
\hline Minor clause \\
\hline
\end{tabular}

SNOTLOUT 8:

\begin{tabular}{|c|c|c|}
\hline What & was & that? \\
\hline Theme:top & \multicolumn{2}{|c|}{ Rheme } \\
\hline
\end{tabular}




\begin{tabular}{|c|c|c|}
\hline WH/Subject & Finite & Complement? \\
\hline \multicolumn{2}{|c|}{ MOOD } & RESIDUE \\
\hline
\end{tabular}

\begin{tabular}{|c|}
\hline Some kind of trick? \\
\hline Rheme \\
\hline Complement \\
\hline RESIDUE \\
\hline
\end{tabular}

\begin{tabular}{|c|c|c|c|}
\hline What & did & you & do? \\
\hline Theme:top & \multicolumn{3}{|c|}{ Rheme } \\
\hline WH/Complement & Finite & Subject & Predicator \\
\hline RESIDUE... & \multicolumn{2}{|c|}{ MOOD } & $\ldots$ RESIDUE \\
\hline
\end{tabular}

TUFFNUT 15:

\begin{tabular}{|c|c|c|c|c|c|}
\hline Hiccup, & you & 're & totally & $\begin{array}{c}\text { going to } \\
\text { come }\end{array}$ & in first, \\
\hline Theme:top & \multicolumn{5}{|c|}{ Rheme } \\
\hline Adj:Vocative & Subject & Finite & Adj:Mood & Predicator & Adj:Circ \\
\hline RESIDUE... & \multicolumn{3}{|c|}{ MOOD } & ...RESIDUE \\
\hline
\end{tabular}

\begin{tabular}{|c|c|c|}
\hline there & 's no & question. \\
\hline Theme:top & \multicolumn{2}{|c|}{ Rheme } \\
\hline Subject & Finite:Neg & Complement \\
\hline \multicolumn{2}{|c|}{ MOOD } & RESIDUE \\
\hline
\end{tabular}

\section{Scene 12: Tuffnut (Astrid, Hiccup, Snotlout, Fishlegs, Ruffnut)}

TUFFNUT 16:

Ha. 


\begin{tabular}{|c|c|c|c|}
\hline \multicolumn{2}{|c|}{ Minor clause } & \multirow[b]{2}{*}{ like } & \multirow[b]{2}{*}{ the size of my-- } \\
\hline It & 's & & \\
\hline Theme:top & \multicolumn{3}{|c|}{ Rheme } \\
\hline Subject & Finite & Adj:Cont & Adj:Circ \\
\hline \multicolumn{2}{|c|}{ MOOD } & \multicolumn{2}{|c|}{ RESIDUE } \\
\hline
\end{tabular}

TUFFNUT 17:

\begin{tabular}{|c|c|c|}
\hline Get & it & off! \\
\hline Theme:top & \multicolumn{2}{|c|}{ Rheme } \\
\hline Predicator & Complement & Adj:Circ \\
\hline \multicolumn{3}{|c|}{ RESIDUE } \\
\hline
\end{tabular}

\begin{tabular}{|c|c|c|}
\hline Get & it & off! \\
\hline Theme:top & & \multicolumn{2}{|c|}{ Rheme } \\
\hline Predicator & Complement & Adj:Circ \\
\hline \multicolumn{3}{|c|}{ RESIDUE } \\
\hline
\end{tabular}

\begin{tabular}{|c|c|c|c|}
\hline Oh, & I & 'm & hurt, \\
\hline Theme:text & Theme:top & \multicolumn{2}{c|}{ Rheme } \\
\hline Adj:Cont & Subject & Finite & Complement:Attributive \\
\hline & \multicolumn{2}{|c|}{ MOOD } & RESIDUE \\
\hline
\end{tabular}

\begin{tabular}{|c|c|c|c|}
\hline I & am & very much & hurt. \\
\hline Theme:top & \multicolumn{3}{|c|}{ Rheme } \\
\hline Subject & Finite & Adj:Mood & Complement:Attributive \\
\hline \multicolumn{3}{|c}{} & RESIDUE \\
\hline
\end{tabular}


TUFFNUT 18:

\begin{tabular}{|c|c|c|c|}
\hline Wow, & he & 's & better than you ever were. \\
\hline Theme:text & Theme:top & \multicolumn{2}{|c|}{ Rheme } \\
\hline Adj:Cont & Subject & Finite & Complement:Attributive \\
\hline \multicolumn{3}{|c|}{ MOOD } & RESIDUE \\
\hline
\end{tabular}

\section{Scene 13: Astrid, Hiccup}

ASTRID 9:

\begin{tabular}{|c|}
\hline Hiccup? \\
\hline Minor clause \\
\hline
\end{tabular}

ASTRID 10:

\begin{tabular}{|c|c|c|}
\hline Are & you & in there? \\
\hline Theme:int & Theme:top & Rheme \\
\hline Finite & Subject & Adj:Circ \\
\hline \multicolumn{2}{|c|}{ MOOD } & RESIDUE \\
\hline
\end{tabular}

\section{HICCUP 10:}

\begin{tabular}{|c|}
\hline Astrid. \\
\hline Minor clause \\
\hline Hey! \\
\hline Minor clause \\
\hline
\end{tabular}

\begin{tabular}{|c|}
\hline Hi Astrid. \\
\hline Minor clause \\
\hline
\end{tabular}

\section{Hi Astrid.}


Minor clause

Hi Astrid.

Minor clause

ASTRID 11:

\begin{tabular}{|c|c|c|c|c|}
\hline I & normally & don't & care & what people do, \\
\hline Theme:top & \multicolumn{3}{|c|}{ Rheme } \\
\hline Subject & Adj:Mood & Finite:Neg & Predicator & Complement \\
\hline \multicolumn{3}{|c|}{ MOOD } & \multicolumn{3}{c|}{ RESIDUE } \\
\hline
\end{tabular}

\begin{tabular}{|c|c|c|c|c|}
\hline but & you & 're & acting & weird. \\
\hline Theme:text & Theme:top & & \multicolumn{2}{c|}{ Rheme } \\
\hline Adj:Conj & Subject & Finite & Predicator & Complement:Attributive \\
\hline & \multicolumn{2}{|c|}{ MOOD } & \multicolumn{2}{c|}{ RESIDUE } \\
\hline
\end{tabular}

\begin{tabular}{|c|c|}
\hline Well, & weirder. \\
\hline Theme:text & Theme:top \\
\hline Adj:Cont & Complement:Attributive \\
\hline & RESIDUE \\
\hline
\end{tabular}

\section{Scene 14: Astrid, Hiccup}

ASTRID 12:

\begin{tabular}{|c|c|}
\hline Stay & out of my way. \\
\hline Theme:top & Rheme \\
\hline Predicator & Adj:Circ \\
\hline \multicolumn{2}{|c|}{ RESIDUE } \\
\hline
\end{tabular}


ASTRID 12:

\begin{tabular}{|c|c|c|c|}
\hline I & 'm & winning & this thing. \\
\hline Theme:top & \multicolumn{3}{|c|}{ Rheme } \\
\hline Subject & Finite & Predicator & Complement \\
\hline \multicolumn{2}{|c|}{ MOOD } & \multicolumn{2}{c|}{ RESIDUE } \\
\hline
\end{tabular}

HICCUP 11:

Please, by all means.

Minor clause

\section{$\underline{\text { Scene 15: Hiccup, Astrid }}$}

\section{HICCUP 12:}

\begin{tabular}{|c|}
\hline Aggh! \\
\hline Minor clause \\
\hline
\end{tabular}

\begin{tabular}{|c|}
\hline What the-- \\
\hline Minor clause \\
\hline
\end{tabular}

\begin{tabular}{|c|c|c|c|c|}
\hline What & are & you & doing & here? \\
\hline Theme:top & \multicolumn{4}{|c|}{ Rheme } \\
\hline WH/Complement & Finite & Subject & Predicator & Adj:Circ \\
\hline RESIDUE... & \multicolumn{2}{|c|}{ MOOD } & $\ldots$ RESIDUE \\
\hline
\end{tabular}

ASTRID 13:

\begin{tabular}{|c|c|c|c|}
\hline I & want & to know & what's going on. \\
\hline Theme:top & \multicolumn{3}{|c|}{ Rheme } \\
\hline Subject & Finite & Predicator & Complement \\
\hline \multicolumn{2}{|c|}{ MOOD } & \multicolumn{2}{c|}{ RESIDUE } \\
\hline
\end{tabular}




\begin{tabular}{|c|c|c|c|c|}
\hline No one & just & \multicolumn{2}{c|}{ gets } & as good as you do. \\
\hline Theme:top & \multicolumn{3}{c|}{ Rheme } \\
\hline Subject & Adj:Mood & Finite & Predicator & Complement:Attributive \\
\hline \multicolumn{3}{|c}{ MOOD } & \multicolumn{3}{c|}{ RESIDUE } \\
\hline
\end{tabular}

\begin{tabular}{|l|c|}
\hline Especially & you. \\
\hline Theme:int & Theme:top \\
\hline Adj:Mood & Subject \\
\hline \multicolumn{2}{|c|}{ MOOD } \\
\hline
\end{tabular}

\begin{tabular}{|c|c|}
\hline Start & talking! \\
\hline Theme:top & Rheme \\
\hline Finite & Predicator \\
\hline MOOD & RESIDUE \\
\hline
\end{tabular}

\begin{tabular}{|c|c|c|c|}
\hline Are & you & training & with someone? \\
\hline Theme:int & Theme:top & \multicolumn{2}{|c|}{ Rheme } \\
\hline Finite & Subject & Predicator & Adj:Circ \\
\hline \multicolumn{2}{|c|}{ MOOD } & \multicolumn{2}{|c|}{ RESIDUE } \\
\hline
\end{tabular}

HICCUP 13:

\begin{tabular}{|c|c|}
\hline Uh... & training? \\
\hline Theme:text & Theme:top \\
\hline Adj:Cont & Finite \\
\hline & MOOD \\
\hline
\end{tabular}

ASTRID 14: 


\begin{tabular}{|c|c|c|c|c|}
\hline It & better & not involve... & this. \\
\hline Theme:top & \multicolumn{3}{|c|}{ Rheme } \\
\hline Subject & Adj:Mood & Finite:Neg & Predicator & Complement \\
\hline \multicolumn{4}{|c|}{ MOOD } & \multicolumn{3}{c|}{ RESIDUE } \\
\hline
\end{tabular}

\section{HICCUP 14:}

\begin{tabular}{|c|c|c|c|c|}
\hline I know & this & \multicolumn{2}{|c|}{ looks } & really bad, \\
\hline Theme:int & Theme:top & \multicolumn{3}{|c|}{ Rheme } \\
\hline Adj:Mood & Subject & Finite & Predicator & Complement:Attributive \\
\hline \multicolumn{3}{|c|}{ MOOD } & \multicolumn{3}{|c|}{ RESIDUE } \\
\hline
\end{tabular}

\begin{tabular}{|c|c|c|c|c|}
\hline but & you see.. & this & is, & uh... \\
\hline Theme:text & Theme:text & Theme:top & \multicolumn{2}{|c|}{ Rheme } \\
\hline Adj:Conj & Adj:Cont & Subject & Finite & Adj:Cont \\
\hline & & \multicolumn{2}{|c|}{ MOOD } & \\
\hline
\end{tabular}

HICCUP 15:

\begin{tabular}{|c|c|c|}
\hline You & 're & right! \\
\hline Theme:top & \multicolumn{2}{|c|}{ Rheme } \\
\hline Subject & Finite & Complement:Attributive \\
\hline \multicolumn{2}{|c|}{ MOOD } & RESIDUE \\
\hline
\end{tabular}

\begin{tabular}{|c|c|c|}
\hline You & 're & right. \\
\hline Theme:top & \multicolumn{2}{|c|}{ Rheme } \\
\hline Subject & Finite & Complement:Attributive \\
\hline \multicolumn{2}{|c|}{ MOOD } & RESIDUE \\
\hline
\end{tabular}




\begin{tabular}{|c|c|c|c|}
\hline I & 'm & through & with the lies. \\
\hline Theme:top & & Rheme \\
\hline Subject & Finite & Predicator & Adj:Circ \\
\hline \multicolumn{2}{|c|}{ MOOD } & \multicolumn{2}{|c|}{ RESIDUE } \\
\hline
\end{tabular}

\begin{tabular}{|c|c|c|c|}
\hline I & 've & been making... & outfits. \\
\hline Theme:top & \multicolumn{3}{|c|}{ Rheme } \\
\hline Subject & Finite & Predicator & Complement \\
\hline \multicolumn{3}{|c|}{ MOOD } & \multicolumn{2}{c|}{ RESIDUE } \\
\hline
\end{tabular}

\begin{tabular}{|c|c|c|c|c|}
\hline So & you & \multicolumn{2}{|c|}{ got } & me. \\
\hline Theme:text & Theme:top & \multicolumn{3}{|c|}{ Rheme } \\
\hline Adj:Conj & Subject & Finite & Predicator & Complement \\
\hline & \multicolumn{2}{|c|}{ MOOD } & \multicolumn{2}{|c|}{ RESIDUE } \\
\hline
\end{tabular}

\begin{tabular}{|c|c|c|}
\hline It & 's & time everyone knew. \\
\hline Theme:top & \multicolumn{2}{|c|}{ Rheme } \\
\hline Subject & Finite & Adj:Circ \\
\hline \multicolumn{2}{|c|}{ MOOD } & RESIDUE \\
\hline
\end{tabular}

\begin{tabular}{|c|c|c|}
\hline Drag & me & back. \\
\hline Theme:top & \multicolumn{2}{|c|}{ Rheme } \\
\hline Predicator & Complement & Adj:Circ \\
\hline & RESIDUE \\
\hline
\end{tabular}

Go ahead. 


\begin{tabular}{|l|}
\hline Theme:top \\
\hline Predicator \\
\hline RESIDUE \\
\hline
\end{tabular}

\begin{tabular}{|c|c|c|c|}
\hline Here & we & \multicolumn{2}{|c|}{ go. } \\
\hline Theme:text & Theme:top & \multicolumn{2}{|c|}{ Rheme } \\
\hline Adj:Conj & Subject & Finite & Predicator \\
\hline & \multicolumn{2}{|c|}{ MOOD } & RESIDUE \\
\hline
\end{tabular}

\section{HICCUP 16:}

\begin{tabular}{|c|}
\hline AAAAUUGGGHHH! \\
\hline Minor clause \\
\hline
\end{tabular}

\begin{tabular}{|c|c|c|c|l|}
\hline Why & would & you & do & that? \\
\hline Theme:top & \multicolumn{4}{|c|}{ Rheme } \\
\hline WH/Adj:Circ & Finite & Subject & Predicator & Complement \\
\hline RESIDUE... & \multicolumn{2}{|c|}{ MOOD } & \multicolumn{2}{c|}{... RESIDUE } \\
\hline
\end{tabular}

ASTRID 15:

\begin{tabular}{|c|c|c|}
\hline That & 's & for the lies. \\
\hline Theme:top & \multicolumn{2}{|c|}{ Rheme } \\
\hline Subject & Finite & Adj:Circ \\
\hline \multicolumn{3}{|c|}{ MOOD } \\
\hline
\end{tabular}

ASTRID 16:

\begin{tabular}{|c|c|c|c|}
\hline And & THAT & 's & for everything else. \\
\hline Theme:text & Theme:top & \multicolumn{2}{|c|}{ Rheme } \\
\hline Adj:Conj & Subject & Finite & Adj:Circ \\
\hline
\end{tabular}




\begin{tabular}{|c|c|c|}
\hline & MOOD & RESIDUE \\
\hline
\end{tabular}

HICCUP 17:

\begin{tabular}{|c|}
\hline Oh man. \\
\hline Minor clause \\
\hline
\end{tabular}

ASTRID 17:

\begin{tabular}{|c|c|}
\hline Get & down! \\
\hline Theme:int & Theme:top \\
\hline Finite & Adj:Circ \\
\hline MOOD & RESIDUE \\
\hline
\end{tabular}

\begin{tabular}{|c|}
\hline Run! \\
\hline Theme:top \\
\hline Predicator \\
\hline RESIDUE \\
\hline
\end{tabular}

\begin{tabular}{|c|}
\hline Run! \\
\hline Theme:top \\
\hline Predicator \\
\hline RESIDUE \\
\hline
\end{tabular}

\section{HICCUP 18:}

\begin{tabular}{|c|}
\hline No! \\
\hline Minor clause \\
\hline HICCUP 19: \\
\hline No. \\
\hline Theme:int \\
\hline
\end{tabular}




\begin{tabular}{|c|}
\hline Adj:Polarity \\
\hline MOOD \\
\hline
\end{tabular}

\begin{tabular}{|c|c|c|}
\hline It & 's & okay! \\
\hline Theme:top & \multicolumn{2}{|c|}{ Rheme } \\
\hline Subject & Finite & Complement:Attributive \\
\hline \multicolumn{2}{|c|}{ MOOD } & RESIDUE \\
\hline
\end{tabular}

\begin{tabular}{|c|c|c|}
\hline It & 's & okay... \\
\hline Theme:top & \multicolumn{2}{|c|}{ Rheme } \\
\hline Subject & Finite & Complement:Attributive \\
\hline \multicolumn{2}{|c|}{ MOOD } & RESIDUE \\
\hline
\end{tabular}

..

HICCUP 20:

\begin{tabular}{|c|c|c|c|c|}
\hline You & just & \multicolumn{2}{|c|}{ scared } & him. \\
\hline Theme:top & \multicolumn{3}{|c|}{ Rheme } \\
\hline Subject & Adj:Mood & Finite & Predicator & Complement \\
\hline \multicolumn{4}{|c|}{ MOOD } & \multicolumn{3}{|c|}{ RESIDUE } \\
\hline
\end{tabular}

ASTRID 18:

\begin{tabular}{|c|c|c|c|}
\hline I & \multicolumn{2}{|c|}{ scared } & him?! \\
\hline Theme:top & \multicolumn{3}{|c|}{ Rheme } \\
\hline Subject & Finite & Predicator & Complement \\
\hline \multicolumn{2}{|c|}{ MOOD } & \multicolumn{2}{|c|}{ RESIDUE } \\
\hline
\end{tabular}

ASTRID 19:

Who

is him? 


\begin{tabular}{|c|c|c|}
\hline Theme:top & \multicolumn{2}{c|}{ Rheme } \\
\hline WH/Subject & Finite & Complement \\
\hline \multicolumn{3}{|c|}{ MOOD } \\
\hline
\end{tabular}

HICCUP 21:

\begin{tabular}{|c|c|}
\hline Astrid, & Toothless. \\
\hline Theme:int & Theme:top \\
\hline Adj:Vocative & Complement \\
\hline \multicolumn{2}{|c|}{ RESIDUE } \\
\hline
\end{tabular}

\begin{tabular}{|c|c|}
\hline Toothless, & Astrid. \\
\hline Theme:int & Theme:top \\
\hline Adj:Vocative & Complement \\
\hline \multicolumn{2}{|c|}{ RESIDUE } \\
\hline
\end{tabular}

\section{Scene 16: Hiccup, Astrid}

ASTRID 20:

\begin{tabular}{|c|}
\hline Hiccup! \\
\hline Minor clause \\
\hline
\end{tabular}

\begin{tabular}{|c|c|c|}
\hline Get & me & down from here! \\
\hline Theme:top & \multicolumn{2}{|c|}{ Rheme } \\
\hline Predicator & Complement & Adj:Circ \\
\hline \multicolumn{3}{|c|}{ RESIDUE } \\
\hline
\end{tabular}

\section{HICCUP 22:}

\begin{tabular}{|c|c|c|c|c|}
\hline You & have & to give & me & $\begin{array}{c}\text { a chance to } \\
\text { explain. }\end{array}$ \\
\hline
\end{tabular}




\begin{tabular}{|c|c|c|c|c|}
\hline Theme:top & \multicolumn{3}{c|}{ Rheme } \\
\hline Subject & Finite & Predicator & Complement & Complement \\
\hline \multicolumn{2}{|c|}{ MOOD } & \multicolumn{3}{c|}{ RESIDUE } \\
\hline
\end{tabular}

ASTRID 21:

\begin{tabular}{|c|c|c|c|}
\hline I & 'm not & listening to & ANYTHING you have to say! \\
\hline Theme:top & \multicolumn{3}{|c|}{ Rheme } \\
\hline Subject & Finite:Neg & Predicator & Complement \\
\hline \multicolumn{2}{|c|}{ MOOD } & & RESIDUE \\
\hline
\end{tabular}

HICCUP 23:

\begin{tabular}{|c|c|c|c|}
\hline Then & I & won't & speak. \\
\hline Theme:text & Theme:top & \multicolumn{2}{|c|}{ Rheme } \\
\hline Adj:Conj & Subject & Finite:Neg & Predicator \\
\hline & \multicolumn{2}{|c|}{ MOOD } & RESIDUE \\
\hline
\end{tabular}

\begin{tabular}{|c|c|c|c|c|}
\hline Just & let & me & show & you. \\
\hline Theme:int & Theme:int & Theme:top & \multicolumn{2}{|c|}{ Rheme } \\
\hline Adj:Mood & Finite & Subject & Predicator & Complement \\
\hline \multicolumn{3}{|c|}{ MOOD } & \multicolumn{2}{|c|}{ RESIDUE } \\
\hline
\end{tabular}

HICCUP 24:

\begin{tabular}{|c|}
\hline Please, Astrid. \\
\hline Minor clause \\
\hline
\end{tabular}

ASTRID 22:

\begin{tabular}{|c|c|c|c|}
\hline Now & get & me & down. \\
\hline Theme:text & Theme:top & \multicolumn{3}{|c|}{ Rheme } \\
\hline
\end{tabular}




\begin{tabular}{|c|c|c|c|}
\hline Adj:Conj & Predicator & Complement & Adj:Circ \\
\hline & \multicolumn{3}{|c|}{ RESIDUE } \\
\hline
\end{tabular}

\section{Scene 17: Hiccup, Astrid}

ASTRID 23:

\begin{tabular}{|c|c|c|c|c|}
\hline Alright & I & \multicolumn{2}{c|}{ admit } & it. \\
\hline Theme:text & Theme:top & \multicolumn{3}{c|}{ Rheme } \\
\hline Adj:Conj & Subject & Finite & Predicator & Complement \\
\hline & \multicolumn{2}{|c|}{ MOOD } & \multicolumn{2}{c|}{ RESIDUE } \\
\hline
\end{tabular}

\begin{tabular}{|c|c|c|c|}
\hline This & is & pretty & cool. \\
\hline Theme:top & \multicolumn{3}{|c|}{ Rheme } \\
\hline Subject & Finite & Adj:Mood & Complement:Attributive \\
\hline \multicolumn{3}{|c|}{ MOOD } & RESIDUE \\
\hline
\end{tabular}

\begin{tabular}{|c|c|c|}
\hline It & 's... & amazing. \\
\hline Theme:top & \multicolumn{2}{|c|}{ Rheme } \\
\hline Subject & Finite & Complement:Attributive \\
\hline & & RESIDUE \\
\hline
\end{tabular}

\begin{tabular}{|c|c|c|}
\hline He & 's & amazing. \\
\hline Theme:top & \multicolumn{2}{|c|}{ Rheme } \\
\hline Subject & Finite & Complement:Attributive \\
\hline \multicolumn{2}{|c|}{ REOD } & RESIDUE \\
\hline
\end{tabular}

ASTRID 24:

\section{So}

what now? 


\begin{tabular}{|c|c|c|}
\hline Theme:text & Theme:top & Rheme \\
\hline Adj:Conj & Subject & Adj:Circ \\
\hline & MOOD & RESIDUE \\
\hline
\end{tabular}

\begin{tabular}{|c|c|c|c|}
\hline Hiccup, & your final exam & is & tomorrow. \\
\hline Theme:int & Theme:top & \multicolumn{2}{|c|}{ Rheme } \\
\hline Adj:Vocative & Subject & Finite & Adj:Circ \\
\hline RESIDUE... & \multicolumn{2}{|c|}{ MOOD } & ..RESIDUE \\
\hline
\end{tabular}

\begin{tabular}{|c|c|c|c|c|}
\hline You know & you & 're & $\begin{array}{c}\text { going to have } \\
\text { to kill... kill }\end{array}$ & a dragon \\
\hline Theme:int & Theme:top & & Rheme \\
\hline Adj:Mood & Subject & Finite & Predicator & Complement \\
\hline \multicolumn{3}{|c|}{ MOOD } & \multicolumn{2}{|c|}{ RESIDUE } \\
\hline
\end{tabular}

HICCUP 25:

\begin{tabular}{|c|c|c|}
\hline Don't & remind & me. \\
\hline Theme:int & Theme:top & Rheme \\
\hline Finite:Neg & Predicator & Complement \\
\hline MOOD & \multicolumn{2}{|c|}{ RESIDUE } \\
\hline
\end{tabular}

HICCUP 26:

\begin{tabular}{|c|l|}
\hline Get & down! \\
\hline Theme:top & Rheme \\
\hline Predicator & Adj:Circ \\
\hline \multicolumn{2}{|c|}{ RESIDUE } \\
\hline
\end{tabular}


ASTRID 26:

\begin{tabular}{|c|c|c|}
\hline What & 's & going on? \\
\hline Theme:top & \multicolumn{2}{|c|}{ Rheme } \\
\hline WH/Subject & Finite & Predicator \\
\hline \multicolumn{3}{|c|}{ MOOD } \\
\hline
\end{tabular}

HICCUP 27:

\begin{tabular}{|c|c|c|}
\hline I & don't & know. \\
\hline Theme:top & \multicolumn{2}{|c|}{ Rheme } \\
\hline Subject & Finite:Neg & Predicator \\
\hline \multicolumn{3}{|c|}{ MOOD } \\
\hline
\end{tabular}

...

HICCUP 28:

\begin{tabular}{|c|c|c|c|l|}
\hline It looks like & they & 're & hauling in & their kill. \\
\hline Theme:int & Theme:top & \multicolumn{3}{|c|}{ Rheme } \\
\hline Adj:Mood & Subject & Finite & Predicator & Complement \\
\hline \multicolumn{3}{|c|}{ MOOD } & \multicolumn{2}{|c|}{ RESIDUE } \\
\hline
\end{tabular}

ASTRID 27:

\begin{tabular}{|c|c|c|c|l|}
\hline What & does & that & make & us? \\
\hline Theme:top & \multicolumn{4}{|c|}{ Rheme } \\
\hline WH/Complement & Finite & Subject & Predicator & Complement \\
\hline RESIDUE... & \multicolumn{2}{|c|}{ MOOD } & \multicolumn{2}{|c|}{..RESIDUE } \\
\hline
\end{tabular}

HICCUP 29:

\begin{tabular}{|c|c|c|}
\hline What my dad wouldn't give & to find & this. \\
\hline Theme:top & \multicolumn{2}{|c|}{ Rheme } \\
\hline
\end{tabular}




\begin{tabular}{|c|c|c|c|}
\hline Subject & Finite & Predicator & Complement \\
\hline \multicolumn{2}{|c|}{ MOOD } & \multicolumn{2}{c|}{ RESIDUE } \\
\hline
\end{tabular}

HICCUP 30:

\begin{tabular}{|c|c|c|c|}
\hline \multicolumn{1}{|c|}{ It } & 's & satisfying & $\begin{array}{c}\text { to know that all of our food has } \\
\text { been dumped down a hole. }\end{array}$ \\
\hline Theme:top & \multicolumn{3}{|c|}{ Rheme } \\
\hline Subject... & Finite & Complement:Attributive & $\ldots$. Subject \\
\hline \multicolumn{2}{|c|}{ MOOD... } & RESIDUE & $\ldots$ MOOD \\
\hline
\end{tabular}

ASTRID 28:

\begin{tabular}{|c|c|c|c|}
\hline They & 're not & eating & any of it. \\
\hline Theme:top & & Rheme \\
\hline Subject & Finite:Neg & Predicator & Complement \\
\hline \multicolumn{2}{|c|}{ MOOD } & \multicolumn{2}{|c|}{ RESIDUE } \\
\hline
\end{tabular}

ASTRID 29:

\begin{tabular}{|c|c|c|}
\hline What & is & that? \\
\hline Theme:top & \multicolumn{2}{|c|}{ Rheme } \\
\hline WH/Subject & Finite & Complement \\
\hline & MOOD & RESIDUE \\
\hline
\end{tabular}

\section{$\underline{\text { Scene 18: Hiccup, Astrid }}$}

ASTRID 30:
\begin{tabular}{|c|c|c|c|c|c|c|}
\hline No, & no, & it & totally & makes & sense. \\
\hline Theme:text & Theme:text & Theme:top & \multicolumn{5}{|c|}{ Rheme } \\
\hline Adj:Cont & Adj:Cont & Subject & Adj:Mood & Finite & Predicator & Complement \\
\hline & & \multicolumn{3}{|c|}{ MOOD } & & RESIDUE \\
\hline
\end{tabular}




\begin{tabular}{|c|c|c|}
\hline It & 's & like a giant beehive. \\
\hline Theme:top & \multicolumn{2}{|c|}{ Rheme } \\
\hline Subject & Finite & Complement:Attributive \\
\hline \multicolumn{2}{|c|}{ MOOD } & RESIDUE \\
\hline
\end{tabular}

\begin{tabular}{|c|c|c|}
\hline They & 're & the workers... \\
\hline Theme:top & \multicolumn{2}{|c|}{ Rheme } \\
\hline Subject & Finite & Complement \\
\hline \multicolumn{2}{|c|}{ MOOD } & RESIDUE \\
\hline
\end{tabular}

\begin{tabular}{|c|c|c|c|}
\hline and & that & 's & their queen. \\
\hline Theme:text & Theme:top & \multicolumn{2}{|c|}{ Rheme } \\
\hline Adj:Conj & Subject & Finite & Complement \\
\hline & \multicolumn{2}{|c|}{ MOOD } & RESIDUE \\
\hline
\end{tabular}

\begin{tabular}{|c|c|c|c|}
\hline It & \multicolumn{2}{|c|}{ controls } & them. \\
\hline Theme:top & \multicolumn{3}{|c|}{ Rheme } \\
\hline Subject & Finite & Predicator & Complement \\
\hline \multicolumn{2}{|c|}{ MOOD } & & RESIDUE \\
\hline
\end{tabular}

ASTRID 31:

\begin{tabular}{|c|c|c|c|}
\hline Let's & \multicolumn{2}{|c|}{ find } & your dad. \\
\hline Theme:top & \multicolumn{3}{|c|}{ Rheme } \\
\hline Subject & Finite & Predicator & Complement \\
\hline \multicolumn{2}{|c|}{ MOOD } & \multicolumn{2}{|c|}{ RESIDUE } \\
\hline
\end{tabular}

HICCUP 31: 


\begin{tabular}{|c|c|}
\hline No, & no! \\
\hline Theme:int & Theme:int \\
\hline Adj:Polarity & Adj:Polarity \\
\hline \multicolumn{2}{|c|}{} \\
\hline
\end{tabular}

\begin{tabular}{|c|}
\hline Not yet. \\
\hline Theme:top \\
\hline Adj:Circ \\
\hline RESIDUE \\
\hline
\end{tabular}

\begin{tabular}{|c|c|c|c|}
\hline They & 'll... & kill & Toothless. \\
\hline Theme:top & \multicolumn{3}{|c|}{ Rheme } \\
\hline Subject & Finite & Predicator & Complement \\
\hline \multicolumn{2}{|c|}{ MOOD } & \multicolumn{2}{c|}{ RESIDUE } \\
\hline
\end{tabular}

\begin{tabular}{|c|c|c|c|c|c|}
\hline Astrid, & we & have & to think & this through & carefully. \\
\hline Theme:int & Theme:top & \multicolumn{4}{|c|}{ Rheme } \\
\hline Adj:Vocative & Subject & Finite & Predicator & Adj:Circ & Adj:Comment \\
\hline & \multicolumn{2}{|c|}{ MOOD } & \multicolumn{3}{c|}{ RESIDUE } \\
\hline
\end{tabular}

\section{ASTRID 32:}

\begin{tabular}{|c|c|c|c|c|c|}
\hline Hiccup, & we & just & \multicolumn{2}{|c|}{ discovered } & $\begin{array}{l}\text { the dragons' nest... the } \\
\text { thing we've been after since } \\
\text { Vikings first sailed here. }\end{array}$ \\
\hline Theme:int & Theme:top & \multicolumn{4}{|c|}{ Rheme } \\
\hline \multirow[t]{2}{*}{ Adj:Vocative } & Subject & Adj:Mood & Finite & Predicator & Complement \\
\hline & \multicolumn{3}{|c|}{ MOOD } & \multicolumn{2}{|r|}{ RESIDUE } \\
\hline
\end{tabular}




\begin{tabular}{|c|c|c|c|c|c|}
\hline And & you & want & to keep & it & a secret? \\
\hline Theme:text & Theme:top & \multicolumn{4}{c|}{ Rheme } \\
\hline Adj:Conj & Subject & Finite & Predicator & Complement & Complement \\
\hline & \multicolumn{2}{|c|}{ MOOD } & \multicolumn{3}{c|}{ RESIDUE } \\
\hline
\end{tabular}

\begin{tabular}{|l|c|}
\hline To protect & your pet dragon? \\
\hline Theme:top & Rheme \\
\hline Predicator & Complement \\
\hline \multicolumn{2}{|c|}{ RESIDUE } \\
\hline
\end{tabular}

\begin{tabular}{|c|c|c|}
\hline Are & you & serious? \\
\hline Theme:int & Theme:top & Rheme \\
\hline Finite & Subject & Complement:Attributive \\
\hline \multicolumn{2}{|c|}{ MOOD } & RESIDUE \\
\hline
\end{tabular}

\section{HICCUP 32:}

\begin{tabular}{|c|}
\hline Yes. \\
\hline Theme:int \\
\hline Adj:Polarity \\
\hline MOOD \\
\hline
\end{tabular}

ASTRID 33:

\begin{tabular}{|c|}
\hline Okay. \\
\hline Minor clause \\
\hline
\end{tabular}

\begin{tabular}{|c|c|c|c|c|}
\hline Then & what & do & we & do? \\
\hline Theme:text & Theme:top & \multicolumn{3}{|c|}{ Rheme } \\
\hline
\end{tabular}




\begin{tabular}{|c|c|c|c|c|}
\hline Adj:Conj & WH/Complement & Finite & Subject & Predicator \\
\hline & RESIDUE... & \multicolumn{2}{|c|}{ MOOD } & $\ldots$ RESIDUE \\
\hline
\end{tabular}

HICCUP 33:

\begin{tabular}{|c|c|c|c|c|}
\hline Just & \multicolumn{2}{|c|}{ give } & me & until tomorrow. \\
\hline Theme:int & \multicolumn{2}{|c|}{ Theme:top } & \multicolumn{2}{|c|}{ Rheme } \\
\hline Adj:Mood & Finite & Predicator & Complement & Adj:Circ \\
\hline \multicolumn{2}{|c|}{ MOOD } & \multicolumn{3}{|c|}{ RESIDUE } \\
\hline
\end{tabular}

\begin{tabular}{|c|c|c|c|c|}
\hline I & 'll & figure & something & out. \\
\hline Theme:top & \multicolumn{4}{|c|}{ Rheme } \\
\hline Subject & Finite & Predicator... & Complement & ...Predicator \\
\hline \multicolumn{2}{|c|}{ ROOD } & \multicolumn{3}{c}{ RESIDUE } \\
\hline
\end{tabular}

ASTRID 34:

\begin{tabular}{|c|}
\hline Okay. \\
\hline Minor clause \\
\hline
\end{tabular}

ASTRID 35:

\begin{tabular}{|c|c|c|}
\hline That & 's & for kidnapping me. \\
\hline Theme:top & \multicolumn{2}{|c|}{ Rheme } \\
\hline Subject & Finite & Adj:Circ \\
\hline \multicolumn{2}{|c|}{ ROOD } & RESIDUE \\
\hline
\end{tabular}

ASTRID 36:

\begin{tabular}{|c|c|c|}
\hline That & 's & for everything else. \\
\hline Theme:top & \multicolumn{2}{|c|}{ Rheme } \\
\hline Subject & Finite & Adj:Circ \\
\hline
\end{tabular}




\begin{tabular}{|l|c|}
\hline MOOD & RESIDUE \\
\hline
\end{tabular}

\section{$\underline{\text { Scene 19: Hiccup, Astrid }}$}

ASTRID 37:

\begin{tabular}{|c|c|c|}
\hline Be & careful & with that dragon. \\
\hline Theme:top & \multicolumn{2}{|c|}{ Rheme } \\
\hline Predicator & Complement:Attributive & Adj:Circ \\
\hline \multicolumn{2}{|c|}{ RESIDUE } \\
\hline
\end{tabular}

HICCUP 34:

\begin{tabular}{|c|c|c|}
\hline It & 's not & the dragon \\
\hline Theme:top & \multicolumn{2}{|c|}{ Rheme } \\
\hline Subject & Finite:Neg & Complement \\
\hline \multicolumn{2}{|c|}{ MOOD } & RESIDUE \\
\hline
\end{tabular}

\begin{tabular}{|c|c|c|c|}
\hline I & 'm & worried & about. \\
\hline Theme:top & \multicolumn{3}{|c|}{ Rheme } \\
\hline Subject & Finite & Pdj:Circ \\
\hline & & \multicolumn{2}{c|}{ RESIDUE } \\
\hline
\end{tabular}

ASTRID 38:

\begin{tabular}{|c|c|c|c|}
\hline What & are & you & going to do? \\
\hline Theme:top & \multicolumn{3}{|c|}{ Rheme } \\
\hline WH/Complement & Finite & Subject & Predicator \\
\hline RESIDUE... & \multicolumn{2}{|c|}{ MOOD } & ... RESIDUE \\
\hline
\end{tabular}

HICCUP 35:

\begin{tabular}{|c|c|c|}
\hline Put & an end & to this. \\
\hline
\end{tabular}




\begin{tabular}{|c|c|c|}
\hline Theme:top & \multicolumn{2}{|c|}{ Rheme } \\
\hline Predicator & Complement & Adj:Circ \\
\hline & RESIDUE \\
\hline
\end{tabular}

HICCUP 36:

\begin{tabular}{|c|l|l|}
\hline I & have & to try. \\
\hline Theme:top & \multicolumn{2}{|c|}{ Rheme } \\
\hline Subject & Finite & Predicator \\
\hline \multicolumn{3}{|c|}{ MOOD } \\
\hline
\end{tabular}

HICCUP 36:

\begin{tabular}{|c|}
\hline Astrid. \\
\hline Minor clause \\
\hline
\end{tabular}

\begin{tabular}{|c|c|c|c|c|}
\hline If something goes wrong... & just & \multicolumn{2}{|c|}{ make sure } & they don't find Toothless. \\
\hline Theme:top & \multicolumn{4}{|c|}{ Rheme } \\
\hline Adj:Circ & Adj:Mood & Finite & Predicator & Complement \\
\hline RESIDUE... & \multicolumn{2}{|c|}{ MOOD } & \multicolumn{3}{|c}{...RESIDUE } \\
\hline
\end{tabular}

ASTRID 39:

\begin{tabular}{|c|c|c|}
\hline I & \multicolumn{2}{|c|}{ will. } \\
\hline Theme:top & \multicolumn{2}{|c|}{ Rheme } \\
\hline Subject & Finite & Predicator \\
\hline \multicolumn{2}{|c|}{ MOOD } & RESIDUE \\
\hline
\end{tabular}

\begin{tabular}{|c|c|c|c|c|}
\hline Just & \multicolumn{2}{|c|}{ promise } & \multicolumn{1}{|c|}{ me } & it won't go wrong. \\
\hline Theme:int & \multicolumn{2}{|c|}{ Theme:top } & \multicolumn{2}{|c|}{ Rheme } \\
\hline Adj:Mood & Finite & Predicator & Complement & Adj:Circ \\
\hline
\end{tabular}




\begin{tabular}{|l|l|}
\hline MOOD & RESIDUE \\
\hline
\end{tabular}

\section{Scene 20: Hiccup, Astrid}

ASTRID 40:

\begin{tabular}{|c|c|c|}
\hline It & 's & a mess. \\
\hline Theme:top & \multicolumn{2}{|c|}{ Rheme } \\
\hline Subject & Finite & Complement \\
\hline \multicolumn{2}{|c|}{ MOOD } & RESIDUE \\
\hline
\end{tabular}

ASTRID 41:

\begin{tabular}{|c|c|c|c|}
\hline You & must & feel & \multicolumn{1}{c|}{ horrible. } \\
\hline Theme:top & \multicolumn{3}{|c|}{ Rheme } \\
\hline Subject & Finite & Predicator & Complement:Attributive \\
\hline \multicolumn{2}{|c|}{ MOOD } & \multicolumn{2}{c|}{ RESIDUE } \\
\hline
\end{tabular}

\begin{tabular}{|c|c|c|c|}
\hline You & 've & lost & everything. \\
\hline Theme:top & \multicolumn{3}{|c|}{ Rheme } \\
\hline Subject & Finite & Predicator & Complement \\
\hline \multicolumn{2}{|c|}{ MOOD } & \multicolumn{2}{c|}{ RESIDUE } \\
\hline
\end{tabular}

Your father, your tribe, your best friend.

Theme:top

Complement

RESIDUE

HICCUP 37:

Thank you for summing that up.

Minor clause 


\begin{tabular}{|c|c|c|c|c|c|}
\hline Why & couldn't & I & have killed & that dragon & $\begin{array}{c}\text { when I found him } \\
\text { in the woods. }\end{array}$ \\
\hline Theme:top & \multicolumn{5}{|c|}{ Rheme } \\
\hline WH/Adj:Circ & Finite:Neg & Subject & Predicator & Complement & Adj:Circ \\
\hline RESIDUE... & \multicolumn{2}{|c|}{ MOOD } & \multicolumn{3}{c|}{..RESIDUE } \\
\hline
\end{tabular}

\begin{tabular}{|c|c|c|c|c|}
\hline It & would & have been & better & for everyone. \\
\hline Theme:top & \multicolumn{3}{|c|}{ Rheme } \\
\hline Subject & Finite & Predicator & Complement:Attributive & Adj:Circ \\
\hline \multicolumn{2}{|c|}{ MOOD } & RESIDUE \\
\hline
\end{tabular}

ASTRID 42:

\begin{tabular}{|c|}
\hline Yep. \\
\hline Theme:int \\
\hline Adj:Polarity \\
\hline MOOD \\
\hline
\end{tabular}

\begin{tabular}{|c|c|c|c|}
\hline The rest of us & would & have done & it. \\
\hline Theme:top & & Rheme \\
\hline Subject & Finite & Predicator & Complement \\
\hline \multicolumn{2}{|c|}{ MOOD } & \multicolumn{2}{|c|}{ RESIDUE } \\
\hline
\end{tabular}

\begin{tabular}{|c|c|c|c|}
\hline So & why & didn't & you? \\
\hline Theme:text & Theme:top & \multicolumn{2}{|c|}{ Rheme } \\
\hline Adj:Conj & WH/Adj:Circ & Finite:Neg & Subject \\
\hline & RESIDUE & \multicolumn{2}{|c|}{ MOOD } \\
\hline
\end{tabular}


ASTRID 43:

\begin{tabular}{|c|c|c|}
\hline Why & didn't & you? \\
\hline Theme:top & \multicolumn{2}{|c|}{ Rheme } \\
\hline WH/Adj:Circ & Finite:Neg & Subject \\
\hline RESIDUE & \multicolumn{2}{|c|}{ MOOD } \\
\hline
\end{tabular}

HICCUP 38:

\begin{tabular}{|c|c|c|}
\hline I & don't & know. \\
\hline Theme:top & \multicolumn{2}{|c|}{ Rheme } \\
\hline Subject & Finite:Neg & Predicator \\
\hline \multicolumn{3}{|c|}{ MOOD } \\
\hline
\end{tabular}

\begin{tabular}{|c|c|c|}
\hline I & \multicolumn{2}{|c|}{ couldn't. } \\
\hline Theme:top & \multicolumn{2}{|c|}{ Rheme } \\
\hline Subject & Finite:Neg & Predicator \\
\hline \multicolumn{2}{|c|}{ MOOD } & RESIDUE \\
\hline
\end{tabular}

ASTRID 44:

\begin{tabular}{|c|c|c|}
\hline That & 's not & an answer. \\
\hline Theme:top & \multicolumn{2}{|c|}{ Rheme } \\
\hline Subject & Finite:Neg & Complement \\
\hline \multicolumn{3}{|c|}{ MOOD } \\
\hline
\end{tabular}

\section{HICCUP 39:}

\begin{tabular}{|c|c|c|c|c|c|c|}
\hline Why & is & this & so & important & to you & $\begin{array}{c}\text { all of a } \\
\text { sudden? }\end{array}$ \\
\hline Theme:top & \multicolumn{5}{|c|}{ Rheme } \\
\hline WH/Adj:Circ & Finite & Subject & Adj:Mood & $\begin{array}{c}\text { Complement: } \\
\text { Attributive }\end{array}$ & Adj:Circ & Adj:Circ \\
\hline
\end{tabular}




\begin{tabular}{|l|l|l|}
\hline RESIDUE... & MOOD & ...RESIDUE \\
\hline
\end{tabular}

ASTRID 45:
\begin{tabular}{|c|c|c|c|c|}
\hline Because & I & want & to remember & $\begin{array}{c}\text { what you say } \\
\text { right now. }\end{array}$ \\
\hline Theme:text & Theme:top & & Rheme \\
\hline Adj:Conj & Subject & Finite & Predicator & Complement \\
\hline & \multicolumn{2}{|c|}{ MOOD } & RESIDUE \\
\hline
\end{tabular}

\section{HICCUP 40: \\ HICCUP 40:}

Oh, for the love of--

Minor clause

\begin{tabular}{|c|c|c|}
\hline I & was & a coward! \\
\hline Theme:top & \multicolumn{2}{|c|}{ Rheme } \\
\hline Subject & Finite & Complement \\
\hline \multicolumn{2}{|c|}{ MOOD } & RESIDUE \\
\hline
\end{tabular}

\begin{tabular}{|c|c|c|}
\hline I & was & weak. \\
\hline Theme:top & \multicolumn{2}{|c|}{ Rheme } \\
\hline Subject & Finite & Complement:Attributive \\
\hline \multicolumn{2}{|c|}{ RESIDUE } \\
\hline
\end{tabular}

\begin{tabular}{|c|c|c|c|}
\hline I & wouldn't & kill & a dragon. \\
\hline Theme:top & \multicolumn{3}{|c|}{ Rheme } \\
\hline Subject & Finite:Neg & Predicator & Complement \\
\hline \multicolumn{2}{|c|}{ ROOD } & \multicolumn{2}{c|}{ RESIDUE } \\
\hline
\end{tabular}

ASTRID 46: 


\begin{tabular}{|c|c|c|c|c|}
\hline You & \multicolumn{2}{|c|}{ said } & 'wouldn't' & that time. \\
\hline Theme:top & \multicolumn{3}{|c|}{ Rheme } \\
\hline Subject & Finite & Predicator & Complement & Adj:Circ \\
\hline MOOD & \multicolumn{3}{|c}{ RESIDUE } \\
\hline
\end{tabular}

\section{HICCUP 41:}

\begin{tabular}{|c|}
\hline Whatever! \\
\hline Minor clause \\
\hline
\end{tabular}

\begin{tabular}{|c|c|c|}
\hline I & \multicolumn{2}{|c|}{ wouldn't! } \\
\hline Theme:top & \multicolumn{2}{|c|}{ Rheme } \\
\hline Subject & Finite & Predicator \\
\hline \multicolumn{2}{|c|}{ MOOD } & RESIDUE \\
\hline
\end{tabular}

\begin{tabular}{|c|c|c|c|c|}
\hline Three hundred years & and & I & 'm & $\begin{array}{c}\text { the first Viking who wouldn't kill } \\
\text { a dragon! }\end{array}$ \\
\hline Theme:top & \multicolumn{5}{|c|}{ Rheme } \\
\hline Adj:Circ & Adj:Conj & Subject & Finite & Complement \\
\hline RESIDUE... & \multicolumn{2}{|c|}{ MOOD } & ...RESIDUE \\
\hline
\end{tabular}

ASTRID 47:

\begin{tabular}{|c|c|}
\hline First to ride one, & though. \\
\hline Theme:top & Rheme \\
\hline Complement & Adj:Cont \\
\hline \multicolumn{2}{c}{ RESIDUE } \\
\hline
\end{tabular}

ASTRID 48:

$$
\text { So... }
$$


Minor clause

HICCUP 42:

\begin{tabular}{|c|c|c|c|}
\hline ...I & wouldn't & kill & him \\
\hline Theme:top & & \multicolumn{3}{|c|}{ Rheme } \\
\hline Subject & Finite & Predicator & Complement \\
\hline \multicolumn{2}{|c|}{ MOOD } & \multicolumn{2}{|c|}{ RESIDUE } \\
\hline
\end{tabular}

\begin{tabular}{|c|c|c|c|c|}
\hline because & he & \multicolumn{2}{c|}{ looked } & just as frightened as I was. \\
\hline Theme:text & \multicolumn{3}{|c|}{ Rheme } \\
\hline Adj:Conj & Subject & Finite & Predicator & Complement:Attributive \\
\hline & \multicolumn{2}{|c|}{ MOOD } & \multicolumn{3}{c}{ RESIDUE } \\
\hline
\end{tabular}

\begin{tabular}{|c|c|c|c|}
\hline I & \multicolumn{2}{|c|}{ looked } & at him \\
\hline Theme:top & \multicolumn{3}{|c|}{ Rheme } \\
\hline Subject & Finite & Predicator & Adj:Circ \\
\hline \multicolumn{2}{|c|}{ MOOD } & \multicolumn{2}{|c|}{ RESIDUE } \\
\hline
\end{tabular}

\begin{tabular}{|c|c|c|c|}
\hline and & \multicolumn{2}{|c|}{ saw } & myself. \\
\hline Theme:text & \multicolumn{3}{|c|}{ Theme:top } \\
\hline Adj:Conj & Finite & Predicator & Complement \\
\hline & MOOD & \multicolumn{2}{|c|}{ RESIDUE } \\
\hline
\end{tabular}

ASTRID 49:

\begin{tabular}{|c|c|c|c|c|c|}
\hline I bet & he & 's & really & frightened & now. \\
\hline Theme:int & Theme:top & \multicolumn{5}{|c|}{ Rheme } \\
\hline Adj:Mood & Subject & Finite & Adj:Mood & Complement:Attributive & Adj:Circ \\
\hline
\end{tabular}




\begin{tabular}{|l|l|}
\hline MOOD & RESIDUE \\
\hline
\end{tabular}

\begin{tabular}{|c|c|c|c|c|}
\hline What & are & you & gonna do & about it? \\
\hline Theme:top & \multicolumn{4}{|c|}{ Rheme } \\
\hline WH/Complement & Finite & Subject & Predicator & Adj:Circ \\
\hline RESIDUE... & \multicolumn{2}{|c|}{ MOOD } & \multicolumn{2}{|c|}{...RESIDUE } \\
\hline
\end{tabular}

HICCUP 43:

\begin{tabular}{|l|c|c|}
\hline Probably & something & stupid. \\
\hline Theme:int & Theme:top & Rheme \\
\hline Adj:Mood & Subject & Complement:Attributive \\
\hline \multicolumn{2}{|c|}{ MOOD } & RESIDUE \\
\hline
\end{tabular}

ASTRID 50:

\begin{tabular}{|c|}
\hline Good. \\
\hline Minor clause \\
\hline
\end{tabular}

\begin{tabular}{|c|c|c|c|c|c|}
\hline But & you & 've & already & done & that. \\
\hline Theme:text & Theme:top & \multicolumn{4}{|c|}{ Rheme } \\
\hline \multirow[t]{2}{*}{ Adj:Conj } & Subject & Finite & Adj:Mood & Predicator & Complement \\
\hline & \multicolumn{3}{|c|}{ MOOD } & \multicolumn{2}{|c|}{ RESIDUE } \\
\hline
\end{tabular}

\section{HICCUP 44:}

\begin{tabular}{|c|c|c|}
\hline Then & something & crazy. \\
\hline Theme:text & Theme:top & Rheme \\
\hline Adj:Cont & Subject & Complement:Attributive \\
\hline & MOOD & RESIDUE \\
\hline
\end{tabular}

ASTRID 51: 


\begin{tabular}{|c|c|c|}
\hline That & 's & more like it. \\
\hline Theme:top & \multicolumn{2}{c|}{ Rheme } \\
\hline Subject & Finite & Complement:Attributive \\
\hline \multicolumn{2}{|c|}{ MOOD } & RESIDUE \\
\hline
\end{tabular}

\section{Scene 21: Fishlegs, Tuffnut, Hiccup, Snotlout, Ruffnut, Astrid}

\section{FISHLEGS 8:}

\begin{tabular}{|c|c|c|c|c|c|}
\hline $\begin{array}{c}\text { If you are } \\
\text { planning on } \\
\text { getting eaten, }\end{array}$ & I & ,d & definitely & go & $\begin{array}{c}\text { with } \\
\text { Gronckle. }\end{array}$ \\
\hline Theme:top & \multicolumn{5}{|c|}{ Rheme } \\
\hline Adj:Circ & Subject & Finite & Adj:Mood & Predicator & Adj:Circ \\
\hline RESIDUE... & \multicolumn{5}{|c|}{ MOOD } \\
\hline
\end{tabular}

TUFFNUT 19:

\begin{tabular}{|c|c|c|}
\hline You & were & wise \\
\hline Theme:top & \multicolumn{2}{|c|}{ Rheme } \\
\hline Subject & Finite & Complement:Attributive \\
\hline \multicolumn{2}{|c|}{ MOOD } & RESIDUE \\
\hline
\end{tabular}

\begin{tabular}{|c|c|c|c|}
\hline \multicolumn{2}{|c|}{ to seek } & help & $\begin{array}{c}\text { from the world's most deadly } \\
\text { weapon. }\end{array}$ \\
\hline \multicolumn{2}{|c|}{ Theme:top } & \multicolumn{2}{c|}{ Rheme } \\
\hline Finite & Predicator & Complement & Adj:Circ \\
\hline MOOD & \multicolumn{2}{|c|}{ RESIDUE } \\
\hline
\end{tabular}

\begin{tabular}{|c|c|c|}
\hline It & 's & me. \\
\hline Theme:top & \multicolumn{3}{|c|}{ Rheme } \\
\hline
\end{tabular}




\begin{tabular}{|c|c|c|}
\hline Subject & Finite & Complement \\
\hline \multicolumn{2}{|c|}{ MOOD } & RESIDUE \\
\hline
\end{tabular}

HICCUP 45:

\begin{tabular}{|c|}
\hline Uh... \\
\hline Minor clause \\
\hline
\end{tabular}

SNOTLOUT 9:

\begin{tabular}{|c|c|c|c|}
\hline I & \multicolumn{2}{|c|}{ love } & this plan. \\
\hline Theme:top & \multicolumn{3}{|c|}{ Rheme } \\
\hline Subject & Finite & Predicator & Complement \\
\hline \multicolumn{2}{|c|}{ MOOD } & & RESIDUE \\
\hline
\end{tabular}

HICCUP 46:

\begin{tabular}{|c|c|c|}
\hline I & \multicolumn{2}{|c|}{ didn't... } \\
\hline Theme:top & \multicolumn{2}{|c|}{ Rheme } \\
\hline Subject & Finite:Neg & Predicator \\
\hline \multicolumn{2}{|c|}{ MOOD } & RESIDUE \\
\hline
\end{tabular}

RUFFNUT 12:

\begin{tabular}{|c|c|c|}
\hline You & 're & crazy. \\
\hline Theme:top & \multicolumn{2}{|c|}{ Rheme } \\
\hline Subject & Finite & Complement:Attributive \\
\hline \multicolumn{2}{|c|}{ MOOD } & RESIDUE \\
\hline
\end{tabular}

\begin{tabular}{|c|c|c|c|}
\hline I & \multicolumn{2}{|c|}{ like } & that. \\
\hline Theme:top & \multicolumn{3}{|c|}{ Rheme } \\
\hline Subject & Finite & Predicator & Complement \\
\hline
\end{tabular}




\begin{tabular}{|c|c|}
\hline MOOD & RESIDUE \\
\hline
\end{tabular}

ASTRID 52:

\begin{tabular}{|c|c|c|c|}
\hline So & what & 's & the plan? \\
\hline Theme:text & Theme:top & \multicolumn{2}{|c|}{ Rheme } \\
\hline Adj:Conj & WH/Subject & Finite & Complement \\
\hline & \multicolumn{2}{|c|}{ MOOD } & RESIDUE \\
\hline
\end{tabular}

\section{Scene 22: Astrid, Snotlout, Hiccup}

ASTRID 53:

\begin{tabular}{|c|}
\hline Uh-uh. \\
\hline Minor clause. \\
\hline
\end{tabular}

SNOTLOUT 10:

\begin{tabular}{|c|}
\hline Wait! \\
\hline Theme:top \\
\hline Predicator \\
\hline RESIDUE \\
\hline
\end{tabular}

\begin{tabular}{|c|c|c|c|}
\hline Where & are & you & going? \\
\hline Theme:top & \multicolumn{3}{|c|}{ Rheme } \\
\hline WH/Complement & Finite & Subject & Predicator \\
\hline RESIDUE... & \multicolumn{2}{|c|}{ MOOD } & ..RESIDUE \\
\hline
\end{tabular}

\section{HICCUP 47:}

\begin{tabular}{|c|}
\hline Relax. \\
\hline Theme:top \\
\hline Predicator \\
\hline
\end{tabular}




RESIDUE

\begin{tabular}{|c|c|c|}
\hline It & 's & okay... \\
\hline Theme:top & \multicolumn{2}{|c|}{ Rheme } \\
\hline Subject & Finite & Complement:Attributive \\
\hline \multicolumn{2}{|c|}{ MOOD } & RESIDUE \\
\hline
\end{tabular}

\begin{tabular}{|c|c|c|}
\hline It & 's & okay. \\
\hline Theme:top & \multicolumn{2}{|c|}{ Rheme } \\
\hline Subject & Finite & Complement:Attributive \\
\hline \multicolumn{2}{|c|}{ MOOD } & RESIDUE \\
\hline
\end{tabular}

SNOTLOUT 11:

\begin{tabular}{|c|c|c|c|}
\hline Where & are & you & going?! \\
\hline Theme:top & \multicolumn{3}{|c|}{ Rheme } \\
\hline WH/Complement & Finite & Subject & Predicator \\
\hline RESIDUE... & \multicolumn{2}{|c|}{ MOOD } & ..RESIDUE \\
\hline
\end{tabular}

\section{HICCUP 48:}

\begin{tabular}{|c|c|c|c|}
\hline You & are & going to need & something to help you hold on. \\
\hline Theme:top & \multicolumn{3}{|c|}{ Rheme } \\
\hline Subject & Finite & Predicator & Complement \\
\hline \multicolumn{2}{|c|}{ MOOD } & \multicolumn{2}{c|}{ RESIDUE } \\
\hline
\end{tabular}

\section{Scene 23: Hiccup, Astrid, Tuffnut, Ruffnut, Snotlout, Fishlegs}

HICCUP 49:

\begin{tabular}{|c|c|c|c|}
\hline Ruff, & Tuff, & watch & your backs! \\
\hline Theme:int & Theme:int & Theme:top & Rheme \\
\hline
\end{tabular}




\begin{tabular}{|c|c|c|c|}
\hline Adj:Vocative & Adj:Vocative & Predicator & Complement \\
\hline \multicolumn{3}{|c|}{ RESIDUE } \\
\hline
\end{tabular}

\begin{tabular}{|c|c|}
\hline Move, & Fishlegs! \\
\hline Theme:top & Rheme \\
\hline Predicator & Adj:Vocative \\
\hline \multicolumn{2}{|c|}{ RESIDUE } \\
\hline
\end{tabular}

TUFFNUT 20:

\begin{tabular}{|c|c|c|}
\hline \multicolumn{2}{|c|}{ Look } & at us, \\
\hline \multicolumn{2}{|c|}{ Theme:top } & Rheme \\
\hline Finite & Predicator & Adj:Circ \\
\hline MOOD & & RESIDUE \\
\hline
\end{tabular}

\begin{tabular}{|c|c|c|}
\hline we & 're & on a dragon! \\
\hline Theme:top & \multicolumn{2}{|c|}{ Rheme } \\
\hline Subject & Finite & Adj:Circ \\
\hline \multicolumn{3}{|c|}{ MOOD } \\
\hline
\end{tabular}

\begin{tabular}{|c|c|c|c|}
\hline we & 're & on dragons, & all of us! \\
\hline Theme:top & \multicolumn{3}{|c|}{ Rheme } \\
\hline Subject... & Finite & Adj:Circ & ...Subject \\
\hline \multicolumn{2}{|r|}{ MOOD... } & RESIDUE & ...MOOD \\
\hline
\end{tabular}

HICCUP 50:

\begin{tabular}{|c|c|c|}
\hline Up, & let's & move it! \\
\hline Theme:top & \multicolumn{2}{|c|}{ Rheme } \\
\hline
\end{tabular}




\begin{tabular}{|c|c|c|c|}
\hline Adj:Circ & Subject & Finite & Predicator \\
\hline RESIDUE... & \multicolumn{2}{|c|}{ MOOD } & $\ldots$ RESIDUE \\
\hline
\end{tabular}

$\cdots$

HICCUP 51:

\begin{tabular}{|c|c|}
\hline Fishlegs, & break it down. \\
\hline Theme:int & Theme:top \\
\hline Adj:Vocative & Predicator \\
\hline \multicolumn{2}{|c|}{ RESIDUE } \\
\hline
\end{tabular}

FISHLEGS 9:

\begin{tabular}{|c|}
\hline Okay. \\
\hline Minor clause \\
\hline
\end{tabular}

\begin{tabular}{|c|c|c|c|}
\hline $\begin{array}{c}\text { Heavily armored skull and } \\
\text { tail }\end{array}$ & \multicolumn{2}{|c|}{ made } & for bashing and crushing. \\
\hline Theme:top & \multicolumn{3}{|c|}{ Rheme } \\
\hline Subject & Finite & Predicator & Adj:Circ \\
\hline MOOD & & & RESIDUE \\
\hline
\end{tabular}

\begin{tabular}{|c|c|c|}
\hline Steer & clear & of both. \\
\hline Theme:top & \multicolumn{2}{|c|}{ Rheme } \\
\hline Predicator & Adj:Circ & Adj:Circ \\
\hline \multicolumn{3}{|c|}{ RESIDUE } \\
\hline
\end{tabular}

Small eyes, large nostrils.

Theme:top

Subject 


\begin{tabular}{|c|c|c|}
\hline \multicolumn{2}{|c|}{ MOOD } & \\
\hline \multicolumn{2}{|c|}{ Relies } & on hearing and smell. \\
\hline \multicolumn{2}{|c|}{ Theme:top } & Rheme \\
\hline Finite & Predicator & Adj:Circ \\
\hline MOOD & & RESIDUE \\
\hline
\end{tabular}

HICCUP 52:

\begin{tabular}{|c|}
\hline Okay. \\
\hline Minor clause \\
\hline
\end{tabular}

\begin{tabular}{|c|c|c|c|}
\hline Lout, & Legs, & hang & in its blind spot. \\
\hline Theme:int & Theme:int & Theme:top & Rheme \\
\hline Adj:Vocative & Adj:Vocative & Predicator & Adj:Circ \\
\hline \multicolumn{2}{|c|}{} & \multicolumn{2}{|c|}{ RESIDUE } \\
\hline
\end{tabular}

\begin{tabular}{|c|c|c|c|c|}
\hline Make & some noise, & keep & it & \multicolumn{1}{c|}{ confused. } \\
\hline Theme:top & Rheme & Theme:top & \multicolumn{2}{|c|}{ Rheme } \\
\hline Predicator & Complement & Predicator & Complement & Complement:Attributive \\
\hline \multicolumn{2}{|r|}{ RESIDUE } & \multicolumn{3}{|c|}{ RESIDUE } \\
\hline
\end{tabular}

\begin{tabular}{|c|c|c|c|}
\hline Ruff, & Tuff, & find out & if it has a limit. \\
\hline Theme:int & Theme:int & Theme:top & Rheme \\
\hline Adj:Vocative & Adj:Vocative & Predicator & Adj:Circ \\
\hline \multicolumn{2}{|c|}{} & \multicolumn{2}{|c|}{ RESIDUE } \\
\hline
\end{tabular}

Make

it

mad. 


\begin{tabular}{|c|c|c|}
\hline Theme:top & \multicolumn{2}{|c|}{ Rheme } \\
\hline Predicator & Complement & Complement:Attributive \\
\hline \multicolumn{3}{|c}{ RESIDUE } \\
\hline
\end{tabular}

RUFFNUT 13:

\begin{tabular}{|c|c|c|}
\hline That & 's & my specialty. \\
\hline Theme:top & \multicolumn{2}{|c|}{ Rheme } \\
\hline Subject & Finite & Complement \\
\hline \multicolumn{3}{|c|}{ MOOD } \\
\hline
\end{tabular}

TUFFNUT 21:

\begin{tabular}{|c|}
\hline Since when? \\
\hline Theme:top \\
\hline Adj:Circ \\
\hline RESIDUE \\
\hline
\end{tabular}

\begin{tabular}{|c|c|c|c|}
\hline Everyone knows & I & 'm & more irritating. \\
\hline Theme:int & Theme:top & \multicolumn{2}{|c|}{ Rheme } \\
\hline Adj:Mood & Subject & Finite & Complement \\
\hline \multicolumn{3}{|c|}{ MOOD } & RESIDUE \\
\hline
\end{tabular}

\begin{tabular}{|c|}
\hline See. \\
\hline Theme:top \\
\hline Predicator \\
\hline RESIDUE \\
\hline
\end{tabular}

HICCUP 53:

\begin{tabular}{|c|c|c|}
\hline Just & do & what I told you. \\
\hline
\end{tabular}




\begin{tabular}{|c|c|c|c|}
\hline Theme:int & \multicolumn{2}{|c|}{ Theme:top } & Rheme \\
\hline Adj:Mood & Finite & Predicator & Complement \\
\hline \multicolumn{2}{|c|}{ MOOD } & & RESIDUE \\
\hline
\end{tabular}

\begin{tabular}{|c|c|c|c|c|}
\hline I & 'Il & be & back & as soon as I can. \\
\hline Theme:top & \multicolumn{4}{|c|}{ Rheme } \\
\hline Subject & Finite & Predicator & Adj:Circ & Adj:Circ \\
\hline \multicolumn{2}{|c|}{ MOOD } & \multicolumn{3}{|c}{ RESIDUE } \\
\hline
\end{tabular}

\section{TUFFNUT 22:}

\begin{tabular}{|c|c|c|c|c|c|c|}
\hline \\
\hline Don't & worry, & we & & got & it & covered! \\
\hline $\begin{array}{c}\text { Theme: } \\
\text { int }\end{array}$ & $\begin{array}{l}\text { Theme: } \\
\text { top }\end{array}$ & $\begin{array}{c}\text { Theme: } \\
\text { top }\end{array}$ & \multicolumn{4}{|c|}{ Rheme } \\
\hline Finite:Neg & Predicator & Subject & Finite & Predicator & Complement & $\begin{array}{l}\text { Complement: } \\
\text { Attributive }\end{array}$ \\
\hline MOOD & RESIDUE & \multicolumn{2}{|c|}{ MOOD } & \multicolumn{3}{|c|}{ RESIDUE } \\
\hline
\end{tabular}

FISHLEGS 10:

\begin{tabular}{|c|}
\hline Yeah! \\
\hline Minor clause \\
\hline
\end{tabular}

TUFFNUT 23:

\begin{tabular}{|c|}
\hline Troll! \\
\hline Theme:top \\
\hline Complement \\
\hline RESIDUE \\
\hline
\end{tabular}

\section{RUFFNUT 14:}

\section{Butt elf!}




\begin{tabular}{|c|}
\hline Theme:top \\
\hline Complement \\
\hline RESIDUE \\
\hline
\end{tabular}

TUFFNUT 24:

\begin{tabular}{|c|}
\hline Bride of Grendel! \\
\hline Theme:top \\
\hline Complement \\
\hline RESIDUE \\
\hline
\end{tabular}

FISHLEGS 11:

\begin{tabular}{|c|c|c|c|l|}
\hline Uh, & this thing & doesn't & have & a blind spot! \\
\hline Theme:text & Theme:top & & \multicolumn{3}{|c|}{ Rheme } \\
\hline Adj:Cont & Subject & Finite:Neg & Predicator & Complement \\
\hline & \multicolumn{2}{|c|}{ MOOD } & \multicolumn{2}{c|}{ RESIDUE } \\
\hline
\end{tabular}

..

HICCUP 54:

\begin{tabular}{|c|}
\hline There! \\
\hline Theme:top \\
\hline Adj:Circ \\
\hline RESIDUE \\
\hline
\end{tabular}

HICCUP 55:

\begin{tabular}{|c|c|c|}
\hline Go & help & the others! \\
\hline Theme:top & \multicolumn{2}{|c|}{ Rheme } \\
\hline Finite & Predicator & Complement \\
\hline
\end{tabular}




\begin{tabular}{|l|l|}
\hline MOOD & RESIDUE \\
\hline
\end{tabular}

SNOTLOUT 12:

\begin{tabular}{|c|c|c|}
\hline It & 's & working! \\
\hline Theme:top & \multicolumn{2}{|c|}{ Rheme } \\
\hline Subject & Finite & Complement:Attributive \\
\hline \multicolumn{2}{|c|}{ MOOD } & RESIDUE \\
\hline
\end{tabular}

FISHLEGS 12:

\begin{tabular}{|c|}
\hline Yeah! \\
\hline Minor clause \\
\hline
\end{tabular}

\begin{tabular}{|c|c|c|}
\hline It & 's & working. \\
\hline Theme:top & \multicolumn{2}{|c|}{ Rheme } \\
\hline Subject & Finite & Complement:Attributive \\
\hline \multicolumn{2}{|c|}{ MOOD } & RESIDUE \\
\hline
\end{tabular}

SNOTLOUT 13:

\begin{tabular}{|c|}
\hline Agghh! \\
\hline Minor clause \\
\hline
\end{tabular}

\begin{tabular}{|c|c|c|c|c|}
\hline I & ,ve & lost & power & on the Gronckle. \\
\hline Theme:top & \multicolumn{5}{|c|}{ Rheme } \\
\hline Subject & Finite & Predicator & Complement & Adj:Circ \\
\hline \multicolumn{2}{|c|}{ MOOD } & \multicolumn{3}{|c}{ RESIDUE } \\
\hline
\end{tabular}

\section{Snotlout!}


Minor clause

\begin{tabular}{|c|c|}
\hline Do & something! \\
\hline Theme:top & Rheme \\
\hline Predicator & Complement \\
\hline \multicolumn{2}{c}{ RESIDUE } \\
\hline
\end{tabular}

FISHLEGS 14:

\begin{tabular}{|c|c|c|}
\hline I & 'm & okay. \\
\hline Theme:top & \multicolumn{2}{|c|}{ Rheme } \\
\hline Subject & Finite & Complement:Attributive \\
\hline \multicolumn{2}{|c|}{ ROOD } & RESIDUE \\
\hline
\end{tabular}

\section{FISHLEGS 15:}

\begin{tabular}{|c|}
\hline Less okay. \\
\hline Minor clause \\
\hline
\end{tabular}

SNOTLOUT 14:

\begin{tabular}{|c|c|c|}
\hline I & can't & miss! \\
\hline Theme:top & \multicolumn{3}{|c|}{ Rheme } \\
\hline Subject & Finite & Predicator \\
\hline & MOOD & RESIDUE \\
\hline
\end{tabular}

SNOUTLOUT 15:

\begin{tabular}{|c|c|c|c|}
\hline What & 's & wrong, & buddy, \\
\hline Theme:top & \multicolumn{3}{|c|}{ Rheme } \\
\hline WH/Subject & Finite & Complement:Attributive & Adj:Vocative \\
\hline \multicolumn{2}{|c|}{ MOOD } & RESIDUE \\
\hline
\end{tabular}




\begin{tabular}{|c|c|c|c|}
\hline got & something & in your eye? \\
\hline Theme:top & \multicolumn{2}{|c|}{ Rheme } \\
\hline Finite & Subject & Adj:Circ \\
\hline \multicolumn{3}{|c|}{ MOOD } & RESIDUE \\
\hline
\end{tabular}

ASTRID 54:

\begin{tabular}{|c|}
\hline Yeah! \\
\hline Minor clause \\
\hline
\end{tabular}

\begin{tabular}{|c|c|c|}
\hline You & 're & the Viking! \\
\hline Theme:top & \multicolumn{2}{|c|}{ Rheme } \\
\hline Subject & Finite & Complement \\
\hline \multicolumn{3}{|c|}{ MOOD } \\
\hline
\end{tabular}

SNOTLOUT 16:

\begin{tabular}{|c|}
\hline Whoa! \\
\hline Minor clause \\
\hline
\end{tabular}

\section{Scene 24: Astrid, Tuffnut, Ruffnut}

ASTRID 55:

\begin{tabular}{|c|c|c|}
\hline He & 's & up! \\
\hline Theme:top & \multicolumn{3}{|c|}{ Rheme } \\
\hline Subject & Finite & Adj:Circ \\
\hline \multicolumn{2}{|c|}{ MOOD } & RESIDUE \\
\hline
\end{tabular}

ASTRID 56:

\begin{tabular}{|c|c|c|}
\hline Get & Snotlout & out of there! \\
\hline Theme:top & \multicolumn{2}{|c|}{ Rheme } \\
\hline
\end{tabular}




\begin{tabular}{|c|c|c|}
\hline Predicator & Complement & Adj:Circ \\
\hline RESIDUE \\
\hline
\end{tabular}

TUFFNUT 25 \& RUFFNUT 15:

\begin{tabular}{|c|c|c|}
\hline I & 'm & on it! \\
\hline Theme:top & \multicolumn{2}{|c|}{ Rheme } \\
\hline Subject & Finite & Adj:Circ \\
\hline \multicolumn{2}{|c|}{ MOOD } & RESIDUE \\
\hline
\end{tabular}

TUFFNUT 26:

\begin{tabular}{|c|c|c|}
\hline I & 'm & on it first! \\
\hline Theme:top & \multicolumn{2}{|c|}{ Rheme } \\
\hline Subject & Finite & Adj:Circ \\
\hline \multicolumn{2}{|c|}{ MOOD } & RESIDUE \\
\hline
\end{tabular}

\begin{tabular}{|c|c|c|}
\hline I & 'm & ahead of you. \\
\hline Theme:top & \multicolumn{2}{|c|}{ Rheme } \\
\hline Subject & Finite & Adj:Circ \\
\hline \multicolumn{3}{|c|}{ MOOD } \\
\hline
\end{tabular}

RUFFNUT 16:

\begin{tabular}{|c|}
\hline Hey! \\
\hline Minor clause \\
\hline
\end{tabular}

\begin{tabular}{|c|c|c|}
\hline Let & me & drive! \\
\hline Theme:int & Theme:top & Rheme \\
\hline Finite & Subject & Predicator \\
\hline \multicolumn{2}{|c|}{ MOOD } & RESIDUE \\
\hline
\end{tabular}


TUFFNUT 27:

\begin{tabular}{|c|c|c|c|}
\hline I can't believe & that & \multicolumn{2}{|c|}{ worked. } \\
\hline Theme:int & Theme:top & Rheme \\
\hline Adj:Mood:Neg & Subject & Finite & Predicator \\
\hline \multicolumn{3}{|c}{ MOOD } & RESIDUE \\
\hline
\end{tabular}

\section{Scene 25: Hiccup, Astrid}

ASTRID 57:

\begin{tabular}{|c|c|c|}
\hline That & 's & for scaring me. \\
\hline Theme:top & \multicolumn{2}{|c|}{ Rheme } \\
\hline Subject & Finite & Adj:Circ \\
\hline \multicolumn{2}{|c|}{ ROOD } & RESIDUE \\
\hline
\end{tabular}

HICCUP 56:

\begin{tabular}{|c|c|c|c|c|c|}
\hline What, & is & it & always & going to be & this way? \\
\hline Theme:text & Theme:int & Theme:top & \multicolumn{3}{|c|}{ Rheme } \\
\hline \multirow[t]{2}{*}{ Adj:Cont } & Finite & Subject & Adj:Mood & Predicator & Complement \\
\hline & \multicolumn{3}{|c|}{ MOOD } & \multicolumn{2}{|c|}{ RESIDUE } \\
\hline
\end{tabular}

\begin{tabular}{|c|c|}
\hline Cause & I-- \\
\hline Theme:text & Theme:top \\
\hline Adj:Conj & Subject \\
\hline & MOOD \\
\hline
\end{tabular}

HICCUP 57:

\begin{tabular}{|c|c|c|}
\hline ...could & get used to & it. \\
\hline Theme:int & Theme:top & Rheme \\
\hline
\end{tabular}




\begin{tabular}{|c|c|c|}
\hline Finite & Predicator & Complement \\
\hline MOOD & \multicolumn{2}{|c|}{ RESIDUE } \\
\hline
\end{tabular}




\section{C.2 Theme and MOOD analysis in The Hunger Games}

\section{Scene 1: Katniss, Primrose}

PRIMROSE 1:

\begin{tabular}{|c|}
\hline No! \\
\hline Minor clause \\
\hline
\end{tabular}

\begin{tabular}{|c|}
\hline No! \\
\hline Minor clause \\
\hline
\end{tabular}

KATNISS 1:

\begin{tabular}{|c|c|c|c|}
\hline Shh, & it & 's & okay, \\
\hline Theme:text & Theme:top & \multicolumn{2}{c|}{ Rheme } \\
\hline Adj:Cont & Subject & Finite & Complement:Attributive \\
\hline & \multicolumn{2}{|c|}{ MOOD } & RESIDUE \\
\hline
\end{tabular}

\begin{tabular}{|c|c|c|c|}
\hline you & were & just & dreaming. \\
\hline Theme:top & \multicolumn{3}{|c|}{ Rheme } \\
\hline Subject & Finite & Adj:Mood & Predicator \\
\hline \multicolumn{3}{|c|}{ MOOD } & RESIDUE \\
\hline
\end{tabular}

\begin{tabular}{|c|c|c|}
\hline You & were & dreaming. \\
\hline Theme:top & \multicolumn{3}{|c|}{ Rheme } \\
\hline Subject & Finite & Predicator \\
\hline & MOOD & RESIDUE \\
\hline
\end{tabular}

PRIMROSE 2:

\begin{tabular}{|c|c|c|}
\hline It & was & me! \\
\hline
\end{tabular}




\begin{tabular}{|c|c|c|}
\hline Theme:top & \multicolumn{2}{|c|}{ Rheme } \\
\hline Subject & Finite & Complement \\
\hline \multicolumn{3}{|c|}{ MOOD } \\
\hline
\end{tabular}

KATNISS 2:

\begin{tabular}{|c|c|c|}
\hline I & \multicolumn{2}{|c|}{ know. } \\
\hline Theme:top & \multicolumn{2}{|c|}{ Rheme } \\
\hline Subject & Finite & Predicator \\
\hline \multicolumn{2}{|c|}{ MOOD } & RESIDUE \\
\hline
\end{tabular}

\begin{tabular}{|c|c|c|}
\hline I & \multicolumn{2}{|c|}{ know. } \\
\hline Theme:top & \multicolumn{2}{|c|}{ Rheme } \\
\hline Subject & Finite & Predicator \\
\hline \multicolumn{2}{|c|}{ MOOD } & RESIDUE \\
\hline
\end{tabular}

\begin{tabular}{|c|c|c|}
\hline But & it & 's not. \\
\hline Theme:text & Theme:top & Rheme \\
\hline Adj:Conj & Subject & Finite:Neg \\
\hline & \multicolumn{2}{|c|}{ MOOD } \\
\hline
\end{tabular}

\begin{tabular}{|c|c|c|c|}
\hline It & 's & your first year, & Prim. \\
\hline Theme:top & & Rheme \\
\hline Subject & Finite & Complement & Adj:Vocative \\
\hline \multicolumn{2}{|c|}{ MOOD } & \multicolumn{2}{|c|}{ RESIDUE } \\
\hline
\end{tabular}

\begin{tabular}{|l|l|l|l|}
\hline Your name & 's & only & in there once, \\
\hline Theme:top & \multicolumn{3}{|c|}{ Rheme } \\
\hline
\end{tabular}




\begin{tabular}{|c|c|c|c|}
\hline Subject & Finite & Adj:Mood & Adj:Circ \\
\hline \multicolumn{3}{|c|}{ MOOD } & RESIDUE \\
\hline
\end{tabular}

\begin{tabular}{|c|c|c|c|}
\hline they & 're not & gonna pick & you. \\
\hline Theme:top & & \multicolumn{3}{|c|}{ Rheme } \\
\hline Subject & Finite:Neg & Predicator & Complement \\
\hline \multicolumn{2}{|c|}{ MOOD } & \multicolumn{2}{|c|}{ RESIDUE } \\
\hline
\end{tabular}

\begin{tabular}{|c|c|}
\hline Try & to go to sleep. \\
\hline Theme:top & Rheme \\
\hline Finite & Predicator \\
\hline MOOD & RESIDUE \\
\hline
\end{tabular}

PRIMROSE 3:

\begin{tabular}{|c|c|c|}
\hline I & \multicolumn{2}{|c|}{ can't. } \\
\hline Theme:top & \multicolumn{2}{|c|}{ Rheme } \\
\hline Subject & Finite & Predicator \\
\hline \multicolumn{2}{|c|}{ MOOD } & RESIDUE \\
\hline
\end{tabular}

KATNISS 3:

\begin{tabular}{|c|l|}
\hline Just & try. \\
\hline Theme:int & Theme:top \\
\hline Adj:Mood & Predicator \\
\hline MOOD & RESIDUE \\
\hline
\end{tabular}

\begin{tabular}{|c|c|}
\hline Just & try. \\
\hline Theme:int & Theme:top \\
\hline
\end{tabular}




\begin{tabular}{|c|c|}
\hline Adj:Mood & Predicator \\
\hline MOOD & RESIDUE \\
\hline
\end{tabular}

KATNISS 4:

\begin{tabular}{|c|c|c|c|}
\hline You & \multicolumn{2}{|c|}{ remember } & that song? \\
\hline Theme:top & \multicolumn{3}{|c|}{ Rheme } \\
\hline Subject & Finite & Predicator & Complement \\
\hline \multicolumn{2}{|c|}{ MOOD } & & RESIDUE \\
\hline
\end{tabular}

\begin{tabular}{|c|}
\hline Okay. \\
\hline Minor clause \\
\hline
\end{tabular}

\begin{tabular}{|c|c|c|}
\hline I & gotta & go. \\
\hline Theme:top & \multicolumn{2}{|c|}{ Rheme } \\
\hline Subject & Finite & Predicator \\
\hline \multicolumn{2}{|c|}{ MOOD } & RESIDUE \\
\hline
\end{tabular}

PRIMROSE 4:

\begin{tabular}{|c|}
\hline Where? \\
\hline Theme:top \\
\hline Adj:Circ \\
\hline RESIDUE \\
\hline
\end{tabular}

KATNISS 5:

\begin{tabular}{|c|c|c|c|}
\hline I & just & gotta & go. \\
\hline Theme:top & \multicolumn{3}{|c|}{ Rheme } \\
\hline Subject & Adj:Mood & Finite & Predicator \\
\hline \multicolumn{3}{|c|}{ MOOD } & RESIDUE \\
\hline
\end{tabular}




\begin{tabular}{|c|c|c|c|c|}
\hline But & I & 'll & be & back. \\
\hline Theme:text & Theme:top & \multicolumn{3}{c|}{ Rheme } \\
\hline Adj:Conj & Subject & Finite & Predicator & Adj:Circ \\
\hline & \multicolumn{2}{|c|}{ MOOD } & \multicolumn{2}{c|}{ RESIDUE } \\
\hline
\end{tabular}

\begin{tabular}{|c|c|c|c|}
\hline I & \multicolumn{2}{|c|}{ love } & you. \\
\hline Theme:top & \multicolumn{3}{|c|}{ Rheme } \\
\hline Subject & Finite & Predicator & Complement \\
\hline \multicolumn{2}{|c|}{ MOOD } & \multicolumn{2}{|c|}{ RESIDUE } \\
\hline
\end{tabular}

\section{Scene 2: Katniss, Gale}

GALE 1:

\begin{tabular}{|c|c|c|c|c|c|}
\hline What & are & you & gonna do & with that & when you kill it? \\
\hline Theme:top & \multicolumn{5}{|c|}{ Rheme } \\
\hline WH/Complement & Finite & Subject & Predicator & Adj:Circ & Adj:Circ \\
\hline RESIDUE... & \multicolumn{2}{|c|}{ MOOD } & \multicolumn{3}{|c|}{...RESIDUE } \\
\hline
\end{tabular}

KATNISS 6:

\begin{tabular}{|c|c|c|}
\hline Damn & you, & Gale! \\
\hline Theme:top & \multicolumn{2}{|c|}{ Rheme } \\
\hline Predicator & Complement & Adj:Vocative \\
\hline \multicolumn{3}{|c|}{ RESIDUE } \\
\hline
\end{tabular}

\begin{tabular}{|c|c|c|}
\hline It & 's not & funny! \\
\hline Theme:top & \multicolumn{2}{|c|}{ Rheme } \\
\hline Subject & Finite:Neg & Complement:Attributive \\
\hline
\end{tabular}




\begin{tabular}{|l|l|}
\hline MOOD & RESIDUE \\
\hline
\end{tabular}

GALE 2:

\begin{tabular}{|c|c|c|c|c|c|}
\hline What & are & you & gonna do & $\begin{array}{c}\text { with a hundred } \\
\text { pound deer, }\end{array}$ & Catnip? \\
\hline Theme:top & \multicolumn{5}{|c|}{ Rheme } \\
\hline WH/Complement & Finite & Subject & Predicator & Adj:Circ & Adj:Vocative \\
\hline RESIDUE... & \multicolumn{2}{|c|}{ MOOD } & \multicolumn{4}{|c|}{...RESIDUE } \\
\hline
\end{tabular}

\begin{tabular}{|c|c|c|}
\hline It & 's & Reaping Day, \\
\hline Theme:top & \multicolumn{2}{|c|}{ Rheme } \\
\hline Subject & Finite & Complement \\
\hline \multicolumn{2}{|c|}{ MOOD } & RESIDUE \\
\hline
\end{tabular}

\begin{tabular}{|c|c|c|c|}
\hline the place & is & crawling & with Peacekeepers. \\
\hline Theme:top & \multicolumn{3}{|c|}{ Rheme } \\
\hline Subject & Finite & Predicator & Complement \\
\hline \multicolumn{2}{|c|}{ MOOD } & \multicolumn{2}{c|}{ RESIDUE } \\
\hline
\end{tabular}

KATNISS 7:

\begin{tabular}{|c|c|c|c|c|}
\hline I & was & gonna sell & it, & to Peacekeepers. \\
\hline Theme:top & \multicolumn{4}{|c|}{ Rheme } \\
\hline Subject & Finite & Predicator & Complement & Adj:Circ \\
\hline \multicolumn{2}{|c|}{ MOOD } & \multicolumn{3}{c|}{ RESIDUE } \\
\hline
\end{tabular}

GALE 3:

\begin{tabular}{|c|c|c|}
\hline Of course & you & were. \\
\hline Theme:int & Theme:top & Rheme \\
\hline
\end{tabular}




\begin{tabular}{|l|l|l|}
\hline Adj:Conj & Subject & Finite \\
\hline & \multicolumn{2}{|c|}{ MOOD } \\
\hline
\end{tabular}

KATNISS 8:

\begin{tabular}{|c|c|c|c|c|c|}
\hline Oh, & like & you & don't & sell & to Peacekeepers? \\
\hline Theme:text & Theme:text & Theme:top & \multicolumn{3}{|c|}{ Rheme } \\
\hline Adj:Cont & Adj:Conj & Subject & Finite:Neg & Predicator & Adj:Circ \\
\hline & \multicolumn{2}{|c|}{ MOOD } & \multicolumn{2}{|c|}{ RESIDUE } \\
\hline
\end{tabular}

GALE 4:

\begin{tabular}{|c|}
\hline No! \\
\hline Theme:int \\
\hline Adj:Polarity:Neg \\
\hline MOOD \\
\hline
\end{tabular}

\begin{tabular}{|c|}
\hline Not today! \\
\hline Theme:top \\
\hline Adj:Circ \\
\hline RESIDUE \\
\hline
\end{tabular}

KATNISS 9:

\begin{tabular}{|c|c|c|}
\hline It & was & the first deer I had seen in a year. \\
\hline Theme:top & \multicolumn{2}{|c|}{ Rheme } \\
\hline Subject & Finite & Complement \\
\hline \multicolumn{2}{|c|}{ MOOD } & RESIDUE \\
\hline
\end{tabular}

\begin{tabular}{|c|c|c|c|}
\hline Now & I & have & nothing. \\
\hline Theme:top & \multicolumn{3}{|c|}{ Rheme } \\
\hline
\end{tabular}




\begin{tabular}{|c|c|c|c|c|}
\hline Adj:Circ & Subject & Finite & Predicator & Complement \\
\hline RESIDUE $\ldots$ & \multicolumn{2}{|c|}{ MOOD } & \multicolumn{2}{|c|}{...RESIDUE } \\
\hline
\end{tabular}

GALE 5:

\begin{tabular}{|c|}
\hline Okay. \\
\hline Minor clause \\
\hline
\end{tabular}

GALE 6:

\begin{tabular}{|c|c|c|c|}
\hline What if & they & \multicolumn{2}{|c|}{ did? } \\
\hline Theme:text & Theme:top & \multicolumn{2}{|c|}{ Rheme } \\
\hline Adj:Circ & Subject & Finite & Predicator \\
\hline RESIDUE... & \multicolumn{2}{|c|}{ MOOD } & ...RESIDUE \\
\hline
\end{tabular}

\begin{tabular}{|c|c|}
\hline Just & one year. \\
\hline Theme:int & Theme:top \\
\hline Adj:Mood & Subject \\
\hline \multicolumn{2}{|c|}{ MOOD } \\
\hline
\end{tabular}

\begin{tabular}{|c|c|c|c|c|}
\hline What if & everyone & just & stopped & watching? \\
\hline Theme:text & Theme:top & \multicolumn{3}{|c|}{ Rheme } \\
\hline Adj:Circ & Subject & Adj:Mood & Finite & Predicator \\
\hline RESIDUE... & \multicolumn{3}{|c}{ MOOD } & ...RESIDUE \\
\hline
\end{tabular}

KATNISS 10:

\begin{tabular}{|c|c|c|c|}
\hline They & \multicolumn{2}{|c|}{ won't, } & Gale. \\
\hline Theme:top & \multicolumn{3}{|c|}{ Rheme } \\
\hline Subject & Finite & Predicator & Adj:Vocative \\
\hline \multicolumn{2}{|c|}{ MOOD } & \multicolumn{2}{|c|}{ RESIDUE } \\
\hline
\end{tabular}


GALE 7:

\begin{tabular}{|c|c|c|c|c|}
\hline But & what if & they & \multicolumn{2}{|c|}{ did? } \\
\hline Theme:text & Theme:text & Theme:top & \multicolumn{2}{|c|}{ Rheme } \\
\hline Adj:Conj & Adj:Circ & Subject & Finite & Predicator \\
\hline & RESIDUE... & \multicolumn{2}{|c|}{ MOOD } & ...RESIDUE \\
\hline
\end{tabular}

\begin{tabular}{|c|c|c|c|}
\hline What if & we & \multicolumn{2}{|c|}{ did? } \\
\hline Theme:text & Theme:top & \multicolumn{2}{|c|}{ Rheme } \\
\hline Adj:Circ & Subject & Finite & Predicator \\
\hline RESIDUE... & \multicolumn{2}{|c|}{ MOOD } & $\ldots$ RESIDUE \\
\hline
\end{tabular}

KATNISS 11:

\begin{tabular}{|c|c|c|c|}
\hline It & \multicolumn{2}{|c|}{ won't } & happen. \\
\hline Theme:top & \multicolumn{3}{|c|}{ Rheme } \\
\hline Subject & Finite:Neg & Predicator & Adj:Circ \\
\hline \multicolumn{2}{|c|}{ MOOD } & & RESIDUE \\
\hline
\end{tabular}

GALE 8: Statement

\begin{tabular}{|c|c|c|c|}
\hline You & \multicolumn{2}{|c|}{ root } & for your favorites, \\
\hline Theme:top & \multicolumn{3}{|c|}{ Rheme } \\
\hline Subject & Finite & Predicator & Adj:Circ \\
\hline MOOD & \multicolumn{2}{|c|}{ RESIDUE } \\
\hline
\end{tabular}

\begin{tabular}{|c|c|c|c|}
\hline you & \multicolumn{2}{|c|}{ cry } & when they get sick. \\
\hline Theme:top & \multicolumn{3}{|c|}{ Rheme } \\
\hline Subject & Finite & Predicator & Adj:Circ \\
\hline \multicolumn{2}{|c|}{ MOOD } & \multicolumn{2}{|c|}{ RESIDUE } \\
\hline
\end{tabular}




\begin{tabular}{|c|c|c|}
\hline It & 's & sick! \\
\hline Theme:top & \multicolumn{2}{|c|}{ Rheme } \\
\hline Subject & Finite & Complement:Attributive \\
\hline \multicolumn{3}{|c|}{ MOOD } \\
\hline
\end{tabular}

KATNISS 12:

\begin{tabular}{|c|}
\hline Yeah. \\
\hline Minor clause \\
\hline
\end{tabular}

GALE 9:

\begin{tabular}{|c|c|c|c|}
\hline If & no one & \multicolumn{2}{c|}{ watches, } \\
\hline Theme:top & \multicolumn{3}{|c|}{ Rheme } \\
\hline Adj:Circ & Subject & Finite & Predicator \\
\hline RESIDUE... & \multicolumn{2}{|c|}{ MOOD } & ... RESIDUE \\
\hline
\end{tabular}

\begin{tabular}{|c|c|c|c|}
\hline they & don't & have & a game. \\
\hline Theme:top & & \multicolumn{3}{|c|}{ Rheme } \\
\hline Subject & Finite:Neg & Predicator & Complement \\
\hline \multicolumn{2}{|c|}{ MOOD } & \multicolumn{2}{c|}{ RESIDUE } \\
\hline
\end{tabular}

\begin{tabular}{|c|c|c|}
\hline It & 's & as simple as that. \\
\hline Theme:top & \multicolumn{2}{|c|}{ Rheme } \\
\hline Subject & Finite & Complement:Attributive \\
\hline \multicolumn{2}{|c|}{ RESIDUE } \\
\hline
\end{tabular}

GALE 10:

\section{What?}




\begin{tabular}{|c|}
\hline Theme:top \\
\hline WH/Subject \\
\hline MOOD \\
\hline
\end{tabular}

KATNISS 13:

\begin{tabular}{|c|}
\hline Nothing! \\
\hline Theme:top \\
\hline Subject \\
\hline MOOD \\
\hline
\end{tabular}

GALE 11:

\begin{tabular}{|c|c|c|}
\hline Fine, & laugh & at me. \\
\hline Theme:text & Theme:top & Rheme \\
\hline Adj:Conj & Predicator & RESIDUE \\
\hline & \multicolumn{2}{|c|}{ Reside } \\
\hline
\end{tabular}

KATNISS 14:

\begin{tabular}{|c|c|c|c|}
\hline I & 'm not & laughing & at you. \\
\hline Theme:top & \multicolumn{3}{|c|}{ Rheme } \\
\hline Subject & Finite:Neg & Predicator & Adj:Circ \\
\hline \multicolumn{2}{|c|}{ RESIDUE } \\
\hline
\end{tabular}

GALE 12:

\begin{tabular}{|c|c|c|c|c|}
\hline We & could & do & it, & you know. \\
\hline Theme:top & \multicolumn{4}{|c|}{ Rheme } \\
\hline Subject & Finite & Predicator & Complement & Adj:Conj \\
\hline \multicolumn{2}{|c|}{ ROOD } & \multicolumn{3}{|c|}{ RESIDUE } \\
\hline
\end{tabular}




\begin{tabular}{|c|c|c|}
\hline Take off, & live & in the woods. \\
\hline Theme:top & Theme:top & Rheme \\
\hline Predicator & Predicator & Adj:Circ \\
\hline RESIDUE & \multicolumn{2}{|c|}{ RESIDUE } \\
\hline
\end{tabular}

\begin{tabular}{|c|c|c|}
\hline It & 's & what we do anyway. \\
\hline Theme:top & \multicolumn{3}{|c|}{ Rheme } \\
\hline Subject & Finite & Complement \\
\hline \multicolumn{3}{|c|}{ MOOD } \\
\hline
\end{tabular}

KATNISS 15:

\begin{tabular}{|c|c|c|c|}
\hline They & 'd & catch & us. \\
\hline Theme:top & \multicolumn{3}{|c|}{ Rheme } \\
\hline Subject & Finite & Predicator & Complement \\
\hline \multicolumn{2}{|c|}{ MOOD } & \multicolumn{2}{c|}{ RESIDUE } \\
\hline
\end{tabular}

GALE 13:

\begin{tabular}{|c|}
\hline Maybe not. \\
\hline Theme:int \\
\hline Adj:Mood:Neg \\
\hline MOOD \\
\hline
\end{tabular}

KATNISS 16:

\begin{tabular}{|c|c|c|}
\hline Cut out & our tongues, & or worse. \\
\hline Theme:top & \multicolumn{2}{|c|}{ Rheme } \\
\hline Predicator & Complement & Adj:Circ \\
\hline \multicolumn{3}{|c|}{ RESIDUE } \\
\hline
\end{tabular}




\begin{tabular}{|c|c|c|c|}
\hline We & wouldn't & make it & five miles. \\
\hline Theme:top & & Rheme \\
\hline Subject & Finite:Neg & Predicator & Complement \\
\hline \multicolumn{2}{|c|}{ MOOD } & \multicolumn{2}{|c|}{ RESIDUE } \\
\hline
\end{tabular}

GALE 14:

\begin{tabular}{|c|c|c|c|c|}
\hline No, & I & 'd & get & five miles. \\
\hline Theme:int & Theme:top & \multicolumn{3}{|c|}{ Rheme } \\
\hline Adj:Polarity:Neg & Subject & Finite & Predicator & Complement \\
\hline \multicolumn{3}{|c|}{ MOOD } & \multicolumn{2}{|c|}{ RESIDUE } \\
\hline
\end{tabular}

\begin{tabular}{|c|c|c|c|}
\hline I & 'd & go & that way. \\
\hline Theme:top & \multicolumn{3}{|c|}{ Rheme } \\
\hline Subject & Finite & Predicator & Adj:Circ \\
\hline \multicolumn{2}{|c|}{ MOOD } & \multicolumn{2}{|c|}{ RESIDUE } \\
\hline
\end{tabular}

KATNISS 17:

\begin{tabular}{|c|c|c|c|}
\hline I & \multicolumn{2}{|c|}{ have } & Prim \\
\hline Theme:top & \multicolumn{3}{|c|}{ Rheme } \\
\hline Subject & Finite & Predicator & Complement \\
\hline \multicolumn{2}{|c|}{ MOOD } & \multicolumn{2}{|c|}{ RESIDUE } \\
\hline
\end{tabular}

\begin{tabular}{|c|c|c|c|c|}
\hline and & you & \multicolumn{2}{|c|}{ have } & your brothers. \\
\hline Theme:text & Theme:top & \multicolumn{3}{|c|}{ Rheme } \\
\hline Adj:Conj & Subject & Finite & Predicator & Complement \\
\hline & \multicolumn{2}{|c|}{ MOOD } & \multicolumn{2}{|c|}{ RESIDUE } \\
\hline
\end{tabular}

GALE 15: 


\begin{tabular}{|c|c|c|c|}
\hline They & can & come, & too. \\
\hline Theme:top & \multicolumn{3}{|c|}{ Rheme } \\
\hline Subject & Finite & Predicator & Adj:Comment \\
\hline \multicolumn{2}{|c|}{ MOOD } & \multicolumn{2}{c|}{ RESIDUE } \\
\hline
\end{tabular}

KATNISS 18:

\begin{tabular}{|c|c|}
\hline Prim & in the woods? \\
\hline Theme:top & Rheme \\
\hline Subject & Adj:Circ \\
\hline MOOD & RESIDUE \\
\hline
\end{tabular}

GALE 16:

\begin{tabular}{|c|c|}
\hline Well, & maybe not. \\
\hline Theme:text & Theme:int \\
\hline Adj:Cont & Adj:Mood:Neg \\
\hline & MOOD \\
\hline
\end{tabular}

KATNISS 19:

\begin{tabular}{|c|c|c|c|c|}
\hline I & 'm & never & having & kids. \\
\hline Theme:top & \multicolumn{4}{|c|}{ Rheme } \\
\hline Subject & Finite & Adj:Mood:Neg & Predicator & Complement \\
\hline \multicolumn{5}{|c|}{ MOOD } \\
\hline
\end{tabular}

GALE 17:

\begin{tabular}{|c|c|}
\hline I & might. \\
\hline Theme:top & Rheme \\
\hline Subject & Adj:Mood \\
\hline \multicolumn{2}{c}{ MOOD } \\
\hline
\end{tabular}




\begin{tabular}{|c|c|c|c|c|}
\hline If & I & don't & live & here. \\
\hline Theme:text & Theme:top & & \multicolumn{2}{|c|}{ Rheme } \\
\hline Adj:Circ & Subject & Finite:Neg & Predicator & Adj:Circ \\
\hline RESIDUE.. & \multicolumn{2}{|c|}{ MOOD } & \multicolumn{2}{|c}{...RESIDUE } \\
\hline
\end{tabular}

KATNISS 20:

\begin{tabular}{|c|c|c|c|c|}
\hline But & you & do & live & here. \\
\hline Theme:text & Theme:top & & \multicolumn{2}{c|}{ Rheme } \\
\hline Adj:Conj & Subject & Finite & Predicator & Adj:Circ \\
\hline & \multicolumn{2}{|c|}{ MOOD } & \multicolumn{2}{c|}{ RESIDUE } \\
\hline
\end{tabular}

GALE 18:

\begin{tabular}{|c|c|c|}
\hline I & \multicolumn{2}{|c|}{ know. } \\
\hline Theme:top & \multicolumn{2}{|c|}{ Rheme } \\
\hline Subject & Finite & Predicator \\
\hline \multicolumn{2}{|c|}{ MOOD } & RESIDUE \\
\hline
\end{tabular}

\begin{tabular}{|c|c|c|c|}
\hline But & if & I & didn't. \\
\hline Theme:text & Theme:top & Theme:top & Rheme \\
\hline Adj:Conj & Adj:Circ & Subject & Finite:Neg \\
\hline & RESIDUE & \multicolumn{2}{|c|}{ MOOD } \\
\hline
\end{tabular}

\begin{tabular}{|c|c|c|c|}
\hline Oh, & I & \multicolumn{2}{c|}{ forgot. } \\
\hline Theme:text & Theme:top & \multicolumn{2}{|c|}{ Rheme } \\
\hline Adj:Cont & Subject & Finite & Predicator \\
\hline & \multicolumn{2}{|c|}{ MOOD } & RESIDUE \\
\hline
\end{tabular}




\begin{tabular}{|c|}
\hline Here. \\
\hline Theme:top \\
\hline Predicator \\
\hline RESIDUE \\
\hline
\end{tabular}

KATNISS 21:

\begin{tabular}{|l|}
\hline Oh, my God! \\
\hline Minor clause \\
\hline
\end{tabular}

\begin{tabular}{|c|c|c|}
\hline Is & this & real? \\
\hline Theme:int & Theme:top & Rheme \\
\hline Finite & Subject & Complement:Attributive \\
\hline \multicolumn{2}{|c|}{ MOOD } & RESIDUE \\
\hline
\end{tabular}

GALE 19: Answer

\begin{tabular}{|c|}
\hline Yeah! \\
\hline Theme:int \\
\hline Adj:Polarity \\
\hline MOOD \\
\hline
\end{tabular}

\begin{tabular}{|c|c|c|}
\hline It & better & be. \\
\hline Theme:top & \multicolumn{2}{|c|}{ Rheme } \\
\hline Subject & Adj:Mood & Finite \\
\hline \multicolumn{3}{|c|}{ MOOD } \\
\hline
\end{tabular}

\begin{tabular}{|c|c|c|c|}
\hline It & cost & me & a squirrel. \\
\hline Theme:top & \multicolumn{3}{|c|}{ Rheme } \\
\hline
\end{tabular}




\begin{tabular}{|c|c|c|c|c|}
\hline Subject & Finite & Predicator & Complement & Complement \\
\hline \multicolumn{2}{|c|}{ MOOD RESIDUE } \\
\hline
\end{tabular}

GALE 20:

\begin{tabular}{|c|}
\hline Happy Hunger Games. \\
\hline Minor clause \\
\hline
\end{tabular}

KATNISS 22:

\begin{tabular}{|c|c|c|c|c|c|}
\hline And & may & the odds & be & ever & $\begin{array}{l}\text { in your } \\
\text { favour. }\end{array}$ \\
\hline Theme:text & Theme:int & Theme:top & \multicolumn{3}{|c|}{ Rheme } \\
\hline \multirow[t]{2}{*}{ Adj:Conj } & Adj:Mood & Subject & Finite & Adj:Mood & Adj:Circ \\
\hline & \multicolumn{4}{|c|}{ MOOD } & RESIDUE \\
\hline
\end{tabular}

KATNISS 23:

\begin{tabular}{|c|c|c|c|c|}
\hline $\begin{array}{c}\text { How many } \\
\text { times }\end{array}$ & has & your name & entered & it? \\
\hline Theme:top & \multicolumn{4}{|c|}{ Rheme } \\
\hline WH/Adj:Circ & Finite & Subject & Predicator & Complement \\
\hline RESIDUE... & \multicolumn{2}{|c|}{ MOOD } & \multicolumn{2}{|c|}{...RESIDUE } \\
\hline
\end{tabular}

GALE 21:

\begin{tabular}{|c|}
\hline Forty two. \\
\hline Theme:top \\
\hline Adj:Circ \\
\hline RESIDUE \\
\hline
\end{tabular}

\begin{tabular}{|c|c|c|c|c|}
\hline Guess & the odds & aren't & exactly & in my favor. \\
\hline Theme:int & Theme:top & \multicolumn{3}{|c|}{ Rheme } \\
\hline
\end{tabular}




\begin{tabular}{|c|c|c|c|c|}
\hline Adj:Mood & Subject & Finite:Neg & Adj:Mood & Adj:Circ \\
\hline \multicolumn{3}{|c|}{ MOOD } & RESIDUE \\
\hline
\end{tabular}

Scene 3: Katniss, Primrose

KATNISS 24:

\begin{tabular}{|c|c|c|c|}
\hline You & need & to get & out of here! \\
\hline Theme:top & & Rheme \\
\hline Subject & Finite & Predicator & Adj:Circ \\
\hline \multicolumn{2}{|c|}{ MOOD } & \multicolumn{2}{|c|}{ RESIDUE } \\
\hline
\end{tabular}

\begin{tabular}{|c|c|c|c|}
\hline You & need & to get & out of here! \\
\hline Theme:top & & Rheme \\
\hline Subject & Finite & Predicator & Adj:Circ \\
\hline \multicolumn{2}{|c|}{ MOOD } & \multicolumn{2}{|c|}{ RESIDUE } \\
\hline
\end{tabular}

PRIMROSE 5:

\begin{tabular}{|c|}
\hline No! \\
\hline Theme:int \\
\hline Adj:Polarity:Neg \\
\hline MOOD \\
\hline
\end{tabular}

KATNISS 25:

\begin{tabular}{|c|c|c|}
\hline Go & find & mom! \\
\hline Theme:int & Theme:top & Rheme \\
\hline Finite & Predicator & Complement \\
\hline MOOD & \multicolumn{2}{|c|}{ RESIDUE } \\
\hline
\end{tabular}

PRIMROSE 6: 


\begin{tabular}{|c|}
\hline No! \\
\hline Theme:int \\
\hline Adj:Polarity:Neg \\
\hline MOOD \\
\hline
\end{tabular}

KATNISS 26:

\begin{tabular}{|c|c|c|c|}
\hline Prim, & go & find & mom! \\
\hline Theme:top & & \multicolumn{3}{|c|}{ Rheme } \\
\hline Adj:Vocative & Finite & Predicator & Complement \\
\hline RESIDUE $\ldots$ & MOOD & \multicolumn{2}{|c|}{...RESIDUE } \\
\hline
\end{tabular}

PRIMROSE 7:

\begin{tabular}{|c|}
\hline No! \\
\hline Theme:int \\
\hline Adj:Polarity:Neg \\
\hline MOOD \\
\hline
\end{tabular}

KATNISS 27:

\begin{tabular}{|c|c|c|c|}
\hline I & 'm & so & sorry! \\
\hline Theme:top & \multicolumn{3}{|c|}{ Rheme } \\
\hline Subject & Finite & Adj:Mood & Complement:Attributive \\
\hline \multicolumn{3}{|c}{ MOOD } & RESIDUE \\
\hline
\end{tabular}

PRIMROSE 8:

\begin{tabular}{|c|}
\hline No! \\
\hline Theme:int \\
\hline Adj:Polarity:Neg \\
\hline MOOD \\
\hline
\end{tabular}


KATNISS 28:

\begin{tabular}{|c|c|c|}
\hline Go & find & mom! \\
\hline Theme:int & Theme:top & Rheme \\
\hline Finite & Predicator & Complement \\
\hline MOOD & \multicolumn{2}{|c|}{ RESIDUE } \\
\hline
\end{tabular}

PRIMROSE 9:

\begin{tabular}{|c|}
\hline No! \\
\hline Theme:int \\
\hline Adj:Polarity:Neg \\
\hline MOOD \\
\hline
\end{tabular}

\section{Scene 4: Katniss, Primrose}

KATNISS 29:

\begin{tabular}{|c|c|c|c|c|}
\hline Prim, & I & don't & have & much time. \\
\hline Theme:int & Theme:top & \multicolumn{3}{|c|}{ Rheme } \\
\hline Adj:Vocative & Subject & Finite:Neg & Predicator & Complement \\
\hline RESIDUE... & \multicolumn{2}{|c|}{ MOOD } & \multicolumn{2}{|c}{...RESIDUE } \\
\hline
\end{tabular}

\begin{tabular}{|c|c|}
\hline Prim, & listen. \\
\hline Theme:top & Rheme \\
\hline Adj:Vocative & Predicator \\
\hline \multicolumn{2}{|c|}{ RESIDUE } \\
\hline
\end{tabular}

\begin{tabular}{|c|c|c|c|}
\hline You & 're & gonna be & \multicolumn{1}{c|}{ okay. } \\
\hline Theme:top & \multicolumn{3}{|c|}{ Rheme } \\
\hline Subject & Finite & Predicator & Complement:Attributive \\
\hline
\end{tabular}




\begin{tabular}{|c|c|}
\hline MOOD & RESIDUE \\
\hline
\end{tabular}

\begin{tabular}{|c|c|c|c|}
\hline Don't & take & any extra food & from them, \\
\hline Theme:int & Theme:top & \multicolumn{2}{|c|}{ Rheme } \\
\hline Finite:Neg & Predicator & Complement & Adj:Circ \\
\hline MOOD & \multicolumn{3}{|c}{ RESIDUE } \\
\hline
\end{tabular}

\begin{tabular}{|c|c|c|c|}
\hline it & isn't & worth putting in your name more times, & okay? \\
\hline Theme:top & \multicolumn{3}{|c|}{ Rheme } \\
\hline Subject & Finite & Complement & Adj:Cont \\
\hline \multicolumn{2}{|c|}{ MOOD } & RESIDUE \\
\hline
\end{tabular}

\begin{tabular}{|c|c|c|c|c|c|}
\hline \multicolumn{1}{|c|}{ Listen, } & Gale & will & bring & you & extra game, \\
\hline Theme:top & Theme:top & \multicolumn{4}{|c|}{ Rheme } \\
\hline Predicator & Subject & Finite & Predicator & Complement & Complement \\
\hline RESIDUE & \multicolumn{2}{|c|}{ MOOD } & \multicolumn{3}{|c}{ RESIDUE } \\
\hline
\end{tabular}

\begin{tabular}{|c|c|c|c|c|}
\hline you & can & sell & cheese & $\begin{array}{c}\text { from your } \\
\text { goat. }\end{array}$ \\
\hline Theme:top & \multicolumn{4}{|c|}{ Rheme } \\
\hline Subject & Finite & Predicator & Complement & Adj:Circ \\
\hline \multicolumn{2}{|c|}{ MOOD } & \multicolumn{3}{|c|}{ RESIDUE } \\
\hline
\end{tabular}

PRIMROSE 10:

\begin{tabular}{|c|c|c|c|}
\hline Just & try & to win, & if you can. \\
\hline Theme:int & Theme:top & \multicolumn{2}{|c|}{ Rheme } \\
\hline Adj:Mood & Finite & Predicator & Adj:Circ \\
\hline
\end{tabular}




\begin{tabular}{|c|c|}
\hline MOOD & RESIDUE \\
\hline
\end{tabular}

KATNISS 30:

\begin{tabular}{|c|}
\hline Of course. \\
\hline Theme:int \\
\hline Adj:Mood \\
\hline MOOD \\
\hline
\end{tabular}

\begin{tabular}{|c|c|c|c|c|}
\hline And & maybe & I & \multicolumn{2}{|c|}{ can, } \\
\hline Theme:text & Theme:int & Theme:top & \multicolumn{2}{|c|}{ Rheme } \\
\hline Adj:Conj & Adj:Mood & Subject & Finite & Predicator \\
\hline & \multicolumn{3}{|c|}{ MOOD } & RESIDUE \\
\hline
\end{tabular}

\begin{tabular}{|c|c|c|c|}
\hline I & am & smart, & you know. \\
\hline Theme:top & & \multicolumn{2}{|c|}{ Rheme } \\
\hline Subject & Finite & Complement:Attributive & Adj:Cont \\
\hline \multicolumn{2}{|c|}{ MOOD } & \multicolumn{2}{c|}{ RESIDUE } \\
\hline
\end{tabular}

PRIMROSE 11:

\begin{tabular}{|c|c|c|}
\hline You & can & hunt. \\
\hline Theme:top & \multicolumn{2}{|c|}{ Rheme } \\
\hline Subject & Finite & Predicator \\
\hline \multicolumn{3}{|c|}{ MOOD } \\
\hline
\end{tabular}

KATNISS 31:

\begin{tabular}{|c|}
\hline Exactly. \\
\hline Theme:int \\
\hline Adj:Mood \\
\hline
\end{tabular}




MOOD

PRIMROSE 12:

\begin{tabular}{|l|c|}
\hline To protect & you. \\
\hline Theme:top & Rheme \\
\hline Predicator & Complement \\
\hline \multicolumn{2}{|c|}{ RESIDUE } \\
\hline
\end{tabular}

KATNISS 32:

\begin{tabular}{|c|}
\hline Thank you. \\
\hline Minor clause \\
\hline
\end{tabular}

\section{Scene 5: Katniss, Gale}

KATNISS 33:

\begin{tabular}{|c|c|c|}
\hline I & 'm & fine. \\
\hline Theme:top & \multicolumn{2}{|c|}{ Rheme } \\
\hline Subject & Finite & Complement:Attributive \\
\hline \multicolumn{3}{|c|}{ MOOD } \\
\hline
\end{tabular}

GALE 22:

\begin{tabular}{|c|c|c|c|}
\hline Yeah, & I & \multicolumn{2}{|c|}{ know. } \\
\hline Theme:text & Theme:top & \multicolumn{2}{|c|}{ Rheme } \\
\hline Adj:Cont & Subject & Finite & Predicator \\
\hline & \multicolumn{2}{|c|}{ MOOD } & RESIDUE \\
\hline
\end{tabular}

KATNISS 34:

\begin{tabular}{|c|c|}
\hline I & am. \\
\hline Theme:top & Rheme \\
\hline Subject & Finite \\
\hline
\end{tabular}




MOOD

GALE 23:

\begin{tabular}{|c|l|}
\hline Listen & to $\mathbf{m e}$, \\
\hline Theme:top & Rheme \\
\hline Predicator & Adj:Circ \\
\hline \multicolumn{2}{|c|}{ RESIDUE } \\
\hline
\end{tabular}

\begin{tabular}{|c|c|c|}
\hline you & are & stronger than they are. \\
\hline Theme:top & \multicolumn{2}{|c|}{ Rheme } \\
\hline Subject & Finite & Complement:Attributive \\
\hline \multicolumn{2}{|c|}{ MOOD } & RESIDUE \\
\hline
\end{tabular}

\begin{tabular}{|c|c|}
\hline You & are. \\
\hline Theme:top & Rheme \\
\hline Subject & Finite \\
\hline \multicolumn{2}{|c|}{} \\
\hline
\end{tabular}

\begin{tabular}{|c|c|}
\hline Get to & a bow. \\
\hline Theme:top & Rheme \\
\hline Predicator & Complement \\
\hline \multicolumn{2}{|c|}{ RESIDUE } \\
\hline
\end{tabular}

KATNISS 35:

\begin{tabular}{|c|c|c|c|c|}
\hline I & may not & \multicolumn{2}{|c|}{ have } & a bow... \\
\hline Theme:top & \multicolumn{4}{|c|}{ Rheme } \\
\hline Subject & Adj:Mood:Neg & Finite & Predicator & Complement \\
\hline
\end{tabular}




\begin{tabular}{|l|l|}
\hline MOOD & RESIDUE \\
\hline
\end{tabular}

GALE 24:

\begin{tabular}{|c|c|c|}
\hline You & \multicolumn{2}{|c|}{ will } \\
\hline Theme:top & \multicolumn{2}{|c|}{ Rheme } \\
\hline Subject & Finite & Predicator \\
\hline \multicolumn{2}{|c|}{ MOOD } & RESIDUE \\
\hline
\end{tabular}

\begin{tabular}{|c|c|c|c|c|c|}
\hline if & you & \multicolumn{2}{|c|}{ show } & 'em & how good you are. \\
\hline Theme:text & Theme:top & \multicolumn{3}{|c|}{ Rheme } \\
\hline Adj:Circ & Subject & Finite & Predicator & Complement & Adj:Circ \\
\hline RESIDUE... & \multicolumn{2}{|c|}{ MOOD } & \multicolumn{3}{|c|}{...RESIDUE } \\
\hline
\end{tabular}

\begin{tabular}{|c|c|c|c|c|}
\hline They & just & want & a good show, \\
\hline Theme:top & \multicolumn{4}{|c|}{ Rheme } \\
\hline Subject & Adj:Mood & Finite & Predicator & Complement \\
\hline \multicolumn{3}{|c|}{ MOOD } & \multicolumn{3}{|c|}{ RESIDUE } \\
\hline
\end{tabular}

\begin{tabular}{|c|c|c|}
\hline that & 's & all they want. \\
\hline Theme:top & \multicolumn{2}{|c|}{ Rheme } \\
\hline Subject & Finite & Complement \\
\hline \multicolumn{3}{|c|}{ MOOD } \\
\hline
\end{tabular}

\begin{tabular}{|c|c|c|c|c|}
\hline If & they & don't & have & a bow, \\
\hline Theme:text & Theme:top & \multicolumn{3}{|c|}{ Rheme } \\
\hline Adj:Circ & Subject & Finite:Neg & Predicator & Complement \\
\hline
\end{tabular}




\begin{tabular}{|c|c|c|c|c|c|}
\hline RESIDUE. & \multicolumn{2}{|c|}{ MOOD } & \multicolumn{3}{|c|}{...RESIDUE } \\
\hline then & you & \multicolumn{2}{|c|}{ make } & one, & okay? \\
\hline Theme:text & Theme:top & \multicolumn{4}{|c|}{ Rheme } \\
\hline Adj:Circ & Subject & Finite & Predicator & Complement & Adj:Cont \\
\hline RESIDUE... & \multicolumn{2}{|c|}{ MOOD } & \multicolumn{3}{|c|}{...RESIDUE } \\
\hline
\end{tabular}

\begin{tabular}{|c|c|c|c|}
\hline You & \multicolumn{2}{|c|}{ know } & how to hunt. \\
\hline Theme:top & \multicolumn{3}{|c|}{ Rheme } \\
\hline Subject & Finite & Predicator & Adj:Circ \\
\hline \multicolumn{2}{|c|}{ MOOD } & \multicolumn{2}{|c|}{ RESIDUE } \\
\hline
\end{tabular}

KATNISS 36:

\begin{tabular}{|c|}
\hline Animals. \\
\hline Theme:top \\
\hline Complement \\
\hline RESIDUE \\
\hline
\end{tabular}

GALE 25:

\begin{tabular}{|c|c|c|c|}
\hline There & 's & no difference, & Katniss. \\
\hline Theme:top & & Rheme \\
\hline Subject & Finite & Complement & Adj:Vocative \\
\hline \multicolumn{2}{|c|}{ MOOD } & \multicolumn{2}{|c|}{ RESIDUE } \\
\hline
\end{tabular}

KATNISS 37:

\begin{tabular}{|c|c|c|c|}
\hline There & 're & twenty-four of us, & Gale, \\
\hline Theme:top & \multicolumn{3}{|c|}{ Rheme } \\
\hline Subject & Finite & Complement & Adj:Vocative \\
\hline
\end{tabular}




\begin{tabular}{|c|c|c|c|c|}
\hline \multicolumn{2}{|c|}{ MOOD } & \multicolumn{3}{|c|}{ RESIDUE } \\
\hline and & only & one & \multicolumn{2}{|c|}{ comes out. } \\
\hline Theme:text & Theme:int & Theme:top & \multicolumn{2}{|c|}{ Rheme } \\
\hline \multirow[t]{2}{*}{ Adj:Conj } & Adj:Mood & Subject & Finite & Predicator \\
\hline & \multicolumn{3}{|c|}{ MOOD } & RESIDUE \\
\hline
\end{tabular}

GALE 26:

\begin{tabular}{|c|c|c|c|c|c|}
\hline Yeah, & and & it & 's & gonna be & you. \\
\hline Theme:text & Theme:text & Theme:top & \multicolumn{3}{|c|}{ Rheme } \\
\hline Adj:Cont & Adj:Conj & Subject & Finite & Predicator & Complement \\
\hline & & \multicolumn{2}{|c|}{ MOOD } & \multicolumn{2}{c|}{ RESIDUE } \\
\hline
\end{tabular}

Peacekeeper (adult): Okay

KATNISS 38:

\begin{tabular}{|l|l|l|}
\hline Take care & of them, & Gale. \\
\hline Theme:top & & \multicolumn{2}{|c|}{ Rheme Adj:Vocative } \\
\hline Predicator & Adj:Circ \\
\hline \multicolumn{3}{|c|}{ RESIDUE } \\
\hline
\end{tabular}

\begin{tabular}{|c|c|c|c|c|}
\hline Whatever you do, & don't & let & them & starve! \\
\hline Theme:top & \multicolumn{4}{|c|}{ Rheme } \\
\hline Adj:Circ & Finite:Neg & Predicator... & Complement & ...Predicator \\
\hline RESIDUE... & MOOD & \multicolumn{3}{|c}{...RESIDUE } \\
\hline
\end{tabular}

Peacekeeper (adult): Let's go.

GALE 27:

\begin{tabular}{|c|c|c|c|c|c|}
\hline I & 'll & see & you & soon, & okay? \\
\hline
\end{tabular}




\begin{tabular}{|c|c|c|c|c|c|}
\hline Theme:top & \multicolumn{5}{|c|}{ Rheme } \\
\hline Subject & Finite & Predicator & Complement & Adj:Circ & Adj:Cont \\
\hline \multicolumn{2}{|c|}{ MOOD } & \multicolumn{4}{|c|}{ RESIDUE } \\
\hline
\end{tabular}

\section{Scene 6: Peeta (Katniss)}

PEETA 1:

\begin{tabular}{|c|c|c|c|}
\hline Have & you & met & him? \\
\hline Theme:int & Theme:top & \multicolumn{2}{|c|}{ Rheme } \\
\hline Finite & Subject & Predicator & Complement \\
\hline \multicolumn{2}{|c|}{ RESIDUE } \\
\hline
\end{tabular}

\begin{tabular}{|c|}
\hline Haymitch? \\
\hline Theme:top \\
\hline Complement \\
\hline RESIDUE \\
\hline
\end{tabular}

\section{PEETA 2:}

\begin{tabular}{|c|c|c|c|c|}
\hline You know, & Katniss, & he & is & our mentor. \\
\hline Theme:text & Theme:int & Theme:top & \multicolumn{2}{|c|}{ Rheme } \\
\hline Adj:Conj & Adj:Vocative & Subject & Finite & Complement \\
\hline & RESIDUE... & \multicolumn{2}{|c|}{ MOOD } & ... RESIDUE \\
\hline
\end{tabular}

\begin{tabular}{|c|c|c|c|c|}
\hline He & did & win & this thing & once. \\
\hline Theme:top & \multicolumn{4}{|c|}{ Rheme } \\
\hline Subject & Finite & Predicator & Complement & Adj:Circ \\
\hline \multicolumn{2}{|c|}{ MOOD } & \multicolumn{3}{c|}{ RESIDUE } \\
\hline
\end{tabular}

\section{PEETA 3:}




\begin{tabular}{|c|c|c|c|c|c|}
\hline Look, & you know, & if you don't wanna & \multicolumn{2}{|c|}{ I } & \multicolumn{2}{|c|}{ understand. } \\
\hline Theme:text & Theme:text & Theme:top & \multicolumn{3}{|c|}{ Rheme } \\
\hline Adj:Conj & Adj:Conj & Adj:Circ & Subject & Finite & Predicator \\
\hline & & RESIDUE... & \multicolumn{2}{|c|}{ MOOD } & ...RESIDUE \\
\hline
\end{tabular}

\begin{tabular}{|c|c|c|c|c|c|}
\hline But & $\begin{array}{c}\text { I just don't } \\
\text { think }\end{array}$ & there & 's & $\begin{array}{c}\text { anything } \\
\text { wrong }\end{array}$ & $\begin{array}{c}\text { with getting a } \\
\text { little bit of help. }\end{array}$ \\
\hline Theme:text & Theme:int & Theme:top & \multicolumn{3}{|c|}{ Rheme } \\
\hline Adj:Conj & Adj:Mood & Subject & Finite & Complement & Adj:Circ \\
\hline & \multicolumn{3}{|c|}{ MOOD } & \multicolumn{2}{c|}{ RESIDUE } \\
\hline
\end{tabular}

\section{Scene 7: Katniss, Peeta}

KATNISS 39:

\begin{tabular}{|c|c|c|}
\hline Throw & that metal thing & over there. \\
\hline Theme:top & \multicolumn{2}{|c|}{ Rheme } \\
\hline Predicator & Complement & Adj:Circ \\
\hline \multicolumn{3}{|c|}{ RESIDUE } \\
\hline
\end{tabular}

PEETA 4:

\begin{tabular}{|c|}
\hline What? \\
\hline Theme:top \\
\hline Subject \\
\hline MOOD \\
\hline No. \\
\hline Theme:int \\
\hline Adj:Polarity:Neg \\
\hline
\end{tabular}




\begin{tabular}{|c|c|c|c|c|}
\hline \multicolumn{2}{|c|}{ MOOD } & & & \\
\hline Haymitch said & we & 're not & supposed to show & our skills. \\
\hline Theme:int & Theme:top & \multicolumn{3}{|c|}{ Rheme } \\
\hline Adj:Mood & Subject & Finite:Neg & Predicator & Complement \\
\hline \multicolumn{3}{|c|}{ MOOD } & \multicolumn{2}{|c|}{ RESIDUE } \\
\hline
\end{tabular}

KATNISS 40:

\begin{tabular}{|c|c|c|c|}
\hline I & don't & care & what Haymitch said. \\
\hline Theme:top & & \multicolumn{3}{|c|}{ Rheme } \\
\hline Subject & Finite:Neg & Predicator & Complement \\
\hline \multicolumn{2}{|c|}{ RESIDUE } \\
\hline
\end{tabular}

\begin{tabular}{|c|c|c|c|c|}
\hline Those guys & are & looking & at you & like you're a meal. \\
\hline Theme:top & \multicolumn{4}{|c|}{ Rheme } \\
\hline Subject & Finite & Predicator & Adj:Circ & Adj:Circ \\
\hline \multicolumn{2}{|c|}{ MOOD } & \multicolumn{3}{c|}{ RESIDUE } \\
\hline
\end{tabular}

\begin{tabular}{|c|c|}
\hline Throw & it. \\
\hline Theme:top & Rheme \\
\hline Predicator & Complement \\
\hline & RESIDUE \\
\hline
\end{tabular}

\section{Scene 8: Katniss, Peeta}

KATNISS 41:

\begin{tabular}{|c|c|}
\hline Can't & sleep? \\
\hline Theme:int & Theme:top \\
\hline
\end{tabular}




\begin{tabular}{|c|l|}
\hline Finite:Neg & Predicator \\
\hline MOOD & RESIDUE \\
\hline
\end{tabular}

PEETA 5:

\begin{tabular}{|c|}
\hline Of course not. \\
\hline Theme:int \\
\hline Adj:Mood:Neg \\
\hline MOOD \\
\hline
\end{tabular}

KATNISS 42:

\begin{tabular}{|c|c|c|c|c|}
\hline I'm sorry & I & \multicolumn{2}{|c|}{ went } & after you. \\
\hline Theme:int & Theme:top & \multicolumn{3}{|c|}{ Rheme } \\
\hline Adj:Mood & Subject & Finite & Predicator & Adj:Circ \\
\hline \multicolumn{3}{|c|}{ MOOD } & \multicolumn{2}{c|}{ RESIDUE } \\
\hline
\end{tabular}

PEETA 6:

\begin{tabular}{|c|c|c|c|c|c|}
\hline You know & I & \multicolumn{2}{|c|}{ meant } & it & as a compliment. \\
\hline Theme:text & Theme:top & \multicolumn{3}{|c|}{ Rheme } \\
\hline Adj:Conj & Subject & Finite & Predicator & Complement & Adj:Circ \\
\hline & \multicolumn{2}{|c|}{ MOOD } & \multicolumn{3}{c|}{ RESIDUE } \\
\hline
\end{tabular}

KATNISS 43:

\begin{tabular}{|c|c|c|}
\hline I & \multicolumn{2}{|c|}{ know. } \\
\hline Theme:top & \multicolumn{2}{|c|}{ Rheme } \\
\hline Subject & Finite & Predicator \\
\hline \multicolumn{2}{|c|}{ MOOD } & RESIDUE \\
\hline
\end{tabular}

KATNISS 44:

\begin{tabular}{|l|l} 
Listen & to them \\
\hline
\end{tabular}




\begin{tabular}{|l|l|}
\hline Theme:top & Rheme \\
\hline Predicator & Adj:Circ \\
\hline \multicolumn{3}{|c|}{ RESIDUE } \\
\hline
\end{tabular}

PEETA 7:

\begin{tabular}{|c|}
\hline Yeah. \\
\hline Minor clause \\
\hline
\end{tabular}

\begin{tabular}{|c|c|c|c|c|}
\hline I just hope & they & don't & change & \multicolumn{1}{|c|}{ me. } \\
\hline Theme:int & Theme:top & & Rheme \\
\hline Adj:Mood & Subject & Finite:Neg & Predicator & Complement \\
\hline \multicolumn{3}{|c|}{ MOOD } & \multicolumn{2}{|c|}{ RESIDUE } \\
\hline
\end{tabular}

KATNISS 45:

\begin{tabular}{|c|c|c|c|l|}
\hline How & would & they & change & you? \\
\hline Theme:top & \multicolumn{4}{|c|}{ Rheme } \\
\hline WH/Adj:Circ & Finite & Subject & Predicator & Complement \\
\hline RESIDUE... & \multicolumn{2}{|c|}{ MOOD } & \multicolumn{2}{|c|}{...RESIDUE } \\
\hline
\end{tabular}

PEETA 8:

\begin{tabular}{|c|c|c|}
\hline I & don't & know. \\
\hline Theme:top & \multicolumn{2}{|c|}{ Rheme } \\
\hline Subject & Finite:Neg & Predicator \\
\hline \multicolumn{3}{|c|}{ MOOD } \\
\hline
\end{tabular}

\begin{tabular}{|c|c|c|c|}
\hline \multicolumn{2}{|c|}{ Turn } & me & into something I'm not. \\
\hline \multicolumn{2}{|c|}{ Theme:top } & \multicolumn{2}{c|}{ Rheme } \\
\hline Finite & Predicator & Complement & Adj:Circ \\
\hline
\end{tabular}




\begin{tabular}{|c|c|c|c|c|c|c|}
\hline MOOD & \multicolumn{6}{|c|}{ RESIDUE } \\
\hline I & just & don't & wanna be & $\begin{array}{l}\text { another } \\
\text { piece }\end{array}$ & $\begin{array}{l}\text { in their } \\
\text { game, }\end{array}$ & $\begin{array}{c}\text { you } \\
\text { know? }\end{array}$ \\
\hline Theme:top & \multicolumn{6}{|c|}{ Rheme } \\
\hline Subject & Adj:Mood & Finite:Neg & Predicator & Complement & Adj:Circ & Adj:Cont \\
\hline \multicolumn{3}{|c|}{ MOOD } & \multicolumn{4}{|c|}{ RESIDUE } \\
\hline
\end{tabular}

KATNISS 46:

\begin{tabular}{|c|c|c|c|c|}
\hline You mean & you & won't & kill & anyone? \\
\hline Theme:int & Theme:top & & Rheme \\
\hline Adj:Mood & Subject & Finite:Neg & Predicator & Complement \\
\hline \multicolumn{3}{|c|}{ MOOD } & \multicolumn{2}{|c|}{ RESIDUE } \\
\hline
\end{tabular}

\section{PEETA 9:}

\begin{tabular}{|c|}
\hline No. \\
\hline Theme:int \\
\hline Adj:Polarity:Neg \\
\hline MOOD \\
\hline
\end{tabular}

\begin{tabular}{|c|c|c|c|c|c|}
\hline I'm sure & I & \multicolumn{2}{|c|}{ would, } & $\begin{array}{c}\text { just like } \\
\text { anybody else }\end{array}$ & $\begin{array}{l}\text { when the } \\
\text { time came }\end{array}$ \\
\hline Theme:int & Theme:top & \multicolumn{4}{|c|}{ Rheme } \\
\hline Adj:Mood & Subject & Finite & Predicator & Adj:Circ & Adj:Circ \\
\hline \multicolumn{3}{|c|}{ MOOD } & \multicolumn{3}{|c|}{ RESIDUE } \\
\hline
\end{tabular}

\begin{tabular}{|c|c|c|c|c|c|c|}
\hline But, & you know, & $\begin{array}{c}\text { I just } \\
\text { keep } \\
\text { wishing }\end{array}$ & I & could & think of & $\begin{array}{c}\text { a way to } \\
\text { show them } \\
\text { that they }\end{array}$ \\
\hline
\end{tabular}




\begin{tabular}{|c|c|c|c|c|c|c|}
\hline & & & & & & $\begin{array}{c}\text { don't own } \\
\text { me. }\end{array}$ \\
\hline Theme:text & Theme:text & Theme:int & Theme:top & \multicolumn{3}{|c|}{ Rheme } \\
\hline Adj:Conj & Adj:Cont & Adj:Mood & Subject & Finite & Predicator & Complement \\
\hline & & \multicolumn{3}{|c|}{ MOOD } & \multicolumn{2}{c|}{ RESIDUE } \\
\hline
\end{tabular}

\begin{tabular}{|c|c|c|c|c|c|c|}
\hline You know, & $\begin{array}{c}\text { if I'm } \\
\text { gonna die, }\end{array}$ & I & wanna & still & be & me. \\
\hline Theme:text & Theme:top & \multicolumn{5}{|c|}{ Rheme } \\
\hline Adj:Cont & Adj:Circ & Subject & Finite & Adj:Mood & Predicator & Complement \\
\hline & RESIDUE... & \multicolumn{5}{|c|}{ MOOD } \\
\hline
\end{tabular}

\begin{tabular}{|c|c|c|c|}
\hline Does & that & make & \multicolumn{1}{c|}{ any sense? } \\
\hline Theme:int & Theme:top & \multicolumn{2}{|c|}{ Rheme } \\
\hline Finite & Subject & Predicator & Complement:Attributive \\
\hline \multicolumn{2}{|c|}{ MOOD } & \multicolumn{2}{|c|}{ RESIDUE } \\
\hline
\end{tabular}

\section{KATNISS 47:}

\begin{tabular}{|c|}
\hline Yeah. \\
\hline Theme:int \\
\hline Adj:Polarity \\
\hline MOOD \\
\hline
\end{tabular}

\begin{tabular}{|c|c|c|c|c|}
\hline I & just & can't & afford to think & like that. \\
\hline Theme:top & \multicolumn{4}{|c|}{ Rheme } \\
\hline Subject & Adj:Mood & Finite & Predicator & Adj:Circ \\
\hline \multicolumn{3}{|c|}{ MOOD } & \multicolumn{2}{|c|}{ RESIDUE } \\
\hline
\end{tabular}




\begin{tabular}{|c|c|c|}
\hline I & have & my sister. \\
\hline Theme:top & \multicolumn{2}{|c|}{ Rheme } \\
\hline Subject & Finite & Complement \\
\hline \multicolumn{2}{|c|}{ MOOD } & RESIDUE \\
\hline
\end{tabular}

PEETA 10:

\begin{tabular}{|c|c|c|c|}
\hline Yeah, & I & \multicolumn{2}{|c|}{ know. } \\
\hline Theme:text & Theme:top & \multicolumn{2}{|c|}{ Rheme } \\
\hline Adj:Cont & Subject & Finite & Predicator \\
\hline & \multicolumn{2}{|c|}{ MOOD } & RESIDUE \\
\hline
\end{tabular}

PEETA 11:

\begin{tabular}{|c|c|c|c|c|c|}
\hline I guess & I & 'll & see & you & tomorrow. \\
\hline Theme:int & Theme:top & \multicolumn{4}{|c|}{ Rheme } \\
\hline Adj:Mood & Subject & Finite & Predicator & Complement & Adj:Circ \\
\hline \multicolumn{3}{|c|}{ MOOD } & \multicolumn{3}{c|}{ RESIDUE } \\
\hline
\end{tabular}

KATNISS 48:

\begin{tabular}{|c|c|c|c|}
\hline \multicolumn{2}{|c|}{ See } & you & tomorrow. \\
\hline \multicolumn{2}{|c|}{ Theme:top } & \multicolumn{2}{|c|}{ Rheme } \\
\hline Finite & Predicator & Complement & Adj:Circ \\
\hline MOOD & \multicolumn{2}{|c|}{ RESIDUE } \\
\hline
\end{tabular}

\section{Scene 9: Peeta, Cato (Clove, Katniss)}

PEETA 12:

\begin{tabular}{|c|c|c|c|c|c|}
\hline Let's & just & \multicolumn{2}{|c|}{ wait } & her & out. \\
\hline Theme:top & \multicolumn{5}{|c|}{ Rheme } \\
\hline Subject & Adj:Mood & Finite & Predicator & Complement & Adj:Circ \\
\hline
\end{tabular}




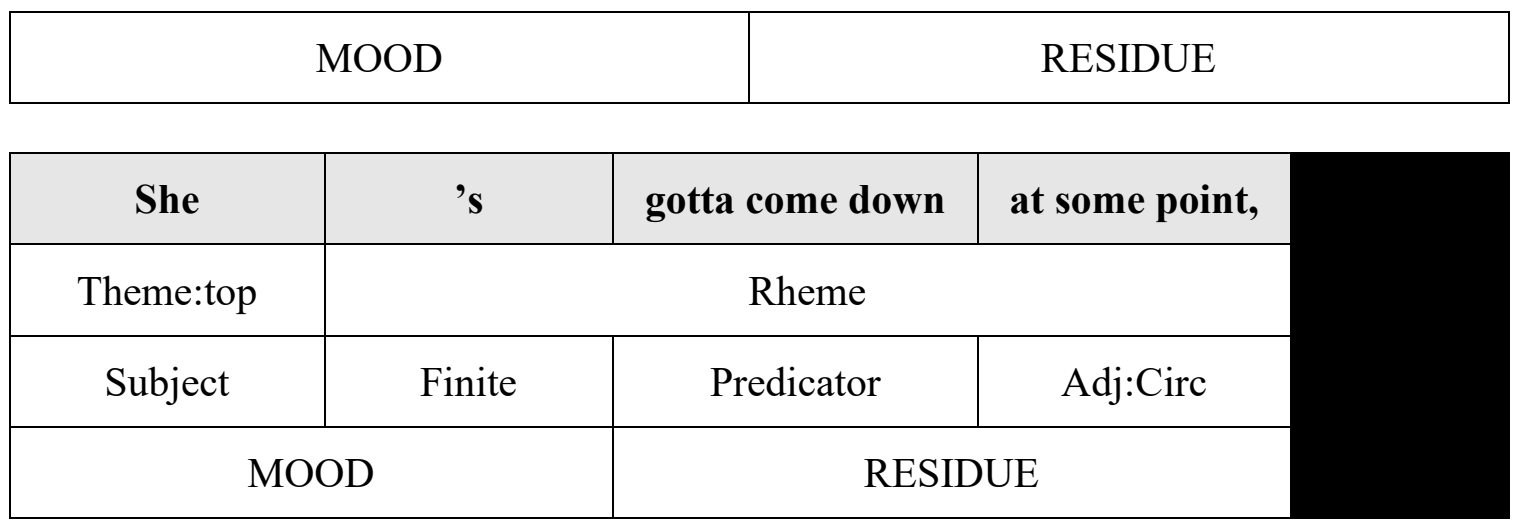

\begin{tabular}{|c|c|c|}
\hline it & 's & that or starve to death. \\
\hline Theme:top & \multicolumn{2}{|c|}{ Rheme } \\
\hline Subject & Finite & Complement \\
\hline \multicolumn{2}{|c|}{ MOOD } & RESIDUE \\
\hline
\end{tabular}

\begin{tabular}{|c|c|c|c|c|}
\hline Let's & \multicolumn{2}{|c|}{ kill } & her & then. \\
\hline Theme:top & \multicolumn{3}{|c|}{ Rheme } \\
\hline Subject & Finite & Predicator & Complement & Adj:Circ \\
\hline \multicolumn{2}{|c|}{ MOOD } & \multicolumn{3}{|c|}{ RESIDUE } \\
\hline
\end{tabular}

CATO 1:

\begin{tabular}{|c|}
\hline Okay. \\
\hline Minor clause \\
\hline
\end{tabular}

\begin{tabular}{|c|c|c|c|}
\hline Somebody & \multicolumn{2}{|c|}{ make } & a fire. \\
\hline Theme:top & \multicolumn{3}{|c|}{ Rheme } \\
\hline Subject & Finite & Predicator & Complement \\
\hline \multicolumn{2}{|c|}{ MOOD } & \multicolumn{2}{|c|}{ RESIDUE } \\
\hline
\end{tabular}

\section{Scene 10: Katniss, Rue}

KATNISS 49: 


\begin{tabular}{|c|c|c|c|}
\hline How long & was & I & asleep? \\
\hline Theme:top & \multicolumn{3}{|c|}{ Rheme } \\
\hline WH/Adj:Circ & Finite & Subject & Complement:Attributive \\
\hline RESIDUE $\ldots$ & \multicolumn{2}{|c|}{ MOOD } & ...RESIDUE \\
\hline
\end{tabular}

RUE 1:

\begin{tabular}{|c|}
\hline Couple of days. \\
\hline Theme:top \\
\hline Adj:Circ \\
\hline RESIDUE \\
\hline
\end{tabular}

\begin{tabular}{|c|c|c|c|c|}
\hline I & \multicolumn{2}{|c|}{ changed } & your leaves & twice. \\
\hline Theme:top & \multicolumn{3}{|c|}{ Rheme } \\
\hline Subject & Finite & Predicator & Complement & Adj:Circ \\
\hline \multicolumn{2}{|c|}{ MOOD } & \multicolumn{3}{|c}{ RESIDUE } \\
\hline
\end{tabular}

KATNISS 50:

\begin{tabular}{|c|}
\hline Thank you. \\
\hline Minor clause \\
\hline
\end{tabular}

\begin{tabular}{|c|c|c|c|c|}
\hline So & what & \multicolumn{2}{|c|}{ happened } & when I was out? \\
\hline Theme:text & Theme:top & \multicolumn{3}{|c|}{ Rheme } \\
\hline Adj:Conj & Subject & Finite & Predicator & Adj:Circ \\
\hline & \multicolumn{2}{|c|}{ MOOD } & \multicolumn{2}{|c|}{ RESIDUE } \\
\hline
\end{tabular}

RUE 2:

The girl from 1 and the boy from 10.

Theme:top 


\begin{tabular}{|l|}
\hline Subject \\
\hline MOOD \\
\hline
\end{tabular}

KATNISS 51:

\begin{tabular}{|c|c|c|c|c|c|}
\hline And & the & uhh... & and & the boy & from my district? \\
\hline Theme:text & Theme:text & Theme:text & Theme:text & Theme:top & Rheme \\
\hline Adj:Conj & Adj:Cont & Adj:Cont & Adj:Conj & Subject & Adj:Circ \\
\hline & & & & MOOD & RESIDUE \\
\hline
\end{tabular}

RUE 3:

\begin{tabular}{|c|c|c|c|}
\hline Yeah, & he & 's & okay. \\
\hline Theme:int & Theme:top & \multicolumn{2}{|c|}{ Rheme } \\
\hline Adj:Polarity & Subject & Finite & Complement:Attributive \\
\hline \multicolumn{3}{|c}{} & RESIDUE \\
\hline
\end{tabular}

\begin{tabular}{|c|c|c|c|}
\hline I think & he & 's & down by the river. \\
\hline Theme:int & Theme:top & \multicolumn{2}{|c|}{ Rheme } \\
\hline Adj:Mood & Subject & Finite & Adj:Circ \\
\hline \multicolumn{3}{|c|}{ MOOD } & RESIDUE \\
\hline
\end{tabular}

RUE 4:

\begin{tabular}{|c|c|c|}
\hline Is & all of that & true? \\
\hline Theme:int & Theme:top & Rheme \\
\hline Finite & Subject & Complement:Attributive \\
\hline \multicolumn{2}{c}{ MOOD } & RESIDUE \\
\hline
\end{tabular}

KATNISS 52:

\section{What?}




\begin{tabular}{|c|}
\hline Theme:top \\
\hline Subject \\
\hline MOOD \\
\hline
\end{tabular}

RUE 5:

\begin{tabular}{|c|}
\hline You and him? \\
\hline Theme:top \\
\hline Subject \\
\hline MOOD \\
\hline
\end{tabular}

KATNISS 53:

\begin{tabular}{|c|c|c|c|}
\hline So & where & are & Cato and the others? \\
\hline Theme:text & Theme:top & \multicolumn{2}{c|}{ Rheme } \\
\hline Adj:Conj & WH/Subject & Finite & Complement \\
\hline & \multicolumn{2}{|c|}{ MOOD } & RESIDUE \\
\hline
\end{tabular}

RUE 6:

\begin{tabular}{|c|c|c|c|c|}
\hline They & \multicolumn{2}{|c|}{ got } & \multicolumn{1}{c|}{$\begin{array}{c}\text { all their } \\
\text { supplies }\end{array}$} & $\begin{array}{c}\text { down by the lake, piled up } \\
\text { in this great big pyramid. }\end{array}$ \\
\hline Theme:top & & \multicolumn{3}{|c|}{ Rheme } \\
\hline Subject & Finite & Predicator & Complement & Adj:Circ \\
\hline \multicolumn{2}{|c|}{ MOOD } & \multicolumn{4}{|c}{ RESIDUE } \\
\hline
\end{tabular}

KATNISS 54:

\begin{tabular}{|c|c|c|c|}
\hline That & \multicolumn{2}{|c|}{ sounds } & tempting. \\
\hline Theme:top & \multicolumn{3}{|c|}{ Rheme } \\
\hline Subject & Finite & Predicator & Complement:Attributive \\
\hline \multicolumn{2}{|c|}{ MOOD } & & RESIDUE \\
\hline
\end{tabular}




\section{Scene 11: Katniss, Rue}

KATNISS 55: Command

\begin{tabular}{|c|c|c|c|c|}
\hline Now & this green stuff & is & gonna smoke & like crazy, \\
\hline Theme:text & Theme:top & \multicolumn{3}{|c|}{ Rheme } \\
\hline Adj:Conj & Subject & Finite & Predicator & Adj:Circ \\
\hline & \multicolumn{2}{|c|}{ MOOD } & \multicolumn{2}{|c|}{ RESIDUE } \\
\hline
\end{tabular}

\begin{tabular}{|c|c|c|c|}
\hline so & as soon as you light it, & move & on to the next fire. \\
\hline Theme:text & Theme:top & \multicolumn{2}{|c|}{ Rheme } \\
\hline Adj:Conj & Adj:Circ & Predicator & Adj:Circ \\
\hline & & RESIDUE \\
\hline
\end{tabular}

\begin{tabular}{|c|c|c|}
\hline Light & this one & last \\
\hline Theme:top & \multicolumn{2}{|c|}{ Rheme } \\
\hline Predicator & Complement & Adj:Circ \\
\hline \multicolumn{3}{|c|}{ RESIDUE } \\
\hline
\end{tabular}

\begin{tabular}{|c|c|c|c|c|c|}
\hline and & I & 'll & meet & you & back over there. \\
\hline Theme:text & Theme:top & \multicolumn{3}{c|}{ Rheme } \\
\hline Adj:Conj & Subject & Finite & Predicator & Complement & Adj:Circ \\
\hline & \multicolumn{2}{|c|}{ MOOD } & \multicolumn{3}{c}{ RESIDUE } \\
\hline
\end{tabular}

RUE 7:

\begin{tabular}{|c|}
\hline Right. \\
\hline Minor clause \\
\hline
\end{tabular}

\section{KATNISS 56:}




\begin{tabular}{|c|c|c|c|c|c|}
\hline And then, & I & 'Il & destroy & their stuff & $\begin{array}{c}\text { while they're } \\
\text { chasing you. }\end{array}$ \\
\hline Theme:top & \multicolumn{5}{|c|}{ Rheme } \\
\hline Adj:Circ & Subject & Finite & Predicator & Complement & Adj:Circ \\
\hline RESIDUE... & \multicolumn{2}{|c|}{ MOOD } & \multicolumn{5}{|c}{...RESIDUE } \\
\hline
\end{tabular}

RUE 8:

\begin{tabular}{|c|c|c|c|c|}
\hline We & \multicolumn{2}{|c|}{ need } & a signal, & in case one of us gets held up. \\
\hline Theme:top & \multicolumn{3}{|c|}{ Rheme } \\
\hline Subject & Finite & Predicator & Complement & Adj:Circ \\
\hline \multicolumn{2}{|c|}{ MOOD } & & \multicolumn{3}{|c|}{ RESIDUE } \\
\hline
\end{tabular}

KATNISS 57:

\begin{tabular}{|c|}
\hline Okay. \\
\hline Minor clause \\
\hline
\end{tabular}

\begin{tabular}{|c|}
\hline Like what? \\
\hline Theme:top \\
\hline Adj:Circ \\
\hline RESIDUE \\
\hline
\end{tabular}

RUE 9:

\begin{tabular}{|c|c|c|}
\hline Here, & watch & this. \\
\hline Theme:text & Theme:top & Rheme \\
\hline Adj:Conj & Predicator & RESIDement \\
\hline & \multicolumn{2}{|c|}{ RESIDE } \\
\hline
\end{tabular}

KATNISS 58:

\section{Mockingjays.}




\begin{tabular}{|c|}
\hline Theme:top \\
\hline Subject \\
\hline MOOD \\
\hline
\end{tabular}

\begin{tabular}{|c|c|c|}
\hline That & 's & great. \\
\hline Theme:top & \multicolumn{2}{|c|}{ Rheme } \\
\hline Subject & Finite & Complement:Attributive \\
\hline \multicolumn{2}{|c|}{ MOOD } & RESIDUE \\
\hline
\end{tabular}

RUE 10:

\begin{tabular}{|c|c|c|c|c|c|}
\hline Back home & we & use & them & to signal & all the time. \\
\hline Theme:top & \multicolumn{5}{|c|}{ Rheme } \\
\hline Adj:Circ & Subject & Finite & Complement & Predicator & Adj:Circ \\
\hline RESIDUE... & \multicolumn{2}{|c|}{ MOOD } & \multicolumn{3}{|c}{...RESIDUE } \\
\hline
\end{tabular}

\begin{tabular}{|c|c|c|}
\hline You & \multicolumn{2}{|c|}{ try. } \\
\hline Theme:top & \multicolumn{2}{|c|}{ Rheme } \\
\hline Subject & Finite & Predicator \\
\hline \multicolumn{2}{|c|}{ MOOD } & RESIDUE \\
\hline
\end{tabular}

RUE 11:

\begin{tabular}{|c|}
\hline Okay. \\
\hline Minor clause \\
\hline
\end{tabular}

\begin{tabular}{|c|c|c|c|c|c|}
\hline So, & if we hear that & \multicolumn{1}{|c|}{ it } & \multicolumn{2}{|c|}{ means } & $\begin{array}{c}\text { we're okay and we'll } \\
\text { be back real soon. }\end{array}$ \\
\hline Theme:text & Theme:top & \multicolumn{4}{|c|}{ Rheme } \\
\hline Adj:Conj & Adj:Circ & Subject & Finite & Predicator & Complement \\
\hline
\end{tabular}




\begin{tabular}{|l|l|l|l|}
\hline & RESIDUE ... & MOOD & ...RESIDUE \\
\hline
\end{tabular}

KATNISS 59:

\begin{tabular}{|c|c|c|c|}
\hline We & 're & gonna be & \multicolumn{1}{c|}{ okay. } \\
\hline Theme:top & \multicolumn{3}{|c|}{ Rheme } \\
\hline Subject & Finite & Predicator & Complement:Attributive \\
\hline \multicolumn{2}{|c|}{ MOOD } & \multicolumn{2}{|c|}{ RESIDUE } \\
\hline
\end{tabular}

KATNISS 60:

\begin{tabular}{|c|c|c|c|c|c|}
\hline Hey, & I & 'll & see & you & for supper. \\
\hline Theme:text & Theme:top & \multicolumn{5}{|c|}{ Rheme } \\
\hline Adj:Cont & Subject & Finite & Predicator & Complement & Adj:Circ \\
\hline & \multicolumn{2}{|c|}{ MOOD } & \multicolumn{3}{|c}{ RESIDUE } \\
\hline
\end{tabular}

RUE 12:

\begin{tabular}{|c|}
\hline Okay. \\
\hline Minor clause \\
\hline
\end{tabular}

\section{Scene 12: Katniss, Rue}

KATNISS 61:

\begin{tabular}{|c|c|c|}
\hline It & 's & okay. \\
\hline Theme:top & \multicolumn{2}{|c|}{ Rheme } \\
\hline Subject & Finite & Complement:Attributive \\
\hline \multicolumn{3}{|c|}{ MOOD } \\
\hline
\end{tabular}

\begin{tabular}{|c|c|c|}
\hline You & 're & okay. \\
\hline Theme:top & \multicolumn{2}{|c|}{ Rheme } \\
\hline Subject & Finite & Complement:Attributive \\
\hline
\end{tabular}




\begin{tabular}{|l|l|}
\hline MOOD & RESIDUE \\
\hline
\end{tabular}

\begin{tabular}{|c|c|c|}
\hline You & 're & okay. \\
\hline Theme:top & \multicolumn{2}{|c|}{ Rheme } \\
\hline Subject & Finite & Complement:Attributive \\
\hline \multicolumn{2}{|c|}{ MOOD } & RESIDUE \\
\hline
\end{tabular}

\begin{tabular}{|c|c|c|}
\hline You & 're & okay. \\
\hline Theme:top & \multicolumn{2}{|c|}{ Rheme } \\
\hline Subject & Finite & Complement:Attributive \\
\hline \multicolumn{2}{|c|}{ MOOD } & RESIDUE \\
\hline
\end{tabular}

RUE 13:

\begin{tabular}{|c|c|c|c|}
\hline Did & you & blow up & the food? \\
\hline Theme:int & Theme:top & \multicolumn{2}{|c|}{ Rheme } \\
\hline Finite & Subject & Predicator & Complement \\
\hline \multicolumn{2}{|c|}{ MOOD } & \multicolumn{3}{|c|}{ RESIDUE } \\
\hline
\end{tabular}

\section{KATNISS 62:}

\begin{tabular}{|c|}
\hline Every bit of it. \\
\hline Theme:top \\
\hline Complement \\
\hline RESIDUE \\
\hline
\end{tabular}

RUE 14:

\begin{tabular}{|c|}
\hline Good. \\
\hline Minor clause \\
\hline
\end{tabular}




\begin{tabular}{|c|c|c|}
\hline You & have & to win. \\
\hline Theme:top & \multicolumn{2}{|c|}{ Rheme } \\
\hline Subject & Finite & Predicator \\
\hline \multicolumn{3}{|c|}{ MOOD } \\
\hline
\end{tabular}

RUE 15:

\begin{tabular}{|c|c|c|}
\hline Can & you & sing? \\
\hline Theme:int & Theme:top & Rheme \\
\hline Finite & Subject & Predicator \\
\hline \multicolumn{2}{c}{ MOOD } & RESIDUE \\
\hline
\end{tabular}

KATNISS 63:

\begin{tabular}{|c|}
\hline Okay. \\
\hline Theme:int \\
\hline Adj:Polarity \\
\hline MOOD \\
\hline
\end{tabular}

\section{Scene 13: Katniss, Peeta}

KATNISS 64:

\begin{tabular}{|c|c|c|}
\hline What & was & it? \\
\hline Theme:top & \multicolumn{2}{|c|}{ Rheme } \\
\hline WH/Complement & Finite & Subject \\
\hline RESIDUE & \multicolumn{2}{|c|}{ MOOD } \\
\hline
\end{tabular}

\section{PEETA 13:}

\begin{tabular}{|c|}
\hline A sword. \\
\hline Theme:top \\
\hline Complement \\
\hline
\end{tabular}




\begin{tabular}{|c|c|c|c|}
\hline \multicolumn{2}{|c|}{ RESIDUE } & \multirow[b]{2}{*}{ bad, } & \multirow[b]{2}{*}{ huh? } \\
\hline It & 's & & \\
\hline Theme:top & \multicolumn{3}{|c|}{ Rheme } \\
\hline Subject & Finite & Complement:Attributive & Adj:Cont \\
\hline \multicolumn{2}{|c|}{ MOOD } & \multicolumn{2}{|c|}{ RESIDUE } \\
\hline
\end{tabular}

KATNISS 65:

\begin{tabular}{|c|c|c|c|}
\hline It & 's & gonna be & \multicolumn{1}{c|}{ fine. } \\
\hline Theme:top & \multicolumn{3}{|c|}{ Rheme } \\
\hline Subject & Finite & Predicator & Complement:Attributive \\
\hline \multicolumn{2}{|c|}{ RESIDUE } \\
\hline
\end{tabular}

PEETA 14:

\begin{tabular}{|c|}
\hline Katniss. \\
\hline Minor clause \\
\hline
\end{tabular}

PEETA 15:

\begin{tabular}{|c|}
\hline Katniss. \\
\hline Minor clause \\
\hline
\end{tabular}

KATNISS 66:

\begin{tabular}{|c|c|c|c|}
\hline \multicolumn{2}{|c|}{ No! } & & \\
\hline \multicolumn{2}{|c|}{ Theme:int } & & \\
\hline \multicolumn{2}{|c|}{ Adj:Polarity } & & \\
\hline \multicolumn{2}{|c|}{ MOOD } & & \\
\hline I & 'm not & going to leave & you. \\
\hline Theme:top & & Rheme & \\
\hline
\end{tabular}




\begin{tabular}{|c|c|c|c|}
\hline Subject & Finite:Neg & Predicator & Complement \\
\hline \multicolumn{2}{|c|}{ MOOD } & \multicolumn{2}{|c|}{ RESIDUE } \\
\hline
\end{tabular}

\begin{tabular}{|c|c|c|c|}
\hline I & 'm not & going to do & that. \\
\hline Theme:top & & Rheme \\
\hline Subject & Finite:Neg & Predicator & Complement \\
\hline \multicolumn{3}{|c|}{ MOOD } & \multicolumn{2}{|c|}{ RESIDUE } \\
\hline
\end{tabular}

PEETA 16:

\begin{tabular}{|c|}
\hline Why not? \\
\hline Theme:top \\
\hline Adj:Circ \\
\hline RESIDUE \\
\hline
\end{tabular}

\section{Scene 14: Katniss, Peeta}

KATNISS 67:

\begin{tabular}{|c|c|c|c|c|}
\hline Nobody & 's & gonna find & you & in here. \\
\hline Theme:top & \multicolumn{4}{|c|}{ Rheme } \\
\hline Subject & Finite & Predicator & Complement & Adj:Circ \\
\hline \multicolumn{2}{|c|}{ MOOD } & \multicolumn{3}{|c|}{ RESIDUE } \\
\hline
\end{tabular}

PEETA 17:

\begin{tabular}{|c|c|c|c|c|}
\hline They & already & \multicolumn{2}{|c|}{ found } & me. \\
\hline Theme:top & \multicolumn{3}{|c|}{ Rheme } \\
\hline Subject & Adj:Mood & Finite & Predicator & Complement \\
\hline & MOOD & \multicolumn{2}{|c|}{ RESIDUE } \\
\hline
\end{tabular}

\section{KATNISS 68:}




\begin{tabular}{|c|c|c|c|c|c|}
\hline We & 'll & just & get & you & some medicine. \\
\hline Theme:top & \multicolumn{5}{c|}{ Rheme } \\
\hline Subject & Finite & Adj:Mood & Predicator & Complement & Complement \\
\hline \multicolumn{3}{|c|}{ MOOD } & \multicolumn{3}{c}{ RESIDUE } \\
\hline
\end{tabular}

PEETA 18:

\begin{tabular}{|c|c|c|c|}
\hline I & 'm not & gonna get & many parachutes. \\
\hline Theme:top & \multicolumn{3}{|c|}{ Rheme } \\
\hline Subject & Finite:Neg & Predicator & Complement \\
\hline \multicolumn{2}{|c|}{ ROOD } & \multicolumn{2}{c|}{ RESIDUE } \\
\hline
\end{tabular}

KATNISS 69:

\begin{tabular}{|c|c|c|c|c|}
\hline We & 'll & figure & something & out. \\
\hline Theme:top & \multicolumn{5}{|c|}{ Rheme } \\
\hline Subject & Finite & Predicator... & Complement & ...Predicator \\
\hline \multicolumn{2}{|c|}{ ROOD } & \multicolumn{3}{c}{ RESIDUE } \\
\hline
\end{tabular}

PEETA 19:

\begin{tabular}{|c|}
\hline Like what? \\
\hline Theme:top \\
\hline Adj:Circ \\
\hline RESIDUE \\
\hline
\end{tabular}

KATNISS 70:

\begin{tabular}{|c|}
\hline Something. \\
\hline Theme:top \\
\hline Subject \\
\hline MOOD \\
\hline
\end{tabular}


Scene 15: Katniss, Peeta

PEETA 20:

\begin{tabular}{|c|c|c|}
\hline That & 's & nice. \\
\hline Theme:top & \multicolumn{2}{|c|}{ Rheme } \\
\hline Subject & Finite & Complement:Attributive \\
\hline \multicolumn{2}{|c|}{ ROOD } & RESIDUE \\
\hline
\end{tabular}

KATNISS 71:

\begin{tabular}{|c|c|c|c|c|c|}
\hline Well, & you & \multicolumn{2}{c|}{ fed } & me & once. \\
\hline Theme:text & Theme:top & \multicolumn{3}{|c|}{ Rheme } \\
\hline Adj:Cont & Subject & Finite & Predicator & Complement & Adj:Circ \\
\hline & \multicolumn{2}{|c|}{ MOOD } & \multicolumn{3}{c}{ RESIDUE } \\
\hline
\end{tabular}

PEETA 21:

\begin{tabular}{|c|c|c|c|c|}
\hline I & \multicolumn{2}{|c|}{ think } & about that & all the time. \\
\hline Theme:top & \multicolumn{5}{|c|}{ Rheme } \\
\hline Subject & Finite & Predicator & Adj:Circ & Adj:Circ \\
\hline \multicolumn{2}{|c|}{ MOOD } & \multicolumn{3}{c}{ RESIDUE } \\
\hline
\end{tabular}

\section{How I tossed you that bread.}

\begin{tabular}{|c|}
\hline Theme:top \\
\hline Adj:Circ \\
\hline RESIDUE \\
\hline
\end{tabular}

KATNISS 72:

\begin{tabular}{|c|}
\hline Peeta! \\
\hline Minor clause \\
\hline
\end{tabular}


PEETA 22: Statement

\begin{tabular}{|c|c|c|c|}
\hline I & should & have gone & to you, \\
\hline Theme:top & \multicolumn{3}{|c|}{ Rheme } \\
\hline Subject & Finite & Predicator & Adj:Circ \\
\hline \multicolumn{2}{|c|}{ MOOD } & \multicolumn{2}{|c|}{ RESIDUE } \\
\hline
\end{tabular}

\begin{tabular}{|c|c|c|c|c|c|c|}
\hline I & should & have & just & gone & $\begin{array}{c}\text { out in } \\
\text { the rain }\end{array}$ & and... \\
\hline Theme:top & \multicolumn{5}{|c|}{ Rheme } \\
\hline Subject & Finite & Predicator... & Adj:Mood & ..Predicator & Adj:Circ & Adj:Conj \\
\hline \multicolumn{5}{|c|}{ RESIDUE } \\
\hline \multicolumn{2}{|c|}{ MOOD } & \multicolumn{5}{|c|}{ REST }
\end{tabular}

KATNISS 73:

\begin{tabular}{|c|}
\hline Ssh. \\
\hline Minor clause \\
\hline
\end{tabular}

Ssh.

Minor clause

KATNISS 74:

\begin{tabular}{|c|c|c|c|}
\hline You & \multicolumn{2}{|c|}{ feel } & hot. \\
\hline Theme:top & \multicolumn{3}{|c|}{ Rheme } \\
\hline Subject & Finite & Predicator & Complement:Attributive \\
\hline \multicolumn{2}{|c|}{ MOOD } & & RESIDUE \\
\hline
\end{tabular}

PEETA 23:

\begin{tabular}{|c|c|}
\hline I remember & the first time I saw you. \\
\hline Theme:int & Theme:top \\
\hline Adj:Mood & Adj:Circ \\
\hline
\end{tabular}




\begin{tabular}{|c|c|c|}
\hline MOOD & RESIDI & \\
\hline Your hair & was & in two braids instead of one. \\
\hline Theme:top & \multicolumn{2}{|c|}{ Rheme } \\
\hline Subject & Finite & Adj:Circ \\
\hline \multicolumn{2}{|c|}{ MOOD } & RESIDUE \\
\hline
\end{tabular}

\begin{tabular}{|c|c|c|}
\hline And & I remember & when you... you sang in music assembly, \\
\hline Theme:text & Theme:int & Theme:top \\
\hline Adj:Conj & Adj:Mood & WH/Adj:Circ \\
\hline & MOOD & RESIDUE \\
\hline
\end{tabular}

\begin{tabular}{|c|c|c|c|}
\hline the teacher & \multicolumn{2}{|c|}{ said; } & who knows The Valley Song? \\
\hline Theme:top & \multicolumn{3}{|c|}{ Rheme } \\
\hline Subject & Finite & Predicator & Complement \\
\hline MOOD & \multicolumn{3}{c}{ RESIDUE } \\
\hline
\end{tabular}

\begin{tabular}{|c|c|c|c|c|}
\hline And & your hand & \multicolumn{2}{c|}{ shot } & straight up. \\
\hline Theme:text & Theme:top & \multicolumn{3}{|c|}{ Rheme } \\
\hline Adj:Conj & Subject & Finite & Predicator & Adj:Circ \\
\hline & \multicolumn{2}{|c|}{ MOOD } & \multicolumn{2}{c|}{ RESIDUE } \\
\hline
\end{tabular}

KATNISS 75:

\begin{tabular}{|c|c|}
\hline Peeta, & stop. \\
\hline Theme:int & Theme:top \\
\hline Adj:Vocative & Predicator \\
\hline & RESIDUE \\
\hline
\end{tabular}


PEETA 24:

\begin{tabular}{|c|c|c|c|c|c|c|}
\hline After that, & I & watched & you & going & home & every day. \\
\hline Theme:top & \multicolumn{5}{|c|}{ Rheme } \\
\hline Adj:Circ & Subject & Finite & Complement & Predicator & Adj:Circ & Adj:Circ \\
\hline RESIDUE... & \multicolumn{2}{|c|}{ MOOD } & \multicolumn{5}{|c|}{..RESIDUE } \\
\hline
\end{tabular}

\begin{tabular}{|c|}
\hline Every day. \\
\hline Theme:top \\
\hline Adj:Circ \\
\hline RESIDUE \\
\hline
\end{tabular}

PEETA 25:

\begin{tabular}{|c|c|c|}
\hline Well, & say & something. \\
\hline Theme:text & Theme:top & Rheme \\
\hline Adj:Cont & Predicator & Complement \\
\hline & \multicolumn{2}{|c|}{ RESIDUE } \\
\hline
\end{tabular}

\section{KATNISS 76:}

\begin{tabular}{|c|c|c|c|}
\hline I & 'm not & good & at saying something. \\
\hline Theme:top & \multicolumn{3}{|c|}{ Rheme } \\
\hline Subject & Finite:Neg & Complement:Attributive & Adj:Circ \\
\hline \multicolumn{2}{|c|}{ MOOD } & RESIDUE \\
\hline
\end{tabular}

PEETA 26:

\begin{tabular}{|c|c|c|}
\hline Then & come & here. \\
\hline Theme:text & Theme:top & Rheme \\
\hline Adj:Cont & Predicator & Adj:Circ \\
\hline
\end{tabular}




\begin{tabular}{|c|c|}
\hline & RESIDUE \\
\hline
\end{tabular}

Please.

Minor clause

PEETA 27:

\begin{tabular}{|c|c|}
\hline Even & if I don't make it... \\
\hline Theme:int & Theme:top \\
\hline Adj:Mood & Adj:Circ \\
\hline MOOD & RESIDUE \\
\hline
\end{tabular}

KATNISS 77:

\begin{tabular}{|c|}
\hline Ssh! \\
\hline Minor clause \\
\hline
\end{tabular}

\section{Scene 16: Katniss, Peeta}

KATNISS 78:

\begin{tabular}{|c|}
\hline Your medicine. \\
\hline Theme:top \\
\hline Subject \\
\hline MOOD \\
\hline
\end{tabular}

PEETA 28:

\begin{tabular}{|c|c|c|c|}
\hline You & 're not & going & alone. \\
\hline Theme:top & \multicolumn{3}{|c|}{ Rheme } \\
\hline Subject & Finite:Neg & Predicator & Complement:Attributive \\
\hline \multicolumn{2}{|c|}{ MOOD } & \multicolumn{2}{|c|}{ RESIDUE } \\
\hline
\end{tabular}

KATNISS 79: 


\begin{tabular}{|c|c|c|c|c|}
\hline Yeah, & you & \multicolumn{2}{|c|}{ need } & it \\
\hline Theme:int & Theme:top & \multicolumn{3}{|c|}{ Rheme } \\
\hline Adj:Polarity & Subject & Finite & Predicator & Complement \\
\hline \multicolumn{3}{|c|}{ MOOD } & \multicolumn{2}{|c|}{ RESIDUE } \\
\hline
\end{tabular}

\begin{tabular}{|c|c|c|c|}
\hline and & you & can't & walk. \\
\hline Theme:text & Theme:top & \multicolumn{2}{|c|}{ Rheme } \\
\hline Adj:Cont & Subject & Finite:Neg & Predicator \\
\hline & \multicolumn{2}{|c|}{ MOOD } & RESIDUE \\
\hline
\end{tabular}

\section{PEETA 29:}

\begin{tabular}{|c|c|c|c|c|c|}
\hline Katniss, & you & 're not & $\begin{array}{c}\text { going to } \\
\text { risk }\end{array}$ & your life & for me. \\
\hline Theme:int & Theme:top & & \multicolumn{2}{c|}{ Rheme } \\
\hline Adj:Vocative & Subject & Finite:Neg & Predicator & Complement & Adj:Circ \\
\hline & \multicolumn{2}{|c|}{ MOOD } & \multicolumn{3}{c|}{ RESIDUE } \\
\hline
\end{tabular}

\begin{tabular}{|c|c|c|c|}
\hline I & 'm not & going to let & you. \\
\hline Theme:top & & \multicolumn{3}{|c|}{ Rheme } \\
\hline Subject & Finite:Neg & Predicator & Complement \\
\hline \multicolumn{2}{|c|}{ MOOD } & \multicolumn{2}{|c|}{ RESIDUE } \\
\hline
\end{tabular}

KATNISS 80:

\begin{tabular}{|c|c|c|c|c|}
\hline You & would & do & it & for me. \\
\hline Theme:top & \multicolumn{4}{|c|}{ Rheme } \\
\hline Subject & Finite & Predicator & Complement & Adj:Circ \\
\hline \multicolumn{2}{|c|}{ MOOD $\ldots$} & \multicolumn{3}{|c|}{ RESIDUE } \\
\hline
\end{tabular}




\begin{tabular}{|c|c|}
\hline Wouldn't & you? \\
\hline Theme:int & Theme:top \\
\hline Finite:Neg & Subject \\
\hline \multicolumn{2}{|c|}{ MOOD } \\
\hline
\end{tabular}

PEETA 30:

\begin{tabular}{|c|c|c|c|c|}
\hline Why & are & you & doing & this? \\
\hline Theme:top & \multicolumn{4}{|c|}{ Rheme } \\
\hline WH/Adj:Circ & Finite & Subject & Predicator & Complement \\
\hline RESIDUE... & \multicolumn{2}{|c|}{ MOOD } & ...RESIDUE \\
\hline
\end{tabular}

PEETA 31:

\begin{tabular}{|c|c|c|c|}
\hline Now & there & 's & no way I'm letting you go. \\
\hline Theme:top & \multicolumn{3}{|c|}{ Rheme } \\
\hline Adj:Circ & Subject & Finite & Complement \\
\hline RESIDUE... & \multicolumn{2}{|c|}{ MOOD } & ... RESIDUE \\
\hline
\end{tabular}

KATNISS 81:

\begin{tabular}{|c|}
\hline Peeta. \\
\hline Minor clause \\
\hline
\end{tabular}

PEETA 32:

\begin{tabular}{|c|}
\hline Please. \\
\hline Minor clause \\
\hline
\end{tabular}

\begin{tabular}{|c|}
\hline Stay. \\
\hline Theme:top \\
\hline Predicator \\
\hline
\end{tabular}


RESIDUE

KATNISS 82:

\begin{tabular}{|c|}
\hline Okay. \\
\hline Minor clause \\
\hline
\end{tabular}

\begin{tabular}{|c|c|c|}
\hline I & 'Il & stay. \\
\hline Theme:top & \multicolumn{2}{|c|}{ Rheme } \\
\hline Subject & Finite & Predicator \\
\hline \multicolumn{3}{|c|}{ MOOD } \\
\hline
\end{tabular}

\section{$\underline{\text { Scene 17: Clove, Thresh (Katniss) }}$}

CLOVE 1:

\begin{tabular}{|c|c|c|}
\hline Where & 's & lover boy? \\
\hline Theme:top & \multicolumn{3}{|c|}{ Rheme } \\
\hline WH/Subject & Finite & Complement \\
\hline \multicolumn{3}{|c|}{ MOOD } \\
\hline
\end{tabular}

\begin{tabular}{|c|c|c|c|}
\hline Oh, & I & \multicolumn{2}{|c|}{ see. } \\
\hline Theme:text & Theme:top & \multicolumn{2}{|c|}{ Rheme } \\
\hline Adj:Cont & Subject & Finite & Predicator \\
\hline & \multicolumn{2}{|c|}{ MOOD } & RESIDUE \\
\hline
\end{tabular}

\begin{tabular}{|c|c|c|c|}
\hline You & were & going to help & him. \\
\hline Theme:top & & \multicolumn{3}{|c|}{ Rheme } \\
\hline Subject & Finite & Predicator & Complement \\
\hline \multicolumn{2}{|c|}{ MOOD } & \multicolumn{2}{c|}{ RESIDUE } \\
\hline
\end{tabular}




\begin{tabular}{|c|c|c|c|}
\hline Well & that & 's & sweet! \\
\hline Theme:text & Theme:top & \multicolumn{2}{c|}{ Rheme } \\
\hline Adj:Cont & Subject & Finite & Complement:Attributive \\
\hline & \multicolumn{2}{|c|}{ MOOD } & RESIDUE \\
\hline
\end{tabular}

\begin{tabular}{|c|c|c|c|c|}
\hline Well, & it & 's & too bad & $\begin{array}{c}\text { that you couldn't help } \\
\text { your little friend. }\end{array}$ \\
\hline Theme:text & Theme:top & \multicolumn{3}{|c|}{ Rheme } \\
\hline Adj:Cont & Subject & Finite & Complement:Attributive & Adj:Circ \\
\hline & \multicolumn{2}{|c|}{ MOOD } & \multicolumn{2}{|c|}{ RESIDUE } \\
\hline
\end{tabular}

\begin{tabular}{|c|c|c|c|c|}
\hline That little girl, & what & was & her name & again? \\
\hline Theme:int & Theme:top & & \multicolumn{2}{c|}{ Rheme } \\
\hline Adj:Vocative & WH/Subject & Finite & Complement & Adj:Circ \\
\hline & \multicolumn{2}{|c|}{ MOOD } & \multicolumn{2}{c|}{ RESIDUE } \\
\hline
\end{tabular}

\begin{tabular}{|c|}
\hline Rue? \\
\hline Minor clause \\
\hline
\end{tabular}

\begin{tabular}{|c|c|c|c|c|c|}
\hline Yeah, & well & we & \multicolumn{2}{|c|}{ killed } & her. \\
\hline Theme:text & Theme:text & Theme:top & \multicolumn{3}{|c|}{ Rheme } \\
\hline Adj:Cont & Adj:Cont & Subject & Finite & Predicator & Complement \\
\hline & & \multicolumn{2}{|c|}{ MOOD } & \multicolumn{2}{|c|}{ RESIDUE } \\
\hline
\end{tabular}

\begin{tabular}{|c|c|c|c|c|c|c|}
\hline And & now, & we & 're & gonna kill & you & too. \\
\hline Theme:text & Theme:top & \multicolumn{5}{|c|}{ Rheme } \\
\hline Adj:Cont & Adj:Circ & Subject & Finite & Predicator & Complement & Adj:Circ \\
\hline
\end{tabular}




\begin{tabular}{|l|l|l|l|}
\hline & RESIDUE $\ldots$ & MOOD & ...RESIDUE \\
\hline
\end{tabular}

THRESH 1:

\begin{tabular}{|c|c|c|c|}
\hline You & \multicolumn{2}{|c|}{ killed } & her? \\
\hline Theme:top & \multicolumn{3}{|c|}{ Rheme } \\
\hline Subject & Finite & Predicator & Complement \\
\hline \multicolumn{2}{|c|}{ MOOD } & \multicolumn{2}{|c|}{ RESIDUE } \\
\hline
\end{tabular}

CLOVE 2:

\begin{tabular}{|c|}
\hline No! \\
\hline Theme:int \\
\hline Adj:Polarity \\
\hline MOOD \\
\hline
\end{tabular}

\section{THRESH 2:}

\begin{tabular}{|c|c|c|c|}
\hline I & \multicolumn{2}{|c|}{ heard } & you! \\
\hline Theme:top & \multicolumn{3}{|c|}{ Rheme } \\
\hline Subject & Finite & Predicator & Complement \\
\hline \multicolumn{2}{|c|}{ MOOD } & \multicolumn{2}{|c|}{ RESIDUE } \\
\hline
\end{tabular}

CLOVE 3:

\begin{tabular}{|c|}
\hline Cato! \\
\hline Theme:int \\
\hline Adj:Vocative \\
\hline RESIDUE \\
\hline
\end{tabular}

\section{THRESH 3:}

\begin{tabular}{|c|c|c|}
\hline You & said & her name! \\
\hline Theme:top & \multicolumn{3}{|c|}{ Rheme } \\
\hline
\end{tabular}




\begin{tabular}{|c|c|c|c|}
\hline Subject & Finite & Predicator & Complement \\
\hline \multicolumn{2}{|c|}{ MOOD } & \multicolumn{2}{c|}{ RESIDUE } \\
\hline
\end{tabular}

CLOVE 4:

\begin{tabular}{|c|}
\hline Cato! \\
\hline Theme:int \\
\hline Adj:Vocative \\
\hline MOOD \\
\hline
\end{tabular}

\section{THRESH 4:}

\begin{tabular}{|c|c|c|c|}
\hline You & \multicolumn{2}{|c|}{ said } & her name! \\
\hline Theme:top & \multicolumn{3}{|c|}{ Rheme } \\
\hline Subject & Finite & Predicator & Complement \\
\hline \multicolumn{2}{|c|}{ MOOD } & \multicolumn{2}{|c|}{ RESIDUE } \\
\hline
\end{tabular}

\section{THRESH 5:}

\begin{tabular}{|c|c|c|}
\hline Just & this time, & Twelve. \\
\hline Theme:int & Theme:top & Rheme \\
\hline Adj:Mood & Adj:Circ & Adj:Vocative \\
\hline \multicolumn{3}{|c}{ Minor clause } \\
\hline
\end{tabular}

\begin{tabular}{|c|}
\hline For Rue. \\
\hline Theme:top \\
\hline Adj:Circ \\
\hline RESIDUE \\
\hline
\end{tabular}

\section{$\underline{\text { Scene 18: Katniss, Peeta }}$}

\section{KATNISS 83:}




\begin{tabular}{|c|c|c|c|c|}
\hline Peeta, & I & \multicolumn{2}{|c|}{ got } & it. \\
\hline Theme:int & Theme:top & \multicolumn{3}{|c|}{ Rheme } \\
\hline Adj:Vocative & Subject & Finite & Predicator & Complement \\
\hline & \multicolumn{2}{|c|}{ MOOD } & \multicolumn{2}{|c|}{ RESIDUE } \\
\hline
\end{tabular}

\begin{tabular}{|c|c|c|c|}
\hline I & \multicolumn{2}{|c|}{ got } & the medicine \\
\hline Theme:top & \multicolumn{3}{|c|}{ Rheme } \\
\hline Subject & Finite & Predicator & Complement \\
\hline \multicolumn{2}{|c|}{ MOOD } & \multicolumn{2}{|c|}{ RESIDUE } \\
\hline
\end{tabular}

PEETA 33:

\begin{tabular}{|c|c|c|c|}
\hline What & \multicolumn{2}{|c|}{ happened } & to you? \\
\hline Theme:top & \multicolumn{3}{|c|}{ Rheme } \\
\hline WH/Subject & Finite & Predicator & Adj:Circ \\
\hline \multicolumn{2}{|c|}{ MOOD } & & \multicolumn{2}{|c|}{ RESIDUE } \\
\hline
\end{tabular}

KATNISS 84:

\begin{tabular}{|c|c|c|}
\hline I & 'm & fine. \\
\hline Theme:top & \multicolumn{2}{|c|}{ Rheme } \\
\hline Subject & Finite & Complement:Attributive \\
\hline \multicolumn{2}{|c|}{ MOOD } & RESIDUE \\
\hline
\end{tabular}

PEETA 34:

\begin{tabular}{|c|c|c|}
\hline No, & you & 're not. \\
\hline Theme:int & Theme:top & Rheme \\
\hline Adj:Polarity & Subject & Finite:Neg \\
\hline \multicolumn{3}{|c}{} \\
\hline
\end{tabular}




\begin{tabular}{|c|c|c|}
\hline What & \multicolumn{2}{|c|}{ happened? } \\
\hline Theme:top & \multicolumn{2}{|c|}{ Rheme } \\
\hline WH/Subject & Finite & Predicator \\
\hline \multicolumn{2}{|c|}{ MOOD } & \\
\hline
\end{tabular}

KATNISS 85:

\begin{tabular}{|c|c|c|c|c|}
\hline The girl from 2, & she & \multicolumn{2}{|c|}{ threw } & a knife, \\
\hline Theme:top & \multicolumn{4}{|c|}{ Rheme } \\
\hline Adj:Vocative & Subject & Finite & Predicator & Complement \\
\hline RESIDUE & \multicolumn{2}{|c|}{ MOOD } & \multicolumn{3}{|c|}{ RESIDUE } \\
\hline
\end{tabular}

\begin{tabular}{|c|c|c|c|}
\hline but & I & 'm & okay. \\
\hline Theme:text & Theme:top & \multicolumn{2}{c|}{ Rheme } \\
\hline Adj:Conj & Subject & Finite & Complement:Attributive \\
\hline & \multicolumn{2}{|c|}{ MOOD } & RESIDUE \\
\hline
\end{tabular}

PEETA 35:

\begin{tabular}{|c|c|c|}
\hline You & shouldn't & have gone, \\
\hline Theme:top & \multicolumn{2}{|c|}{ Rheme } \\
\hline Subject & Finite:Neg & Predicator \\
\hline \multicolumn{2}{|c|}{ MOOD } & RESIDUE \\
\hline
\end{tabular}

\begin{tabular}{|c|c|c|c|}
\hline you said & you & weren't & gonna go. \\
\hline Theme:int & Theme:top & \multicolumn{2}{|c|}{ Rheme } \\
\hline Adj:Mood & Subject & Finite:Neg & Predicator \\
\hline \multicolumn{3}{|c|}{ MOOD } & RESIDUE \\
\hline
\end{tabular}

\section{KATNISS 86:}




\begin{tabular}{|c|c|c|c|}
\hline You & \multicolumn{2}{|c|}{ got } & worse. \\
\hline Theme:top & \multicolumn{3}{|c|}{ Rheme } \\
\hline Subject & Finite & Predicator & Complement:Attributive \\
\hline \multicolumn{2}{|c|}{ MOOD } & & \multicolumn{2}{|c|}{ RESIDUE } \\
\hline
\end{tabular}

PEETA 36:

\begin{tabular}{|c|c|c|c|c|}
\hline You & \multicolumn{2}{|c|}{ need } & some of that & too. \\
\hline Theme:top & \multicolumn{4}{|c|}{ Rheme } \\
\hline Subject & Finite & Predicator & Complement & Adj:Circ \\
\hline MOOD & & \multicolumn{3}{c}{ RESIDUE } \\
\hline
\end{tabular}

KATNISS 87:

\begin{tabular}{|c|c|c|}
\hline I & 'm & okay. \\
\hline Theme:top & \multicolumn{2}{|c|}{ Rheme } \\
\hline Subject & Finite & Complement:Attributive \\
\hline \multicolumn{2}{|c|}{ MOOD } & RESIDUE \\
\hline
\end{tabular}

PEETA 37:

\begin{tabular}{|c|c|c|c|}
\hline That & \multicolumn{2}{|c|}{ feels } & better. \\
\hline Theme:top & \multicolumn{3}{|c|}{ Rheme } \\
\hline Subject & Finite & Predicator & Complement:Attributive \\
\hline \multicolumn{2}{|c|}{ MOOD } & & RESIDUE \\
\hline
\end{tabular}

PEETA 37:

\begin{tabular}{|c|c|c|}
\hline Okay, & now & you. \\
\hline Theme:text & Theme:top & Rheme \\
\hline Adj:Cont & Adj:Circ & Subject \\
\hline & RESIDUE & MOOD \\
\hline
\end{tabular}


KATNISS 88:

\begin{tabular}{|c|c|c|}
\hline I & 'm & okay. \\
\hline Theme:top & \multicolumn{2}{|c|}{ Rheme } \\
\hline Subject & Finite & Complement:Attributive \\
\hline \multicolumn{3}{|c|}{ MOOD } \\
\hline
\end{tabular}

PEETA 38:

\begin{tabular}{|c|l|}
\hline No, & come on. \\
\hline Theme:int & Theme:top \\
\hline Adj:Polarity & Predicator \\
\hline MOOD & RESIDUE \\
\hline
\end{tabular}

PEETA 38:

\begin{tabular}{|c|c|c|c|c|}
\hline You & \multicolumn{2}{|c|}{ need } & it & too. \\
\hline Theme:top & \multicolumn{3}{|c|}{ Rheme } \\
\hline Subject & Finite & Predicator & Complement & Adj:Circ \\
\hline \multicolumn{2}{|c|}{ MOOD } & \multicolumn{3}{|c}{ RESIDUE } \\
\hline
\end{tabular}

\begin{tabular}{|l|}
\hline Come on. \\
\hline Theme:top \\
\hline Predicator \\
\hline RESIDUE \\
\hline
\end{tabular}

KATNISS 89:

\begin{tabular}{|c|}
\hline Alright. \\
\hline Minor clause \\
\hline
\end{tabular}

KATNISS 90: 


\begin{tabular}{|c|}
\hline Oh, my God, Peeta! \\
\hline Minor clause \\
\hline
\end{tabular}

PEETA 39:

\begin{tabular}{|c|c|c|c|c|}
\hline I & can & hardly & feel & anything! \\
\hline Theme:top & & \multicolumn{3}{|c|}{ Rheme } \\
\hline Subject & Finite & Adj:Mood & Predicator & Complement \\
\hline \multicolumn{5}{|c|}{ MOOD } \\
\hline
\end{tabular}

\section{KATNISS 91:}

\begin{tabular}{|c|c|c|c|}
\hline We & could & go & home. \\
\hline Theme:top & \multicolumn{3}{|c|}{ Rheme } \\
\hline Subject & Finite & Predicator & Complement \\
\hline \multicolumn{2}{|c|}{ MOOD } & \multicolumn{2}{c|}{ RESIDUE } \\
\hline
\end{tabular}

\begin{tabular}{|c|c|c|}
\hline We & \multicolumn{2}{|c|}{ could. } \\
\hline Theme:top & \multicolumn{2}{|c|}{ Rheme } \\
\hline Subject & Finite & Predicator \\
\hline \multicolumn{2}{|c|}{ MOOD } & RESIDUE \\
\hline
\end{tabular}

\begin{tabular}{|c|c|c|}
\hline We & 're & the only team left. \\
\hline Theme:top & \multicolumn{2}{|c|}{ Rheme } \\
\hline Subject & Finite & Complement \\
\hline \multicolumn{2}{|c|}{ ROOD } & RESIDUE \\
\hline
\end{tabular}

PEETA 40:

\begin{tabular}{|c|c|c|c|}
\hline We & could & go & home. \\
\hline Theme:top & \multicolumn{3}{|c|}{ Rheme } \\
\hline
\end{tabular}




\begin{tabular}{|c|c|c|c|}
\hline Subject & Finite & Predicator & Complement \\
\hline \multicolumn{2}{|c|}{ MOOD } & \multicolumn{2}{c|}{ RESIDUE } \\
\hline
\end{tabular}

\section{Scene 19: Katniss, Peeta}

PEETA 41:

\begin{tabular}{|c|c|c|c|}
\hline We know & Thresh & \multicolumn{2}{|c|}{ took off. } \\
\hline Theme:int & Theme:top & \multicolumn{2}{|c|}{ Rheme } \\
\hline Adj:Mood & Subject & Finite & Predicator \\
\hline \multicolumn{3}{|c|}{ MOOD } & RESIDUE \\
\hline
\end{tabular}

\begin{tabular}{|c|c|c|c|}
\hline Cato & 's & gonna be & by the Cornucopia, \\
\hline Theme:top & \multicolumn{3}{|c|}{ Rheme } \\
\hline Subject & Finite & Predicator & Adj:Circ \\
\hline \multicolumn{2}{|c|}{ MOOD } & \multicolumn{2}{|c|}{ RESIDUE } \\
\hline
\end{tabular}

\begin{tabular}{|c|c|c|c|}
\hline he & 's not & gonna go & someplace he doesn't know. \\
\hline Theme:top & \multicolumn{3}{|c|}{ Rheme } \\
\hline Subject & Finite:Neg & Predicator & Complement \\
\hline \multicolumn{2}{|c|}{ ROOD } & & RESIDUE \\
\hline
\end{tabular}

\begin{tabular}{|c|c|c|c|l|}
\hline Foxface, & she & could & be & anywhere. \\
\hline Theme:top & \multicolumn{4}{|c|}{ Rheme } \\
\hline Adj:Vocative & Subject & Finite & Predicator & Complement \\
\hline & \multicolumn{3}{|c|}{ MOOD } & \multicolumn{2}{c|}{ RESIDUE } \\
\hline
\end{tabular}

KATNISS 92:

We should probably

hunt around here. 


\begin{tabular}{|c|c|c|c|c|}
\hline Theme:top & \multicolumn{3}{|c|}{ Rheme } \\
\hline Subject & Finite & Adj:Mood & Predicator & Adj:Circ \\
\hline \multicolumn{3}{|c|}{ MOOD } & \multicolumn{2}{c|}{ RESIDUE } \\
\hline
\end{tabular}

\begin{tabular}{|c|c|c|c|}
\hline We & don't & have & any food left. \\
\hline Theme:top & & \multicolumn{3}{|c|}{ Rheme } \\
\hline Subject & Finite:Neg & Predicator & Complement \\
\hline \multicolumn{2}{|c|}{ MOOD } & \multicolumn{2}{c|}{ RESIDUE } \\
\hline
\end{tabular}

\section{PEETA 42:}

\begin{tabular}{|c|c|c|c|}
\hline \multicolumn{2}{|c|}{ Okay. } & & \\
\hline \multicolumn{4}{|c|}{ Minor clause } \\
\hline I & 'Il & take & the bow. \\
\hline Theme:top & \multicolumn{3}{|c|}{ Rheme } \\
\hline Subject & Finite & Predicator & Complement \\
\hline \multicolumn{2}{|c|}{ MOOD } & \multicolumn{2}{|c|}{ RESIDUE } \\
\hline
\end{tabular}

\section{PEETA 43:}

\begin{tabular}{|c|c|c|c|}
\hline I & 'm & just & kidding. \\
\hline Theme:top & \multicolumn{3}{|c|}{ Rheme } \\
\hline Subject & Finite & Adj:Mood & Predicator \\
\hline \multicolumn{3}{|c|}{ MOOD } & RESIDUE \\
\hline
\end{tabular}

\begin{tabular}{|c|c|c|c|}
\hline I & 'll & go locate & some stuff. \\
\hline Theme:top & \multicolumn{3}{|c|}{ Rheme } \\
\hline Subject & Finite & Predicator & Complement \\
\hline
\end{tabular}




\begin{tabular}{|l|l|}
\hline MOOD & RESIDUE \\
\hline
\end{tabular}

\section{Scene 20: Katniss, Peeta}

PEETA 44:

\begin{tabular}{|c|c|}
\hline You & okay? \\
\hline Theme:top & Rheme \\
\hline Subject & Complement:Attributive \\
\hline MOOD & RESIDUE \\
\hline
\end{tabular}

KATNISS 93:

\begin{tabular}{|c|c|c|c|}
\hline I & \multicolumn{2}{|c|}{ heard } & the cannon! \\
\hline Theme:top & \multicolumn{3}{|c|}{ Rheme } \\
\hline Subject & Finite & Predicator & Complement \\
\hline \multicolumn{2}{|c|}{ MOOD } & \multicolumn{2}{|c|}{ RESIDUE } \\
\hline
\end{tabular}

\section{KATNISS 94:}

\begin{tabular}{|c|c|c|c|}
\hline That & 's & nightlock, & Peeta! \\
\hline Theme:top & & \multicolumn{3}{|c|}{ Rheme } \\
\hline Subject & Finite & Complement & Adj:Vocative \\
\hline \multicolumn{2}{|c|}{ MOOD } & \multicolumn{2}{c|}{ RESIDUE } \\
\hline
\end{tabular}

KATNISS 95:

\begin{tabular}{|c|c|c|c|c|}
\hline You & 'd & be & dead & in a minute! \\
\hline Theme:top & \multicolumn{3}{|c|}{ Rheme } \\
\hline Subject & Finite & Predicator & Complement:Attributive & Adj:Circ \\
\hline \multicolumn{2}{|c|}{ MOOD } & \multicolumn{3}{|c|}{ RESIDUE } \\
\hline
\end{tabular}

PEETA 45:

\begin{tabular}{l|l|l} 
I & didn't & know.
\end{tabular}




\begin{tabular}{|c|c|c|}
\hline Theme:top & \multicolumn{2}{|c|}{ Rheme } \\
\hline Subject & Finite:Neg & Predicator \\
\hline \multicolumn{2}{|c|}{ MOOD } & RESIDUE \\
\hline
\end{tabular}

KATNISS 96:

\begin{tabular}{|c|c|c|c|c|}
\hline You & \multicolumn{2}{|c|}{ scared } & me & to death. \\
\hline Theme:top & \multicolumn{3}{|c|}{ Rheme } \\
\hline Subject & Finite & Predicator & Complement & Adj:Circ \\
\hline \multicolumn{2}{|c|}{ MOOD } & \multicolumn{3}{|c}{ RESIDUE } \\
\hline
\end{tabular}

\begin{tabular}{|c|c|c|}
\hline \multicolumn{2}{|c|}{ Damn } & you! \\
\hline \multicolumn{2}{|c|}{ Theme:top } & Rheme \\
\hline Finite & Predicator & Complement \\
\hline MOOD & & RESIDUE \\
\hline
\end{tabular}

PEETA 46:

\begin{tabular}{|c|c|c|}
\hline I & 'm & sorry. \\
\hline Theme:top & \multicolumn{2}{|c|}{ Rheme } \\
\hline Subject & Finite & Complement:Attributive \\
\hline \multicolumn{2}{|c|}{ MOOD } & RESIDUE \\
\hline
\end{tabular}

\begin{tabular}{|c|c|c|}
\hline I & 'm & sorry. \\
\hline Theme:top & \multicolumn{2}{|c|}{ Rheme } \\
\hline Subject & Finite & Complement:Attributive \\
\hline \multicolumn{2}{|c|}{ MOOD } & RESIDUE \\
\hline
\end{tabular}

\section{$\underline{\text { Scene 21: Katniss, Peeta }}$}

PEETA 47: 


\begin{tabular}{|c|c|c|c|c|}
\hline I never even knew & she & was & following & me. \\
\hline Theme:int & Theme:top & \multicolumn{3}{|c|}{ Rheme } \\
\hline Adj:Mood:Neg & Subject & Finite & Predicator & Complement \\
\hline \multicolumn{3}{|c|}{ MOOD } & \multicolumn{2}{|c|}{ RESIDUE } \\
\hline
\end{tabular}

KATNISS 97:

\begin{tabular}{|c|c|c|}
\hline She & was & clever. \\
\hline Theme:top & \multicolumn{2}{|c|}{ Rheme } \\
\hline Subject & Finite & Complement:Attributive \\
\hline \multicolumn{2}{|c|}{ MOOD } & RESIDUE \\
\hline
\end{tabular}

PEETA 48:

\begin{tabular}{|c|}
\hline Too clever. \\
\hline Rheme \\
\hline Complement:Attributive \\
\hline RESIDUE \\
\hline
\end{tabular}

PEETA 49:

\begin{tabular}{|c|c|c|c|}
\hline What & are & you & doing? \\
\hline Theme:top & \multicolumn{3}{|c|}{ Rheme } \\
\hline Subject & Finite & Complement & Predicator \\
\hline \multicolumn{2}{|c|}{ ROOD } & RESIDUE \\
\hline
\end{tabular}

\section{KATNISS 98:}

\begin{tabular}{|c|c|c|c|c|c|}
\hline Maybe & Cato & \multicolumn{2}{c|}{ likes } & berries & too. \\
\hline Theme:int & Theme:top & \multicolumn{3}{c|}{ Rheme } \\
\hline Adj:Mood & Subject & Finite & Predicator & Complement & Adj:Circ \\
\hline \multicolumn{3}{|c|}{ MOOD } & & \multicolumn{3}{c}{ RESIDUE } \\
\hline
\end{tabular}


Scene 22: Katniss, Peeta, Cato

PEETA 50:

\begin{tabular}{|c|c|c|}
\hline What time & is & it? \\
\hline Theme:top & \multicolumn{2}{|c|}{ Rheme } \\
\hline WH/Complement & Finite & Subject \\
\hline RESIDUE & \multicolumn{2}{|c|}{ MOOD } \\
\hline
\end{tabular}

KATNISS 99:

\begin{tabular}{|c|}
\hline A little after noon. \\
\hline Theme:top \\
\hline Adj:Circ \\
\hline RESIDUE \\
\hline
\end{tabular}

PEETA 51:

\begin{tabular}{|c|c|c|c|c|}
\hline Why & is & it & getting & so dark? \\
\hline Theme:top & \multicolumn{4}{|c|}{ Rheme } \\
\hline WH/Adj:Circ & Finite & Subject & Predicator & Complement:Attributive \\
\hline RESIDUE... & \multicolumn{2}{|c|}{ MOOD } & \multicolumn{2}{|c|}{...RESIDUE } \\
\hline
\end{tabular}

KATNISS 100:

\begin{tabular}{|c|c|c|c|c|c|}
\hline They & \multicolumn{1}{|c|}{ must } & be & in a hurry & to end & it. \\
\hline Theme:top & \multicolumn{5}{|c|}{ Rheme } \\
\hline Subject & Adj:Mood & Finite & Adj:Circ & Predicator & Complement \\
\hline \multicolumn{5}{|c|}{ MOOD } & \multicolumn{3}{c|}{ RESIDUE } \\
\hline
\end{tabular}

CATO 2:

\begin{tabular}{|c|c|}
\hline Go on, & shoot. \\
\hline Theme:int & Theme:top \\
\hline
\end{tabular}




\begin{tabular}{|c|l|}
\hline Finite & Predicator \\
\hline MOOD & RESIDUE \\
\hline
\end{tabular}

CATO 2:

\begin{tabular}{|c|c|c|c|c|}
\hline And & we & 'd & both & go down \\
\hline Theme:text & Theme:top & \multicolumn{3}{|c|}{ Rheme } \\
\hline Adj:Conj & Subject & Finite & Adj:Mood & Predicator \\
\hline & \multicolumn{3}{|c|}{ MOOD } & RESIDUE \\
\hline
\end{tabular}

\begin{tabular}{|c|c|c|c|}
\hline and & you & 'd & win. \\
\hline Theme:text & Theme:top & \multicolumn{2}{|c|}{ Rheme } \\
\hline Adj:Conj & Subject & Finite & Predicator \\
\hline & \multicolumn{2}{|c|}{ MOOD } & RESIDUE \\
\hline
\end{tabular}

CATO 3:

\begin{tabular}{|c|}
\hline Go on. \\
\hline Theme:top \\
\hline Predicator \\
\hline RESIDUE \\
\hline
\end{tabular}

CATO 3:

\begin{tabular}{|c|c|c|}
\hline I & 'm & dead anyway! \\
\hline Theme:top & \multicolumn{2}{|c|}{ Rheme } \\
\hline Subject & Finite & Complement:Attributive \\
\hline \multicolumn{2}{|c|}{ MOOD } & RESIDUE \\
\hline
\end{tabular}

\begin{tabular}{|c|c|c|c|}
\hline $\mathbf{I}$ & always & was, & right? \\
\hline Theme:top & \multicolumn{3}{|c|}{ Rheme } \\
\hline
\end{tabular}




\begin{tabular}{|c|c|c|c|}
\hline Subject & Adj:Mood & Finite & Adj:Cont \\
\hline \multicolumn{3}{|c|}{ MOOD } & \\
\hline
\end{tabular}

\begin{tabular}{|c|c|c|c|c|}
\hline I & didn't & know & that & until now. \\
\hline Theme:top & \multicolumn{4}{|c|}{ Rheme } \\
\hline Subject & Finite:Neg & Predicator & Complement & Adj:Circ \\
\hline \multicolumn{3}{|c|}{ ROOD } & \multicolumn{3}{|c|}{ RESIDUE } \\
\hline
\end{tabular}

\begin{tabular}{|c|c|c|c|}
\hline Isn't & that & what they want, & huh? \\
\hline Theme:int & Theme:top & \multicolumn{2}{|c|}{ Rheme } \\
\hline Finite & Subject & Complement & Adj:Cont \\
\hline \multicolumn{2}{|c|}{ MOOD } & RESIDUE & \\
\hline
\end{tabular}

\section{CATO 4:}

\begin{tabular}{|c|}
\hline No! \\
\hline Minor clause \\
\hline
\end{tabular}

\begin{tabular}{|c|c|c|c|c|}
\hline I & can & still & do & this. \\
\hline Theme:top & \multicolumn{4}{|c|}{ Rheme } \\
\hline Subject & Finite & Adj:Mood & Predicator & Complement \\
\hline \multicolumn{3}{|c|}{ MOOD } & \multicolumn{2}{|c|}{ RESIDUE } \\
\hline
\end{tabular}

\begin{tabular}{|c|c|c|c|c|}
\hline I & can & still & do & this. \\
\hline Theme:top & \multicolumn{4}{|c|}{ Rheme } \\
\hline Subject & Finite & Adj:Mood & Predicator & Complement \\
\hline \multicolumn{5}{|c|}{ MOOD } \\
\hline
\end{tabular}




\begin{tabular}{|c|}
\hline One more kill. \\
\hline Theme:top \\
\hline Subject \\
\hline MOOD \\
\hline
\end{tabular}

\begin{tabular}{|c|c|c|}
\hline It & 's & the only thing I know how to do. \\
\hline Theme:top & \multicolumn{2}{|c|}{ Rheme } \\
\hline Subject & Finite & Complement \\
\hline \multicolumn{2}{|c|}{ MOOD } & RESIDUE \\
\hline
\end{tabular}

\begin{tabular}{|c|c|c|c|}
\hline \multicolumn{2}{|c|}{ Bring } & pride & to my district. \\
\hline \multicolumn{2}{|c|}{ Theme:top } & \multicolumn{2}{|c|}{ Rheme } \\
\hline Finite & Predicator & Complement & Adj:Circ \\
\hline MOOD & \multicolumn{3}{|c|}{ RESIDUE } \\
\hline
\end{tabular}

\begin{tabular}{|c|c|c|c|}
\hline Not & that & it & matters. \\
\hline Theme:int & Theme:int & Theme:top & Rheme \\
\hline Finite:Neg... & Complement & Subject & ...Finite:Neg \\
\hline MOOD ... & RESIDUE & \multicolumn{2}{|c|}{...MOOD } \\
\hline
\end{tabular}

\section{Scene 23: Katniss, Peeta}

PEETA 52:

\begin{tabular}{|l|}
\hline Go ahead. \\
\hline Theme:top \\
\hline Predicator \\
\hline RESIDUE \\
\hline
\end{tabular}




\begin{tabular}{|c|c|c|c|}
\hline One of us & should & go & home. \\
\hline Theme:top & \multicolumn{3}{|c|}{ Rheme } \\
\hline Subject & Finite & Predicator & Complement \\
\hline \multicolumn{2}{|c|}{ MOOD } & \multicolumn{2}{c|}{ RESIDUE } \\
\hline
\end{tabular}

\begin{tabular}{|c|c|c|}
\hline One of us & has & to die, \\
\hline Theme:top & \multicolumn{2}{|c|}{ Rheme } \\
\hline Subject & Finite & Predicator \\
\hline \multicolumn{2}{|c|}{ MOOD } & RESIDUE \\
\hline
\end{tabular}

\begin{tabular}{|c|c|c|c|}
\hline they & have & to have & their victor. \\
\hline Theme:top & \multicolumn{3}{|c|}{ Rheme } \\
\hline Subject & Finite & Predicator & Complement \\
\hline \multicolumn{2}{|c|}{ RESIDUE } \\
\hline
\end{tabular}

KATNISS 101:

\begin{tabular}{|c|}
\hline No. \\
\hline Theme:int \\
\hline Adj:Polarity \\
\hline MOOD \\
\hline
\end{tabular}

KATNISS 102:

\begin{tabular}{|c|c|c|}
\hline They & \multicolumn{2}{|c|}{ don't. } \\
\hline Theme:top & \multicolumn{2}{|c|}{ Rheme } \\
\hline Subject & Finite & Predicator \\
\hline \multicolumn{2}{|c|}{ MOOD } & RESIDUE \\
\hline
\end{tabular}




\begin{tabular}{|c|c|c|c|}
\hline Why & \multicolumn{2}{|c|}{ should } & they? \\
\hline Theme:top & \multicolumn{3}{|c|}{ Rheme } \\
\hline WH/Adj:Circ & Predicator & Finite & Subject \\
\hline RESIDUE & & \multicolumn{2}{|c|}{ MOOD } \\
\hline
\end{tabular}

PEETA 53:

\begin{tabular}{|c|}
\hline No! \\
\hline Minor clause \\
\hline
\end{tabular}

KATNISS 103:

\begin{tabular}{|c|c|}
\hline Trust & me. \\
\hline Theme:top & Rheme \\
\hline Predicator & Complement \\
\hline & RESIDUE \\
\hline
\end{tabular}

\begin{tabular}{|c|c|}
\hline Trust & me. \\
\hline Theme:top & Rheme \\
\hline Predicator & Complement \\
\hline & RESIDUE \\
\hline
\end{tabular}

PEETA 54:

\begin{tabular}{|c|}
\hline Together? \\
\hline Theme:top \\
\hline Adj:Circ \\
\hline RESIDUE \\
\hline
\end{tabular}

KATNISS 104:

\section{Together.}




\begin{tabular}{|c|}
\hline Theme:top \\
\hline Adj:Circ \\
\hline RESIDUE \\
\hline
\end{tabular}

PEETA 55:

\begin{tabular}{|c|}
\hline Okay. \\
\hline Minor clause \\
\hline
\end{tabular}

\begin{tabular}{|c|}
\hline One. \\
\hline Minor clause \\
\hline
\end{tabular}

KATNISS 105:

\begin{tabular}{|c|}
\hline Two. \\
\hline Minor clause \\
\hline
\end{tabular}

PEETA 56:

\begin{tabular}{|c|}
\hline Three. \\
\hline Minor clause \\
\hline
\end{tabular}

\section{Scene 24: Katniss, Peeta}

PEETA 57:

\begin{tabular}{|c|c|c|c|c|}
\hline So & what & \multicolumn{2}{|c|}{ happens } & when we get back? \\
\hline Theme:text & Theme:top & \multicolumn{3}{c|}{ Rheme } \\
\hline Adj:Conj & WH/Subject & Finite & Predicator & Adj:Circ \\
\hline & \multicolumn{2}{|c|}{ MOOD } & \multicolumn{2}{c|}{ RESIDUE } \\
\hline
\end{tabular}

KATNISS 106:

\begin{tabular}{|c|c|c|}
\hline I & don't & know. \\
\hline Theme:top & \multicolumn{3}{|c|}{ Rheme } \\
\hline
\end{tabular}




\begin{tabular}{|c|c|c|}
\hline Subject & Finite & Predicator \\
\hline MOOD & RESIDUE \\
\hline
\end{tabular}

\begin{tabular}{|c|c|c|c|c|}
\hline I guess & we & just & \multicolumn{2}{|c|}{ forget. } \\
\hline Theme:int & Theme:top & \multicolumn{3}{|c|}{ Rheme } \\
\hline Adj:Mood & Subject & Adj:Mood & Finite & Predicator \\
\hline \multicolumn{4}{|c|}{ MOOD } & RESIDUE \\
\hline
\end{tabular}

PEETA 58:

\begin{tabular}{|c|c|c|}
\hline I & don't & want to forget. \\
\hline Theme:top & \multicolumn{2}{|c|}{ Rheme } \\
\hline Subject & Finite & Predicator \\
\hline & & RESIDUE \\
\hline
\end{tabular}




\section{References}

Afra, K. (2016). PG-13, ratings creep, and the legacy of screen violence: The MPAA responds to the FTC's 'marketing violent entertainment to children' (2000-2009). Cinema Journal, 55(3), 40-64. https://doi.org/10.1353/cj.2016.0024

American Academy of Pediatrics. (2020). Definitions of key terms. Retrieved from https://www.aap.org/en-us/advocacy-and-policy/aap-healthinitiatives/Screening/Pages/Definitions-of-Key-Terms.aspx

Androutsopoulos, J. K., \& Georgakopoulou, A. (Eds.) (2003). Discourse constructions of youth identities. Amsterdam: John Benjamins.

Aryani, A. N. (2016). Conversational styles and misunderstanding in cross-sex conversations in He's Just Not That Into You movie. Language and Language Teaching Journal, 19(1), 1-11. https://doi.org/10.24071/11t.2016.190101

Bernstein, S., \& Chatelain, E. M. (2016). Twenty-first century teenage monsters: Representations of coming of age on the fringes of America. Studies in the humanities, 43(1/2), 52-64.

Bloor, T., \& Bloor, M. (2004). The functional analysis of English: A Hallidayan approach (Second Edition). London: Arnold.

Blum-Kulka, S. (2004). The role of peer interaction in later pragmatic development: The case of speech representation. In R. Berman (Ed.), Language development across childhood and adolescence (pp. 191-210). Amsterdam: John Benjamins.

Bonsignori, V. (2015). “Mind you, that's just, like, a guestimation”: A diachronic analysis of morphological creativity in American teen talk and dubbing. Lingue $E$ Linguaggi, 15, 53-68. https://doi.org/10.1285/i22390359v15p53 
Bram, B., \& Putra, P. K. (2019). Swear words used by Jordan Belfort in The Wolf of Wall Street movie. SKASE Journal of Theoretical Linguistics, 16(2), 129-138. Retrieved from http://www.skase.sk/Volumes/JTL40/pdf_doc/07.pdf.

Brechwald, W. A., \& Prinstein, M. J. (2011). Beyond homophily: A decade of advances in understanding peer influence processes. Journal of Research on Adolescence, 21(1), 166-179. https://doi.org/10.1111/j.1532-7795.2010.00721.x

Brown, B. B., \& Dietz, E. L. (2009). Informal peer groups in middle childhood and adolescence. In Rubin, K. H., Bukowski, W. M., \& Laursen, B. P. (Eds.), Handbook of peer interactions, relationships, and groups (pp. 361-376). New York: Guilford Press.

Brown, B. B., \& Larson, J. (2009). Peer relationships in adolescence. In Lerner, R. M., \& Steinberg, L. (Eds.), Handbook of adolescent psychology (pp. 74-103). https://doi.org/10.1002/9780470479193.adlpsy002004

Callister, M., Stern, L. A., Coyne, S. M., Robinson, T., \& Bennion, E. (2011). Evaluation of sexual content in teen-centered films from 1980 to 2007. Mass Communication \& Society, 14(4), 454-474. https://doi.org/10.1080/15205436.2010.500446

Christie, F. (2012). A language theory for educational practice. Language Learning, 62(s1), 1- 31. https://doi.org/10.1111/j.1467-9922.2012.00678.x

Ciampi, D. (2015). Compliment patterning among young speakers: A diachronic and translational study of English and dubbed Italian film dialogue. Quaderni di Linguistica e Studi Orientali / Working Papers in Linguistics and Oriental Studies, 1, 159-177. http://dx.doi.org/10.13128/QULSO-2421-7220-16521 
Ciampi, D. (2019). Constructing youth identities in dubbed movies. In Ranzato, I. and Zanotti, S. (Eds.), Reassessing dubbing: Historical approaches and current trends (pp. 263-280). Amsterdam: John Benjamins.

Corrigan, T. (2012). Introduction: Movies and the 2000s. In Corrigan, T., Rehak, B., Alter, N., Beckman, K., Everett, A., Morris, N., Willis, S., Schatz, T., Williams, L. R., \& Smith, D., American cinema of the 2000s: Themes and variations (pp. 118). New Brunswick, NJ: Rutgers University Press.

Cressman, D. L., Callister, M., Robinson, T., \& Near, C. (2009). Swearing in the cinema: An analysis of profanity in US teen-oriented movies, 1980-2006. Journal of Children and Media, 3(2), 117-135. https://doi.org/10.1080/17482790902772257

Dalton, M. A., Adachi-Mejia, A. M., Longacre, M. R., Titus-Ernstoff, L. T., Gibson, J. J., Martin, S. K., Sargent, J. D., \& Beach, M. L. (2006). Parental rules and monitoring of children's movie viewing associated with children's risk for smoking and drinking. Pediatrics, 118(5), 1932-1942. https://doi.org/10.1542/peds.2005-3082

Dibbets, K. (1999). Sound. In Nowell-Smith, G. (Ed.), The Oxford history of world cinema (pp. 211-219). Oxford, UK: Oxford University Press.

Donohue, J. P. (2012). Using systemic functional linguistics in academic writing development: An example from film studies. Journal of English for Academic Purposes, 11(1), 4-16. https://doi.org/10.1016/j.jeap.2011.11.003 
Driscoll, C. (n.d.). Modernism, cinema, adolescence: Another history for teen film. Screening the Past. Retrieved from https://www.screeningthepast.com/2011/11/modernism-cinema-adolescenceanother-history-for-teen-film/

Eggins, S. (2004). An introduction to systemic functional linguistics (2nd ed.). New York; London: Continuum.

Erikson, E. H. (1950). Childhood and society. New York: W. W. Norton and Company. Evaldsson, A.-C., \& Cekaite, A. (2010). “'Schwedis' he can’t even say Swedish”Subverting and reproducing institutionalized norms for language use in multilingual peer groups. Pragmatics, 20(4), 587-604. https://doi.org/10.1075/prag.20.4.05eva

Gálvez, R. H., Tiffenberg, V., \& Altszyler, E. (2019). Half a century of stereotyping associations between gender and intellectual ability in films. Sex Roles, 81(9), 643-654. https://doi.org/10.1007/s11199-019-01019-x

Garrett, M. (2019). Coming of age in films. Newcastle upon Tyne: Cambridge Scholars Publishing.

Gilleard, C., \& Higgs, P. (2016). Connecting life span development with the sociology of the life course: A new direction. Sociology, 50(2), 301-315. https://doi.org/10.1177/0038038515577906

Goodwin, M. H., \& Kyratzis, A. (2007). Children socializing children: Practices for negotiating the social order among peers. Research on Language \& Social Interaction, 40(4), 279-289. https://doi.org/10.1080/08351810701471260 
Goodwin, M. H., \& Kyratzis, A. (2011). Peer language socialization. In Duranti, A., Ochs, E., \& Schieffelin, B. B. (Eds.), The handbook of language socialization (pp. 365-390). West Sussex: Wiley.

Halliday, M. A. K., \& Matthiessen, C. M. I. M. (2004). An introduction to functional grammar (3rd ed.). London; New York: Arnold.

Huffaker, D. A., \& Calvert, S. L. (2005). Gender, identity, and language use in teenage blogs. Journal of Computer-Mediated Communication, 10(2). https://doi.org/10.1111/j.1083-6101.2005.tb00238.x

Hughes, T. (2019, July 8). What the evolution of coming-of-age movies means for representation. Queen's Journal. Retrieved from https://www.queensjournal.ca/story/2019-07-07/pop-culture/what-the-evolutionof-coming-of-age-movies-means-for-representation/

Johnson, T. (2019, September 18). Motion Picture Association rebrands with unified name and updated logo. Deadline. Retrieved from https://deadline.com/2019/09/motion-picture-association-logo-1202737759/

Kaye, B. K., \& Sapolsky, B. S. (2001). Offensive language in prime time television: Before and after content ratings. Journal of Broadcasting \& Electronic Media, 45(2), 303. https://doi.org/10.1207/s15506878jobem4502_7

Kaye, B. K., \& Sapolsky, B. S. (2004). Watch your mouth! An analysis of profanity uttered by children on prime-time television. Mass Communication \& Society, 7(4), 429-452. https://doi.org/10.1207/s15327825mcs0704_4

Kelly, D. M., \& Pomerantz, S. (2009). Mean, wild, and alienated: Girls and the state of feminism in popular culture. Girlhood Studies, 2(1), 1-19. 
Kirkham, S., \& Moore, E. (2013). Adolescence. In J. K. Chambers and N. Schilling (Eds.), Handbook of language variation and change (2nd edition) (pp. 277-296). Hoboken, NJ: Wiley-Blackwell.

Kozloff, S. (2007). Dialogue. In Grant, B. K. (Ed.), Schirmer encyclopedia of films, Volume 2 (1st ed.). Detroit: Schirmer reference.

Krisnadi, Y. A. D. D., \& Ardi, P. (2018). English phrasal compounds and their Indonesian translation in Spider-Man: Into the Spider-Verse movie. ELTR Journal, 2(2), 56-73. https://doi.org/10.37147/eltrj.v2i2.43

Kristiano, J. T., \& Ardi, P. (2018). Swear words in Bad Boys II: A semantic analysis. Language and Language Teaching Journal, 21(2), 191-198. doi.org/10.24071/1lt.2018.210208

Kyratzis, A. (2004). Talk and interaction among children and the co-construction of peer groups and peer culture. Annual Review of Anthropology, 33(1), 625-649. https://doi.org/10.1146/annurev.anthro.33.070203.144008

Leone, R., \& Barowski, L. (2011). MPAA ratings creep: A longitudinal analysis of the PG-13 rating category in US movies. Journal of Children and Media, 5(1), 53-68. https://doi.org/10.1080/17482798.2011.533488

Leone, R., \& Houle, N. (2006). 21st century ratings creep: PG-13 and R. Communication Research Reports, 23(1), 53-61. https://doi.org/10.1080/17464090500535897

Leone, R., \& Osborn, L. (2004). Hollywood's triumph and parents' loss: An examination of the PG-13 rating. Popular Communication, 2(2), 85-101. https://doi.org/10.1207/s15405710pc0202_2 
Lytra, V. (2003). Nicknames and teasing: A case study of a linguistically and culturally mixed peer-group. In Androutsopoulos, J. K., \& Georgakopoulou, A. (Eds.), Discourse constructions of youth identities (pp. 47-73). Amsterdam: John Benjamins.

McLeod, S. (2018). Erik Erikson's stages of psychosocial development. Psychology today. Retrieved from https://www.simplypsychology.org/Erik-Erikson.html

Medved, M. (2001, August 11). Hollywood's trojan horse. Aish.com. Retrieved from https://www.aish.com/ci/a/48931762.html

Merriam-Webster. (2020). Peer. In Merriam-Webster.com dictionary. Retrieved from https://www.merriam-webster.com/dictionary/peer.

Millard, K. (2007). Coming of age in contemporary American fiction. Edinburgh: Edinburgh University Press.

Motion Picture Association. (2020). Film ratings. Motion Picture Association. Retrieved from https://www.motionpictures.org/film-ratings/

Motion Picture Association. (2018). G is for golden: The MPAA film ratings at 50. Retrieved from https:/www.motionpictures.org/wp-content/uploads/2018/11/Gis-for-Golden.pdf

Nippold, M. A. (2000). Language development during the adolescent years: Aspects of pragmatics, syntax, and semantics. Topics in language disorders, 20(2), 15-28. https://doi.org/10.1097/00011363-200020020-00004

Nippold, M. A. (2006). Language development in school-age children, adolescents, and adults. In Brown, K. (Ed.), Encyclopedia of language \& linguistics, second edition (pp. 368-373). https://doi.org/10.1016/B0-08-044854-2/00852-X 
Nippold, M. A. (2014). Language sampling with adolescents: Implications for intervention, second edition. San Diego: Plural Publishing.

Nippold, M. A., \& Sun, L. (2008). Knowledge of morphologically complex words: A developmental study of older children and young adolescents. Language, Speech \& Hearing Services in Schools, 39(3), 365-373. https://doi.org/10.1044/0161$1461(2008 / 034)$

Ochs, E., \& Schieffelin, B. B. (2011). The theory of language socialization. In Duranti, A., Ochs, E., and Schieffelin, B. B. (Eds.), The handbook of language socialization. West Sussex: Wiley.

Parsons, T. (1942). Age and sex in the social structure of the United States. American Sociological Review, 7(5), 604-616. https://doi.org/10.2307/2085686

Pomerantz, A. \& Mandelbaum, J. (2005) Conversation analytic approaches to the relevance and uses of relationship categories in interaction. In K. L. Fitch \& R. F. Sanders (eds.), Handbook of Language and Social Interaction (pp. 149-171). Mahwah, New Jersey: Lawrence Erlbaum.

Potts, R., \& Belden, A. (2009). Parental guidance: A content analysis of MPAA motion picture rating justifications 1993-2005. Current Psychology, 28(4), 266-283. https://doi.org/10.1007/s12144-009-9065-y

Probosini, N. (2020). Politeness strategies in the main characters of The Devil Wears Prada movie. Jurnal ASPIKOM, 5(1), 166-175. https://doi.org/10.24329/aspikom.v5i1.516 
Ratri, A., \& Ardi, P. (2019). Power and impoliteness in The Devil Wears Prada movie. ELITE: English and Literature Journal , 6(1), 33-50. Retrieved from https://repository.usd.ac.id/34787/1/5299_Power+and+impoliteness+in+The+Dev il + Wears + Prada+Movie.pdf

Roberts, M. (2019). Virtual Realities: Social media and coming of age in Eighth Grade. Screen Education, 96, 24-31.

Sargent, J. (2005). Smoking in movies: Impact on adolescent smoking. Adolescent medicine clinics, 16(2), 345-370. https://doi.org/10.1016/j.admecli.2005.02.003

Sargent, J. D., Heatherton, T. F., Ahrens, M. B., Dalton, M. A., Tickle, J. J., \& Beach, M. L. (2002). Adolescent exposure to extremely violent movies. Journal of Adolescent Health, 31(6), 449-454. https://doi.org/10.1016/S1054$139 X(02) 00399-3$

Schmeink, L. (2016). How Bilbo lost his innocence: Media audiences and the evaluation of The Hobbit as a 'children's film.' Participations: Journal of Audience and Reception Studies, 13(2), 430-439. Retrieved from https://www.participations.org/Volume\%2013/Issue\%202/s1/14.pdf

Schmidt, M. P. (2002). Coming of age in American cinema: Modern youth films as genre [Doctoral dissertation, University of Massachusetts Amherst]. ProQuest Dissertations \& Theses Global.

Shafaei, M., Samghabadi, N. S., Kar, S., \& Solorio, T. (2020). Age suitability rating: Predicting the MPAA rating based on movie dialogues. Proceedings from The 12th Language Resources and Evaluation Conference (pp. 1327-1335).

Marseille, France: European Language Resources Association. 
Silalahi, T. S., Rafli, Z., \& Dewanti, R. (2021). Discourse strategy in The Great Debaters film dialogue (critical discourse analysis). BAHTERA : Jurnal Pendidikan Bahasa Dan Sastra, 20(1), 109-122. https://doi.org/10.21009/bahtera.201.10

Smith, D. (2012). 2007: Movies and the art of living dangerously. In Corrigan, T., Rehak, B., Alter, N., Beckman, K., Everett, A., Morris, N., Willis, S., Schatz, T., Williams, L. R., \& Smith, D., American cinema of the 2000s: Themes and variations (pp. 172-193). New Brunswick, NJ: Rutgers University Press.

Stace, L. (2017, February 17). What is a "coming-of-age" story? Slap Happy Larry. Retrieved from https://www.slaphappylarry.com/what-is-a-coming-of-age-story/

Starks, D., Leech, K.-T., \& Willoughby, L. (2012). Nicknames in Australian secondary schools: Insights into nicknames and adolescent views of self. Names, 60(3), 135149. https://doi.org/10.1179/0027773812Z.00000000019

Stenström, A.-B., Andersen, G., \& Hasund, I. K. (2002). Trends in teenage talk: Corpus compilation, analysis and findings. Amsterdam: John Benjamins.

Sussman, S., Pokhrel, P., Ashmore, R. D., \& Brown, B. B. (2007). Adolescent peer group identification and characteristics: A review of the literature. Addictive Behaviors, 32(8), 1602-1627. https://doi.org/10.1016/j.addbeh.2006.11.018

Thompson, K. M., \& Yokota, F. (2004). Violence, sex, and profanity in films: Correlation of movie ratings with content. Medscape General Medicine, 6(3), 3+. Retrieved from https://www.ncbi.nlm.nih.gov/pmc/articles/PMC1435631/

Thurlow, C. (2003). Teenagers in communication, teenagers on communication. Journal of Language and Social Psychology, 22(1), 50-57. https://doi.org/10.1177/0261927X02250055 
Tolchin, K. R. (2000). Part blood, part ketchup: Coming of age in America with J. D. Salinger, Philip Roth, John Irving, Edith Wharton and Jamaica Kincaid [Ph.D., Brandeis University]. ProQuest Dissertations \& Theses Global.

Top Lifetime Grosses by MPAA Rating (PG-13). (n.d.). BoxOfficeMojo.Com. Retrieved October 16, 2020, from https://www.boxofficemojo.com/chart/mpaa_title_lifetime_gross/?by_mpaa=PG13

Top Lifetime Grosses by MPAA Rating (PG). (n.d.). BoxOfficeMojo.Com. Retrieved October 16, 2020, from https://www.boxofficemojo.com/chart/mpaa_title_lifetime_gross/?by_mpaa=PG \&ref_=bo_cso_ac

Tynan, M. A., Polansky, J. R., Driscoll, D., Garcia, C., \& Glantz, S. A. (2019). Tobacco use in top-grossing movies-United States, 2010-2018. MMWR: Morbidity \& Mortality Weekly Report, 68(43), 974-978. https://doi.org/10.15585/mmwr.mm6843a4

UNICEF. (1989). Conventions on the Right of the Child text. Retrieved from https://www.unicef.org/child-rights-convention/convention-text\#

The UN Refugee Agency (UNHCR). (2001). Action for the Rights of Children (ARC): Foundations - Child and adolescent development. Retrieved from https://www.unhcr.org/3bb81bad4.pdf

Walsh, D. A., \& Gentile, D. A. (2001). A validity test of movie, television, and videogame ratings. Pediatrics, 107(6), 1302-1308.

https://doi.org/10.1542/peds.107.6.1302 
Webster, W. S. C. L. (2017). The artifice of dialogic exchange in film - "The Sunset Limited" as a test case for the application of systemic functional description [Thesis, Macquarie University]. Retrieved from http://hdl.handle.net/1959.14/1268224

Wilson, B. J., Linz, D., \& Randall, B. (1990). Applying social science research to film ratings: A shift from offensiveness to harmful effects. Journal of Broadcasting \& Electronic Media, 34(4), 443-468. https://doi.org/10.1080/08838159009386754

Zanotti, S. (2012). Censorship or profit? The manipulation of dialogue in dubbed youth films. Meta: Journal des Traducteurs / Meta: Translators'Journal, 57(2), 351368. https://doi.org/10.7202/1013950ar 